ON THE TEMPORAL INTERPRETATION OF NOUN PHRASES

by

Renate Musan

M.A., Universität Konstanz, 1987

Submitted to the Department of Linguistics and Philosophy in Partial Fulfillment of the Requirements for the Degree of

Doctor of Philosophy

at the

Massachusetts Institute of Technology

September 1995

(C) 1995 Renate Musan

All rights reserved

The author hereby grants to MIT permission to reproduce and to distribute publicly paper and electronic copies of this thesis document in whole or in part.

Signature of Author

Department of Linguistics and Philosophy

August 7, 1995

Certified by

Professor Kai von Fintel

Thesis Supervisor

Accepted by

Department Chair, Department of Linguistics and Philosophy OF TECHNOLOGY

SEP 281995 Humi 


\title{
ON THE TEMPORAL INTERPRETATION OF NOUN PHRASES
}

by

\author{
RENATE MUSAN
}

Submitted to the Department of Linguistics and Philosophy in partial fulfillment of the requirements for the Degree of Doctor of Philosophy in Linguistics

\begin{abstract}
This thesis investigates the temporal interpretation of noun phrases. The leading questions throughout are the following: (1) Is the temporal interpretation of a noun phrase determined by the temporal interpretation of the rest of its clause? (2) What kind of further interactions take place between the interpretation of noun phrases and the temporal interpretation of the main predicate of a clause? The framework in which these questions are answered exploits an ontology that assumes individuals, stages of individuals, and kinds as basic entities. Determinerquantification is argued to be quantification over stages of individuals rather than individuals in their whole temporal extendedness.
\end{abstract}

Chapter I provides a survey of the main topics of this thesis. It is argued that an account of the temporal interpretation of noun phrases must investigate at least two issues that are to be distinguished: the temporal location of individuals and the temporal location of predication times.

In Chapter II, the temporal location of individuals is explained as an effect of lifetime presuppositions that are introduced by the lexical semantics of stage-level predicates and individual-level predicates, but not by a third type of predicate, existence-independent predicates. Life-time effects associated with individuallevel predicates are captured as a pragmatic phenomenon in terms of Grice's Maxim of Informativity and related implicatures. In temporally specific contexts, life-time effects are neutralized. This is related to certain effects that topic-focus structure has on temporal interpretation.

Chapter III explains the temporal location of predication times associated with noun phrases. In contrast to previous research, it is argued that the temporal location of predication times of nouns depends on the temporal interpretation of the rest of the clause. The notions of 'temporally dependent' and 'temporally independent' noun phrases are introduced. It is shown that the distribution of temporally dependent and temporally independent noun phrases involves the distinction between weak (or cardinal) and strong (or presuppositional) noun phrases as well as the distinction between existence-independent arguments and 
other arguments. This distribution is explained as a consequence of (1) determiner-quantification being analyzed as quantification over stages of individuals, (2) independently motivated mechanisms of implicit quantifier restriction, and (3) a particular account of weak and strong determiners. This account analyzes both types of determiners as restrictive quantifiers, and attributes differences between them to whether the noun is mapped at LF into the restrictive clause or into the nuclear scope of the determiner. The mechanisms introduced in this chapter are also applied to generic noun phrases, certain kinddenoting noun phrases, and to the distinction between object-related readings and event-related readings.

Chapter IV deals with the semantics of certain types of noun phrase internal temporal modifiers, in-modifiers and of-modifiers. It is argued that in-modifiers are obligatory restrictors of quantifiers. Moreover, they impose constraints on the tense interpretation of their clause by activating the Upper Limit Constraint, which has also been used to explain certain aspects of the behavior of sequenceof-tense constructions and double-access constructions.

Chapter V offers a summary of results achieved in the preceding chapters and suggestions for future research.

Thesis Supervisor: Prof. Kai von Fintel 
"Adknowledgements

are supposed to be embarrassing.

You should definitely write something

you'll regret having written

five years from now."

$-\mathrm{Alec}-$

\section{ACKNOWLEDGEMENTS}

When I came to MIT, I thought four years are an incredibly long time. Now that it's over, these four years seem to me to have been much too short. I have learned a lot during those years. Not only about linguistics and about what a good department should be like, but also about life. Although I haven't forgotten that there were many downs in between the ups, I wouldn't want to have missed a single second of the years I had here. Especially my last year was much too short, somehow - and not for reasons that have to do with the finishing of my thesis. Thanks to everybody who helped making my fourth year what it was!

I want to thank all my teachers at MIT: Noam Chomsky, Kai von Fintel, Ken Hale, Morris Halle, Irene Heim, Jim Higginbotham, Michael Kenstowicz, Alec Marantz, Wayne O'Neil, David Pesetsky, Roger Schwarzschild, Bob Stalnaker, Ken Wexler. Among them, there are, of course, some whom I want to thank particularly.

Kai von Fintel, my supervisor, is not only the first in alphabetical order, but also the most important one in every respect that is relevant for being a teacher and advisor. I don't even want to think about what it might have been like to write my thesis without Kai's help, advice, encouragement, and unconditional support in all professional matters. Kai came to MIT at the beginning of my third year, when I was in the middle of finishing my semantics generals. Since then we have had countless appointments. Kai brought many phenomena to my attention, provided me with literature, improved my examples as well as the prose in between, sometimes pointed out to me that data I viewed as counterevidence to some aspect of my proposal were in fact additional evidence, and often suggested how to do things in a more elegant way. Also, I enjoyed listening to Kai's classes, and I was lucky enough to TA for one of Kai's introductory semantics classes.

Morris Halle supervised my work in phonology, and I profited tremendously from working with him - far beyond phonology. He has the rare and invaluable ability to give students confidence in their work even when criticizing them. I gained some confidence in my work that turned out to be transferrable to other areas.

Irene Heim was my first semantics teacher at MIT and also advised my work. I profited a lot from Irene's patience, encouragement, knowledge, and her accurate and precise semantic mind. I had many fruitful and constructive arguments and discussions with Irene. Beyond that, Irene was an important friend.

David Pesetsky helped me in many ways during my time at MIT. Aside from being one of my syntax teachers in my first year and being a member of my thesis committee, David seemed to me like an understanding and discretely respecting person. It's good to know that such people are around.

Roger Schwarzschild visited MIT as a replacement for Irene in my last semester. Having Roger around and working with Roger was fun, and I enjoyed our meetings quite a lot. Also, I learned a lot about some issues I had obviously not thought about enough before, e.g. informativity and implicatures. Special thanks to Roger for his kindness despite my utter confusion at times. Although not all of Roger's comments found their way into my thesis, I am sure that many of them will find their way somewhere, at some time.

Bob Stalnaker agreed to be a member of my thesis committee and to have appointments with me despite my ignorance and my silly remarks. I found it enlightening 
to learn about the more philosophical perspective. Through Bob, I got a much broader perspective on many problems.

For comments, occasional appointments, conversations about semantics, about how to write a thesis, or about other things, I would also like to thank Sigrid Beck, Daniel Büring, Elena Herburger, Angelika Kratzer, Gereon Müller, Arnim von Stechow, Wolfgang Sternefeld, and the semantics group consisting of Diana Cresti, Danny Fox, Orin Percus, and Uli Sauerland. Special thanks to my proof-readers Diana Cresti, David McKay, Colin Phillips, Hubert Truckenbrodt, and Susi Wurmbrand. Also to all my informants, who almost never protested against being asked again about these weird sentences. And to Andrew Carnie, without whom this thesis probably wouldn't be printed yet.

Further thanks go to my classmates Masha Babyonyshev, Andrew Carnie, Heidi Harley, Shawn Kern, Masa Koizumi, Orin Percus, Colin Phillips, and Hubert Truckenbrodt; to our unbeatable departmental softball team; to the pingpong players; to Hamida Demirdache, who taught me how to do weightlifting - which turned out to be amazingly important for working on temporal interpretation; to my roommates: Diana Cresti and Chris Tancredi in my first year, Pilar Barbosa, Tom Green, and Orin Percus in my second year, and the non-linguists Mike Reamer, Stephen Rhen, and Kara Rossomando in my third and fourth year - the unproblematic life at home helped me in the final stages of thesis-writing about as much as my wordprocessor. I also quite enjoyed the occasional chat with Pilar Barbosa, Jonathan Bobaljik, Tony Bures, Lenny Clapp, Carlos Corais, Aviv Hoffmann, John Pyrovolakis, Norvin Richards, Vaijayanthi Sarma, Jason Stanley, Rob Streiffer, Susi Wurmbrand, and Andrea Zukowski, the music of Ingvar Lofstedt and Rob Pensalfini, and Martha McGinnis's laughter somewhere in the fore- or background.

Many incidents made an enormous difference at certain points - here is just a small selection: a short conversation with Jason Stanley when I was close to giving up on stages; running into Alberto Haddad from the Sloan School in the middle of the biggest chaos ever; some friendly words from Wayne O'Neil; a significant confusion that put at least other things back into proportion; an interested and approving smile from someone; lots of emails from a good friend; an up-cheering dinner (You each know who you are!).

Warmest thanks to Diana Cresti for being a good friend again and again. To Danny Fox for his friendship and the peaceful hours of work we spent together, and for our special deal. To Hubert Truckenbrodt for his friendship, for all the silly things we did together, for his patience to listen to almost all the stories I told him, and for his ability to make me laugh even about the more sad stories. To Katharina Hartmann, who was in Boston during all of my first year and became one of my most important friends. To Yosef Grodzinsky, who knows all about how to write a thesis. To Claudia Nohl; the poem Claudia wrote up for me before I went to the US hung in my room for four years (and I'm sure will again when I'm back in Germany - at least for a while). To Arnim von Stechow for keeping in touch with me for that long time, and for all the fun we had together.

Thanks to my late grandmother Hildegard Schwill, to my brother Gunnar, and to my great aunt Tante Christel for at least sometimes finding great what I do; thanks to my parents Dietrich and Regina Musan and to my sister Angela for not objecting to it - and for supporting me in ever so many ways.

There are some people whom I want to thank particularly for the role they played for my becoming a linguist: Klaus Wöhler, from whom I learned that language is interesting; Arnim von Stechow, from whom I learned why language is interesting; Ede Zimmermann, from whom I learned that linguistics is interesting; Morris Halle, from whom I learned that I might finally become a linguist; and all those people at MIT from whom I learned that being a linguist can be fun. 


\section{TABLE OF CONTENTS*}

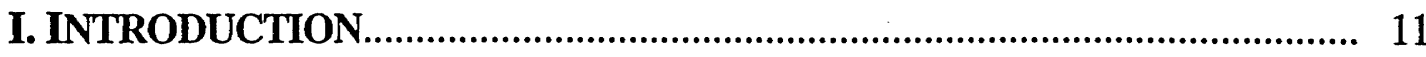

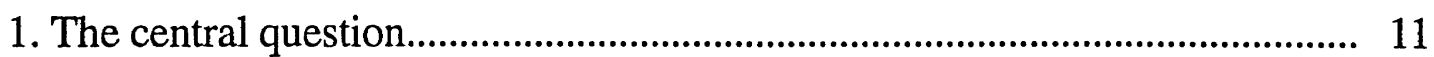

2. Previous results and counterevidence.......................................................... 13

2.1. Predication times.............................................................................. 13

2.2. Times of existence.................................................................... 18

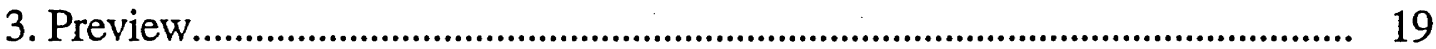

II. TEMPORAL LOCATION OF INDIVIDUALS.......................................... 22

1. Introduction: Life-time effects with individual-level predicates.................. 22

2. A pragmatic explanation of life-time effects.................................................... 24

2.1. Preliminaries............................................................................ 24

2.2. Informativity................................................................................. 29

2.3. A Gricean explanation: Life-time effects as implicature................ 34

2.4. Stage-level predicates and the Gricean explanation....................... 35

2.5. Predictions for existence-independent predicates........................ 37

2.6. Predicates with more than one argument........................................ 38

3. Contextual relativization of life-time effects................................................... 40

3.1. The blocking of life-time effects in certain contexts.................... $\quad 40$

3.2. On temporal interpretation.............................................................. 42

Appendix to Section 3.2.: Definite and indefinite temporal adverbials, quantifier restrictions, scrambling, and related issues........ 47

3.3. Informativity in temporally specific contexts................................ 54

3.4. Informativity and life-time effects in out-of-the-blue sentences:

the final analysis.......................................................................................... 56

3.5. Overt temporal adverbials and individual-level predicates.......... 61

4. A comparison with Kratzer's (1988) proposal.................................................. 62

4.1. Kratzer's treatment of life-time effects.............................................. 62

4.2. Wrong predictions with existence-independent predicates

and ergative verbs................................................................................. 66

4.3. "Relating to the external argument".............................................. 68

4.4. Problems with the interaction of tense and adverbs of

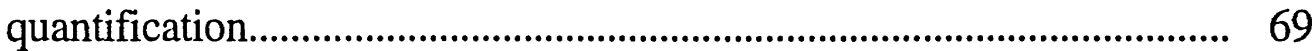

5. Conclusion ......................................................................................................... 70

* In the table of contents, I have marked the headings of some sections by underlining. These are sections that introduce the general semantic background framework of this thesis and/or show my views on various semantic topics that are of general interest beyond the issues concerning the temporal interpretation of noun phrases. 
1. Introduction.

2. The distribution of temporal dependence with noun phrases.................... 78

3. A scope approach based on the cardinal/presuppositional distinction..... 84

3.1. The general idea............................................................................... 84

3.2. Cardinal subjects of existence-independent predicates................ 87 4. Stages.

3.3. A problem: constructions with adverbs of quantification............ 90

4.1. The basic idea

4.2. On the semantics of quantification............................................... 97

4.2.1. The ontology................................................................. 97

4.2.2. Quantification with resource domain variables.............. 99

4.2.3. On the semantics of cardinal and presuppositional DPs.................................................................... 100

4.2.3.1. The interpretation of cardinal DPs...................... 100

4.2.3.2. The interpretation of resource domain variables.

4.2.3.3. The interpretation of resource domain variables with restrictive nouns.

4.3. Temporally dependent and temporally independent noun phrase interpretations.

4.3.1. Temporal restrictions and temporal adverbials modify resource domain variables.

4.3.2. The difference between restrictive (presuppositional)

noun phrases and unrestrictive (cardinal) noun phrases......... 118 Appendix to Section 4.3.: Modifications of resource domain variables by temporal adverbials are mediated by the context: scope interactions of temporal adverbials and DPs.

5. Unrestrictive noun phrases that get temporally independent

interpretations: an explanation under the stage-approach

6. Constructions with adverbs of quantification................................................ 130

7. Generic noun phrases....................................................................................... 131

8. Remarks on temporally independent noun phrases..................................... 136

8.1. The salience of properties and the choice of nouns....................... 137

8.2. The salience of the time of utterance and the choice of predication times

8.3. Competing times and the salience of established discourse topics.

8.4. Different types of noun phrases...................................................... 143

9. Conclusion.

10.1. Ships passing through locks and how to determine and count stages.

10.1.1. Object-related readings and event-related readings.....

10.1.2. Maximality of stages

10.1.3. How to account for the ambiguity of object-related readings and event-related readings. 
10.2. The president of the U.S. and how to merge stages.................... 156

10.2.1. Stages merging across individuals?............................... 156

10.2.2. Individuals, stages, and kinds............................................ 157

10.2.3. On the behavior of kind-nouns..................................... 158

IV. ON TEMPORAL NP-MODIFIERS AND UPPER LIMIT EFFECTS.. 160

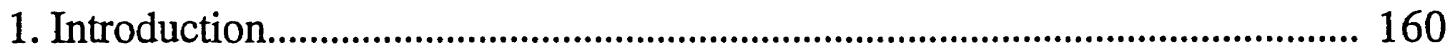

1.1. Preliminaries on temporal NP-modifiers........................................... 160

1.2. In-modifiers and of-modifiers............................................................ 163

2. On the distribution of in-modifiers: restrictive and unrestrictive DPs........ 165

3. In-modifiers as obligatory restrictors............................................................ 170

3.1. The restricted distribution of in-modifiers.......................................... 170

3.2. Obligatory restrictors in natural language....................................... 174

4. Interactions of in-modifiers and tense............................................................ 176

4.1. What precisely are the effects?....................................................... 176

4.2. Abusch's (1994) Upper Limit Constraint in complex sentences. 180

4.3. Other combinations of in-modifiers and tenses............................. 184

5. In-modifiers and upper limits........................................................................ 187

5.1. Do in-modifiers pragmatically provide local evaluation times?... 188

5.2. The syntactic relation between ULC-related elements.................. 196

6. Conclusion................................................................................................. 200

7. How to interpret in-modifiers .................................................................... 202

V. CONCLUSION AND SPECULATIONS................................................ 207

1. Results achieved in previous chapters.......................................................... 207

2. Possible extensions I: Time and space......................................................... 211

3. Possible extensions II: Times and worlds....................................................... 213

3.1. Basic considerations............................................................. 214

3.2. Previous results: Bäuerle (1983)....................................................... 216

3.3. Individuals and worlds.............................................................. 218

3.4. Properties of individuals and worlds................................................ 218

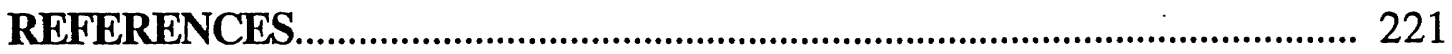


This thesis is dedicated to my best friend, who has been, is, and will be, asource of comfort, support, fun, advice, friendship, and, sometimes, bve.

(SeeChapterIII, Section 10.2.) 
"Viböjar omigen. Vigeross inte."

- Lars Gustafsson, En biodlares död-

\section{Chapter I. INTRODUCTION}

\section{The central question}

This thesis is about the temporal interpretation of noun phrases. For a first illustration of the issues we will be concerned with, consider the examples in (1) and (2). (1a) and (1b) exhibit a contrast with respect to the times at which the individuals talked about are fugitives. Thus, the individuals talked about in (1a) can be former fugitives - in particular, they can be individuals who escaped from jail at some earlier time, got caught, and are back in jail now. But the individuals mentioned in (1b) have to be fugitives now - i.e. they are individuals that escaped from something else but the jail.

(1). a. Many fugitives are now in jail.

b. There are now many fugitives in jail.

Why is it that the individuals talked about in (1a) do not have to be fugitives at the time of being in jail, but the individuals talked about in (1b) do?

$(2 a)$ and (2b) also show an interesting contrast. When confronted with (2b), one concludes that Gregory is dead; but when confronted with (2a), one doesn't conclude anything about Gregory's being alive or dead.

(2) a. Gregory was silent.

b. Gregory was from America. 
How come (2a) and (2b) exhibit this contrast?

The contrasts between sentences like (1a) and (1b) on the one hand and (2a) and $(2 \mathrm{~b})$ on the other hand concern the temporal interpretation of noun phrases.

Although the temporal interpretation of verbs is by no means a settled issue today, all of us have at least a vague idea of how it works: sentences contain verbs and tenses and sometimes temporal adverbials, and in some way or other the tense of a clause tells us roughly whether the state of affairs denoted by the main predicate of the clause - or at least a crucial part of it - is located at a past, present, or future time. And in some way or other, temporal adverbials can specify the time at which the state of affairs is located. Thus, because of the past tense, it is clear that the jumping of the cat in (3a) took place at some time in the past. And because of the combination of past tense and the temporal adverbial yesterday morning the jumping in (3b) took place yesterday morning. 1

a. The cat jumped from the closet.

b. Yesterday morning, the cat jumped from the closet.

Since at first sight, tenses and temporal adverbials seem to be mainly responsible for the temporal interpretation of verbs (or in general: of main predicates of clauses) and noun phrases do not in general contain tense-like or adverbial-like items, we may ask whether the temporal interpretation of noun phrases is determined by anything at all. Since noun phrases do not in general contain items that might determine their temporal interpretation, any determining effects can only come from outside the noun phrase. Thus, the topic of this dissertation can be made more precise as the question in (4).

(4) Is the temporal interpretation of noun phrases determined or affected by the temporal interpretation of the rest of their clause?

It is important to note that there are two core issues concerning the temporal interpretation of noun phrases - times of existence and predication times. The common semantic representation of a noun phrase (except perhaps for proper

1 For detailed investigations of the temporal interpretation of verbs, see, for instance, Bäuerle (1977, 1979), Binnick (1991), Kratzer (1978), Partee (1973, 1984), von Stechow (1992, 1995). 
names), consists at least of two parts. One of these is the noun, which corresponds semantically to a predicate. The other is an individual variable to which the predicate is applied. Thus, the semantic representation of the noun phrase $a$ student is at least an expression like "student $(\mathrm{x})$ ".2

Both the predicate and the individual variable can be temporally located. For the predicate, temporal location concerns the time interval during which the predicate is asserted to hold of an individual. I will call this time interval the PREDICATION TIME of the predicate. For the individual that the variable denotes under a particular variable assignment, temporal location concerns the time at which the individual exists. This time will be referred to as the TIME OF EXISTENCE of the individual. Applied to the example of the noun phrase $a$ student, we may thus ask, first, at what time the time of being a student is located, and second, at what time the individual denoted by $x$ under a particular variable assignment is located. Thus, talking again in general terms, the central question in (4) should be split into two questions:

(5) Is the temporal location of times of existence of individuals affected by the temporal interpretation of the rest of the clause?

(6) Is the temporal location of predication times of nouns affected by the temporal interpretation of the rest of the clause?

In the next section, I want to sketch briefly how these questions have been answered in previous research.

\section{Previous results and counterevidence}

\subsection{Predication times}

As far as the temporal location of predication times is concerned, there is one major contribution in the literature, the thesis of Enç (1981). This work clearly favors the view that the temporal location of predication times is independent of

2 I don't want to go here into a discussion of whether the indefinite determiner corresponds to an existential quantifier. I will assume here that it doesn't, adopting an analysis of indefinites as suggested by Heim (1982). 
the temporal interpretation of the main predicate of the clause. According to Enç, the temporal location of predication times depends only on the context. Enç structures her argument as a critique of a classical analysis of tense where tense is treated as a sentence operator. Her argument is twofold.

First, she illustrates the freedom of interpretation with examples like (7). (7) shows that noun phrases can have readings where the nominal predicate has a temporal interpretation that cannot be provided by the tense of the sentence. The tense in (7a) is present tense. But the predication time of the nominal fugitive can get a past tense interpretation, as indicated in (7b).

(7) a. Every fugitive is now in jail. (p65)

b. Every former fugitive is now in jail.

Thus, there is no past tense morpheme present in (7a) that could account for the past interpretation of the nominal predicate, i.e. there is no appropriate tense operator that could provide the intended reading for the interpretation of the noun phrase in question. Moreover, the present tense of the sentence does not at all affect the temporal interpretation of the noun phrase every fugitive. The freedom of interpretation illustrated here can be used to argue that the temporal interpretation of noun phrases is not be affected by tense, but rather it is completely independent and distinct from tense - irrespectively of particular tense analyses. Thus, given the interpretational freedom illustrated above, the temporal interpretation of noun phrases appears to be independent of tense and only restricted by the context.

Second, Enç shows that the assumption that tense determines the temporal interpretation of noun phrases leads to several wrong predictions. According to the classical analysis of tense, tense is a sentence operator whose interpretation is associated with an existential quantifier. As a consequence, tense and its scope do not only determine what time interval a given expression is to be evaluated in, but also what the scope relations between tense and quantifiers are (p67). Enç develops several arguments that show that the predictions following from this are not borne out.

Due to common assumptions on scope ambiguities, the classical tense analysis predicts that for a sentence like (8a), the two readings (8b, c) can arise. (8b) is a reading where no noun phrase is quantified in (or raised at LF, depending on the 
framework). (8c) represents a reading where the noun phrase all rich men is quantified in (or raised to a position higher than tense).
a. $\quad$ All rich men were obnoxious children. ((1) p58)
b. $\quad$ PAST $\forall x$ [rich-man $(\mathrm{x}) \rightarrow$ obnoxious-child $(\mathrm{x})$ ]
(b) is true iff there is a time in the past when everybody who was a rich man at that time was an obnoxious child at that time.
c. $\quad \forall \mathrm{x}$ [rich-man $(\mathrm{x}) \rightarrow$ PAST (obnoxious-child ( $\mathrm{x})$ )]
(c) is true iff there is a past moment when everybody who is a rich man now was an obnoxious child at that time.

Enç argues that the scope analysis of tense causes several problems in connection with the temporal interpretation of noun phrases. According to her, noun phrases can give rise to certain readings that cannot be explained with the scope analysis of tense.

The first problem arises with readings that involve quantification over more than one tense slot. In (9), for instance, the quantifier must be allowed to range over past and present rich men to account for the reading (9b) of (9a), which is clearly available. And in (10), the quantifier must be allowed to range over present and future representatives of the club to account for the reading (10b).
a. All rich men were obnoxious children. ((1) p58)
b. All present and past rich men were obnoxious children.
a. Every member of our investment club will buy a house. ((4) p60)
b. All present and future members of our investment club will buy a house.

That is, noun phrases have to be interpreted relative to more than one tense slot simultaneously (p63). Enç argues that the classical scope analysis of tense cannot account for this reading. 3,4

A second problem arises when tense cooccurs with two quantificational noun phrases in a clause. These constructions lead to scope paradoxes. Thus, according to Enç, (11a) "may be uttered about a future time after the presidency

3 Bob Stalnaker (pc) pointed out correctly that under slightly different assumptions, this would not be a problem: under the assumption that determiner-quantifiers quantify over all individuals that exist at any past, present, or future time, the desired interpretation could be achieved by implicit restrictions on the quantifier.

4 The examples here exploit only subject noun phrases, but Enç shows that the same effects can be found with object noun phrases. 
has been abolished. At that future time, a party will be given for individuals who are congressmen then, and who are old enough to remember a president. We want every congressman to be in the scope of future tense, a president to be in the scope of every congressman (they may remember different presidents), and $a$ president to be outside the scope of future time (there will not be any president at that time). This, of course, is impossible, because if a president is outside the scope of every congressman, then it cannot be outside the future tense." (pp65f).

(11) a. Every congressman who remembers a president will be at the party. ((17) p65)

b. There will be a future time $f$ such that for every f-congressman $x$ there is a non-f-president $y$ such that $x$ remembers $y$

FUT < every congressman every congressman $<$ a president

$$
\text { a president }<\text { FUT }
$$

A third problem is that sentences like (12) can have readings with nonsimultaneous events that cannot be accounted for under the classical tense analysis. The existential quantifier associated with tense gives rise to a system which is too weak to account for all possible readings where simultaneity and tense interpretation are varied independently of each other. Under the scope analysis, only (12b) and (12c) are predicted to be available. But (12d) is also a possible reading for $(12 a)$.

(12) a. All lizards will die. ((19) p68)

b. $\quad$ FUT $\forall x$ [lizard (x) $\rightarrow$ die (x)]

There is a future time such that everything that is a lizard at that time dies at that time. (The lizards die simultaneously.)

c. $\quad \forall \mathrm{x}[\operatorname{lizard}(\mathrm{x}) \rightarrow$ FUT $($ die $(\mathrm{x}))]$

For every present lizard, there is a future time where that lizard dies. (The lizards die non-simultaneously or, accidentally, simultaneously.)

d. Every future lizard will die, but they will die at different moments.

In order to deal with the sentences and readings indicated above, Enç argues that the temporal interpretation of noun phrases should not be affected by tense operators, but rather should be kept completely independent and distinct from tense. Enç argues that the temporal interpretation of nouns can best be 
captured by an indexical analysis. That is, the context of utterance provides the information for the adequate temporal interpretation of nouns.

Enç argues that the indexical aspect of noun interpretation is not only relevant for the associated temporal interpretation, but it can also account for other restrictions that apply to a noun phrase. E.g. in (13), the context specifies a property $\mathrm{P}$, which is the property relevant to the discussion at hand (p81), namely the property of being a virgin at the moment of death.

\section{(13) All virgins will go to heaven. ((34) p80)}

To summarize, under the assumption of a sentence operator analysis of tense, there seem to be good reasons to conclude that the temporal location of predication times of nouns is independent of tense. This supports Enç's claim that such temporal location is only restricted by the discourse context and criteria of contextual plausibility. 5

Convincing though Enç's arguments appear at first sight, there are data that indicate that her results may be an overgeneralization made on the basis of some cases of temporally independent noun interpretations.

We have already seen such a case in (1b) above. Consider also the contrasts exploited in (14) and (15). (14a) can easily mean "Some of today's directors of tortilla chip factories considered in the eighties shipping their product to Europe", But with the very similar sentence (14b), this reading is not available. (14b) is a sentence about individuals who were directors of tortilla chip factories in the eighties. I.e., the times of being a director of a tortilla chip factory and of considering shipping tortilla chips to Europe have to coincide here.

(14) a. In the eighties, some of the directors of tortilla chip factories considered shipping their product to Europe.

b. In the eighties, there were some directors of tortilla chip factories considering shipping their product to Europe.

Similarly, (15a) can easily mean "All of the individuals who are professors today were young in the fifties", e.g., they may have been kids then. But with (15b), an analogous reading is not available when the underlined noun phrase is

5 Bäuerle (1983, 124f and 130f) and Larson (1983, 196ff and 261f) basically come to the same conclusion. 
interpreted generically. Here, the times of being a professor and of being young have to coincide for any given individual.

(15) a. In the fifties, all professors were young.

b. In the fifties, professors were young.

Thus it seems that the underlined noun phrases in (14b) and (15b) obligatorily get interpretations that are dependent on the temporal interpretation of the main predicate of their clause - or, for short, these noun phrases must get TEMPORALLY DEPENDENT INTERPRETATIONS. In light of Enç's generalization, data like these are surprising and call for a more detailed investigation of the temporal location of predication times.

\subsection{Times of existence}

With regard to the time of existence of individuals, there are to my knowledge only two contributions in the literature that go beyond the footnote level: a paper by Anderson (1973) and a sketch of some important data and hypotheses by Kratzer (1989). Both Anderson (1973) and Kratzer (1989) basically defend the view that at least in some cases, tense applies to individuals. They view LIFETIME EFFECTS as observed in (16) as evidence for this. The crucial observation here is that the past tense in (16) somehow implies that Gregory is dead now. This effect can be explained if one assumes that past tense applies directly to the noun phrase Gregory and consequently locates Gregory, i.e. his time of existence, in the past.

\section{(16) Gregory was from America.}

Thus, Anderson and Kratzer assume that at least sometimes, noun phrases are strongly affected by the temporal interpretation of their clause.

On the other hand, there are data that force us to reconsider this conclusion. In (2a), repeated here as (17), we have already seen a sentence where the effect does not show up at all. Moreover, the effect observed in (16) does not show up consistently with the same predicate. This is illustrated in (18), where the example (16) is put into a more specific context. 
Gregory was silent.

(18) On that day, I was introduced to Gregory and Eva-Lotta. Gregory was from America.

Again, these data make it advisable to investigate the apparent effects of tense on noun phrases in more detail.

"Tmglad weare lost. Oherwise, wecouldn' tsee this."

-Fatima-

\section{Preview}

In Chapter II and Chapter III, I will present a thorough account of the two fundamental questions in (5) and (6).

Chapter II investigates the temporal location of times of existence of individuals. In contrast to Anderson and Kratzer, who assume a strong interaction between tense and individuals, I will argue that tense never applies to individuals directly. I will show that life-time effects can best be explained by a pragmatic account.

Chapter III is concerned with the temporal location of predication times. Since temporal location concerns times of existence as well as predication times, it is important to look at nouns that denote temporary properties of individuals in order to investigate the temporal location of predication times of nouns. Only with these nouns is it really possible to split apart the two issues of the temporal location of times of existence and of the temporal location of predication times. I will show that certain kinds of noun phrases are systematically temporally dependent on the interpretation of their clause. Quite in contrast to the generalizations of Enç and Larson, I will argue that the temporal location of predication times of nouns is in general not at all independent of the temporal interpretation of the rest of their clause. Rather, I will show that the default is in 
fact that the temporal location of predication times of nouns depends highly on the temporal interpretation of the rest of the clause. Whenever temporally independent noun phrase interpretations are available, this is a consequence of additional mechanisms that affect the interpretation of noun phrases. Specifically, I will show that the occurrence of temporally dependent noun phrase interpretations is not a direct effect of tense but rather a consequence of quantification over stages of individuals (instead of quantification over individuals in their whole temporal extendedness) in combination with independently motivated mechanisms of quantifier restriction. I will thus introduce a semantics that assumes stages of individuals as primitives of its ontology.

Aside from the two questions concerning the temporal location of times of existence and of predication times which we have mentioned so far, there are further problems concerning the temporal interpretation of noun phrases. Thus, one may also ask more complex questions like (19).

(19) How is the temporal interpretation of noun phrases affected by temporal modifiers that modify the noun?

Chapter IV investigates a particularly interesting range of phenomena related to the question posed in (19). It is an investigation of a particular type of temporal modifier of nouns, namely prepositional phrases as in the quarrel on Monday.

Chapter $\mathrm{V}$ provides a survey of the interactions between temporal interpretation and noun phrase interpretation that are dealt with in Chapter II to IV and starts investigating some additional questions.

I want to add here that there are of course more questions concerning the temporal interpretation of noun phrases which I wasn't able to deal with in this thesis. One especially interesting topic is the question of how the temporal interpretation of noun phrase internal clauses depends on the mechanisms that determine the interpretation of the noun phrase's time of existence and predication time.

I will introduce and develop the semantic framework of my work step by step in the course of the thesis at the points at which the respective aspects of the semantics become relevant. For ease of reference, I want to mention here that most of the crucial details concerning the temporal interpretation of main 
predicates can be found in Section 3.2. of Chapter II. Section 4.2.1. of Chapter III is a survey of the stage-ontology I will be exploiting. Section 4.2.2. of Chapter III presents some important notions concerning quantification and restrictions. My proposal concerning the interpretation of cardinal noun phrases and presuppositional noun phrases is presented in Section 4.2.3. of Chapter III. The reader who wants to survey the conclusions of this thesis is referred to Chapter V, Section 1. 
"... you are boking for something more formal, right?" -

"T mboking for something tha's right. If it's pragmatics, that's fine."

-in Chomsky's class, November4, 1993 -

\section{Chapter II. \\ TEMPORAL LOCATION OF INDIVIDUALS}

In this chapter, I will explain in which way the temporal location of individuals is determined by the temporal interpretation of a clause. The most drastic effects show up in past tense individual-level clauses (Section 1). I will argue in Section 2 that predicates provide lexically determined minimal requirements on their arguments' life-times. The role of tense for life-time effects is an indirect one: by virtue of its determining the temporal interpretation of the main predicate of a clause, it triggers implicatures which cause life-time effects. This proposal is refined in Section 3 so as to be able to explain the blocking of life-time effects in certain contexts. This blocking is due to the choice of topics and the related choice of values for temporal adverbials. In Section 4 I will compare my proposal to a proposal of Kratzer (1988) and argue that my account is more adequate. Kratzer's main claim that the temporal location of individuals is sometimes directly determined by tense runs into several problems, which are avoided in my account.

\section{Life-time effects with individual-level predicates}

Kratzer (1988) notes that past tense sentences exploiting individual-level predicates, in contrast to stage-level predicates, impose restrictions on the life-time 
of their subjects. Thus, when the sentences in (1) are uttered out of the blue, they suggest that Gregory is dead at the time of utterance of the sentence; the sentence is either false or a case of presupposition failure in a situation where Gregory is still alive. But the sentences in (2) can be true and perfectly acceptable when Gregory is alive. The sentences in (1) contain the INDIVIDUALLEVEL PREDICATES1 be from America, have blue eyes, and resemble Jörg Bieberstein, whereas the sentences in (2) contain the STAGE-LEVEL PREDICATES be happy, have a cold, and eat cookies.

a. Gregory was from America.

b. Gregory had blue eyes.

c. Gregory resembled Jörg Bieberstein.

(2) a. Gregory was happy.

b. Gregory had a cold.

c. Gregory ate cookies.

Kratzer accounts for the contrast between (1) and (2) by proposing that tense in individual-level clauses does not locate the event time of the main predicate, but the subject individual.2 Since the past tense seems thus to limit the life-time of the subject, I will call effects like the one observed in (1) LIFE-TIME EFFECTS.

However, the life-time effects observed disappear systematically when the sentences in (1) are put into certain contexts, as in (3):

a. On that day, I was introduced to Gregory and Eva-Lotta. Gregory was from America, and Eva-Lotta was from Switzerland.

b. I had a chance to have a closer look at him. Gregory had blue eyes.

1 Some of the predicates can also have stage-level readings. Here and below, the predicates are to be understood as having the individual-level reading. Thus, I am only referring to have blue eyes and resemble Jörg Bieberstein under their individual-level reading. Since be from America is a predicate that cannot have a stage-level reading at all, it will be my favorite predicate for my argument in this chapter. The use of this predicate was recommended to me by Angelika Kratzer.

2 For details of Kratzer's account, see below. These and related phenomena were in fact already discussed in Anderson (1973). Interestingly, Anderson has basically the same intuition as Kratzer - namely that in the relevant examples tense, which is overtly associated with the verb, applies to the existence of subject individuals (p485). Moreover, Anderson is already aware of some related phenomena that will become relevant later in this chapter: that life-time effects can be neutralized in certain discourse contexts ( $\mathrm{p} 484$ ), and that subject noun phrases and object noun phrases exhibit asymmetries with respect to life-time effects (p488). 
c. Suddenly I realized a remarkable thing: Gregory resembled Jörg Bieberstein.

Thus, it seems that the context can play a crucial role for the occurrence or nonoccurrence of life-time effects.

In the following section, I will explain how the life-time effect observed in (1) comes about and provide an account of the contrast between (1) and (2). The contrast is explained independently of any systematic grammatical differences between stage-level predicates and individual-level predicates. ${ }^{3}$ In Section 3, I will refine my proposal in order to deal with the contrast between (1) and (3). finally, in Section 4, I will compare my proposal to the one of Kratzer.

"Dead men don't wear plaid"

-Movie title-

"Gene Kelly, 81, amerikanischerFilmschauspieler..., dementiete sein Ableben. Der Eindruck, daß der frïhereFilmstar womöglich längst gestorben sei, entstand aufgrund einer Werbeanzeige der ModefimaGap. (...) Verwirend an der Kelly-Gap-Anzeige ist dieZeile: 'Gene Kelly tug Khakis.' In einem Interview bestätigte der Amerikaner. 'Ichlebenoch." -DerSpiegel, 37/1993-

\section{A pragmatic explanation of life-time effects}

\subsection{Preliminaries}

The data discussed in this chapter involve mainly past tense sentences and present tense sentences. Thus, let me introduce a simple, tentative semantics for past tense and present tense as a first basis for considering the relevant data. I will adopt for the purpose of this chapter a semantics that exploits three basic types, $e, t$, and $i$, which are the semantic types ${ }_{z}$ of entities, truth values, and

3 That is not to say that I claim there are no grammatical differences between stage-level predicates and individual-level predicates. I simply remain neutral on this issue. 
(possibly instantaneous) time intervals, respectively. Tenses are defined as functions from properties of time intervals into properties of time intervals. Since I won't be concerned with complex sentences in this chapter, and the evaluation time and the time of utterance coincide for matrix clauses, the time interval that a tensed clause applies to, for the present purpose, can safely be identified with the time of utterance. For ease of presentation, I will identify the time of utterance with the present time, i.e. now.

[PAST $\Phi \rrbracket=$ the function $\mathrm{f}: \mathrm{D}_{\mathrm{i}} \rightarrow\{0,1\}$

such that, for any $t \in D_{i}, f(t)=1$

iff $\exists t^{*} \in D_{i}$ such that $t^{*}<t$ and $\left[\llbracket \Phi \rrbracket\left(t^{*}\right)=1\right.$.

Thus, according to the definition of a past tense clause in (4) and the role attributed to the time of utterance, Gregory was happy (which corresponds to PAST Gregory be happy) uttered now is true if and only if there is a time t* before now such that Gregory was happy at $t^{*}$.

For present tense clauses to be true, I will assume that present tense requires the tenseless proposition to be true at an environment of the evaluation time, where an environment of a time is defined as follows:

(5) A time interval $t$ is an environment of a time interval $t^{\prime}$ iff $\exists \mathrm{t}^{*}, \mathrm{t}^{* *}$ such that $\mathrm{t}^{*}$ and $\mathrm{t}^{* *}$ are included in $\mathrm{t}$ and $\mathrm{t}^{*}$ and $\mathrm{t}^{* *}$ are not included in $\mathrm{t}^{\prime}$ and $t^{*}$ is located before $t^{\prime}$ and $t^{* *}$ is located after $t^{\prime}$.

Thus, the tenseless proposition has to be true at an interval that properly includes the evaluation time and reaches beyond it on both sides. 4 - The truth conditions of a present tense clause are for the present purpose defined as in (6).

$$
\begin{aligned}
& \text { [PRES } \Phi \rrbracket=\text { the function } f: D_{i} \rightarrow\{0,1\} \\
& \text { such that, for any } t \in D_{i}, f(t)=1 \\
& \text { iff } \exists t^{*} \in D_{i} \text { such that } t^{*} \text { is an environment of } t \text { and }\left[\left[\Phi \rrbracket\left(t^{*}\right)=1\right.\right. \text {. }
\end{aligned}
$$

According to this definition, Gregory is happy (which corresponds to PRES Gregory be happy) uttered now is true if and only if there is a time interval $t^{*}$

4 For theory internal reasons I need to define "environment $t$ of $t$ ' " to contain an interval $t *$ that precedes t'. As far as I can see, it doesn't have to contain an interval $t^{* *}$ that follows $t^{\prime}$. I am adding the latter condition to the definition mainly for reasons of symmetry. 
such that $t^{*}$ properly includes now and reaches beyond now on both sides and Gregory is happy at $t^{*}$. - The definitions in (4) and (6) will later be revised, but as a first approximation they are sufficiently adequate.

The contrast between (1) and (2) involves individual-level predicates and stage-level predicates. The relevant difference between these two types of predicates concerns the relationship between the time when the predicate can be asserted of an individual and the time of existence of that individual. In the following, I will refer to the time interval for which a predicate is asserted to hold of an individual as the PREDICATION TIME of the predicate. The time interval at which a certain individual is located, i.e. the time at which the individual exists, will be referred to as the TIME OF EXISTENCE of the individual.

STAGE-LEVEL PREDICATES - such as, for instance, be happy, have a cold, or eat cookies - refer to temporary properties of individuals. Their predication time usually covers only a relatively small part of the time of existence of an individual. Thus, an individual that is eating cookies does so usually only for a certain time. Thus, eat cookies can be truly predicated of an individual $\mathrm{x}$ if and only if the predication time of eat cookies covers a certain part of the time of existence of $\mathrm{x}$, but its predication time does not have to cover all of the time of existence of $\mathrm{x}$.

INDIVIDUAL-LEVEL PREDICATES - such as, for instance, be from America, have blue eyes or resemble Jörg Bieberstein - refer to long-time properties of individuals. They cover at least a relatively large part of the individual's time of existence; with ideal individual-level predicates - as is clearly the case with the predicate be from America - their predication time covers all of the time of the individual in question. Thus, a person who is from America is from America during all his/her life. Thus, be from America can be truly predicated of an individual $\mathrm{x}$ if and only if be from America can be truly predicated of $\mathrm{x}$ during all the time when $x$ exists.

Note that I assumed above that the predicates mentioned so far can only be predicated of an individual if that individual is alive at the time when the property is asserted to hold of the individual. This can be shown with the sentence Gregory is from America, which is uttered in two different situations in (7). I will assume here and below that Gregory was born in 1947 and that he is or was in fact from America. In (7a), the sentence is uttered in a situation where Gregory is 
still alive, and in (7b) in a situation where Gregory is dead. (7a) is perfectly acceptable, while $(7 b)$ is inappropriate.

(7) a. Utterance: "Gregory is from America." - Situation: Gregory is still alive.

b. \# Utterance: "Gregory is from America." - Situation: Gregory is dead.

All predicates we have encountered so far behave the same in this respect; somehow they require the individuals they are predicated of to be alive. Here is a stage-level clause that shows an analogous effect.

a. Utterance: "Gregory is happy." - Situation: Gregory is still alive.

b. \# Utterance: "Gregory is happy." - Situation: Gregory is dead.

Note though that not all predicates impose such a requirement on their subjects. The predicate famous is one that doesn't:

(9) a. Utterance: "Gregory is famous." - Situation: Gregory is still alive.

b. Utterance: "Gregory is famous." - Situation: Gregory is dead.

Since these predicates do not impose any requirements on their subject's existence, I will henceforth distinguish them from both stage-level predicates and individual-level predicates and call them EXISTENCE-INDEPENDENT PREDICATES. - I will come back to their behavior and the behavior of of stagelevel predicates later; at the moment, I want to focus only on individual-level predicates.

I account for the inappropriateness of (7b) by assuming that lexical entries of individual-level predicates specify LIFE-TIME PRESUPPOSITIONS, i.e., presuppositions that impose minimal requirements on the temporal location of individuals relative to the time at which the predicate is asserted to hold of the individual. In order to capture this basic idea, I suggest lexical entries for individual-level predicates as exemplified in (10). 5

[ be-from-America $\rrbracket=$ the function $\mathrm{f}: \mathrm{Di} \rightarrow \mathrm{D}<\mathrm{e}, \mathrm{\downarrow}$, such that, for any $t \in D i, f(t)=$ the partial function $g: D \rightarrow\{0,1\}$, such that, for any $\mathrm{x} \in \mathrm{D}, \mathrm{x}$ is in the domain of $\mathrm{g}$ iff $\mathrm{x}$ is alive at $\mathrm{t}$, and for each $\mathrm{x}$ in the domain of $\mathrm{g}, \mathrm{g}(\mathrm{x})=1$ iff $\mathrm{x}$ is from America at $\mathrm{t}$.

5 For ease of presentation, I am treating certain complex expressions as lexical items. 
Thus, the lexical entries for individual-level predicates contain a presuppositional condition on their argument's being alive.

Consequently, the inappropriateness of $(7 \mathrm{~b})$ is explained as a case of presupposition failure: since the assumption was that Gregory is dead now, there is no environment $t$ of now such that Gregory is alive at $t$. Thus, there is no environment $t$ of now such that Gregory is in the domain of be from America at $t$. Hence (7b) doesn't receive a truth value at all.

(7a) on the other hand is predicted to be true. The truth conditions of (7a) are shown in (7a'). Note that since I will be looking at cases where the presupposition is satisfied and the sentence as a whole is true, it is sufficient - for the present purpose - to treat the presupposition as part of the truth conditions of the sentence. For ease of presentation, I will do so when giving explicit truth conditions, as in $\left(7 \mathrm{a}^{\prime}\right) .6$

【Gregory is from America 】 $\left(\mathrm{t}_{\mathrm{u}}\right)=1$

iff [ $\left[\right.$ PRES Gregory be from America $\rrbracket\left(t_{u}\right)=1$

iff $\exists t$, s. t. $t$ is an environment of $t_{u}$ and [ Gregory be from America ] $(t)=1$

iff $\exists t$, s. $t$. $t$ is an environment of $t_{u}$ and Gregory is alive at $t$ and Gregory is from America at $t$.

6 Note that there is a serious problem here that concerns the way in which the presupposition can be integrated into a statement of the truth conditions. Thus, it is obviously not enough to state that

"Gregory was happy has a truth value iff $\exists \mathrm{t}^{*}$, such that $\mathrm{t}^{*}<\mathrm{t}_{\mathrm{u}}$ and Gregory is alive at $\mathrm{t}^{*}$. If Gregory was happy has a truth value, then its truth value is 1 iff $\exists \mathrm{t}^{*}$, such that $t^{*}<t_{u}$ and Gregory is happy at $t * . "$

The problem is that since we have two distinct existential quantifiers over times, there can be different times that fulfill the presupposition and make the sentence true. It is equally inadequate to state something like

"Gregory was happy has a truth value iff $\forall \mathrm{t}^{*}$, such that $\mathrm{t}^{*}<\mathrm{t}_{\mathrm{u}}$, Gregory is alive at t*..."

Here the problem is that the presupposition is much too strong. Obviously, Gregory doesn't have to be alive at all times before the time of utterance in order for the sentence to have a truth value. - This problem was already observed by Karttunen and Peters (1979). Since I don't know yet how to solve this problem, I will state the truth conditions of the relevant examples here and below only for the case when the sentence is true and integrate the presupposition as a condition on the sentence's being true. Strictly speaking, this is of course not an adequate treatment of the presupposition, but it seems to me to be the best way to deal with the problem until I can solve it. Note also that it is (somewhat more unexpectedly) not obvious how exactly related problems can be avoided in the modified semantics of tense I use later in this chapter. 
Since Gregory, according to the situation described for (7a), is alive now, he is in the domain of be from America at a set of intervals that are environments of now. Since Gregory is from America, the sentence is true. However, when commenting on the truth conditions of sentences more informally in the text, I will make clear that we are in fact dealing with presuppositions.

\subsection{Informativity}

I want to turn now to a pragmatic aspect of past tense sentences and present tense sentences. In particular, I will claim that the sentences Gregory is from America and Gregory was from America differ with regard to their informativeness. A lack of informativeness of sentences leads to a certain type of inappropriateness. The relevant notion of informativeness will play an important role in the explanation of life-time effects.

Consider the sentence Gregory was from America in (11a, b), which is uttered in spécific situations as indicated - in (11a) in a situation where Gregory is still alive, and in (11b) in a situation where Gregory is dead. Whereas (11a) is inappropriate, $(11 \mathrm{~b})$ is perfectly acceptable. Note that the difference here is simply a question of whether Gregory is alive or dead. Furthermore, (11c) shows that the present tense sentence is, in contrast to the past tense sentence (11a), fine in a situation where Gregory is alive.

(11) a. \# Utterance: "Gregory was from America." - Situation: Gregory is still alive.

b. Utterance: "Gregory was from America." - Situation: Gregory is dead.

c. Utterance: "Gregory is from America." - Situation: Gregory is still alive.

The oddness of (11a) must have a different source than the oddness of (7b). As we have seen above, (7b) is inappropriate because of presupposition failure. This is not the case with (11a). Since Gregory is born in 1947 and is still alive, there is a time $\mathrm{t}$ before now such that Gregory is alive at $\mathrm{t}$. Thus there is a time $\mathrm{t}$ where Gregory is in the domain of be from America. Thus, (10a) does not suffer from presupposition failure. Moreover, according to the semantics sketched so far, (10a) is true. 
(11a') 【Gregory was from America \( $\left.t_{u}\right)=1$

iff [PAST Gregory be from America $\rrbracket\left(t_{u}\right)=1$

iff $\exists$ t, s. $t . t<t_{u}$ and $[[$ Gregory be from America $](t)=1$

iff $\exists$ t, s. t. $t<t_{u}$ and Gregory is alive at $t$ and Gregory is from America at $t$.

Since there is a time in the past such that Gregory is alive at this time and Gregory is from America, (11a) is predicted to be true.

I think that the "inappropriateness status" of sentences can often be identified by considering the type of correction with which one can potentially react to the inappropriateness. With (7b), one would tend to correct the inappropriateness of the utterance by saying something like: "No, he WAS from America; he died last year...". But with (11a), one would tend to say something like: "... and he still IS from America - he is still alive....". Thus, the inappropriateness of (11a) seems to be caused by a lack of information. By saying "... and he still IS from America...", one adds more information. This is not the case with (7b); when correcting the utterance Gregory is from America in (7b) by saying "No, he WAS from America...", one explicitly marks the original utterance Gregory is from America as somehow fundamentally wrong.

Thus, (11a) is odd because it lacks information. The correction of (11a) suggests that the crucial information it lacks concerns the temporal duration of Gregory's being from America. therefore, what I want to argue now is that in a situation where Gregory is still alive, Gregory is from America $(=(11 \mathrm{c}))$ is more informative than Gregory was from America $(=(11 \mathrm{a}))$. The idea is that in contrast to (11a), (11c) exploits the maximally possible degree of informativeness with respect to the temporal duration of Gregory's being from America.

Let's have a closer look at (11a) and (11c) under the assumption that Gregory was born in 1947 and is still alive and is from America. With the semantics for past tense and present tense as proposed in (4) and (6), respectively,

(4) $\left[\right.$ PAST $\Phi \rrbracket=$ the function $\mathrm{f}: \mathrm{D}_{\mathrm{i}} \rightarrow\{0,1\}$

such that, for any $t \in D_{i}, f(t)=1$

iff $\exists t^{*} \in D_{i}$ such that $t^{*}<t$ and $\left[\left[\Phi \rrbracket\left(t^{*}\right)=1\right.\right.$.

(6) $\llbracket$ PRES $\Phi \rrbracket=$ the function $\mathrm{f}: \mathrm{D}_{\mathrm{i}} \rightarrow\{0,1\}$

such that, for any $t \in D_{i}, f(t)=1$

iff $\exists t^{*} \in D_{i}$ such that $t^{*}$ is an environment of $t$ and $\left[\llbracket \Phi \rrbracket\left(t^{*}\right)=1\right.$. 
both (11a) Gregory was from America and (11c) Gregory is from America are predicted to be true. (11a) is true because there is a time $t^{*}$ before now such that Gregory was from America at $t^{*}$. (11c) is true because there is a time interval $t^{*}$ such that $t^{*}$ properly includes now and Gregory is from America at $t^{*}$. But there is a crucial difference with respect to how informative the sentences are about the duration of Gregory's being from America. With (11a) Gregory was from America, the set of times that make the sentence true is the set of all time intervals that start at or after Gregory's birth and end before now. The largest time interval that makes (11a) true is the time interval that starts at Gregory's birth and ends right before now. With Gregory is from America, the set of times that make the sentence true is the set of all time intervals that start at or after Gregory's birth and include now. The largest time interval that makes (11c) true is the time interval that starts at Gregory's birth and ends at some time after now, at the time of his death. The picture below illustrates this; the largest time intervals that make (11a) and (11c) true are marked with a label " $t_{a}$ " and " $t_{c}$ ", respectively.

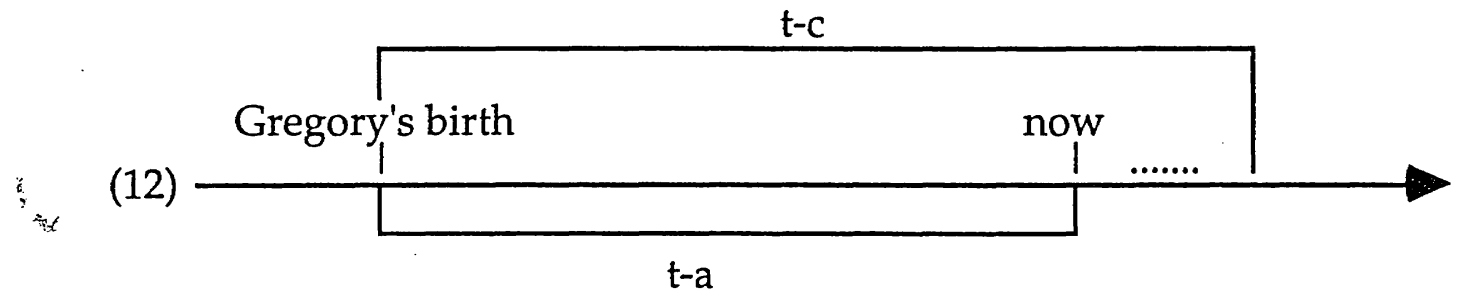

Thus, what makes (11c) more informative than (11a) is the fact that the maximal time interval that makes (11c) true is larger than the maximal time interval that makes (11a) true. In this sense the present tense sentence (11c) provides more information about the duration of Gregory's being from America than the past tense sentence (11a).

It follows from the particular relationship between the present tense clause and the past tense clause in combination with the general definition of INFORMATIVENESS in (13) that the former is more informative than the latter.

(13) A proposition $\Phi$ is more informative than a proposition $\Psi$ if and only if 1. for all worlds w such that $\Phi$ is true in $w, \Psi$ is true in $w$, and 2 . it is not the case that for all worlds $w^{*}$ such that $\Psi$ is true in $w^{*}, \Phi$ is true in $\mathrm{w}^{*}$. 
Thus, $\Phi$ is more informative than $\Psi$ when unilaterally implying $\Psi$.

In order to prove that a present tense clause $A$ is $B$ is more informative than a past tense clause $A$ was $B$, one has to show that both (14-1) and (14-2) are true.7

(14) 1 . For all worlds w such that $A$ is $B$ is true in w, $A$ was $B$ is true in w, and 2. It is not the case that for all worlds w* such that $A$ was $B$ is true in w*, $A$ is $B$ is true in $\mathrm{w}^{*}$.

Here is a proof of (14-1): What we want to show is that for all worlds w such that $A$ is $B$ is true in w, $A$ was $B$ is true in w. According to the semantics of present tense I suggested in (6), $A$ is $B$ is true if and only if there is an environment $\mathrm{t}^{*}$ of now such that $A$ be $B$ is true at $\mathrm{t}^{*}$. With the definition of an environment as given in (5), this translates into the following statement: $A$ is $B$ is true if and only if there is a time interval $t^{*}$ such that $t^{*}$ includes now, and a time interval $\mathrm{t}^{\prime}$ before now, and a time interval $\mathrm{t}^{\prime \prime}$ after now, and $A$ be $B$ is true at $\mathrm{t}^{*}$. Thus, there is a time interval $t^{\prime}$ such that $t^{\prime}$ is located before now and $A$ be $B$ is true at t'. But if that is so, then $A$ was $B$ must be true, because these are precisely the conditions under which the semantics of past tense as suggested in (4) predicts $A$ was $B$ to be true.

The proof of (14-2) goes as follows: We want to show that it is not the case that for all worlds $\mathrm{w}^{*}$ such that $A$ was $B$ is true in $\mathrm{w}^{*}, A$ is $B$ is true in $\mathrm{w}^{*}$. In order to show this, it is enough to find a case where a clause $A$ was $B$ is true in a world $\mathrm{w}^{*}$, but $A$ is $B$ is not true in w*. It is easy to find a world in which this is the case. Suppose A was B from 1947 until 1991, but not after 1991. Then there is a time interval $t^{*}$ such that $t^{*}$ is located before now and A was B at t*, namely for instance the time interval from 1947 until 1991. Thus, the past tense clause $A$ was $B$ is true. But there is no time interval $t *$ that includes now and at which $A$ $b e B$ is true. Thus, the present tense clause $A$ is $B$ is not true in this world.

Since we have thus shown that both (14-1) and (14-2) are true, we have shown that the present tense clause is indeed more informative than the past tense clause.

The idea is now that the relative inappropriateness of (11a) results from there being a more appropriate way of making a statement about Gregory's nationality -

7 Recall that we are looking here at individual-level predicates, i.e. a special class of stative predicates. 
namely (11c). Viewed this way, the inappropriateness of (11a) is explained analogously to the inappropriateness of the sentence Some students slept in a situation where in fact all students slept. In such a situation, the utterance All students slept would be more informative than the utterance Some students slept. Consequently, the utterance of Some students slept seems inappropriate.

The inappropriateness of (11a) can be captured in terms of Grice's $(1975,45)$ assumption that conversation is governed by the COOPERATIVE PRINCIPLE in (15), which guarantees that conversation is purposeful and cooperative,

(15) Make your conversational contribution such as is required, at the stage at which it occurs, by the accepted purpose or direction of the talk exchange in which you are engaged.

and the supplementary maxims of the Cooperative Principle: subsumed under the general Cooperative Principle, Grice distinguishes four categories of more specific maxims: the Maxim of Quality (Be true), the Maxim of Relation (Be relevant), the Maxim of Manner (Be perspicuous), and most important in connection with the data discussed in this chapter, the MAXIM OF QUANTITY (Be as informative as is required - not more and not less). Thus, according to Gricean maxims, utterances should be as informative as possible, unless this is not required. The observation that a present tense clause is more informative than a past tense clause implies a special subcase of the Maxim of Quantity, which may be formulated as in (16).

(16) If for some A and some B both "A is B" and "A was B" are true, then use the utterance "A is B" instead of "A was B".

To summarize, I have explained why (11a) is inappropriate in a situation where Gregory is alive: it is less informative than (11c). Strictly speaking this does not yet account for why (11a) triggers a life-time effect. The fact that (11c) is more appropriate than (11a) in a situation where Gregory is alive might, according to (16), justify the intuition that (11a) is less good than (11c), but it does not explain the life-time effect of (11a). So why is it that (11a) seems to imply that Gregory is dead? The next subsection aims at explaining this effect. 


\subsection{A Gricean explanation: Life-time effects as implicature}

In this subsection, I will argue that the life-time effect of Gregory was from America is triggered by the observed difference between (11a) and (11c) with respect to informativeness. The difference with respect to informativeness is the basis for an implicature which leads to the conclusion that an utterance conveys that Gregory is dead.

I have argued above that the present tense clause (11c) is more informative than the past tense clause (11a). The Cooperative Principle governs conversation in the sense that speakers usually obey it and that hearers usually rely on the assumption that speakers obey it. A hearer must very often have some assumptions about what the speaker means to preserve the supposition that the Cooperative Principle is being observed. Following Grice, a certain class of propositions meant are called CONVERSATIONAL IMPLICATURES. Hearers have access to these conversational implicatures by assuming that the Cooperative Principle is observed by the speaker and interpreting the utterances of the speaker in light of this assumption. Grice assumed that conversational implicatures can always be derived by a general argument pattern $(1975,50)$.

Basically, because of the fact that one assumes maximal informativeness when confronted with utterances, one implicates with Gregory was from America indirectly that Gregory is dead. What one implicates directly is that the property of being from America is "over". The further implication that Gregory is dead follows from the fact that be from America is an individual-level predicate. In (17), a detailed justification schema is spelled out for a situation where a speaker has uttered Gregory was from America. 8

(17) Working out of the implicature of Gregory was from America:

(a) The speaker has expressed the proposition that Gregory was from America.

(b) There is no reason to suppose that the speaker is not observing the Cooperative Principle and maxims, in particular the principle of informativeness.

8 The schema presented here differs somewhat from the one presented in Grice $(1975,50)$. I am leaving out some steps of the derivation that concern the transmission of information between speaker and hearer. Moreover, I am adding steps that concern the consideration of alternative expressions and informativity. 
(c) Thus, the hearer assumes that the speaker is maximally informative about Gregory's being from America - in particular about the duration of Gregory's being from America.

(d) If the speaker thought that Gregory's being from America is not over, he would have expressed the proposition that Gregory is from America, since that would have been a more informative alternative utterance about the duration of Gregory's being from America.

(e) Thus, the speaker couldn't have been maximally informative about Gregory's being from America unless he thought that Gregory's being from America is over.

(f) Thus, the speaker has implicated that Gregory's being from America is over.

(g) Since being from America is a property that, if it holds of an individual at all, it holds of that individual during all its life-time, the hearer concludes further that, since the speaker has implicated that Gregory's being from America is over, the speaker has implicated that Gregory is dead.

In this way, the utterance Gregory was from America triggers a life-time effect.9

\subsection{Stage-level predicates and the Gricean explanation}

We are now in a position to explain why stage-level predicates contrast with individual-level predicates in that they do not trigger life-time effects. I will show shortly why this is so. Moreover, I will show that although stage-level predicates do not trigger life-time effects, they exploit an analogous effect.

Here is a lexical entry of a stage-level predicate. Just like lexical entries for individual-level predicates, the ones for stage-level predicates also specify lifetime presuppositions. Note that it does not differ crucially from the lexical entry of individual-level predicates (cf. (11)).10

9 I think that Krifka et al. (1995, 79 fn.40) have a similar analysis for a certain subcase of life-time effects in mind. They mention that The dodo was a bird clearly suggests that the dodo is extinct and observe that "In general, when a necessary property is asserted of a kind in past tense, we can infer that the kind does not exist anymore." Moreover, they also assume that this is a pragmatic effect. Their intuitions differ from mine insofar as they observe that "the sentence the dodo is a bird is true as well, in spite of the dodo's being extinct".

10 For my present purpose, it is not necessary to assume a systematic formal difference (e.g., different argument structures) between individual-level predicates and stage-level predicates. 
(18)

[eat-cookies $\rrbracket=$ the function $\mathrm{f}: \mathrm{Di} \rightarrow \mathrm{D}<\mathrm{e}, \mathrm{t}\rangle$, such that, for any $t \in D i, f(t)=$ the partial function $g: D \rightarrow\{0,1\}$, such that, for any $\mathrm{x} \in \mathrm{D}, \mathrm{x}$ is in the domain of $\mathrm{g}$ iff $\mathrm{x}$ is alive at $\mathrm{t}$, and for each $\mathrm{x}$ in the domain of $\mathrm{g}, \mathrm{g}(\mathrm{x})=1$ iff $\mathrm{x}$ eats cookies at $\mathrm{t}$.

Recall the contrast between (1) and (2), here illustrated with the individuallevel clause (19) and the stage-level clause (20).

(19) Gregory was from America.

(20) Gregory was happy.

The reason why (20), in contrast to (19), does not trigger a life-time effect is simply that being happy is usually not a property that holds of individuals during all their life-time, but only during certain times. Thus, one would expect that in an analogous justification schema, step ( $\mathrm{g}$ ) of (17) would not be performed; the implicature triggered by the use of the past tense in (20) would be predicted to stop at step (f) of (17), so that (20) ultimately implicates (21).

\section{(21) Implicature of Gregory was happy:}

Gregory's being happy is over.

This prediction is in fact borne out: when a stage-level clause is uttered out of the blue and contains a past tense, a hearer concludes that the predication time of the property, event or activity denoted by the main predicate is over. Thus, (22) for instance seems to imply that Eva-Lotta's walking along the Charles River is over at the time of utterance.

(22) Today, Eva-Lotta walked along the Charles River.

Thus, past tense triggers implicatures concerning the end of the predication time of the main predicate with both individual-level and stage-level predicates. The only difference between the two types of predicates is that the conclusion about the life-time of the subject is not performed with stage-level predicates. This is simply due to the fact that the stage-level predicate is known to usually cover only a small part of the subject's life-time. As a consequence, the being over of states like being happy or activities like walking along the Charles River does not imply anything about the subject's life-time. Thus, to put it simply: 
Gregory's not being happy anymore doesn't imply that he isn't alive anymore, but Gregory's not being from America anymore does.

\subsection{Predictions for existence-independent predicates}

I now want to come back to the issue of existence-independent predicates like be famous. Existence-independent predicates were briefly introduced with (9), repeated here as (23).

(23) a. Utterance: "Gregory is famous." - Situation: Gregory is still alive.

b. Utterance: "Gregory is famous." - Situation: Gregory is dead.

The crucial property of existence-independent predicates is that they do not impose a life-time requirement on their subjects. Thus, a sentence like Gregory is famous can be uttered appropriately regardless of whether Gregory is dead or alive at the time of utterance. This can be captured by assigning lexical entries like (24) to existence-independent predicates which do not contain a life-time presupposition.

[be-famous $\rrbracket=$ the function $\mathrm{f}: \mathrm{Di} \rightarrow \mathrm{D}<\mathrm{e}, \mathrm{t}>$, such that, for any $t \in D i, x \in D, f(t)(x)=1$ iff $x$ is famous at $t$.

Thus, be famous does not impose a restriction on how the life-time of the subject and the predication time of be famous have to relate to each other. That is, be famous can hold of an individual at some time and place even if the individual is completely absent. It can hold of an individual during part of its life-time (e.g., Mikhail Gorbachev), after its life-time (e.g., Paul Gauguin), perhaps even before its life-time (e.g., the baby of Boris Becker ${ }^{11}$ ) or, of course, during any combination of these possibilities (e.g., Pablo Picasso) or of non-existent individuals or fictional characters (e.g., Snow White). 12

What does our analysis predict for existence-independent predicates as far as the presence or absence of life-time effects is concerned? Since be famous does

11 Boris Becker is a German tennis player about whose baby German newspapers wrote pages and pages and pages before the kid was born.

12 This last observation is due to Roger Schwarzschild (pc). 
not impose a life-time presupposition on its subject and since it can hold of an individual during part of its life, we expect that be famous should not trigger any life-time effects. This prediction is borne out. (25) for example does not imply that Boris Becker's child is dead.

(25) Boris Becker's baby was famous.

But, just as with the stage-level predicates and individual-level predicates above, the past tense in (25) seems to imply that the being famous of Boris Becker's baby is over (which is actually true, I believe).

\subsection{Predicates with more than one argument}

Before I refine my analysis in order to be able to capture more data, let me add some remarks about predicates that have more than one argument. Above, we have looked at subject arguments, and we have distinguished three different types of requirements on temporal relationships between the time of the main predicate of a clause and the time of existence of its subject argument: the time of existence of subjects of individual-level predicates is typically identical to the time of the individual-level predicate; the time of a stage-level predicate typically covers only a relatively small part of the time of existence of its subject; finally, existence-independent predicates have subjects whose time of existence is not restricted by the time of the predicate. What we have not looked at so far is what happens to other arguments of predicates with respect to their temporal location.

In general, we can observe that predicates can behave differently with respect to different arguments. 13 Here are a few examples that illustrate this:

(26) a. Lord Peter Wimsey talked about Miss Phelps.

b. Lord Peter Wimsey invited Harriet Vane for dinner.

c. Harriet misunderstood Lord Peter.

d. Harriet gave Lord Peter the manuscript of her latest novel.

13 Referring to Tichy (1985), Vlach (1993, 259f) makes a related observation. $\mathrm{He}$ suggests that agent arguments and theme arguments, but perhaps not arguments associated with other thematic roles should be treated as time (and place) dependent. 
In the sentences in (26), single underlining marks noun phrases that denote individuals who, due to the semantics of the verb of the clause, must be present at the time and place of the event denoted by the verb. Double underlining marks noun phrases that are not subject to such a requirement. Stretching the terminology somewhat, one might say that talk about for instance is a verb that behaves with respect to the temporal location of its subject argument like a stagelevel predicate and with respect to the temporal location of its object argument like an existence-independent predicate.

Another interesting case is the verb resemble. Considering the core meaning of resemble, it seems plausible to assume that it is a symmetric predicate: intuitively, A resembles B if and only if B resembles A. But a closer look at the verb reveals that it is in fact asymmetric, at least as far as the temporal location of its arguments is concerned. Consider the sentence Aunt Theresa resembled my grandmother (taken from Kratzer $(1989$, p44)) with two different situations, (27a) and (27b). 14

a. Utterance: "Aunt Theresa resembled my grandmother." - Situation: Aunt Theresa is dead; the grandmother is still alive.

b. \# Utterance: "Aunt Theresa resembled my grandmother." - Situation: Aunt Theresa is still alive; the grandmother is dead.

In (27b), the sentence is uttered in a situation where the subject argument of resemble, Aunt Theresa, is still alive, whereas the object argument, the grandmother, is dead. In this situation, the sentence seems unfelicitous because it implicates - contrary to fact - that the subject argument, Aunt Theresa, is dead. If resemble were a completely symmetric predicate, one would expect it to show a similar effect in (27a), where the object argument, the grandmother, is still alive, whereas the subject argument, Aunt Theresa, is dead. But (27a) shows no such

14 For a presentation and critique of Kratzer's account of the data see below, Section 4 . Note that, like Kratzer, I am here exclusively interested in the individual-level reading of resemble. Obviously, resemble has also a stage-level reading, as can be nicely illustrated with the following very plausible example (which is due to Arnim von Stechow, pc): Randi used to resemble Franzis, but now she resembles Wladimir. - With the stagelevel reading, of course, there arise no life-time effects. It is admittedly not easy to draw the two readings of resemble apart. If I understand Kratzer right, the idea of the individual-level reading of resemble is to talk about a very fundamental resemblance. Thus, Kratzer introduces the examples in her paper suggesting that Aunt Theresa is/was almost a perfect clone of the grandmother. 
effect; it is perfectly acceptable and does not implicate anything about the grandmother's life-time.

Thus, it seems that resemble behaves like an individual-level predicate with respect to its subject argument, but like an existence-independent predicate with respect to its object argument. I will come back to the case of resemble when discussing Kratzer's analysis of these and other examples.

\section{Contextual relativization of life-time effects}

In Section 2, I have explained how the occurrence of life-time effects with past tense individual-level clauses can be accounted for. The purpose of Section 3 is to refine the analysis in order to account for cases like (3), repeated below as (28), where one might expect life-time effects but where, as it turns out, they are blocked.

\subsection{The blocking of life-time effects in certain contexts}

Consider again (3), repeated here as (28). It seems that implicatures of the type derived in (17) can be deleted or blocked in certain contexts. None of the underlined clauses in (28) triggers life-time effects, although it was precisely the same clauses that triggered life-time effects in (1), where they appeared out of context.

(28) a. On that day, I was introduced to Gregory and Eva-Lotta. Gregory was from America, and Eva-Lotta was from Switzerland.

b. I had a chance to have a closer look at him. Gregory had blue eyes.

c. Suddenly I realized a remarkable thing: Gregory resembled Jörg Bieberstein.

Why does the life-time effect disappear in these contexts? At first sight, there appear to be two plausible explanations for the blocking of life-time effects in (28).

First, it is widely assumed that past tense is not always interpreted as past tense, but seems to be sometimes deleted in the semantic representation when 
embedded under another occurrence of past tense. These so-called sequence-oftense constructions then get a simultaneous interpretation. Thus, in addition to an interpretation roughly like (29b), (29a) can get an interpretation like (29c), where the embedded past tense does not seem to be interpreted relative to the evaluation time provided by the matrix clause. This phenomenon can be captured by saying that the embedded past tense in these cases is semantically empty.

(29) a. Gregory said that he was bored.

b. There is a time $t^{*}$ before now, such that Gregory said at $t^{*}$ that he was bored at a time $t^{* *}$ before $t^{*}$.

c. There is a time $t^{*}$ before now, such that Gregory said at $t^{*}$ that he was bored at $t^{*}$.

In light of sequence-of-tense constructions, one might assume that the sentences in (28) exhibit a sequence-of-tense effect across sentence boundaries. Thus, the past tense in constructions like (28) could perhaps be regarded, as well, as only a morphologically relevant element which for some reason is eliminated in the semantic representation. If that were so, then it would seem plausible that past tense in such constructions loses its ability to trigger life-time effects.

Although appealing at first sight, this approach proves to be untenable. This is because other languages that don't show sequence-of-tense effects in general show the same effect as the one observed in (28). As David Pesetsky pointed out to me, Russian does not have sequence-of-tense phenomena and, therefore, provides a possibility to test the hypothesis that the occurrence of past tense in the second sentence is a consequence of sequence-of-tense. Maria Babyonyshev (pc) said that the Russian translation corresponding to (28c) is acceptable. Thus, we can conclude that sequence-of-tense phenomena don't play a role in $(28 \mathrm{c})$ or similar examples.

The second analysis of the effect in (28) is based on the assumption that constructions like (28) may be viewed as constructions where a specific temporal context relativizes the temporal interpretation of clauses to particular times and, consequently, neutralizes life-time effects. In (28a) for example, such a relativizing time is explicitly given by a temporal adverbial in the preceding sentence. In $(28 b, c)$, it seems that the event mentioned in the preceding sentence sets a time relative to which the underlined sentences are interpreted. Before I 
explain why this leads to a blocking of the life-time effect, let me first introduce some more background about temporal interpretation.

\subsection{On temporal interpretation}

All accounts of temporal interpretation have to solve the problem of how to deal with the fact that sentences can apparently have either definite or indefinite tense readings. INDEFINITE or QUANTIFICATIONAL TENSE READINGS are readings that can apparently only be represented with a quantifier over times. This is the case with the sentence Today, Eva-Lotta didn't smile, which has the reading "It is not the case that there is a time $t$, such that $t$ is today and Eva-Lotta smiles at $t$ ". DEFINITE or DEICTIC TENSE READINGS are readings which imply a contextually salient time interval that is relevant for the representation of the reading, as with Partee's (1973) well-known example I didn't turn off the stove. The strongly preferred reading of this sentence is neither "It is not the case that there is a time $t$ such that I turned off the stove at $t$ " nor "There is a time $t$ such that it is not the case that I turned off the stove at $t$ " but something like "At the designated time $t$ (e.g. for the sentence here, right before I left the house) it is not the case that I turned off the stove at $t$. Thus, the most salient reading of the sentence is a definite or deictic one, in the sense that the speaker has a particular, contextually salient time interval in mind. Based on the existence of such definite tense readings, Partee (1973) argued that an adequate analysis of tense must provide the option to interpret tense as denoting specific time intervals similarly as deictic pronouns denote specific individuals.

But neither the existence of indefinite tense readings nor the existence of socalled definite tense readings must necessarily lead to the conclusion that tense itself is responsible for the indefiniteness or definiteness. Thus, adopting basically the accounts of Bäuerle $(1977,1979)$ and Kratzer (1978), and a recent version of these accounts by von Stechow (1992), I will assume that both aspects of tense interpretation are provided by independent elements in LF. With von Stechow, I will treat tense as a relation between two times or assume, equivalently, that tense is a predicate that takes two times as arguments. For the purpose of this chapter, I will adopt a slightly modified version of his semantics. The lexical entry for past tense for instance is as follows. 
[IPAST ] $=$ the function $\mathrm{f}: \mathrm{Di} \rightarrow \mathrm{D}<\mathrm{i}, \mathrm{t}$ such that for any $t, t^{*} \in D i, f(t)\left(t^{*}\right)=1$ iff $t^{*}<t$.

Being a predicate of times, tense itself is neither definite nor indefinite. As a consequence, any definite or indefinite aspects of tense readings have to come from other sources, sometimes from phonetically empty elements.

The indefiniteness effect is caused by an OBLIGATORY TEMPORAL ADVERB OF QUANTIFICATION that can be overt - like always - or phonetically empty, in which case it gets by default an existential quantifier meaning, represented as "ヨ".15

$\llbracket \exists \rrbracket=$ the function $\mathrm{f}: \mathrm{D}<\mathrm{i}, \triangleright \rightarrow \mathrm{D}<\mathrm{it}, \mathrm{t}>$ such that for any $p, q \in D<i, \downarrow, f(p)(q)=1$ iff there is a time $\mathrm{t}^{*}$ such that: $\mathrm{p}\left(\mathrm{t}^{*}\right)=1$ and $\mathrm{q}\left(\mathrm{t}^{*}\right)=1$.

As we will see shortly, tense functions as a restrictor of the obligatory adverb of quantification.

Temporal definiteness is treated as a phenomenon caused either by explicit DEFINITE TEMPORAL ADVERBIALS (like today) or by IMPLICIT DEFINITE TEMPORAL RESTRICTIONS of the adverb of quantifiation $\exists$. Implicit temporal restrictions are provided by the context and represented as a variable "C". Technically, I will assume that these variables are elements of type $\langle i, t\rangle$ that are interpreted by intersection with other restrictive material in the restrictive clause of $\exists .16$ The interpretation of $C$ is captured in (32). Since temporal interpretation is thus evaluated relative to the discourse context, interpretations will henceforth be made relative to contexts, as marked with the superscript "c".17

15 Note that there are also empty operators with a generic or universal meaning.

16 See also von Fintel (1994) on implicit restrictions of quantifiers.

17 In a Bäuerle/Kratzer/Stechow type account, temporal definiteness is caused by an obligatory definite time adverbial. This obligatory time adverbial can be overt - like today or phonetically empty, in which case it is represented as "then*". It functions as a frame adverbial that provides a contextually relevant definite time. The main difference between von Stechow's proposal and my version of it is that I treat implicit definite temporal adverbials as part of the restrictive clause of the adverb of quantification that will shortly be introduced. The motivation for the modification is that it assigns a generalized quantifier type to the adverb of quantification. Furthermore, as Kai von Fintel pointed out to me, this step makes it possible to treat temporal definiteness as a special case of implicit restrictions of quantifiers that are commonly assumed anyway (cf. von Fintel (1994)). 
[IC] ] $]^{c}=$ the function $\mathrm{f}: \mathrm{Di} \rightarrow \mathrm{Dt}$, such that for any $t^{*} \in \mathrm{Di}, \mathrm{f}\left(\mathrm{t}^{*}\right)=1$

iff $t^{*}$ is a subinterval of the time the speaker in $c, s_{c}$, refers to.

In order to implement the proposal on temporal interpretation I just sketched, we will make furthermore the following assumptions:

- There are three basic semantic types: $e$ (entities), $t$ (truth values), and $i$ (times).

- Time variables are made explicit and occupy positions in the syntactic structure.

- Verbs have time arguments. Syntactically, the time arguments appear as a sister of the verb.

- Above TP, there are (at least) the functional categories AGRs-P, and CP.

- LFs correspond, as far as temporal adverbials, adverbs of quantification, and tense are concerned, to the unmarked surface order of sentences.

- The syntactic surface tree has noun phrase arguments in case positions. At LF, noun phrases can occur in their base position when they are reconstructed.

- The LF is not in general interpretable just by functional application between daughters of any binary branching node. Instead, the following mechanism applies: For the interpretation of any quantifier - i.e. an element of type $<\sigma t$ $\langle\sigma t, t\rangle>$, where $\sigma$ may be of any type - a tripartite semantic representation is constructed, consisting of the quantifier, a restrictive clause, and a nuclear scope. The restrictive clause and the nuclear scope get filled with any material of the appropriate type that can be found below the next dominating node of type $t$, which defines the maximal scope of the quantifier. In the sample structure below, which contains the phonetically empty adverb of quantification $\exists$ this is the highest of the TP-nodes. - The quantifier $\exists$ is of type $\langle i t,\langle i t, t\rangle>$. Thus, it needs at least two arguments of type $\langle i, t\rangle$, which are to be filled into the restrictive clause and the nuclear scope, respectively. The mapping into restrictive clause and nuclear scope proceeds as follows: first, the lowest argument of the appropriate type is mapped into the nuclear scope; second, all other arguments of the appropriate type are filled into the restrictive clause and are conjoined there. Thus we have the principle of Tripartite Structure Construction: The lowest appropriate argument gets into the nuclear scope. All other arguments of the appropriate type get into the restrictive clause.

- The following semantic rules apply:

Functional Application: $[[\alpha \beta \rrbracket=\llbracket \alpha \rrbracket(\llbracket \beta \rrbracket)$ or $=\llbracket[\beta \rrbracket(\llbracket \alpha \rrbracket)$

Predicate Abstraction: (with $\mathrm{i}$ index) $[[\mathrm{i} \alpha \rrbracket \mathrm{g}=\lambda \mathrm{x}[[\alpha] \mathrm{g}[\mathrm{x} \rightarrow \mathrm{i}]$

$\lambda$-Conversion: $\left[\left[\lambda \mathrm{x} \alpha \rrbracket^{\mathrm{g}}(\mathrm{i})=\llbracket[\alpha]^{\mathrm{g}}[\mathrm{x} \rightarrow \mathrm{i}]\right.\right.$

Predicate Modification (here for predicates of times, when there are several restricting elements in the restrictive clause of an adverb of quantification):

$\llbracket \alpha \& \beta \rrbracket(i)=1$ iff $\llbracket \alpha \rrbracket(i)=1$ and $[[\beta \rrbracket(i)=1$. 
Let me now briefly illustrate with an example how this proposal works. Suppose Eva-Lotta smiled is uttered in the context given in (33a). According to the proposal of temporal interpretation I just sketched, Eva-Lotta smiled has a hidden structure roughly like (33b), which corresponds to the LF (33c). In order to save space in the LF-representation, I attach $\lambda$-binders directly to category nodes. With such nodes, semantic types appear below and above the category node. The types are the types before and after $\lambda$-abstraction, respectively.

(33) a. On Sunday afternoon, I met Eva-Lotta and Gregory at Harvard Square. Eva-Lotta smiled.

b. $\quad \exists$ C Eva-Lotta smiled

c.

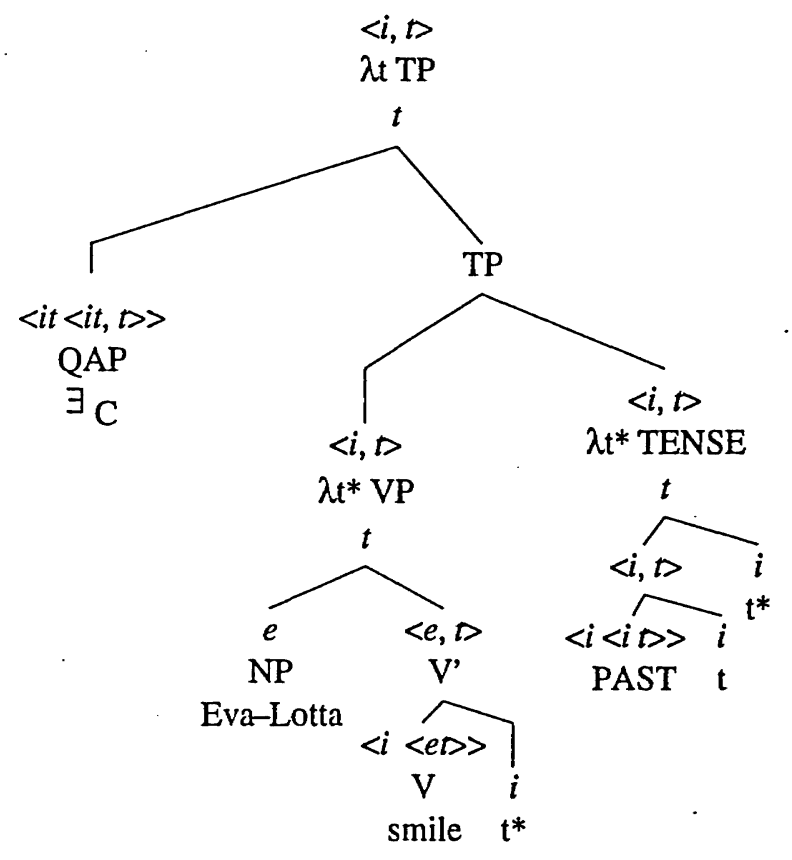

From this LF, the semantic representation (33d) is constructed. The adverb of quantification takes tense and the temporal variable $C$ as its restrictors, whereas the rest of the clause is mapped into its nuclear scope.

$$
\text { d. } \quad \lambda t\left(\exists\left[\lambda t^{*}\left(\mathrm{C}\left(\mathrm{t}^{*}\right)\right) \& \lambda \mathrm{t}^{*}\left(\operatorname{PAST}(\mathrm{t})\left(\mathrm{t}^{*}\right)\right)\right]\left[\lambda \mathrm{t}^{*}\left(\text { smile }\left(\mathrm{t}^{*}\right)(\text { Eva-Lotta })\right)\right]\right)
$$

Because of the context provided by the first sentence in (33a), the most preferred reading of the underlined clause is one where the implicit $C$ in the underlined 
sentence refers to the time on last Sunday afternoon when I met Eva-Lotta and Gregory. The lexical entries of verbs and proper names are given in (34) and (35), respectively.

$\llbracket$ smile $\rrbracket^{c}=$ the function $\mathrm{f}: \mathrm{Di} \rightarrow \mathrm{D}<\mathrm{e}, \mathrm{D}$ such that for any $t \in D i, x \in D, f(t)(x)=1$ iff $x$ smiles at $t$.

[Eva-Lotta $\prod^{\mathrm{c}}=$ the individual Eva-Lotta (of type $e$ ).

Suppose (33a) is uttered now. The truth conditions of Eva-Lotta smiled in (33a) are then calculated as shown in (36).

$$
\begin{aligned}
& \llbracket \exists \text { C Eva-Lotta smiled }]^{c} \text { (now) }=1 \\
& \text { iff [by Tripartite Structure Construction }] \\
& {\left[\lambda t \left(\exists\left[\lambda t^{*}\left(C\left(t^{*}\right)\right) \& \lambda t^{*}\left(\operatorname{PAST}(t)\left(t^{*}\right)\right)\right]\right.\right.} \\
& \left.\left.\left[\lambda t^{*}\left(\text { smile }\left(t^{*}\right)(\text { Eva-Lotta) })\right]\right)\right]\right]^{c}(\text { now })=1
\end{aligned}
$$

iff [by $\lambda$-Conversion]

$\llbracket \exists\left[\lambda t^{*}\left(\mathrm{C}\left(\mathrm{t}^{*}\right)\right) \& \lambda \mathrm{t}^{*}\left(\operatorname{PAST}(\mathrm{t})\left(\mathrm{t}^{*}\right)\right)\right]$

$\left[\lambda t^{*}\left(\right.\right.$ smile $\left(t^{*}\right)$ (Eva-Lotta) $\left.\left.\left.)\right]\right]\right]^{c,[t \rightarrow \text { now }]}=1$

iff [by lexical entry of $\exists$ ]

there is a time $\mathrm{t}^{*}$ such that

$\left.\left[\pi \lambda t^{*}\left(\mathrm{C}\left(\mathrm{t}^{*}\right)\right) \& \lambda \mathrm{t}^{*}\left(\operatorname{PAST}(\mathrm{t})\left(\mathrm{t}^{*}\right)\right)\right]\right]^{\mathrm{c},[\mathrm{t} \rightarrow \mathrm{now}]}\left(\mathrm{t}^{*}\right)=1$ and

$\left[\lambda t^{*}\left(\text { smile }\left(t^{*}\right) \text { (Eva-Lotta)) }\right]\right]^{c,[t \rightarrow \text { now }]}\left(\mathrm{t}^{*}\right)=1$

iff [by Predicate Modification applied to the restrictive clause]

there is a time $t^{*}$ such that

$\left.\left[\pi t^{*}\left(C\left(t^{*}\right)\right)\right]\right]^{c},\left[t \rightarrow\right.$ now] $\left(t^{*}\right)=1$ and

[I $\left.\left.\left.\lambda t^{*}\left(\operatorname{PAST}(t)\left(t^{*}\right)\right)\right]\right]\right]^{c},\left[t \rightarrow\right.$ now] $\left(t^{*}\right)=1$ and

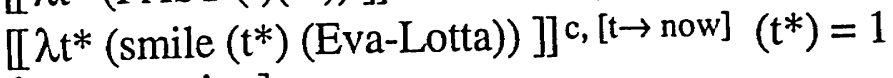

iff [by $\lambda$-Conversion]

there is a time $t^{*}$ such that

$\left[\left[C\left(t^{*}\right)\right]\right]^{c,}{ }^{\left[\begin{array}{l}\mathrm{t} \rightarrow \text { now } \\ \mathrm{t}^{*} \rightarrow \mathrm{t}^{*}\end{array}\right]}=1$ and

$\left.\left.\operatorname{mPAST}(\mathrm{t})\left(\mathrm{t}^{*}\right)\right]\right]^{\mathrm{c},}{ }^{\left[\begin{array}{l}\mathrm{t} \rightarrow \text { now } \\ \mathrm{t}^{*} \rightarrow \mathrm{t}^{*}\end{array}\right]}=1$ and

$\left[\text { s smile }\left(t^{*}\right)(\text { Eva-Lotta) }]\right]^{c,}{ }^{\left[\begin{array}{l}t \rightarrow \text { now } \\ t^{*} \rightarrow t^{*}\end{array}\right]}=1$ 
iff [by lexical entries of the remaining elements, variable assignment applied to $\mathrm{t}$ and $\mathrm{t}^{*}$ ]

there is a time $t^{*}$

such that $t^{*}$ is a subinterval of the time of last Sunday afternoon

when I met Eva-Lotta and Gregory, and

$\mathrm{t}^{*}<$ now, and

(Eva-Lotta is alive at $t^{*}$, and)

Eva-Lotta smiles at $t^{*}$.

In the next subsection, I want to show how the framework of temporal interpretation I just sketched can be used to account for the blocking of life-time effects in certain contexts. Before I go into this, I want to add in an appendix to this section a brief discussion of some aspects of my treatment of temporal adverbials as restrictors of temporal adverbs of quantification. Since the material presented therein is not crucial to the following discussion, the appendix can be skipped.

\section{Appendix to Section 3.2.: Definite and indefinite temporal adverbials, quantifier restrictions, scrambling, and related issues}

Definite temporal adverbials as restrictors. I adopted in Section 3.2. the view that temporal (frame) adverbials function as restrictors of the obligatory temporal adverb of quantification of a clause, no matter whether they are definite like on that Monday or indefinite like on Mondays.

This is not an inevitable assumption. For example, von Stechow (1992) assumes that definite temporal adverbials have wide scope over the adverb of quantification, whereas indefinite temporal adverbials function as restrictors of temporal adverbs of quantification. A consequence of his analysis is that he has to assume different semantic types for definite and indefinite temporal adverbials $<<i t>, t>>>$ and $\langle i, t>$, respectively - and that the temporal adverb of quantification has a relatively complicated type, namely $\langle i,\langle<i t\rangle,\langle<i t\rangle, t\rangle\rangle>$.

In my analysis, definite and indefinite temporal adverbials are of the same type, namely simply $<\mathrm{i}, \mathrm{t}\rangle$. And temporal adverbs of quantification are of type $<<\mathrm{it}>,<<\mathrm{it}>, \mathrm{t}>>$; since this type is a generalized quantifier type analogous to the commonly assumed type of determiner-quantifiers, this analysis seems more desirable to me. Thus, instead of assuming two different semantic types for 
temporal adverbials and an undesirable type of adverbs of quantification, I assume a uniform semantic type for temporal adverbials and a generalized quantifier type for adverbs of quantification.

In the following, I want to sketch the background assumptions of my analysis and integrate them into a more general picture of the syntax/semantics interface. Although I cannot present a thorough investigation of the relevant issues here, I believe that it can be shown that the difference between definite and indefinite temporal adverbials with respect to their surface position can be derived from more general, independently motivated principles of scrambling. Basically, I want to propose that scrambling of noun phrases and scrambling of temporal adverbials have the same triggers. This suggests that there are significant similarities between noun phrases and temporal adverbials. As we will see, there are also significant differences between noun phrases and temporal adverbials - namely as far as their mapping at LF is concerned. It seems that semantic differences between scrambled noun phrases and scrambled temporal adverbials on the one hand, and between unscrambled noun phrases and unscrambled temporal adverbials on the other hand, can also be derived from independent principles of mapping and differences concerning the $\mathrm{D}$-structural properties of the elements in question.

If I understand von Stechow correctly, the motivation for his analysis is the unmarked surface order of the adverbials in German clauses in connection with the idea that the surface position of adverbials corresponds to their scope at LF. Consider (37).
a. weil Hanna [TAdef im letzten Mai] immer angeln ging since Hanna in-the last May always fishing went
b. ? weil Hanna immer [TAdef im letzten Mai] angeln ging since Hanna always in-the last May fishing went
c. ? weil Hanna, [TAindef wenn es regnete] immer angeln ging since Hanna when it rained always fishing went
d. weil Hanna immer, [TAindef wenn es regnete] angeln ging since Hanna always when it rained fishing went

The crucial observation is that (37a), which contains a definite temporal adverbial, is less marked than (37b), whereas (37c), which contains an indefinite temporal adverbial, is more marked than its counterpart (37d). 
However, what I am proposing is that definite temporal frame adverbials are semantically always part of the restrictor of an adverb of quantification. Their surface position does not affect their semantic function. Rather, it is the result of syntactic movements that are associated with topic-focus structure, i.e. scrambling and sometimes topicalization.

Temporal adverbials can be scrambled. That topicalization applies to temporal adverbials is well-known. I.e., the English construction (38a) and the German construction (38b) are obviously the result of topicalization movements that are typical for the respective language.

(38) a. On Monday, the subway broke down.

b. Am Montag brach die U-Bahn zusammen. on Monday broke the subway together

('On Monday, the subway broke down.')

The assumption that temporal adverbials in German undergo scrambling may seem at first sight unusual. Although there is much literature on scrambling of noun phrases in German (e.g. Büring (1994), Jäger (1995) and others), little has been said about the surface positions of temporal adverbials. Büring (1994) mentions that adverbials in general do not have a completely fixed position and states that if they are moved away from their base position they can only be raised but never lowered, but he doesn't say what conditions are associated with the raising of adverbials.

It seems to me that raising of temporal adverbials is associated with similar properties similar to those associated with scrambling of noun phrases. I don't want to go here into a detailed discussion of what the triggers for scrambling of noun phrases are. Let me just state here that according to Büring (1994), von Fintel (1994), and Jäger (1995), scrambling of noun phrases is associated with properties like definiteness, specificity, or topicality - where definiteness and specificity can be analyzed as a special case of topicality.

What is important here is that in some respects, the positions of temporal adverbials and of noun phrases relative to adverbs of quantification seem to be associated with similar properties. Both noun phrases and temporal adverbials tend to be located to the left of adverbs of quantification when they are definite, or, when they are indefinite and specifically interpreted - where "specific" means 
that the speaker has a particular individual or time interval in mind which is characterized by the indefinite noun phrase or the indefinite temporal adverbial, respectively.

Thus, (39a) and (40a), where a definite noun phrase or temporal adverbial appear to the right of the adverb of quantification immer ('always') are marked when not combined with a particular focus articulation. ${ }^{18}(39 \mathrm{~b})$ and (40b) on the other hand are fine, because here the definite items appear on the left of the adverb of quantification. In (39c, d) and (40c, d), indefinite noun phrases and temporal adverbials appear on the right hand side and on the left hand side of the adverb of quantification, respectively. When they appear on the right hand side, they are preferredly unspecific, but when they appear on the left hand side, the resulting sentences appear strange unless the items are specifically interpreted, i.e. unless the speaker has a particular woman or a particular Sunday in mind, respectively.

(39) a. ?? weil immer die Frau angeln ging since always the woman fishing went

b. weil die Frau immer angeln ging since the woman always fishing went

c. weil immer eine Frau angeln ging [preferredly unspecific] since always a woman fishing went

d. weil eine Frau immer angeln ging [preferredly specific] since a woman always fishing went

(40) a. ?? weil Hanna immer an diesem schrecklichen Sonntag angeln ging since Hanna always on that terrible Sunday fishing went

b. weil Hanna an diesem schrecklichen Sonntag immer angeln ging since Hanna on that terrible Sunday always fishing went

c. weil Hanna immer an einem Sonntag angeln ging [pref. unspecific] since Hanna always on a Sunday fishing went

d. weil Hanna an einem Sonntag immer angeln ging [pref. specific] since Hanna on a Sunday always fishing went

Let us thus assume that temporal adverbials as well as noun phrases can be scrambled in German and that scrambling of both items is associated with some property in the range of topichood.

18 E.g., the noun phrase must be focused. 
Scrambling of noun phrases and temporal adverbials and mapping at LF. The issue of base positions and scrambling positions of elements is related to another issue - namely the issue of how the positions of elements affect their mapping at LF. With respect to noun phrases, the work of Diesing (1992) resulted in some relatively clear-cut observations: Diesing (1992) argued that in German, indefinite noun phrases on the right of adverbs of quantification are mapped at LF into the nuclear scope (NS), whereas indefinite noun phrases on the left of adverbs of quantification are mapped into the restrictive clause (RC) of the adverb of quantification. Here is an illustration of this effect.

a. weil Feuerwehrmänner immer verfügbar sind [mapped into RC] since firemen always available are

ALWAYS $_{\mathrm{X}}$ [firemen (x)] [available (x)]

b. weil immer Feuerwehrmänner verfügbar sind [mapped into NS] since always firmen available are ALWAYSt $[C(t)] \exists_{x}[$ fireman $(x) \&$ available $(x, t)]$

One may ask whether there are similar observations with temporal adverbials and how these are related to scrambling of temporal adverbials. 19

Instead of going into a detailed discussion of this question, let me present here a schematic structure that shows the relevant positions of noun phrases, temporal adverbials, and operators, and gives some impression of what the mapping behavior of temporal adverbials (TAs) and noun phrases (DPs) seems to be like. Note that I assume here that the existential closure operator is to be distinguished from the implicit temporal adverb of quantification $\exists .20$ I assume

19 Johnston (1994) has argued that the interpretation of temporal adverbials is affected by their position, in a similar way as the interpretation of noun phrases.

20 This claim may be in need of a thorough further investigation. Evidence for the distinction between the existential closure operator and adverbs of quantification may be that the existential closure operator is unrestrictive, whereas adverbs of quantification are restrictive. Furthermore, existential closure can obviously occur when an overt adverb of quantification is present, as we have seen with Diesing's example above.

Thus, I think it is not possible to identify the implicit existential temporal adverb of quantification with the existential closure operator that is commonly assumed to close the VP existentially (cf. Heim (1982), Diesing (1992) and others). I adopt here the view of Beck (1994, 25f) according to whom the existential closure operator is of a completely different nature than quantifiers in a narrower sense. The existential closure operator is not part of LF as a syntactic object; it is rather "part of the process of interpreting the LF, that is, one of the general rules that can be used in deriving the interpretation of a logical form", Beck argues and concludes that the existential closure operator lacks the tripartite structure characteristic of quantification in the narrow sense. 
that both the existential closure operator and the temporal adverb of quantification are obligatory elements in the structure.

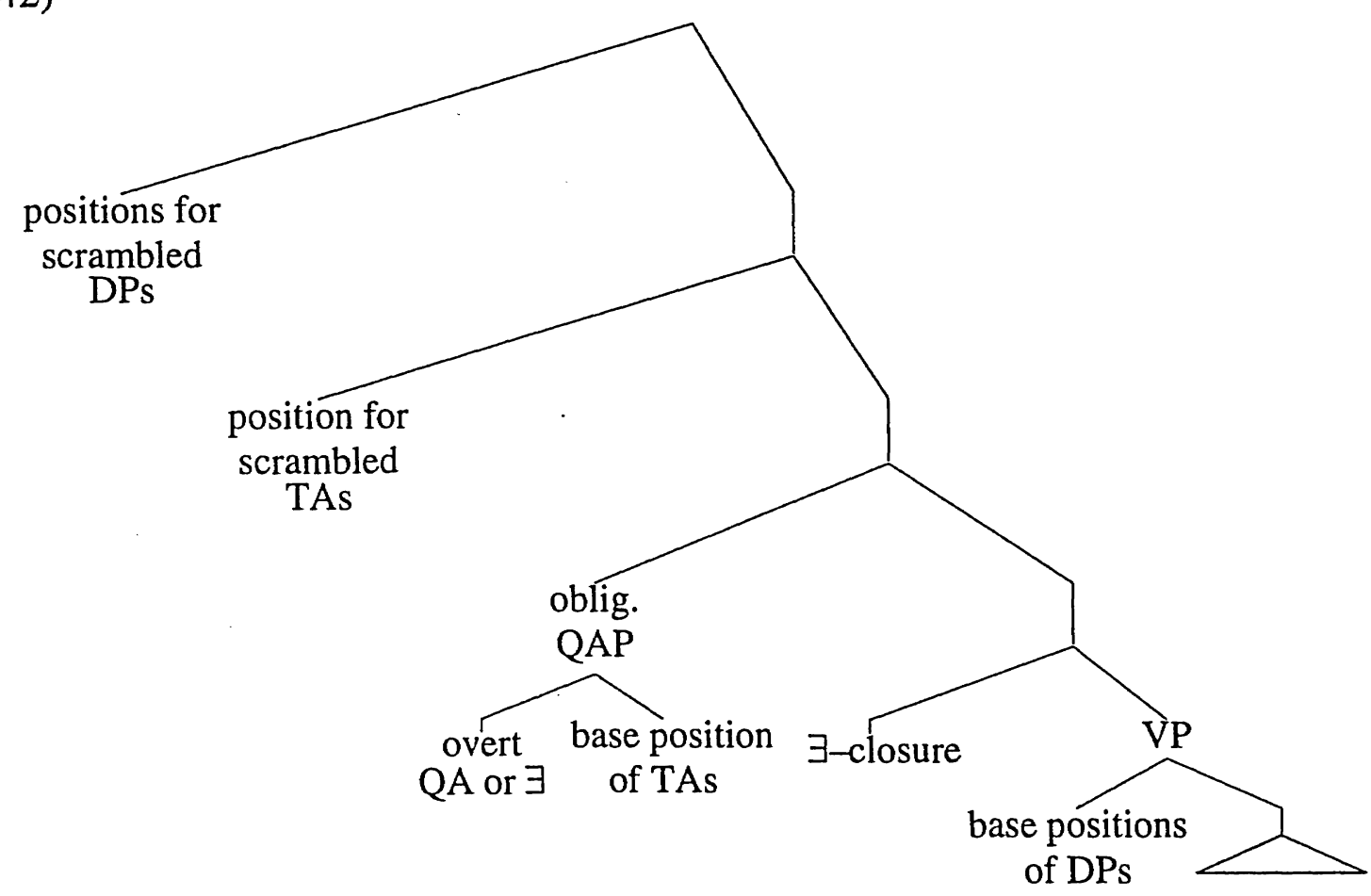

Another assumption I am making here is that temporal adverbials are basegenerated as complements of adverbs of quantification; thus, adverbs of quantification relate to temporal adverbials just as determiners relate to NPs. 21 Here are some crucial hypotheses and predictions related to the structure in (42):

Note here that the obligatory temporal adverb of quantification should also not be assumed to be an operator that can replace the generic operator that is responsible for the generic quantificational force of some indefinite noun phrases. This can be concluded from the fact that generic noun phrases can appear in a clause with existential quantification over (truth-) time intervals:

(A) a. In 1943, farmers didn't smile.

b. = For farmers in general there is no subinterval of 1943 , such that any farmer smiles.

To summarize, the existential quantifier needed for temporal interpretation in the absence of overt adverbs of quantification and the operators needed for noun phrase interpretation are crucially distinct.

21 This assumption is also open to further debate. Evidence in favor of it is that in V-2 clauses in German, adverbs of quantification and temporal adverbials can be topicalized together:

(A) a. weil Hanna immer am Montag angeln geht 
(43) Noun phrases and temporal adverbials appear in a scrambled position when they are topical (and perhaps sometimes for other reasons).

(44) When a noun phrase appears to the right of the adverb of quantification, it is presumably not a good candidate for restricting the adverb of quantification. This is because a noun phrase in this position is in the scope of the existential closure operator that captures unbound variables within the noun phrase.

(45) When a temporal adverbial appears to the right of the adverb of quantification, it is not in the scope of the existential closure operator. Since there is no other operator around that could capture unbound variables introduced by an temporal adverbial, temporal adverbials always serve as restrictors of the adverb of quantification.

(46) I assume that temporal adverbials can give rise to readings as follows:

a. weil Hans mich immer am Montag besucht hat

b. definite interpretation: On the contextually salient Monday, Hans visited me all the time.

ALWAYS $t$ [ $t$ is a time of the contextually salient Monday]

[Hans visited me at $\mathrm{t}$ ]

c. indefinite interpretation, where the TA restricts an overt adverb of quantification: Hans visited me on every Monday. ALWAYSt [t is a Monday] [Hans visited me at $\mathrm{t}$ ]

d. indefinite interpretation, where the TA restricts a second, silent, existential quantifier 22: Whenever Hans visited me, it was MONDAY. $\overline{\text { ALWAYS }}_{\mathrm{t}}$ [Hans visited me at $\left.\mathrm{t}\right]$

$$
\left[\exists_{\mathrm{t}} *[\mathrm{t} * \text { is a time on a Monday }][\mathrm{t} \text { is part of } \mathrm{t} *]\right]
$$

Whether these ideas are on the right track is an empirical question which I have to leave to future research.

\section{since Hanna always on Monday fishing goes \\ b. Immer am Montag geht Hanna angeln. always on Monday goes Hanna fishing}

22 This is very similar to what Johnston (1994) suggests. There is some indication that this structure is adequate: as observed by Bäuerle (1979), there are constructions where two adverbs of quantification can appear explicitly.

(A) a. weil Hans mich in Schaltjahren immer zweimal besucht hat since Hans me in leap-years always twice visited has

b. In all leap-years, Hans visited me twice. ALWAYSt $t \mathrm{t}$ is a leap-year \& $\mathrm{t}$ is before now]

[TWICE $\mathrm{T}^{*}[\mathrm{t} *$ is part of $\mathrm{t}]$ [Hans visits me at $\left.\mathrm{t}^{*}\right]$ ]

Thus, one can treat the implicit existential quantifier in (46d) as a special case of a second adverb of quantification as in (A). - Note that in iterative constructions of adverbs of quantification, the tense of the clause is apparently always mapped into the outermost restrictive clause. 


\subsection{Informativity in temporally specific contexts}

With the semantics sketched in Subsection 3.2., we have almost gained a tool for explaining the neutralization of life-time effects in sentences like the ones in (3) or (28). What these sentences have in common is that they appear in temporally specific contexts, and I will propose in this subsection that the temporal specifications serve as implicit restrictors of $\exists$ and thus give sentences in temporally specific contexts a semantic representation that differs from that of sentences that are uttered out of the blue. When informativity requirements apply to the context-restricted structures, life-time effects are predicted to be neutralized.

Consider again the sentences in (28). According to our refined semantics, these sentences have implicit temporal adverbials which get a value from the context assigned - in this case a value that is provided by the preceding linguistic context. In (47) the contextually provided temporal restriction is represented as the expression in square brackets. 23

(47) a. On that day, I was introduced to Gregory and Eva-Lotta.

[when I was introduced to Gregory and Eva-Lotta on that day] Gregory was from America, ...

b. I had a chance to have a closer look at him. [when I looked at him] Gregory had blue eyes.

c. Suddenly I realized a remarkable thing:

[when I looked at him] Gregory resembled Jörg Bieberstein.

In Section 2, I presented an account of life-time effects that was based on the assumption that life-time effects with past tense clauses are triggered by a lack of informativity of past tense individual-level clauses in situations where a present tense clause is also true. Specifically, I observed that the relevant aspect of informativeness concerns the duration of the time during which the main predicate can be truly predicated of its subject.

Since the sentences where life-time effects are blocked have in common that they appear in temporally specific contexts, the minimal hypothesis about these sentences is that the temporal specifications change the conclusions drawn from considerations of informativity. Let us see how this helps to explain the blocking

23 The choice of values is a bit arbitrary here and only one of several possibilities. 
of life-time effects in (47). The truth conditions of Gregory was from America in the temporally specific context (47a), repeated here as (48a), can be stated as in (48b).

(48) a. On that day, I was introduced to Gregory and Eva-Lotta. [when I was introduced to Gregory and Eva-Lotta on that day] Gregory was from America, ...

b. $\quad[\exists$ [when I was introduced to Gregory and Eva-Lotta on that day] Gregory was from America $\prod^{c}$ (now) $=1$ iff there is a time $t^{*}$ such that $t^{*}$ is a subinterval of the time when I was introduced to Gregory and Eva-Lotta on that day, and $\mathrm{t}^{*}<$ now, and (Gregory is alive at $\mathrm{t}^{*}$, and) Gregory is from America at $t^{*}$.

The fact that (48a) does not trigger a life-time effect can now be derived as shown in (49).

(49) Derivation of the lack of the life-time implicature of (48a):

(a) The speaker has expressed the proposition that there is a time $t^{*}$ such that $t^{*}$ is a subinterval of the time when I was introduced to Gregory and Eva-Lotta on that day, and $t^{*}<$ now, and Gregory is from America at $t^{*}$.

Since the day denoted by that day is over at the time of utterance of (48a), the time during which Gregory is from America that is located within that day is over at the time of utterance of (48a) anyway.

Consequently, the speaker does not have any alternatives of expressing anything about the duration of Gregory's being from America - i.e., the choice of the use of present tense does not exist, because the time interval of that day is not an environment of now.

Because of the impossibility of combining present tense with a restriction to that day, there is no way of expressing a more informative proposition about the duration of Gregory's being from America. Thus, informativity considerations cannot take place with (48a). As a consequence, (48a) does not implicate anything about the duration of Gregory's being from America, and hence it does not implicate anything about Gregory's life-time being over now. Thus, the analysis predicts the blocking of life-time effects with temporally specific sentences like (48a). 


\subsection{Informativity and life-time effects in out-of-the-blue sentences: the final analysis}

Let's go back to the sentences where the life-time effects are not neutralized by temporally specific contexts, e.g. (1). In order to treat these cases adequately in our refined semantics, we have to develop a hypothesis of what happens to $C$ when there is no explicit contextually salient time interval provided.

I propose that in temporally unspecific contexts, when there is no better candidate for assigning values around, elements whose denotation does not directly provide a time interval are able to supply values for $C$. In particular, I want to argue that noun phrases are able to supply values for $C$ in such cases. Specifically, they provide the time of existence of the individual they denote as a value for $C$. Thus, let us assume that Gregory provides the value for $C$ in Gregory was from America when uttered in a temporally unspecific context. The truth conditions of this sentence can then be stated as in (50c).

(50) a. $\exists$ [Gregory's time of existence] Gregory was from America.

b. $\quad \lambda t\left(\exists\left[\lambda t^{*}\left(\left[\right.\right.\right.\right.$ Gregory's time of existence $\left.\left.\left(t^{*}\right)\right) \& \lambda t^{*}\left(\operatorname{PRET}(t)\left(t^{*}\right)\right)\right]$

$$
\left.\left[\lambda t^{*} \text { (be-from-America }\left(\mathrm{t}^{*}\right)(\text { Gregory })\right)\right] \text { ) }
$$

c. $\llbracket \exists\left[\right.$ Gregory's time of existence] Gregory was from America $\rrbracket^{c}$ (now) $=1$ iff there is a time $t^{*}$

such that $t^{*}$ is a subinterval of Gregory's time of existence, and

$\mathrm{t}^{*}<$ now, and

(Gregory is alive at $t^{*}$, and)

Gregory is from America at $t *$.

The fact that (50a) triggers a life-time effect can now be derived with the pragmatic justification schema (51) that differs only minimally from (17).

(51) Working out of the implicature of (50a):

(a) The speaker has expressed the proposition that there is a time $t^{*}$ such that $t^{*}$ is a subinterval of Gregory's time of existence, and $t^{*}<$ now, and Gregory is from America at $\mathrm{t}^{*}$.

(b) There is no reason to suppose that the speaker is not observing the Cooperative Principle and maxims, in particular the principle of informativeness.

(c) Thus, the hearer assumes that the speaker is maximally informative about Gregory's being from America - in particular about the duration of Gregory's being from America. 
(d) If the speaker thought that Gregory's being from America is not over, he would have expressed the proposition that Gregory is from America, since that would have been a more informative alternative utterance about the duration of Gregory's being from America.

(e) Thus, the speaker couldn't have been maximally informative about Gregory's being from America unless he thought that Gregory's being from America is over.

(f) Thus, the speaker has implicated that Gregory's being from America is over.

(g) Since being from America is a property that, if it holds of an individual at all, holds of that individual during all its life-time, the hearer concludes further that, since the speaker has implicated that Gregory's being from America is over, the speaker has implicated that Gregory is dead.

The crucial difference between (48a) and (50a) is thus that (48a) cannot implicate anything about whether the duration of Gregory's being from America reaches into the present, because the specific temporal restriction restricts the perspective on Gregory's being from America exclusively to the past. With (50a), no such restriction applies.

There is of course another question to be asked: why is it the subject noun phrase whose denotation provides a value for $C$ ? So far I have just stipulated that Gregory is the relevant noun phrase in our example. But at first sight it seems just as plausible to assume that America may serve as the relevant provider of a temporal value. If that were the case, then no serious problem would arise because the time of existence of America includes in fact the time of existence of Gregory.

But consider the sentence (52) in a situation where Gregor is still alive. The USSR doesn't exist anymore.

Gregor was from the USSR.

. There is a very clear intuition that in this situation, Gregor was from the USSR still triggers a life-time effect. If the USSR could serve as the provider of the value for $C$ in this example, this would be unexpected. Since the time of existence of the USSR is over now, the life-time effect should disappear. But it does not.

Thus, to come back to our earlier example, there must be at least some strong preference for taking Gregory instead of America as the value providing noun phrase. I want to propose here that this effect is due to a preference to take 
topical noun phrases as providers of values for $C$. Since subject noun phrases are default topics, it follows automatically that in our example Gregory is the strongly preferred value provider. 24 The preference for topical elements as value providers is actually not very surprising. Topical elements are in general contextually especially salient and particularly good providers of restrictive material for quantifiers (see von Fintel (1994)).

Note that at first sight, there is another possibility conceivable for the treatment of Gregory was from America when uttered out of the blue - namely that $C$ simply does not get a value assigned from the context and thus simply does not provide a restrictor for $\exists$, as in (53a). Let's assume that this gives us the truth conditions in (53b).
a. $\quad \exists$ Gregory was from America.
b. $\llbracket \exists$ Gregory was from America $\rrbracket^{c}$ (now) $=1$
iff there is a time $t^{*}$ such that $t^{*}<$ now, and
(Gregory is alive at $t^{*}$, and)
Gregory is from America at $t^{*}$.

With this reading, considerations similar to (51) apply, and it seems that (53) provides a possible, and simpler, approach to the fact that the utterance of Gregory was from America in a temporally unspecified context triggers life-time effects. The approach would be simpler, because reference to implicit temporal restrictions would be unnecessary. But would this approach really be able to treat all phenomena in connection with life-time effects adequately?

There is in fact evidence that the approach just sketched is insufficient. Thus, it is unable to explain a shifting of life-time effects that occurs under certain circumstances with predicates that have more than one argument. Consider (54)

24 This observation can probably be productively related to another observation: Declerck (1991, 344f) discusses briefly the pair of sentences

(A) Einstein has visited Princeton.

(B) Princeton has been visited by Einstein.

that illustrates a related phenomenon with present perfect. Here, (A) suggests (wrongly) that Einstein is still alive, whereas (B) suggests that Princeton still exists. This observation goes apparently back to work by Curme and Jespersen in the thirties: G. O. Curme (1931): Syntax. Boston: D. C. Heath. O.Jespersen (1931): A Modern English Grammar on Historical Principles, part 4: Syntax (vol.3). London: Allen \& Unwin; Copenhagen: Ejnar Munksgaard. 
in contrast to the English sentence Aunt Theresa resembled my grandmother, which was introduced in (27), and its German equivalent Tante Theresa ähnelte meiner Großmutter: here the sequencing of the noun phrases is changed. The dative object meiner Großmutter is topicalized into the preverbal position.25

Meiner Großmutter ähnelte Tante Theresa. [OBJ my grandmother] resembled [sUBJ Aunt Theresa]

('Aunt Theresa resembled my grandmother.')

The interesting observation about (54) is that compared to (27), the life-time effect has shifted. Recall that with (27), repeated here as (55), we observed a lifetime effect concerning Aunt Theresa; in order for the sentence to be appropriate when uttered out of the blue, Aunt Theresa had to be dead. The grandmother being dead with Aunt Theresa being alive did not save the sentence.

Aunt Theresa resembled my grandmother.

But with (54) it seems that the state of being dead of either one of Aunt Theresa and the grandmother is sufficient to make the sentence fully acceptable. With the simplified approach of (53), the contrast between (54) and (27) remains a mystery.

With the approach based on implicit temporal restrictions provided by topical elements on the other hand, the shift of the life-time effect in (54) can be easily explained. Let's assume that the topicalization of meiner Großmutter leads to a situation where this noun phrase is preferredly understood as the topic of the sentence. 26 Thus, for (54) we predict the truth conditions in (56).

[I $\exists$ [my grandmother's time of existence]

iff there is a time $t^{*}$ meiner Großmutter ähnelte Tante Theresa $\prod^{c}$ (now) $=1$

such that $t^{*}$ is a subinterval of my grandmother's time of existence, and $\mathrm{t}^{*}<$ now, and

(Aunt Theresa is alive at $t^{*}$, and)

Aunt Theresa resembled my grandmother at $t^{*}$.

25 The possessive pronoun meiner ('my') is added in this example to make clear that the noun phrase in topicalized position is the dative object.

26 Things are in fact not that simple. It seems that topicalization in German can lead either to a preferredly topical or to a preferredly focal nature of the topicalized element. But since the life-time effect in (53) can apparently concern either the grandmother or Aunt Theresa, this is no problem for my approach. 
Thus, because of the temporal restriction provided by the topical noun phrase meiner Großmutter,

(57) Working out of the implicature of (56):

(a) The speaker has expressed the proposition that there is a time t* such that $\mathrm{t}^{*}$ is a subinterval of the grandmother's time of existence, and $\mathrm{t}^{*}<$ now, and Aunt Theresa resembled the grandmother at $t^{*}$.

(b) There is no reason to suppose that the speaker is not observing the Cooperative Principle and maxims, in particular the principle of informativeness.

(c) Thus, the hearer assumes that the speaker is maximally informative about Aunt Theresa's resembling the grandmother during a subinterval of the grandmother's existence - in particular about the duration of Aunt Theresa's resembling the grandmother during a maximally long subinterval of the grandmother's existence. 27

(d) If the speaker thought that Aunt Theresa's resembling the grandmother during a maximally long subinterval of the grandmother's existence is not over, he would have expressed the proposition that Aunt Theresa resembles the grandmother, since that would have been a more informative alternative utterance about the duration of Aunt Theresa's resembling the grandmother.

(e) Thus, the speaker couldn't have been maximally informative about Aunt Theresa's resembling the grandmother unless he thought that Aunt Theresa's resembling the grandmother is over.

(f) Thus, the speaker has implicated that Aunt Theresa's resembling the grandmother is over.

(g) Aunt Theresa's resembling the grandmother during a maximally long subinterval of the grandmother's existence can be over if and only if either Aunt Theresa is dead (since resembling my grandmother is a property that, if it holds of an individual at all, holds of that individual during all its life-time), or the grandmother is dead.

Thus, the hearer concludes further that, since the speaker has implicated that Aunt Theresa's resembling my grandmother during a maximally long subinterval of my grandmother's existence is over, the speaker has implicated that either Aunt Theresa or the grandmother is dead.

27 The reference to a maximally long interval is necessary in order to guarantee maximal informativity about the duration. 


\subsection{Overt temporal adverbials and individual-level predicates}

So far one phenomenon remains unexplained in my account, namely the inappropriateness of overt temporal adverbials with individual-level predicates: The underlined sentence in (58) is at least strange if not ungrammatical.

(58) \# [On that day, I was introduced to Gregory and Eva-Lotta.] When I was introduced to them, Gregory was from America.

Since an implicit element with a meaning similar to the one of when I was introduced to them was able to provide a value for $C$ in (48a), it seems unexpected that the underlined sentence in (58) is so strange. The reason why (58) is strange seems to depend only on the fact that (58) is an individual-level clause; there seems to be some kind of incompatibility between temporal adverbials and individual-level predicates involved.

Kai von Fintel pointed out to me that the inappropriateness may be explained under the assumption that the temporal adverbial when I was introduced to them functions as a contrastive topic. Explicit topics in English have in general a tendency to function as contrastive topics. Implicit topics on the other hand can crucially not function as contrastive topics.

Under the assumption that when I was introduced to them functions as a contrastive topic, (58) would imply that Gregory was from America on that day but not on another day. Whichever other day we consider, we will run into trouble with this implication. Consider first a day during which Gregory isn't alive anymore. In this case, being from America can't be predicated of Gregory because, according to our assumptions about lexical properties of predicates, Gregory wouldn't be in the domain of be from America for that time. Thus, for such a day, the implication that Gregory was not from America is odd for reasons of presupposition failure. But if we consider a day during which Gregory is still alive, the implication is plainly false: being from America is an individual-level property that holds of Gregory for all his life, and thus it holds of Gregory in particular for that day.

Under the contrastive-topic-hypothesis, a sentence like (59) would also correctly be predicted to be at least inappropriate: Let us assume that Gregory Smith was born in 1876, died in 1950, and was from America. 
(59) \# From 1876 until 1950, Gregory Smith was from America.

Under the assumption that the temporal adverbial provides a contrastive topic, (59) implies that Gregory Smith was not from America at a time other than between 1876 and 1950. But since all other times reach beyond the life-time of Gregory Smith and the lexical entry of be from America contains a presupposition requiring Gregory Smith to be alive at a time during which he is asserted to be from America (or not from America), any other contrastive alternative is ruled out by presupposition failure. Thus, (59) is predicted to be inappropriate: 28

\section{A comparison with Kratzer's (1988) proposal}

\subsection{Kratzer's treatment of life-time effects}

In her paper on "Stage-Level and Individual-Level Predicates" (1988, 42-45), Kratzer proposes that tense is a predicate that relates in general to external arguments. When combined with Kratzer's analysis of the difference between stage-level predicates and individual-level predicates, the proposal that tense always relates to the external argument makes interesting predictions. Kratzer argues that stage-level predicates and individual-level predicates differ in what their underlying external arguments are. Stage-level predicates always have a DAVIDSONIAN ARGUMENT or LOCATION ARGUMENT denoting a spatiotemporal location as external argument. Individual-level predicates have an external argument denoting an individual (if they are unergative); furthermore, they do not have any location argument analogous to the location argument of stage-level predicates. Roughly speaking, the individual denoting external

28 Alternatively, the unacceptability of (57) may also be due to the argument structure of individual-level predicates. Suppose that although both individual-level clauses and stagelevel clauses can have an implicit restriction $C$ of the quantificational adverb $\exists$, individuallevel predicates do not have a location argument, as was suggested by Kratzer (1988). If overt temporal adverbials are only licensed with predicates that provide a slot for location arguments, the unacceptability of (52) would then be predicted. 
arguments of individual-level predicates are usually syntactically realized as noun phrases, whereas the external location arguments of stage-level predicates are often phonetically empty, although they can be made explicit by overt location arguments.

The generalization predicts that in stage-level clauses, tense is applied to a location argument. For individual-level clauses, the generalization predicts that tense is applied to a noun phrase argument, implying (in contrast to a proposal of Enç (1981)) that, at least in some cases, tense plays an important role for the temporal interpretation of noun phrases. Thus, in Kratzer's account, a stage-level clause like (60a), Gregory was available, has the logical form (60b), where the external location argument of the stage-level predicate available is represented by the variable $L$, and past tense is represented by the predicate before now that applies to the location argument.

(60) a. Gregory was available.

b. $\quad[\text { before now (L)] \& [available (Gregory, L) }]^{29}$

Because of the fact that individual-level predicates do not have a location argument, tense cannot combine with a location argument as it does in stage-level clauses. But, since individual-level clauses contain tenses just as stage-level clauses do, tense must combine with some other element in logical form. Kratzer suggests that tense in general combines with the external argument of the main predicate of its clause.

(61) Kratzer's generalization on tense and external arguments (original version) The tense predicate always relates to the external argument of the main predicate.

Thus, an individual-level clause like (62a) has the logical form (62b).

29 Note that (60b) contains free occurrences of $L$. Kratzer assumes that free occurrences of the location variable $L$ can get bound by quantifiers if they appear as part of a more complex construction, or else they may be supplied with a value by the context of use (p6). Thus, $L$ in (60b) is a kind of deictic temporal pronoun, suggesting an account of tense reference in terms of Partee's (1973) proposal that tense can denote a particular, contextually determined time interval (see also Section 3.2. above). Although there are problems with the assumption of free occurrences of $L$ (cf. Bäuerle $(1977,1979)$ ) and the tense semantics I exploited above differs somewhat from Kratzer's approach, I will keep my discussion in this section as close to Kratzer's assumptions as possible. 
(62) a. Gregory was intelligent.

b. [before now $($ Gregory 3$)]$ \& [intelligent $\left.\left(\mathrm{he}_{3}\right)\right]$

Kratzer argues that - much as past tense in (60) ultimately locates the contextually relevant event of Gregory's being available in the past - so past tense in (62) locates the individual Gregory in the past. Kratzer's comments suggest that the denotation of the tense predicate before now applied to the denotation of a proper name, i.e. applied to an individual, yields a proposition that is true if and only if the individual in question is totally located in the past, that is, the individual existed in the past but not in the present.30 "Existence" of a person means that person's being alive. Thus, locating an individual temporally in the past means nothing else but locating that individual's existence or life-time totally in the past. E.g., before now (Gregory) is true if and only if Gregory lived in the past and is dead now. This prediction is in accordance with intuitions - as we have seen in Section 1, individual-level clauses with past tense exhibit life-time effects.

To summarize, Kratzer accounts for the occurrence of life-time effects with past tense individual-level clauses by proposing that in these constructions, tense relates to the subject argument of the main predicate. The motivation for this proposal lies in the assumptions that tense always relates to the external argument of the main predicate of its clause and that individual-level predicates have individuals as externl arguments.

This proposal gains even more support from the behavior of the predicate resemble. Recall my brief discussion of resemble in Section 2.6. The surprising observation with resemble was that it is an asymmetric predicate as far as the temporal location of its arguments is concerned, although its core meaning seems to be symmetric. The relevant sentences and descriptions of situations are repeated here as $(63)[=(27)$ above $]$.

30 Note that this assumption in itself implies an asymmetry between the application of tense to individuals and to location arguments: whereas before now (Gregory) locates Gregory totally in the past, before now $(L)$ typically does not locate the whole event associated with $L$ in the past. We have seen an example of this in Section 2.4.: Today, Eva-Lotta walked along the Charles River. 
(63) a. Utterance: "Aunt Theresa resembled my grandmother." - Situation: Aunt Theresa is dead; the grandmother is still alive.

b. \# Utterance: "Aunt Theresa resembled my grandmother." - Situation: Aunt Theresa is still alive; the grandmother is dead.

(63) suggests that the past tense imposes a life-time effect on the subject argument (as can be concluded from the oddness of (63b)) but not on the object argument (as can be concluded from the acceptability of (63a)). Within Kratzer's account, this is strong support for her claim that tense locates the external argument temporally. Under the assumption that resemble is a symmetric predicate, the asymmetry can only be caused by the different status of the arguments as external or internal argument.

Kratzer suggests that the tense predicate can also relate to an external noun phrase argument by relating to the Davidson-argument of the noun in a quantificational noun phrase. This is illustrated with the quantificational noun phrase all applicants in (64).

(64) a. All applicants were from America.

b. $\quad a_{x}$ [applicant $(x, L) \&$ before now (L)] [from America (x)]

(64) clearly shows that the relevant notion of "external argument" is a syntactic one as suggested by Williams (1981), and not a semantic one - i.e. Kratzer's generalization captures the intuition that tense relates to that argument of the main predicate which is generated VP-externally. For individual-level predicates, this argument is usually realized as a noun phrase. As we can see with (64b), relating tense to a noun phrase is associated with the possibility that tense can, for instance, relate to the location argument of the nominal predicate if it is a stage-level predicate. Thus, "relate to a noun phrase" is supposed to mean "relate to some semantic part of the noun phrase". The syntactic notion of "external argument" contrasts with a semantic notion, according to which the external argument of a predicate can be described as that argument which is taken as the last argument of the predicate in question, i.e. eventually saturates the predicate. If the generalization were supposed to refer to semantic external arguments, then tense in (64) could only relate to the individual variable $x$, which represents the semantic external argument of the predicate be from America. 
The claim that tense always relates to the external argument of a clause is connected to Diesing's $(1988,1992)$ proposal, according to which material within the VP is mapped into the nuclear scope in logical form, whereas material in IP is mapped into the restrictive clause in logical form. At S-structure, tense is realized by INFL. Hence tense is realized outside of VP and - according to Diesing's mapping hypothesis - has to appear in the restrictive clause at logical form. Thus, we can reformulate and specify (61) in the spirit of Kratzer's work as follows:

(65) Kratzer's generalization on tense and external arguments (explicit version) The tense predicate always applies to some part of the syntactic external argument of the main predicate and appears at LF in the restrictive clause.

As Kratzer mentions, her proposal can be considered under two different perspectives: tense might either be interpreted as part of the truth-conditional meaning of its clause or as part of the clause's presuppositions.

In the remainder of this section, I will pursue the generalization (65). I will argue that it runs into a number of problems. First, the proposal cannot account in a uniform way for all cases where life-time effects occur. This is because there are predicates that trigger life-time effects, although they arguably have an argument structure where this is, within the assumptions of Kratzer's theory, unexpected. Second, other predicates that, according to grammatical criteria, are classified as individual-level predicates, do not trigger life-time effects. Third, the proposal leaves open the question of what happens in ergative individual-level predicate constructions; i.e., it is not clear what tense relates to in constructions that do not provide a D-structure external argument. Finally, it seems to be impossible to represent certain scope readings of sentences that contain adverbs of quantification and quantificational noun phrases. I will conclude that the problems mentioned provide strong arguments against Kratzer's generalization, which should thus be abandoned.

\subsection{Wrong predictions with existence-independent predicates and ergative verbs}

The first problem with Kratzer's account is that, with existence-independent predicates, tense applied to an individual can refer to times that reach beyond the life-time of that individual, even if the predicate behaves with respect to 
grammatical tests like an individual-level predicate. (66a) for example is a completely acceptable sentence, although berühmt sein ('be famous') seems to be an individual-level predicate, as suggested by the unacceptability of (66b) in connection with Kratzer's criteria for individual-level predicates versus stage-level predicates; thus, according to Kratzer's assumptions, the external argument of berühmt sein is an individual, and furthermore, according to her generalization, tense should apply to this individual. Moreover, the tense of (66a) is present tense and would thus locate Picasso's life-time in the present, if tense located lifetimes in the way suggested by Kratzer: but Picasso is dead now.
a. Picasso ist berühmt
Picasso is famous
b. * Keine Philosophen sind berühmt. no philosophers are famous

A further problem is that the effect of individual location Kratzer observes with external arguments also shows up with syntactically non-external arguments - namely in cases where this is predicted by pragmatic reasoning. For instance, the effect arises with the surface subject of some ergative individual-level predicates. Surface subjects of ergative verbs are supposed to be syntactically underlyingly VP-internal arguments. Perlmutter and Postal (1984, pp98f) list ergative verbs. Among those are several that give rise to life-time effects: exist, happen, occur, and predicates describing sizes, shapes, weights, and colors. Without an appropriate context narrowing down the relevant time, the following examples are only acceptable in case Gregory is dead and Isolde is sunk or destroyed or something like that, respectively.

Gregory existed.

(68) Isolde [a boat] was almost oval.

Thus, life-time effects can also occur with non-external arguments. This does not, of course, show that Kratzer's generalization is inadequate. But it shows that there are at least some cases of life-time effects that have to be explained independently of her generalization. There must be some mechanism or principle responsible for the life-time effects in those cases which cannot be captured by this generalization. We need to assume the existence of an appropriate device 
anyway. Thus, the question arises of whether this device may also be able to explain the cases that were supposed to be captured by Kratzer's generalization. If this is so, then Kratzer's explanation will lose much of its explanatory value. The temporal location of individuals is obviously sometimes independent of tense. This raises the question of whether the temporal location of individuals has anything directly to do with the application of tense to them or just with predicate semantics.

\section{3. "Relating to the external argument"}

In this subsection, I just want to point out a startling point about Kratzer's generalization. I mentioned above that Kratzer suggests that the tense predicate can also relate to an external noun phrase argument by relating to the Davidsonargument of the noun in a quantificational noun phrase as shown in (64), repeated here as (69).

(69) a. All applicants were from America.

b. $\quad a_{1}$ [applicant $(x, L) \&$ before now (L)] [from America (x)]

Obviously, Kratzer exploits a syntactic notion of "external argument"; thus, tense is claimed to be able to relate to the syntactic external argument of the main predicate - in the case of (unergative) individual-level predicates, to a noun phrase. The syntactic notion of "external argument" contrasts with a semantic notion, according to which the external argument of a predicate can be described as that argument which is taken as the last argument of the predicate in question. If the generalization were supposed to refer to semantic external arguments, then tense in (69) could only relate to the individual variable $x$, which represents the semantic external argument of the predicate be from America.

Note though that there is no motivation for why another possibility should be excluded, namely that tense relates to the variable $\mathrm{x}$ within the restrictor of the quantifier - thus giving rise to the hypothetical LF (69c).

(69) c. $\quad a_{\mathrm{x}}[\operatorname{applicant}(\mathrm{x}, \mathrm{L})$ \& before now (x)] [from America (x)] 
But such an LF must be excluded, for it predicts the availability of a reading for (69a) that is clearly not available: "For all $x$ such that $x$ was an applicant and $x$ is dead now, $x$ was from America." - Thus, if (69c) were a possible LF for (69a), then the sentence should be able to be judged true in a situation where there have been five applicants $\mathrm{A}, \mathrm{B}, \mathrm{C}, \mathrm{D}$, and $\mathrm{E}$ for a certain position last year, one of which died meanwhile. The one who died was A; A was from America. The other four applicants, B, C, D, and E, are from France and still alive. It is clear that (69a) in such a situation would not be judged true. Thus, (69c) must be excluded as an LF for (69a); tense never functions as (part of) a restrictor for nominal determiner quantifiers. Within Kratzer's framework, it is not obvious how to account for this fact.

\subsection{Problems with the interaction of tense and adverbs of quantification}

In this subsection, I will finally argue that the interaction of adverbs of quantification and determiner-quantifiers raises serious problems for Kratzer's approach: it is not at all clear how certain readings that arise in clauses with adverbs of quantification and determiner-quantifiers can be represented.

When adverbs of quantification and determiner-quantifiers cooccur in a clause, they display scope ambiguities. Thus, there are readings where the adverb of quantification has wide scope over the determiner-quantifier, and readings where the determiner-quantifier has wide scope over the adverb of quantification. In this subsection, we will be concerned with certain cases of readings of the former type. In German, scope readings of adverbs of quantification and determiner-quantifiers are in general strongly determined by the surface ordering of these operators.

Consider the individual-level clause in (70a). For (70a), only the wide scope reading of the adverb of quantification in (70b) is available.

(70) a. weil meistens die meisten Professoren intelligent waren since mostly the most professors intelligent were ('since mostly most professors were intelligent')

b. For most times $t^{*}$ such that $t^{*}$ is before now, for most $\mathrm{x}$ such that $\mathrm{x}$ is a professor at $t^{*}, \mathrm{x}$ is intelligent. 
How can this reading be representend in accordance with Kratzer's generalization, her assumptions on LF, and their consequences?

Since intelligent sein is an individual-level predicate, tense should apply to the external argument of intelligent sein, i.e. to the noun phrase die meisten Professoren. Thus, tense should appear as part of the restrictive clause of the determiner-quantifier, and the account would thus generate the tripartite structure (70c) as part of the LF-representation of (70b).

(70) c. ... $\operatorname{MOST}_{\mathrm{X}}[\mathrm{RC}$ professor $(\mathrm{x}, \mathrm{L}) \&$ before now (L)] [NS intelligent (x)]

But if tense appears in the restrictive clause of the determiner-quantifier, then it cannot simultaneously appear in the restrictive clause of the adverb of quantification. This consequence is certainly unwanted: first, intuitions are very clear about the fact that tense serves as the restrictor of the adverb of quantification in reading (70b), and second, if tense cannot appear in the restrictive clause of the adverb of quantification, then the resulting LF will be illformed because the adverb of quantification does not bind a variable in its restrictive clause, as shown in (70d).

$$
\begin{aligned}
& \text { d. } * \underset{\operatorname{MOSTLY}}{\mathrm{t}}\left[\mathrm{RC}^{\prime}-\right]\left[\mathrm{NS}^{\prime} \operatorname{MOST}_{\mathrm{X}}[\mathrm{RC} \text { professor }(\mathrm{x}, \mathrm{L}) \&\right. \\
& \text { before now }(\mathrm{L})][\mathrm{NS} \text { intelligent }(\mathrm{x})]]
\end{aligned}
$$

Thus, it is not at all obvious how reading (70b) can be represented within Kratzer's framework. This is a serious problem for Kratzer's generalization on the application of tense.

\section{Conclusion}

In this chapter, I adopted an account of temporal interpretation where obligatory, possibly phonetically empty definite temporal adverbials and adverbs of quantification take care of definite and quantificational aspects of tense readings, respectively. The definite temporal adverbials provide topic times which can crucially also be restricted by various elements of the clause which serve as 
topics, or at least as part of the background of the clause. I argued that noun phrases can determine the value of implicit temporal adverbials. This opens up the possibility for noun phrases to play an important role in the temporal interpretation of clauses.

As part of the lexical entries of stage-level and individual-level predicates, but not of existence-independent predicates, I introduced minimal temporal presuppositions that require for individuals to be alive in order to serve as arguments for these predicates. The temporal presuppositions explain why the application of stage-level predicates or individual-level predicates to dead individuals leads to inappropriate clauses.

The inappropriateness of applying individual-level predicates in connection with a past tense to individuals who are still alive and who provide the only topic time restrictor for the clause is explained by pragmatic considerations involving the Gricean maxim of informativeness.

The temporal location of individuals is in no case directly determined by tense. Rather, effects of temporal location of individuals are directly caused by lexical properties of the predicates that are involved. This holds for subjects as well as objects and for internal arguments as well as external arguments. Given this mechanism, tense is predicted to play an indirect role by virtue of its determining the temporal interpretation of the main predicate of a clause.

I want to add here that the effects that predicates can have on individuals by virtue of their life-time presuppositions have a wider range of application than explained in this chapter. What I investigated in this chapter were life-time presuppositions that main predicates of clauses have on their arguments. It is important to note that quite in general, all classes of semantic predicates have the ability to impose life-time presuppositions on their arguments. For example, a noun like student, which is semantically a predicate, imposes a life-time presupposition on its external argument, just as a verb like sneeze does. Consequently, for a sentence like (71a), which has a simplified semantic represention as in (71b), two life-time presuppositions apply to different occurrences of the variable $x$ as indicated by the arrows. 
(71) a. A student sneezed.

b.

There is an $\mathrm{x}$ such that [student $(\mathrm{x})$ \& sneezed ( $\mathrm{x}$ ]]

Thus, the value of $x$ under any particular variable assignment ultimately has to fulfill two life-time presuppositions.

I have also presented Kratzer's account of life-time effects with past tense individual-level clauses, and I have shown that the proposal runs into many problems which can be avoided under my proposal. Thus, my own proposal seems to be more adequate for dealing with the phenomena that were discussed in this chapter. 
"Wie soll's denn sonstsein?!"

-Amim-

"Local trains are always late," said Wimsey. "It's one of the rules. I's done so that the guard and the engine driver can step out and admire the station-master's garden at every stop. You know those gardening competitions they have in railway magazines. Well. Tha' s how they' renu.

The guard sets off at Kiikgunzeon or Brig o' Dee with ayard measurein his hand and measures the prize marrow and says: 'Twa fut four inches - tha'll no dew, Mr. MbGeoch. They' ve got one a Dalbeatie that beats ye by twainches. Here, George, come and look at this.' So the enginedriver strolls over and says, ' Och, ay, imph'm, ye'll dew weel tre gie' ta mulcho' liquid guano and aspidistra tonic.' And then they go back to Dalbeatie and tell them that the marrow at Kirkgunzeon is hauling up on them hand ove fist. I's no good laughing. Iknow they do it. If not, what on earth do they do, hanging everastingly about a these three-by-four stations?"

-DorothyL Sayers, The Five Red Herings, Chapter XIII-

\section{Chapter III. Temporal Location of Predication Times}

\section{Introduction}

Just as verbs in finite sentences refer to actions, events, states, or properties that can truly be predicated of individuals at certain times, nouns refer to actions, events, states, or properties that can also truly be predicated of individuals at certain times. That is, He hid behind the curtain is true if and only if the individual referred to by he hid behind the curtain at a time in the past. Similarly, the noun murderer can be truly predicated of an individual $\mathrm{x}$ just in case $\mathrm{x}$ commits a murder at some time.1 I will call the time interval during which a

1 David Pesetsky (pc) informs me that Beth Levin has noted that professional titles do - in contrast to the noun murderer for instance - not entail actual practice of a profession. E.g. a soldier might not yet have acted as a soldier; he can be called a soldier as soon as he was 
predicate can truly be predicated of an individual the PREDICATION TIME of the predicate relative to that individual.

While the time of predication of verbs is usually located by the tense of the clause in which the verb occurs (1a) as indicated in (1b), the time of predication of a noun is apparently not explicitly located; (Ia) contains the noun murderer. Intuitively, an individual is a murderer from the time on at which he/she committed his or her first murder. After committing his or her first murder, the individual in question remains a murderer for the rest of his or her life. (1c) captures the intuition that the individual mentioned in (1a) can commit his or her first murder at any time in the past, present, or future, in order to be truly described by the noun phrase the murderer.

(1) a. The murderer hid behind the curtain.

b. If (a) is true, then the hiding talked about took place at some time in the past. We know that, because the tense of the clause tells us so. We do not know when exactly in the past the hiding took place.

c. If (a) is true, then the individual that is talked about commits a murder at some time in the past/present/future.2, 3 There is nothing contained in the sentence that tells us when, besides the noun "murderer".

Given the tense in a clause, one has relatively little freedom to locate the denotation of the verb temporally, i.e. past tense for instance locates the denotation of the verb in the past. But with nouns, we apparently have much more freedom. (2a), for example, can be intuitively judged to be true with each of the three situations described in $(2 b-d)$ :

a. John's murderer hid behind the curtain.

b. John was murdered on May 15th 1992. At some time in the past, the man who murdered John (which was that man's first murder) hid behind the curtain.

declared being one. However, in my opinion, this does not show that these nouns work fundamentally differently. Rather what seems to me crucial is a variety of criteria for predicating predicates truthfully of individuals. Thus, in order to be truthfully called to be a murderer, one has to act at some point like a murderer, i.e. kill someone. But in order to be truthfully called a soldier, one doesn't have to do anything else but be declared a soldier or sign a statement about joining the army or something like that.

2 Another example that shows this even better was suggested to me by David Pesetsky: The murderer was a little baby when he lost his teddy bear.

3 The same holds in case the sentence is false. 
c. John is being murdered just while (2a) is uttered. At some time in the past, the man who is murdering John (which is that man's first murder) hid behind the curtain.

d. It is known that a certain man plans to murder John. According to what we know about that man (whatever he plans, he does it), we know that he will commit the murder. At some time in the past, the man who will murder John (which will be that man's first murder) hid behind the curtain.

In (2b), the individual in question starts being a murderer on May 15th 1992. Thus, at the moment of his hiding - which happens a short while after the murder he is a murderer. In (2c), he or she is not yet a murderer when hiding, nor at any other time in the past, but starts to be a murderer only at the time of utterance of (2a). In (2d), the individual has not yet committed a murder at the time of utterance of (2a), but in the situation described, we can nonetheless refer to him as the murderer. In fact, if the context is sufficiently clear, it is possible to utter a sentence like (3a) or (3b) appropriately:4

(3) a. John's murderer is not yet a murderer.

b. As he hid behind the curtain, John's murderer wasn't yet a murderer.

Thus it seems that the temporal interpretation of noun phrases is very free and determined only by additional contextual information, but not by the temporal interpretation of the rest of their clause - I will call this a TEMPORALLY INDEPENDENT NOUN PHRASE INTERPRETATION.

Recall from Chapter I that this impression led Enç (1981) to the claim that the temporal interpretation of noun phrases is not at all dependent on the temporal intepretation of the rest of their clause: according to Enç's view, by getting some kind of time index that denotes some contextually salient time interval, noun phrases are temporally determined only by the context of utterance.

But other data contradict this generalization. There are noun phrases that obligatorily get a TEMPORALLY DEPENDENT INTERPRETATION. Consider, for instance, the underlined noun phrases in (4):

(4) a. In the forties, professors were young.

b. Last year, some congressmen came to the party.

4 These sentences are due to Roger Schwarzschild and Colin Phillips, respectively. 
(4a) does not have a reading "Individuals who are now professors were typically young in the forties". And (4b) can hardly mean "Some of those individuals who are now congressmen came to the party last year" (although this reading is available when some is stressed; for an explanation see below).

Note that the temporally dependent readings in (4) cannot plausibly be explained as being contextually the only possible readings of the sentences in question. Evidence for this is provided by slight changes of the noun phrase that do not seem to change the meaning significantly, but suddenly make temporally independent interpretations possible. Thus, (4a') can easily be understood as talking about present professors who were young in the forties (because they were kids then). And with ( $\left.4 b^{\prime}\right)$, it is entirely possible to talk about a situation where the party last year was congressmen-free, but since then a certain group of people became congressmen, and some of the people involved are remembered to have shown up at the party.

(4) a'. In the forties, all professors were young.

$b^{\prime}$. Last year, some of the congressmen came to the party.

To summarize, at this point we can conclude that Enç's (1981) account overgeneralizes. Although it is obvious that there are indeed cases of merely contextual determination of predication times with noun phrases (as in (1)-(3)), the temporal interpretation of noun phrases is at least in some cases dependent on the temporal interpretation of the rest of the clause.

Thus, two questions must be raised: First, what syntactic and/or semantic mechanisms cause temporally dependent interpretations? Second, why do the crucial mechanisms apply to some noun phrases but not to others? In order to answer these questions, it is important to investigate what the precise distribution of temporally dependent and temporally independent noun phrases is. Obviously, their distribution probably follows from the nature of the mechanisms. Thus, their distribution will allow us to draw conclusions about the underlying mechanisms. In the remainder of this chapter, I will try to answer the questions raised above.

I will begin the discussion by looking at a limited range of data, namely subjects of various predicates that contain an overt determiner. Thus, I will mostly ignore bare plurals until Section 8.5 Furthermore, (as throughout all of this

5 Proper names will of course be ignored anyway, because they don't contain nouns. 
chapter) I will only consider noun phrases that do not contain any temporal modifiers.

In Section 2, I will show that the distribution of temporally dependent and temporally independent noun phrases correlates largely, but not in all cases, with the distinction between cardinal and presuppositional noun phrases6: in most cases, a subject noun phrase can be temporally independent if and only if it is presuppositional. As I will show, this generalization holds for stage-level predicates and individual-level predicates. It does not hold for existenceindependent predicates though.

Assuming that cardinal and presuppositional noun phrases are associated with different structural positions at LF (Diesing (1992)), the generalization for cardinal and presuppositional noun phrases suggests that the occurrence of temporally dependent interpretations may be due to the binding of time arguments of nouns by a temporal operator at LF. According to this hypothesis, which will be explored in Section 3, temporally dependent interpretations of noun phrases would be due to their position at LF and the scope of temporal operators. But the proposal fails because of scope paradoxes that arise with certain readings of clauses containing adverbs of quantification: Presuppositional noun phrases in the scope of the operator that would presumably be responsible for the binding of time arguments can be temporally independent. Thus, it seems most likely that the occurrence of temporally dependent interpretations is not due to scope, but hinges on noun phrase internal properties in combination with the way in which predicates relate to their arguments.

In Section 4, I argue that a semantics of quantification based on a stageontology is able to explain the occurrence of temporally dependent noun phrase interpretations. In particular, I propose that determiner-quantifiers quantify over stages of individuals rather than individuals in their maximal temporal extendedness. Furthermore, I will present an account of the semantics of determiners according to which determiners of cardinal noun phrases receive basically the same interpretation as determiners of presuppositional noun phrases.

\footnotetext{
6 For the moment, I will be using the terms "cardinal noun phrase" and "presuppositional noun phrase" in order to refer to weak noun phrases in their "weak readings" on the one hand and weak noun phrases in their "strong readings" or strong noun phrases on the other hand, respectively. In Section 4.2.3., where I will sketch the semantics of these two kinds of noun phrases, I will introduce the terms "unrestrictive noun phrase" and "restrictive noun phrase", which capture the essence of the difference between the two kinds of noun phrases much better.
} 
Semantic differences between presuppositional and cardinal noun phrases are in general caused by the mapping of the noun: a noun that appears as part of a DP can be mapped either into the restrictive clause or into the nuclear scope of the determiner. Nouns that appear as part of a presuppositional noun phrase are mapped into the restrictive clause, whereas nouns that appear as part of a cardinal noun phrase are mapped into the nuclear scope. This difference will then be used to explain the distribution of temporal dependence with most DPs. The semantics I will develop is conceptually very simple, although its formalization may seem somewhat complicated.

As I show in Section 5 and Section 6, this proposal can also deal adequately with the constructions that were problematic for the scope-approach.

Section 7 explains the behavior of generic noun phrases. Section 8 deals with temporally independent interpretations of noun phrases. The main goal of this section is to describe the felicity constraints that temporally independent noun phrases are subject to. Section 9 draws together the results of the preceding sections of the chapter. Finally, Section 10 tackles some additional questions that arise under a stage-account; these questions concern the ways in which stages can be determined and counted and the ways in which stages can be merged.

\section{The distribution of temporal dependence with noun phrases}

In this section, I want to show what the distribution of temporally dependent and temporally independent noun phrases is. Basically, what we will see is that subjects of stage-level predicates and individual-level predicates can have temporally independent interpretations only if they are presuppositional. Additionally, subjects of existence-independent predicates and certain object noun phrases can have temporally independent interpretations even if they are not presuppositional but cardinal.

The underlined noun phrases in (5) differ insofar as some of them easily allow temporally independent interpreations ("i"), whereas other noun phrases only allow temporally dependent interpretations ("d"). Thus, (5a, b, d, f) can easily get interpretations where the professors mentioned are individuals who are professors now but were not professors in the sixties. (5a) for instance can mean "Most of 
the individuals who are now professors were happy in the sixties". On the other hand, (5c, e) can only be understood as talking about individuals who were professors in the sixties. Thus, $(5 \mathrm{c})$ can only mean "Some of the individuals who were professors in the sixties were happy in the sixties", but it cannot mean "Some of the individuals who are now professors were happy in the sixties".
a. Die meisten Professoren waren in den sechziger Jahren glücklich. (i) the most professors were in the sixties happy ('Most profssors were happy in the sixties.')
b. EINIGE Professoren waren in den sechziger Jahren glücklich. (i) some professors were in the sixties happy ('Some professors were happy in the sixties.)
c. Einige PROFESSOREN waren in den sechziger Jahren glücklich. (d) some professors were in the sixties happy ('Sm professors were happy in the sixties.')
d. Einige von den Professoren waren in den sechziger Jahren glücklich.(i) some of the professors were in the sixties happy ('Some of the professors were happy in the sixties.')
e. In den sechziger Jahren waren ja doch Professoren glücklich. (d) in the sixties were (indeed) professors happy
('In the sixties, [some] professors were (indeed) happy.')
f. Professoren waren ja doch in den sechziger Jahren glücklich. (i) professors were (indeed) in the sixties happy ('Professors [in general] were (indeed) happy in the sixties.')

The underlined noun phrases in (5) differ not only with respect to their ability to exploit temporally independent readings, but also with respect to whether they are cardinal or presuppositional.

The distinction between cardinal and presuppositional noun phrases concerns the occurrence of existence presuppositions with noun phrases: presuppositional noun phrases presuppose the existence of individuals that have the property denoted by their noun, whereas cardinal noun phrases do not. The distinction is based on Milsark's (1974) distinction between weak and strong determiners. Noun phrases with strong determiners such as all, every, each, most,... are always presuppositional. The same holds for partitive noun phrases like some of the Ns. Noun phrases with weak determiners such as many, some, $a, \ldots$ are ambiguous between a cardinal and a presuppositional reading. Diesing (1992) argues that noun phrases with weak determiners are preferentially interpreted as cardinal or presuppositional, depending on their syntactic position. Thus, noun phrases with weak determiners are preferentially interpreted presuppositional when they are located outside VP - in German: to the left of the particle ja doch. Weak noun phrases which are located within VP - in German: to 
the right of the particle ja doch - are preferentially interpreted cardinal. Furthermore, stress also plays a role in whether a noun phrase gets a cardinal or a presuppositional reading: when the determiner is stressed, the noun phrase is preferredly presuppositional; when the noun is stressed, it has a strong preference towards a cardinal reading.

Thus, (5a, b, d, f) contain presuppositional noun phrases, whereas $(5 c, e)$ contain cardinal noun phrases. In particular, the underlined noun phrase in $(5 \mathrm{a})$ is presuppositional, because it contains a strong determiner; with $(5 b)$, the stress on the determiner triggers the presuppositional reading of the weak noun phrase; the noun phrase in (5d) is presuppositional because partitive; and the one in (6f) is presuppositional, because it is a bare plural located on the left of the particle $j a$ doch. With the noun phrase in $(5 \mathrm{c})$, stress on the noun of the weak noun phrase triggers the cardinal reading; and the noun phrase in (5e) is cardinal, because it is a bare plural on the right of the particle ja doch.

Relating the distribution of presuppositional and cardinal noun phrases to the distribution of temporally dependent and temporally independent noun phrase interpretations, there is an obvious correlation: cardinal noun phrases can only receive temporally dependent readings, whereas presuppositional noun phrases can receive temporally independent readings. This generalization seems to be fairly consistent, although sometimes intuitions are less clear than one might wish. Other examples that illustrate the same point are the ones in (6) and (7), which show again the particularly clear contrast between simple quantificational noun phrases where a cardinal reading is triggered (a) and partitive noun phrases (b).

(6) a. Es ist noch kein Meister vom Himmel gefallen. it is yet no master from-the sky fallen ('No master fell from the sky.' = 'Rome wasn't built in a day.')

b. Es ist noch keiner von den Meistern vom Himmel gefallen. it is yet noone of the masters from-the sky fallen ('Noone of the masters fell from the sky.')

(7) a. Heute waren viele Kranke da. today were many sick-people there ('Today, many sick people have been here.')

b. Heute waren viele von den Kranken da. today were many of the sick-people there ('Today, many of the sick people have been here.')

The clearly preferred reading of the noun phrase in (6a) suggests that one is talking about people that fall as masters from the sky. This is not the case with 
the partitive construction in (6b). (6b) can easily be understood as talking about individuals that are a master at some arbitrary time. Similarly, under its preferred reading, (7a) is true if and only if many people were there (= at some designated place) today who were there at the time of their being sick. (7b) can easily be understood to be true in a situation where many people were there today who belong to some group of people which have been sick at some time in the past but are healthy now.

An analogous effect can be observed in (8). (8a) contains an English thereconstruction. This construction triggers a cardinal reading for the underlined noun phrase. The noun phrase here can only have a temporally dependent reading, i.e., the homeless people have to be homeless people at the time of the rally. The partitive noun phrase in (8b) can talk about people who are homeless people now but who weren't homeless at the time of the rally.

(8) a. There were many homeless people at the rally.

b. Many of the homeless people were at the rally.

Furthermore, predicate nominals, which are a special case of obligatorily cardinal noun phrases, are unable to display temporally independent readings: (9) contains the predicate nominal a student of French literature. Unlike being a murderer, being a student of French literature is a property individuals acquire temporarily; once they finished their studies, they are not students of French literature anymore. Thus, the fact that (9) cannot be understood as "Anne is a former student of French literature" shows that the predicate nominal cannot get a reading that is temporally independent of the tense of the clause.

(9) Anne is a student of French literature.

To summarize, so far it seems that presuppositional noun phrases can have temporally independent readings, whereas cardinal noun phrases can only have temporally dependent interpretations. That is, at this point we can state the descriptive generalization (10):

(10) Distribution of temporally (in)dependent noun phrases (to be revised): A noun phrase can be temporally independent if and only if it is presuppositional. 
But there is at least one type of noun phrase whose behavior is not adequately captured by (10): in contrast to subjects of stage-level predicates and subjects of individual-level predicates, subjects of existence-independent predicates can get temporally independent interpretations even if they are cardinal.

In Chapter II, I introduced the notion of existence-independent predicates. Recall that existence-independent predicates like famous are predicates that can be predicated of an individual at times when the individual no longer exists - i.e., in this sense they are independent of the individual's existence. An example of this type of predicate is shown in (11a). In this respect, existence-independent predicates differ from stage-level predicates like available (11b) and individuallevel predicates like intelligent (11c).
a. Frege is famous.
b. \# Frege is (un-)available.
c. \# Frege is intelligent.

What is important here is that existence-independent predicates can have cardinal subject noun phrases that can be temporally independently interpreted. Compare (12a) to (12b). The noun phrase lauter Studenten ('many students') is cardinal in both sentences; this is guaranteed by the fact that lauter ('many') is a determiner that can probably only have cardinal readings, 7 and it is further supported by the VP-internal position of the noun phrase. Suppose now we have just been talking about the people that were members of the MIT linguistics department at around 1980 - people who were students then as well as people who were professors then. Imagine that the sentences in (12) are uttered in this context.
a. Es sind heutzutage lauter Studenten krank. it are today many students sick ('Today, many students are sick.')
b. Es sind heutzutage lauter Studenten berühmt. it are today many students famous ('Today, many students are famous.')

The crucial observation with (12) is that the cardinal noun phrase in (12a) cannot, as predicted by generalization (10), get a temporally independent interpretation,

7 This was pointed out to me by Irene Heim (pc). Roger Schwarzschild suggested that evidence for this point may be provided by the fact that lauter does not allow for partitive constructions, i.e. *lauter von den Studenten ('many of the students'). 
whereas the cardinal noun phrase in (12b) can.8 Thus, (12a) can only have a reading where the time of being sick intersects with the time of being a student. Consequently, (12a) cannot be used in order to make a statement about the present state of health of students of 1980 . Rather, (12a) can only be understood as a statement about present students. This is illustrated in (13a).

*student $(\mathrm{x}) \quad \begin{gathered}\text { x's being sick } \\ \text { student (x) }\end{gathered}$

But (12b) can have a reading where the time of being famous is located at the time of utterance and does not intersect with the time of being a student. Consequently, this sentence can be used to say something about the fame of the students in 19.80, as is illustrated in (13b).

(13b) $\stackrel{\text { student }(\mathrm{x})}{\mathrm{x} \text { 's being famous }}$

Thus, the behavior of subject noun phrases of existence-independent predicates is not captured by the generalization (10).

Thus, we have to revise the generalization in (10), in order to capture the behavior of subjects of existence-independent predicates on a descriptive level.

(14) Distribution of temporally (in)dependent noun phrases:

A subject noun phrase of a stage-level predicate or of an individual-level predicate can be temporally independent iff it is presuppositional.

A subject noun phrase of an existence-independent predicate can be temporally independent.

Based on the descriptive generalization (14), I will develop in the remainder of this chapter a proposal that explains the distribution of temporally dependent and temporally independent noun phrases.

8 I observed that some informants don't get the contrast immediately or get it only weakly at first. The contrast gets apparently stronger after a while. I think this is due to the contextual salience of present students. For a description of relevant effects of contextual salience, see Section 8. 


\section{A scope-approach based on the cardinal/presuppositional distinction}

We observed in Section 2 that the distribution of temporally dependent and temporally independent noun phrase interpretations corresponds largely to the distinction between cardinal and presuppositional noun phrases. This section investigates the adequacy of an approach that is based on the cardinal/ presuppositional distinction. According to Diesing $(1988,1992)$, cardinal and presuppositional noun phrases are associated with different structural positions at LF. In particular, cardinal noun phrases seem to be associated with lower positions than presuppositional noun phrases. This suggests that the occurrence of temporally dependent interpretations may be due to scope configurations at LF. Thus, the approach explored in this section tries to derive the distribution of temporally dependent and temporally independent noun phrases from the scope they take at LF. At first sight, the approach appears very appealing, because it is based on an independently motivated proposal by Diesing $(1988,1992)$. It seems to be able to capture most, if not all, of the data presented in Section 2 without additional stipulations. I will argue though that the success of the scopeapproach is rather limited, because it is not at all obvious how it could deal with certain constructions that involve adverbs of quantification: with these constructions, the approach runs into a scope paradox.

\subsection{The general idea}

The proposal of Diesing (1988, 1992) states a general asymmetry between presuppositional noun phrases and cardinal noun phrases with respect to their behavior at LF. According to Diesing, presuppositional noun phrases undergo Quantifier Raising at LF, adjoin to IP, and open tripartite structures if they have implicit quantificational force. If they do not have quantificational force of their own (as indefinites), they move into the restrictive clause of a quantifier - usually into the restrictive clause of an adverb of quantification. Cardinal noun phrases do not undergo Quantifier Raising and do not open tripartite structures; they are interpreted as part of the nuclear scope (of an adverb of quantification), and the 
variables they introduce get bound by existential closure. (15) illustrates the LFs for readings that can thus arise for an indefinite noun phrase.

(15) a. I always write up a witty story about Millard Fillmore.

b. Quantificational/presuppositional reading of the indefinite: Whenever I hear a witty story about Millard Fillmore, I always write it up.

LF: ALWAYS $\mathrm{x}$ [ $\mathrm{x}$ is a story about Millard Fillmore] [I write up $\mathrm{x}$ ]

c. Existential/cardinal reading of the indefinite: First thing in the morning, I always write up a witty story about Millard Fillmore. (The restrictor is here contextually supplied.)

LF: ALWAYS $\mathrm{t}_{\mathrm{t}}\left[\mathrm{t}\right.$ is in the morning] $\exists_{\mathrm{x}}$ [ $\mathrm{x}$ is a witty story about Millard Fillmore \& I write up $\mathrm{x}$ at $\mathrm{t}]$

Since presuppositional and cardinal subjects of stage-level predicates and individual-level predicates differ with respect to their temporal interpretation (as we have established in Section 2), and since Diesing's approach states a basic asymmetry between presuppositional and cardinal noun phrases with respect to their location at LF, it is plausible to assume that there is some connection between Diesing's account and the observations concerning temporal interpretation. Thus, some extension of Diesing's approach might be used to account for the distribution of temporally dependent and independent readings of noun phrases. The obvious hypothesis is that when presuppositional noun phrases are moved by Quantifier Raising, they are thereby raised out of the scope of an operator that determines their temporal interpretation by binding a time variable they introduce.

What kind of operator might, in such an approach, be responsible for the binding of time variables of nouns of course highly depends on the theory of temporal interpretation entertained. Since temporally dependent noun phrases are by definition temporally "bound" (in a pre-theoretical sense) to the event time of the main predicate of their clause, the crucial operator must be an operator that also binds the event time of the main predicate. Depending on the general framework of temporal interpretation entertained, the operator in question might be tense itself (if tense is represented as a quantifier), or it might be some other operator. In the framework I am exploiting in this thesis the (obligatory and possibly implicit) adverb of quantification that takes tense as its restrictor is certainly the most promising candidate for an operator that binds the event time of the main predicate. In order to avoid confusion, I will refer to this adverb of 
quantification in the following as THE TEMPORAL ADVERB OF QUANTIFICATION (TAQ).

Thus, let us assume that noun phrases in general have time arguments 9 and investigate the hypothesis that cardinal noun phrases (with the exception of cardinal subjects of existence-independent predicates, which I will ignore for the moment) are in the scope of the TAQ at LF. The TAQ obligatorily binds their time variable. Because of this, they get obligatorily temporally dependent interpretations. Moreover, presuppositional noun phrases are moved to a position outside the scope of the TAQ where their time variable escapes from being bound.

As indicated above, the relevant LFs used by Diesing have the basic form (16), where "QA" stands for an adverb of quantification.

$$
\text { QA [RC presuppositional NP] [NS cardinal NP] }
$$

In order to have the time arguments of noun phrases in the nuclear scope bound by the TAQ, but not noun phrases in the restrictive clause, the TAQ must be located directly in front of the nuclear scope. Thus, let us assume that LFs are of the basic form (17).

$$
\text { QA [RC presuppositional NP] TAQ [NS cardinal NP] }
$$

According to (17), cardinal noun phrases, which stay in the nuclear scope, are in the scope of the TAQ, whereas presuppositional noun phrases, which are raised into the restrictive clause, are outside the scope of the TAQ. Thus, the TAQ can bind the time arguments of cardinal noun phrases, but not time arguments of presuppositional noun phrases.

Note that any approach of this type gives us the desired result only under the assumption that TAQ binds nominal time arguments in its scope obligatorily. If it bound time arguments in its scope only optionally, then one would expect always to have the option of having noun phrases with temporally free readings in the nuclear scope. But this expectation is not borne out.

To summarize, according to the scope-approach, the LF-position of a noun phrase determines its temporal interpretation. Semantic partitioning maps cardinal

\footnotetext{
9 Note that there is a fundamental question of whether nouns do have time arguments (cf. some remarks by Wilkinson $(1991,30))$. If it turns out that nouns don't have time arguments, then the whole account can of course not work simply for that reason.
} 
noun phrases into the nuclear scope where they are in the scope of the TAQ, which binds their time variable obligatorily. Presuppositional noun phrases are mapped into the restrictive clause where they escape out of the scope of the TAQ and are consequently temporally independent. Since so far the account does not introduce any additional stipulations but integrates the relevant data into a system that is independently motivated, it sounds very desirable at first sight. Moreover, as I will show in the next subsection, it seems that the account is also able to cope with the behavior of subjects of existence-independent predicates.

However, the approach fails because it makes wrong predictions with certain constructions that involve both overt adverbs of quantification and quantificational noun phrases. This is shown in Subsection 3.3.

\subsection{Cardinal subjects of existence-independent predicates}

We have seen in Section 2 that there is an exception to the correlation of the distinction between temporally dependent and temporally independent noun phrases on the one hand and the distinction between cardinal and presuppositional noun phrases on the other hand. This exception is found with cardinal subjects of existence-independent predicates: contrary to expectations, such noun phrases are able to exploit temporally independent readings. Thus, the question must be raised in which way the scope-approach might be able to deal with these cases.

There is an obvious way to account for these cases without assuming stipulative additions to the theory: this is to claim that for some reason, subjects of existence-independent predicates are base-generated in a position that maps them outside the scope of the TAQ at LF.10 Let us thus pursue this possibility and see whether it works.

As far as I can see, the claim that subjects of existence-independent predicates are base-generated in a position that maps them outside the scope of the TAQ at LF predicts basically that these noun phrases should behave like subjects of individual-level predicates as described in Kratzer (1988). As we have seen above, subjects of existence-independent predicates are able to have cardinal subject noun phrases. At least in this respect, they differ from the

10 Since the alternative possibility to assume that cardinal subjects of existence-independent predicates are raised at LF runs against the basic ideas of the Diesing-approach, I don't want to pursue this possibility at all. 
commonly acknowledged behavior of individual-level predicates (cf. Carlson (1977), Kratzer (1988)). Thus, I will assume that although they are not a subcase of individual-level predicates, their behavior may in some respects be analogous.

Kratzer describes a number of grammatical phenomena with respect to which individual-level predicates differ crucially from stage-level predicates. Here is a list of the relevant constructions that also contains a brief investigation of the behavior of existence-independent predicates. The (a)-sentences show the behavior of a typical stage-level predicate, the (b)-sentences the behavior of a typical individual-level predicate, and the (c)-sentences the behavior of an existence-independent predicate. At least with the (c)-sentences, judgements are unfortunately not ver clear in all cases. 11

there- construction:

a. There are firemen available.

b. * There are firemen altruistic.

c. * There are firemen famous.

(19) Distribution of existential/generic readings with bare plurals:

a. Firemen are available. (can be understood existentially)

b. Firemen are altruistic. (only generic reading)

c. Firemen are famous. (perhaps only generic reading)

(20) Absolute constructions:

a. Standing on a chair, John can touch the ceiling. $=$ If John stands on a chair, he can touch the ceiling.

b. Having unusually long arms, John can touch the ceiling. $\neq$ If John has unusually long arms, he can touch the ceiling.

c. Being famous, John can give horrible lectures without people getting angry.

$\neq$ If John is famous, he can give horrible lectures without people getting angry.

(21) Quantifier split in German:
a. weil uns viele Lehrer geholfen haben since us many teachers helped have ('since many teachers helped us')
a'. Lehrer haben uns viele geholfen
b. weil das viele Lehrer wissen since that many teachers know ('since many teachers know that')
b'. ? Lehrer wissen das viele

11 The (a)- and (b)-sentences are taken from Kratzer (1988). 


\section{c. weil damals viele Lehrer berühmt waren since then many teachers famous were ('since many teachers were famous then') \\ c'. (?) Lehrer waren damals viele berühmt}

(22) Negative quantifiers in German
a. weil keine Ärzte verfügbar sind since no physicians available are ('since no doctors are available')
b. ? weil keine Ärzte altruistisch sind since no physicians altruistic are ('since no doctors are altruistic')
c. (?) weil keine Ärzte berühmt sind since no physiciansfamous are ('since no doctors are famous')

(23) Relative clause extraction

a. weil zwei Kinder hier waren, mit denen niemand spielen wollte since two children here were, with who nobody play wanted ('since two children were here who nobody wanted to play with')

b. ? weil zwei Bücher teuer waren, die niemand lesen wollte since two books expensive were, who nobody read wanted ('since two books were expensive which nobody wanted to buy')

c. (?) weil vier Semantiker berühmt sind, die nicht Softball spielen since four semanticists famous are who not softball play wollten wanted

('since four semanticists are famous who didn't want to play softball')

To summarize, it seems that existence-independent predicates behave at least in some respects very much like individual-level predicates. Thus, it seems likely that a Diesing-approach can somehow cope with the fact that cardinal subjects of existence-independent predicates can get temporally independent interpretations.

Note that the approach I have sketched implies that if subjects of individuallevel predicates are base-generated in a position that maps them at LF to a position outside the scope of the TAQ, then subjects of individual-level predicates should also in general be able to get temporally independent interpretations even when being cardinal. As far as I can see, this prediction is irrelevant for the present purpose because it is probably not testable anyway: if individual-level predicates denote life-time properties of their subjects, then it won't be possible to see whether the subject noun phrase is temporally dependent or independent; because of the life-time duration of the property of the main predicate, the 
predication time of the property denoted by the noun will always intersect with the predication time of the individual-level main predicate.

\subsection{A problem: constructions with adverbs of quantification}

According to what we said in Subsection 3.1., the operator that is reponsible for the occurrence of temporally dependent noun phrases should have the following properties:

- it must be located in an LF-position that includes cardinal noun phrases in its scope but excludes presuppositional noun phrases;

- it must not only be able to bind time arguments of nouns, but it must moreover be able to co-bind the time argument of the noun and the time argument of the main predicate;

- the binding of time arguments of noun phrases should happen obligatorily. Since the second property can only be achieved by the TAQ in our framework of temporal interpretation, we have identified the operator that is responsible for the occurrence of temporally dependent noun phrases with this quantifier. Recall that, by the demands of the temporal interpretation of main predicates in combination with tenses, temporal adverbials, and implicit temporal restrictions, the TAQ crucially has the following property:

- it is restricted by the tense, temporal adverbials, and implicit temporal restrictions of its clause.

In this subsection, I will show that the TAQ cannot possibly always fulfill all these demands. In particular, there are cases which show that, if the TAQ is responsible for the occurrence of temporally dependent noun phrases, then it cannot always be a binder of tense and temporal adverbials. This is because tense and temporal adverbials can be shown to sometimes occur outside the scope of the operator that is responsible for the occurrence of temporally dependent noun phrases. Thus, a contradiction arises that shows that the scope-approach cannot work as sketched above. The argument goes as follows.

Sentence (24a) contains a presuppositional quantificational noun phrase and an adverb of quantification. It can have the reading (24b), where the adverb of quantification has wide scope over the quantificational noun phrase. In particular, reading (24b) is possible in the version of (24c), where the noun Professoren has a temporally independent interpretation. 
(24) a. In den sechziger Jahren spielten meistens alle Professoren, deren in the sixties played mostly all professors whose Eltern gerade in Urlaub waren, Federball. parents just in vacation were badminton ('In the forties, most often all professors whose parents were just then on vacation, played badminton.')

b. For most times $t$, such that $t$ is in the past and in the sixties, all $x$ such that $\mathrm{x}$ is a professor and $\mathrm{x}$ 's parents were on vacation at $\mathrm{t}$, $\mathrm{x}$ played badminton at $t$.

c. For most times $t$, such that $t$ is in the past and in the sixties, all $x$ such that $\mathrm{x}$ is now a professor and $\mathrm{x}$ 's parents were on vacation at $t, \mathrm{x}$ played badminton at $t$.

In both (24b) and (24c), tense and the temporal adverbial are predicates of times that serve as restrictors of the adverb of quantification. Thus, the adverb of quantification functions here as the TAQ, and tense and the temporal adverbial (TA) appear in the restrictive clause of the TAQ as shown in (25).

TAQ [RC TENSE \& TA ... ] [NS ...VP...]

As we have seen, the presuppositional noun phrase in (24a) under the reading (24c) is in the scope of the TAQ. Thus, (24c) has an LF roughly of the form (26), where the TAQ has wide scope over the quantificational noun phrase.

TAQ [RC TENSE \& TA ... ] [NS Q-DET [RC N...] [NS ...VP...]]

As we have seen with the availability of reading (24c), the quantificational noun phrase can have a temporally independent interpretation, although it appears in the scope of the TAQ. Considering that we were forced to assume that the TAQ must bind time arguments of nouns in its scope obligatorily, if it is to be held responsible for the occurrence of obligatorily temporally dependent noun phrases at all, this is rather unexpected. Thus, I conclude that the TAQ cannot be responsible for the occurrence of obligatorily temporally dependent noun phrases.

Note that one cannot get around this conclusion by stipulating that the TAQ binds only time arguments that are introduced in its restrictive clause (framed in (27)), but not time arguments that are introduced in its nuclear scope.

TAQ [RC TENSE \& TA ...] [NS Q-DET [RCN...] [NS...VP...]] 
This stipulation would predict falsely that cardinal noun phrases should be able to be temporally free in a construction (28a) with reading (28b). But reading (28b) seems impossible when the cardinal reading is triggered by stressing the noun.

a. In den vierziger Jahren spielten meistens viele PROFESSOREN, in the forties played nostly many professors deren Eltern gerade in Ferien waren, Federball. whose parents just in vacation were badminton ('In the forties, most often many professors whose parents were just then on vacation were playing badminton.')

b. For most times $t$, such that $t$ is in the forties, many $x$ such that $x$ is a professor and $x$ 's parents were on vacation at $t, x$ played badminton at $\mathrm{t}$.

Thus, we have arrived at the conclusion that the TAQ cannot be responsible for the occurrence of obligatorily temporally dependent noun phrases. But since the TAQ ultimately binds the event time of the main predicate and temporally dependent noun phrases and the event time of the main predicate must be cobound, the TAQ seems to be the only operator that could be responsible for the occurrence of temporally dependent noun phrases. Thus, we must conclude at this point that the whole approach is misled, because it leads to a contradiction that cannot be eliminated.

Of course, one could avoid the contradiction by assuming a stipulation like "The TAQ binds time arguments of cardinal noun phrases in its scope obligatorily but not time arguments of presuppositional noun phrases in its scope". But if one adopts this stipulation, then one reaches a point where the distribution of temporally dependent and temporally independent noun phrase interpretations is attributed to some internal property of cardinal and presuppositional noun phrases and doesn't depend crucially on scope anymore.

To summarize, we have seen that the scope-approach fails because of scope paradoxes that arise with certain readings of clauses containing adverbs of quantification: noun phrases in the scope of the crucial operator can be temporally independent if they are presuppositional. In light of this result, it seems likely that the occurrence of temporally dependent interpretations is not due to scope, but hinges on noun phrase internal properties.

Thus, at this point, we don't have an explanation for the occurrence and distribution of temporally dependent noun phrases. Temporally dependent noun phrase interpretations do not seem to be due to the noun phrase's position at LF but to some inherent property of cardinal noun phrases. Furthermore, we have 
seen that there are certain cases where cardinal noun phrases can be temporally independent. The occurrence of these cases is dependent on the nature of the main predicate the noun phrase is an argument of. In particular, it seems to be crucial that the predicate is existence-independent. Thus, we can conclude that it is not only noun phrase internal properties that decide about the occurrence of temporally dependent or temporally independent interpretations, but also the way in which the main predicate relates to the argument.

In the next sections, I will argue that a semantics of quantification based on a stage-ontology is not only able to explain the occurrence of temporally dependent noun phrase interpretations, but is also able to deal adequately with the constructions that are problematic for the scope-approach.

\section{Stages}

Somehow it seems that not only the properties of the noun phrase play a role but also the way in which the main predicate relates to the noun phrase - or, to be more precise, the subject of the noun.

In this section, I suggest an alternative approach that is based on the assumption that determiner-quantifiers quantify over stages of individuals rather than individuals in their maximal temporal extendedness. Furthermore, I argue that determiners of cardinal noun phrases and determiners of presuppositional noun phrases receive (in principle) exactly the same interpretation. Differences between them are in general caused by the mapping of the noun: a noun that appears as part of a DP can be mapped either into the restrictive clause or into the nuclear scope of the determiner. Nouns that appear as part of a presuppositional noun phrase are mapped into the restrictive clause, whereas nouns that appear as part of a cardinal noun phrase are mapped into the nuclear scope. This difference is also responsible for the fact that presuppositional noun phrases can receive temporally independent interpretations, whereas cardinal noun phrases (with the exception of arguments of existence-independent predicates) cannot.

I show that the data that proved problematic for the approaches in Section 3 follow from this account in combination with the semantics of existenceindependent predicates I suggested in Chapter II. 


\subsection{The basic idea}

At this point, there are still two questions to be answered: First, what syntactic and/or semantic mechanisms cause temporally dependent interpretations of noun phrases? Second, why do the crucial mechanisms apply to some noun phrases but not to others? In this section, I argue that the occurrence of temporally dependent noun phrase interpretations is due to an ontology that contains stages of individuals as primitive elements. In particular, I argue that determiner quantification is not quantification over individuals in their whole temporal extendedness but quantification over STAGES OF INDIVIDUALS. With regard to the extendedness of the stages a particular quantifier quantifies over, I will assume that the temporal length of a stage (st) is determined by the predication time(s) introduced by the restricting predicates of the determiner. Based on this assumption, I then argue that the distribution of temporally dependent and temporally independent noun phrase interpretations results from the interaction of general, mostly independently motivated principles of quantification and the lexical semantics of predicates.

A common assumption about determiner quantification is that it is quantification over whole individuals in the sense of individuals in their entire temporal extendedness. Semantic representations like (29a) and (29b)12 may be interpreted as (29c) and (29d), respectively.
a. $\quad$ professor $(x, t)$
b. professor $(\mathrm{x})$
c. $\quad \mathrm{x}$ (in its entire temporal extendedness) is a professor at $\mathrm{t}$
d. $\quad x$ (in its entire temporal extendedness) is a professor at some time

The counterpart of this idea with the interpretation of main predicates is that a main predicate like was sick is basically interpreted like (30b).13
a. $\quad$ was $\operatorname{sick}\left(\mathrm{x}, \mathrm{t}^{*}\right)$
b. $x$ is sick at $t^{*}$ and $t^{*}$ is before now

12 (29a) exploits the idea that (stage-level) nouns have time arguments, whereas (29b) exploits the idea that nouns do not have time arguments.

13 I assume here that there is no doubt about the presence of time arguments with (stagelevel, non-nominal) predicates and furthermore, for ease of presentation, I make use of a very simple representation of past tense. At this point, nothing hinges on this. 
Putting together these two parts, a sentence like There was a professor sick (31a) gets roughly a representation like (31b), which can be paraphrased as (31c).

(31) a. There was a professor sick.

b. $\quad \exists x \exists_{t} \exists *$ professor $(x, t) \&$ was sick $\left.(x, t *)\right]$

c. There is an individual $x$ and a time $t$ and a time $t^{*}$, such that $x$ is a professor at $t$ and $x$ is sick at $t *$ and $t *$ is before now.

In principle, this representation allows for the predicates professor and the predicate sick to be predicated of $\mathrm{x}$ at entirely distinct times (as long as these times are included in the life-time of $\mathrm{x}$ ). This can be illustrated as in (32).

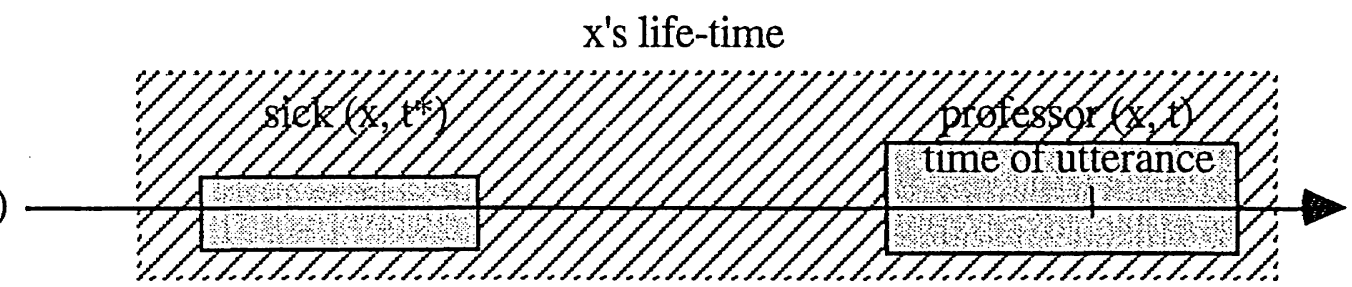

As we have seen, this Enç-type prediction is wrong; the predication times of sick and of professor have to intersect. Obviously, we need some mechanism for explaining the occurrence of temporally dependent interpretations.

Contrasting with the general approach I just sketched, the basic idea of my proposal is that determiner-quantifiers do not quantify over whole individuals but over stages of individuals. Thus, the entities predicates are predicated of are not whole individuals but temporal parts of individuals. Consequently, There was a professor sick will now have a representation like (33b) and be interpreted like (33c). The subscript-notation is used here to indicate that $x_{S t}$ is a variable that ranges over stages of individuals. Here and below, I will talk about stages $\mathrm{x}_{\mathrm{St}}$ that are temporal parts of their "host individual" $\mathrm{x}$.
a. There was a professor sick.
b. $\quad \exists_{x-s t} \exists_{t} \exists_{t} *\left[\right.$ professor $\left(x_{s t}, t\right) \&$ was sick $\left(x_{s t}, t^{*}\right){ }^{14}$
c. There is a stage $x_{S t}$ and a time $t$ and a time $t^{*}$, such that $x_{S t}$ is a professor at $\mathrm{t}$ and $\mathrm{x}_{\mathrm{St}}$ is sick at $\mathrm{t}^{*}$ and $\mathrm{t}^{*}$ is before now.

14 Note that at this point there are several possibilities conceivable how to interpret an expression like $\exists x_{s t} \exists t$ professor $\left(x_{S t}, t\right)$. One may assume that the time of $t$ must be included in the time covered by $x_{s t}$. Alternatively, one my assume that $t$ must cover the whole temporal extendedness of $x_{S t}$. At this point, I don't want to go into a discussion of these possibilities and their consequences. 
If the stage $\mathrm{x}_{\mathrm{St}}$ is not extended beyond the whole individual's time of being a professor, it follows that at least part of the host individual's time of being sick must be included in its time of being a professor. This is illustrated in (34).

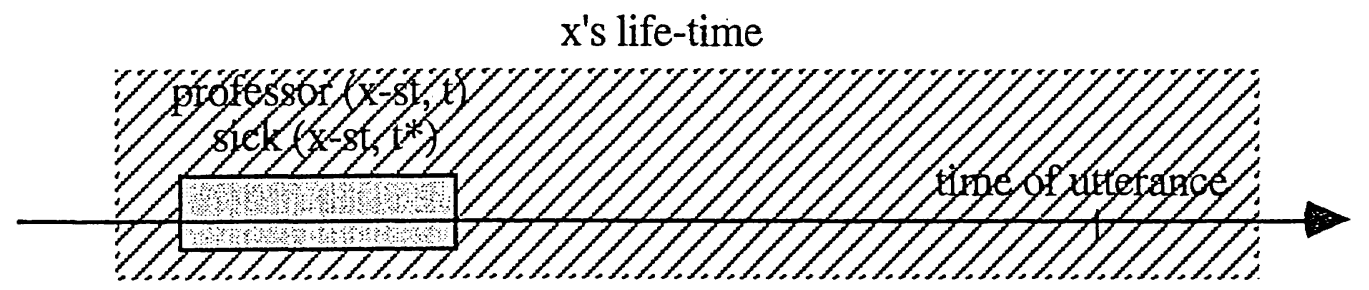

This approach predicts that if the stages determiner-quantifiers quantify over never extended beyond the predication time of the noun, then all quantificational noun phrases should always have temporally dependent interpretations. We have seen above that this is not so; presuppositional noun phrases in general and certain cardinal noun phrases are able to get temporally independent interpretations. I will argue below that the distribution of temporally dependent and temporally independent noun phrase interpretations is due to independently motivated principles of how quantification works and independently motivated principles concerning life-time presuppositions of predicates (see Chapter II).

Roughly speaking, presuppositional noun phrases can introduce larger stages than cardinal noun phrases, because their noun is part of the restriction of the quantifier involved; this is one of the mechanisms that lead to temporally independent interpretations. And stages introduced by cardinal noun phrases that are existence-independent arguments of the main predicate are independent of the event-time of the main predicate, because the main predicate does not impose life-time presuppositions on them; this is the other mechanism leading to temporally independent noun phrase-interpretations.

The observation that a stage-ontology under certain circumstances predicts the occurrence of temporally dependent NP-interpretations is not entirely new. Schubert and Pelletier $(1987,424 f)$ mention possible effects that point in this direction. They view these possible effects as problematic and argue that it poses difficulties for approaches that are based on a stage-ontology. Contrary to this view, I am making use of these effects and show that a stage-ontology gives us exactly the right results with regard to the temporal interpretation of noun 
phrases, if it is embedded into the appropriate framework.15, 16 Also, Carlson $(1982,174)$ observes a temporal dependency effect implied by the set-up of his stage framework: he notes that if a predicate $\mathrm{P}$ is true of a stage $\mathrm{u}$ at a time $\mathrm{t}$, and a predicate $Q$ is true of stage $u$ at a time $t^{\prime}$, then $t=t^{\prime}$. This is a temporal dependency effect like the one I sketched above, but just viewed from another standpoint Carlson main purpose is to point out problems concerning the identity or nonidentity of stages, whereas I am aiming at explaining intersections of predication times.

In the next subsection, I explain and motivate the assumptions on which my proposal is based; these remarks concern the ontology, the theory of quantifier restrictions, and the semantics of cardinal and presuppositional noun phrases,

\subsection{On the semantics of quantification}

\subsubsection{The ontology}

I will make use of an ontology whose domain of entities consists not only of individuals in their whole temporal extendedness, but also of "stages". STAGES are temporal parts or slices of individuals. One may probably take stages to be spatio-temporal parts of individuals, but since I am not going to discuss matters of their possible spatial dimension, I will refer to them just as temporal parts of individuals.

Both individuals in their whole temporal extendedness and stages are elements of the domain of entities, i.e., of type $e$. The domain of entities has to be somehow sorted, so that it is possible to distinguish individuals in their whole temporal extendedness from stages - although I assume "whole individuals" to be a special case of stages. Thus, within the domain of entities, "whole individuals" have to be somehow designated.

When a particular stage $\alpha_{\text {st }}$ is a part of the individual $\alpha$, I will refer to $\alpha$ as the HOST INDIVIDUAL of $\alpha_{\text {st. }}$. For the purpose of this section, I will assume that any

15 The framework I will be exploiting here exploits the same basic idea as my (1993) proposal on the temporal interpretation of noun phrases, but differs quite crucially as far as details of the surrounding semantics are concerned.

16 Paul (1994) exploits a stage-semantics for proper names in order to explain certain phenomena concerning the spatio-temporal modification of proper names. As far as I can see, he makes more use of the ability of stages to distinguish between predicates being predicated of individuals at different times or places, rather than of the ability of stages to restrict the temporal-spatial regions which predicates are predicated of. 
stage in the domain of entities has exactly one host individual. In Section 10, I will suggest a modification of this assumption though $\mathrm{h}_{2}$ in order to be able to treat more phenomena in natural language adequately. Thus, for the moment we can assume that the host individual of a particular stage is in principle always. recoverable.

In principle, a stage can be of any length that is included in its host individual's time of existence. And an individual in its whole temporal extendedness, as any of its stages, consists of infinitely many stages that can overlap each other. Below, I will be concerned with the question of how long they are in concrete occurrences in semantic representations. Here it is only important to note that they don't need to be of minimal length or instantaneous. 17

Like Carlson (1977, e.g. 455) and Paul (1994, 275), I take stages belonging to the same host individual as entitites that can be merged or fused together such that the resulting entity will again be a stage of that host individual. Stages that belong to different host individuals cannot be merged, since the resulting stage would then have more than one host individual - which would contradict the respective assumption made above.

Note that if my argument in the remainder of this chapter is on the right track, then my work provides interesting evidence in favor of the claim that natural language exploits an ontology that is crucially based on stages of individuals.

17 Since stages have frequently been exploited in semantics, and the term "stage" is used in the literature with various meanings, a few terminological comments are in order: Carlson's (1977a, 1977b, 1979) notion of stages is similar to my notion of stages; for him, stages are spatio-temporal realizations of individuals that are "tied together" by being stages of the same individual. Carlson is not very clear about the details of his ontology, but he classifies stages, like objects, as of type $e$. Lewis (1976), on the other hand, takes stages to be "more or less momentary"; this contrasts with Carlson's concept, who takes stages to be potentially of considerable length. Perhaps inspired by Goodman (1951, cf. e.g. 127ff), Quine (1960,52,172f) considers the possibility that noun denotations are sets of stages or parts of whole enduring individuals. I am not sure about the specific characteristics he attributes to stages, but I think neither he nor Goodman have a restriction of temporal parts to instantaneous parts in mind. Kratzer's (1988) ontology does not contain stages as parts of individuals. For her, stages as such are merely spatio-temporal entities, but not spatiotemporal parts of individuals. 


\subsubsection{Quantification with resource domain variables}

It is well-known that quantifiers are in general not interpreted with respect to the whole universe, but only to a contextually relevant set. For example, when talking about the party of last Friday, a sentence like

(35) Everyone had a great time.

is most likely not intended to say something about all people in the universe, but only about the people that were present at the party. Thus, the quantifier everyone is implicitly restricted by the context. Restriction of quantifiers by the context is a very common process. Moreover, it can be shown that contextual restriction does not happen clause-wide but is a local process - i.e., the following example suggests that each quantificational noun phrase can have its own contextual restriction: 18

(36) Everybody is asleep and is being monitored by a research assistant.

Let us assume that (36) is uttered in the context of a lab, and that in this context, everybody quantifies over the subjects in the lab. The DP a research assistant shows that the contexts relative to which quantifiers are interpreted are not defined for whole sentences. Rather, contexts must be able to change within a sentence, namely when the next DP appears.

In order to account for the locality of the context-dependency of quantificational noun phrases, von Fintel (1994) assumes that the contextdependency is located in the determiner. He implements the context dependency by indexing determiners with a variable $C$. As with variables in general, the resource domain variable can get a value assigned in various ways - deictically, anaphorically, or by a process of binding. When the resource domain variable is free, the value must be provided by the context, i.e., it will then denote a contextually supplied set of individuals, the resource domain. As proposed by Westerståhl $(1984,52)$, the RESOURCE DOMAIN VARIABLE is interpreted as demonstrated in (37), i.e. by intersection with the common noun argument.

$$
\llbracket \text { everyc } \rrbracket(A, B)=[\lceil\text { every } \rrbracket(C \cap A, B)
$$

18 This example is taken from Soames (1986). 
Following (37), (36) is, in the context sketched above, true if and only if for every $\mathrm{x}$ such that $\mathrm{x}$ is a subject in the lab and $\mathrm{x}$ is a person, $\mathrm{x}$ is being monitored by $\mathrm{a}$ research assistant. - In the following, I will adopt von Fintel's account of quantifier restriction.

It is important to note that all determiners are able to provide a resource domain variable for the interpretation of the noun phrase they are part of - i.e., determiners of presuppositional noun phrases as well as determiners of cardinal noun phrases. For presuppositional noun phrases, this was shown above. Here is some evidence showing that cardinal noun phrases can have a contextual restriction: Because of the use of the there-construction in (38), one can safely assume that the underlined noun phrases are cardinal. Imagine a context where we have just been talking about people belonging to the linguistics department of MIT. Talking then with (38a) about where people had lunch today, the noun phrase no professors in (38a) is contextually restricted to professors belonging to the MIT linguistics department. Thus, provided that none of the linguistics professors from MIT had a truck lunch today, (38a) will be judged true even if there were seven biology professors eating at the trucks today. Furthermore, in the context of a conversation about how many people belonging to the MIT linguistics department went to a talk at Harvard today, (38b) may be judged true even if all Harvard professors attended the talk.19

(38) a. There were no professors eating at the trucks today.

b. There were few professors at Harvard today.

(38) shows that contextual restriction with cardinal noun phrases is also locally provided, just as with the presuppositional noun phrases above.

\subsubsection{On the semantics of cardinal and presuppositional DPs}

\subsubsection{The interpretation of cardinal DPs}

Some people have favoured an analysis of the determiners of cardinal noun phrases as cardinal predicates (Milsark (1974), Higginbotham (1987, 48), Diesing $(1992,61))$. Within such an account, a sentence like (39a) might have an LF like

19 These sentences are based on suggestions of David Pesetsky and Kai von Fintel, respectively. 
(39b), where many appears as a cardinal predicate over sets, and the truth conditions in (39c).20, 21

(39) a. There were many students here.

b. $\quad \exists X[$ many $(X) \&$ students $(X) \&$ were-here $(X)]$

c. $\llbracket(39 a) \rrbracket=1$ iff there is a set $X$, such that $X$ has many members and all members of $X$ are students and were here.

With (39b), (39a) is predicted to be true if and only if there is a set X, such that X has many members and all members of $\mathrm{X}$ are students and were here.

A serious problem with this proposal is that it fails with determiners that are neither leftward monotone increasing nor rightward monotone increasing. 22 Thus, for (40), the approach predicts truth conditions that are intuitively completely inappropriate: According to the LF in (40b), for There were few students here in order to be true, there should be a set of individual that are students, and this set should have few members. This situation is of course given, whenever There were many students here is true, since a set of many students has subsets of few students.

(40) a. There were few students here.

b. $\quad \exists X[$ few $(X) \&$ students $(X) \&$ were-here $(X)]$

c. $\llbracket(40 a) \rrbracket=1$ iff there is a set $X$, such that $X$ has few members and all members of $X$ are students and were here.

Here, the wrong prediction could perhaps be overruled by Gricean principles. I.e., in a situation where there were many students here, it might be ruled out to say that there were few students here, because it would be more informative to say that many students were there - just as in a situations where all students were here, it would be true but not optimally informative to say that some students were here

But there are determiners where it is not clear how their treatment in the cardinal-predicate-account could be saved by a Gricean explanation. These are determiners like exactly two and at most two.

20 I assume that these are the LFs intended (cf. Higginbotham $(1987,48)$ ). I don't want to go into details of plural semantics here, because the approach is probably not tenable anyway, as I will argue shortly.

21 I am using the there-construction in order to make sure that the noun phrasemany students appears with its cardinal interpretation.

22 This was already observed by von Stechow (1980) and Heim (1987, 40 fn. 3). 
(41) a. There were exactly two students here.

b. . $\exists X$ [exactly two $(X) \&$ students $(X) \&$ were-here $(X)]$

c. $\llbracket(41 a) \rrbracket=1$ iff there is a set $X$, such that $X$ has exactly two members and all members of $X$ are students and were here.

Suppose there were eight students here. In this situation, (41a) is predicted to be true because there is a set $X$, such that $X$ has exactly two members and all members of $X$ are students and were here. But in fact (41a) is judged plainly false. Thus, the account is unable to predict the intuitive truth conditions of (41a). The analogous problem occurs with (42a).

a. There were at most two students here.

b. $\quad \exists X$ [at most two $(X) \&$ students $(X) \&$ were-here $(X)]$

c. $\llbracket(42 a) \rrbracket=1$ iff there is a set $X$, such that $X$ has at most two members and all members of $X$ are students and were here.

Like (41a), (42a) is also falsely predicted to be true in a situation where eight students were here, because there is a set $\mathrm{X}$, such that $\mathrm{X}$ has at most two members and all members of $\mathrm{X}$ are students and were here.

Finally, the predictions of the cardinal-predicate-account for the determiner $n o$ are definitely at least unintuitive. For example, the predicted truth conditions of There were no students here are quite strange:

a. There were no students here.

b. $\quad \exists X[$ no $(X) \&$ students $(X) \&$ were-here $(X)]$

c. $[(43 a) \rrbracket=1$ iff there is a set $X$, such that $X$ has no members and all members of $X$ are students and were here.

According to (43b), (43a) is true if and only if there is a set $X$, such that $X$ has no members and all members of $X$ are students and were here. I am not sure what this means, but if $[[$ student $\rrbracket(X)$ is true if and only if all members of $X$ are students, then [[student $](X)$ is true for the empty set. The same holds for [[werehere $\rrbracket(\mathrm{X})$. Thus, whenever one can make out an empty set - which is always the case - There were no students here is predicted to be true. If that is so, then there is literally no situation that could make the sentence false. This is of course a false prediction.

Thus, the cardinal-predicate-account seems inadequate. An alternative approach for interpreting the determiners of cardinal noun phrases is to say that they are quantifiers, but - considering the evidence we have so far (but see below) - unrestrictive ones. Then, the LFs for the examples above would be like 
demonstrated in (39' - 43' b) with the truth conditions in (39' - 43' c), where for the moment, I will ignore my proposal to quantify over stages of individuals instead of over individuals in their whole temporal extendedness.

(39') a. There were many students here.

b. MANY [students (x) \& were-here (x)]

c. $\llbracket\left[\left(39^{\prime} a\right) \rrbracket=1\right.$ iff for many $x, x$ is a student and $x$ was here.

(40') a. There were few students here.

b. $\quad$ FEW $_{\mathrm{X}}$ [students (x) \& were-here (x)]

c. $\left[\left(40^{\prime} a\right) \rrbracket=1\right.$ iff for few $x, x$ is a student and $x$ was here.

(41') a. There were exactly two students here.

b. EXACTLY TWO $\mathrm{X}$ [students $(\mathrm{x})$ \& were-here $(\mathrm{x})$ ]

c. $\llbracket\left(41^{\prime} a\right) \rrbracket=1$ iff for exactly two $x, x$ is a student and $x$ was here.

(42') a. There were at most two students here.

b. $\quad$ AT MOST TWO [students (x) \& were-here (x)]

c. $\llbracket\left(42^{\prime} a\right) \rrbracket=1$ iff for at most two $x, x$ is a student and $x$ was here.

(43') a. There were no students here.

b. $\quad \mathrm{NO}_{\mathrm{X}}$ [students (x) \& were-here (x)]

c. $\llbracket\left[\left(43^{\prime} a\right) \rrbracket=1\right.$ iff for no $x, x$ is a student and $x$ was here.

Thus, depending on whether they occur in a presuppositional or in a cardinal noun phrase, nouns are restrictively or unrestrictively interpreted, respectively23: whereas the noun of a presuppositional noun phrase serves as an overt restrictor of the determiner, the noun of a cardinal noun phrase appears at LF as part of the nuclear scope of the determiner and is consequently intersectively interpreted.

In the next subection, I will argue that this does not mean that determiners of cardinal noun phrases have an unrestrictive semantics; in fact, there is evidence that determiners of cardinal noun phrases are actually not unrestrictive quantifiers but restrictive ones: they differ from determiners of presuppositional noun phrases insofar as they have only implicit restrictors but not overt ones. In particular, I will argue that the resource domain variable of cardinal noun phrases is restrictively interpreted.

23 Note that in this respect my proposal to analyze determiners of cardinal NPs as unrestrictive determiners does not differ from approaches that analyze them as cardinal predicates. 


\subsubsection{The interpretation of resource domain variables}

In this subsection, I argue that resource domain variables in general get a restrictive interpretation, regardless of whether they appear in presuppositional or in cardinal noun phrases. I take it that with presuppositional noun phrases, this claim doesn't need any additional motivation, since it is a commonly accepted assumption. But with cardinal noun phrases, things are less obvious. Thus, I will provide in the following evidence for the claim that the resource domain variable of cardinal noun phrases is restrictively interpreted. Evidence for this claim comes from an observation of Herburger (1993).

Herburger (1993) observes that there are weak noun phrases that don't have a symmetric interpretation but one that seems to be proportional. Thus, the underlined common nouns and relative clauses in (44) are apparently not intersectively interpreted - if they were, (44a) and (44b) should have the same truth conditions. As is shown by the fact that (44a) is judged true but (44b) false, this is not the case.

(44) a. There are many speakers of Basque who are Spanish. (true)

b. There are many Spanish people who speak Basque. (false)

Herburger argues that the class of weak quantifiers that can have asymmetric interpretations is the class of quantifiers that can have focus-affected readings. (45a) shows an effect related to (44); it can have a reading like (45b).

(45) a. Few INCOMPETENT cooks applied.

b. Possible reading: Few of the cooks who applied were incompetent.

I.e., here it seems that few has a restrictor that contains cooks and applied and has incompetent in the nuclear scope. Irene Heim (pc) points out that the data can be explained in a framework that makes use of an independently motivated focus semantics as proposed by Rooth $(1985,1992)$ and von Fintel's (1994) approach to quantifier restriction. The explanation is only applicable if determiners of cardinal noun phrases, i.e., quantifiers that appear to be unrestrictive at first sight, have a restrictively interpreted resource domain variable.

In particular, (45a) has an LF (46). The operator " " introduces the focus anaphor $C$. The denotation of $C$ must be a subset of the focus value of the other argument of the operator, i.e., a subset of the focus value of $\alpha$. 


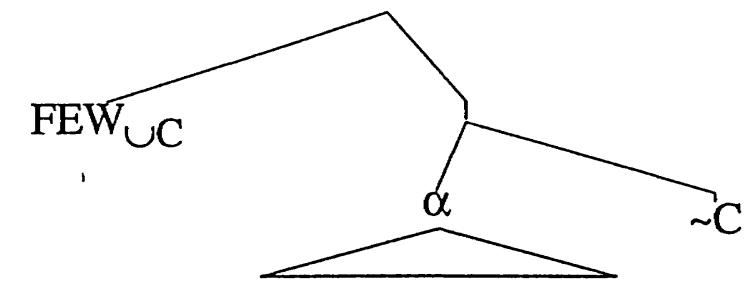

[incompetent $]_{\mathrm{F}}$ cooks applied

The normal semantic value of $\alpha$ is, roughly speaking, the set of individuals $\{\mathrm{x}$ : incompetent (x) \& cook (x) \& applied (x)\}. The focus value of $\alpha$ is the set of alternatives to the expression, where the focussed element is substituted by a variable. Thus, it is the set of sets of individuals, or the set of properties, $\{\mathrm{P}: \exists \mathrm{Q}[\mathrm{P}$ $=\{\mathrm{x}: \mathrm{Q}(\mathrm{x}) \& \operatorname{cook}(\mathrm{x}) \&$ applied $(\mathrm{x})\}]\}$. According to what I said above, the denotation of $C$ must be a subset of the set of properties $\{P: \exists Q[P=\{x: Q(x) \&$ cook $(\mathrm{x})$ \& applied $(\mathrm{x})\}]$ \}. The resource domain variable of the quantifier few is supplied by the same anaphor $C$ (or the resource domain variable provides a licensing antecedent for the focus anaphor). But since the set $\{P: \exists Q[P=\{x: Q$ (x) \& cook (x) \& applied (x)\}]\} is a set of sets of individuals and few is a quantifier over individuals, the restrictor of the quantifier must make use of the set union of $\{\mathrm{P}: \exists \mathrm{Q}[\mathrm{P}=\{\mathrm{x}: \mathrm{Q}(\mathrm{x}) \& \operatorname{cook}(\mathrm{x}) \&$ applied $(\mathrm{x})\}]\}$ in order to have a restrictor of the right type.

Provided that the resource domain variable of $f e w$ is restrictively interpreted, (45a) has thus the truth conditions (47).

(47) [[Few INCOMPETENT cooks applied $\rrbracket=1$

iff $[[$ few $][\mathrm{C} \cup\{\mathrm{P}: \exists \mathrm{Q}[\mathrm{P}=\{\mathrm{x}: \mathrm{Q}(\mathrm{x}) \& \operatorname{cook}(\mathrm{x}) \& \operatorname{applied}(\mathrm{x})\}]\}]$

[NS $\{\mathrm{x}$ : incompetent $(\mathrm{x}) \& \operatorname{cook}(\mathrm{x}) \& \operatorname{applied}(\mathrm{x})\}]$

iff for few $x$, such that there is a $Q$, such that $Q(x)$, and $x$ is a cook and $x$ applied, $\mathrm{x}$ is incompetent and $\mathrm{x}$ is a cook and $\mathrm{x}$ applied

iff [by simplification, i.e. elimination of the redundant parts of the nuclear scope]

for few $\mathrm{x}$, such that there is a $\mathrm{Q}$, such that $\mathrm{Q}(\mathrm{x})$, and $\mathrm{x}$ is a cook and $\mathrm{x}$ applied, $\mathrm{x}$ is incompetent.

iff [by taking, for example, the property of being a cook as a value for $Q$ ] for few $\mathrm{x}$, such that $\mathrm{x}$ is a cook and $\mathrm{x}$ is a cook and $\mathrm{x}$ applied, $\mathrm{x}$ is incompetent.

iff [by simplification, i.e. elimination of the redundant part in the restrictive clause]

for few $\mathrm{x}$, such that $\mathrm{x}$ is a cook and $\mathrm{x}$ applied, $\mathrm{x}$ is incompetent. 
This represents precisely the truth conditions which (45a) has, according to intuitions. 24

Note that an unrestrictive interpretation of the resource domain variable does not give us the desired result. Specifically, if it were intersectively interpreted, then (45a) would be predicted to be true if and only if for few $x, x$ is a cook and $x$ applied and $\mathrm{x}$ is incompetent. These truth conditions do not reflect the asymmetric effect the focus has in (45a).

If this analysis is on the right track, then "unrestrictive quantifiers" are in fact also restrictive. The difference to "restrictive quantifiers" is that restrictive quantifiers are restricted by their nominal complement and by their resource domain variables, whereas the unrestrictive quantifiers are only restricted by their resource domain variables.

To summarize, according to my proposal, all determiners - i.e., weak ones as well as strong ones - are raised at LF and all determiners are associated with a resource domain variable $C$, which can get a value supplied by the context. Cardinal or weak DPs and presuppositional or strong DPs differ with respect to the presence of the restrictive clause: strong DPs have a restrictive clause at LF, whereas weak ones don't. Accordingly, nouns are interpreted differently depending on whether they occur in a weak or in a strong DP. A noun that occurs as the complement of a strong DP is raised into the restrictive clause, whereas a noun that occurs as the complement of a weak DP remains in the nuclear scope.

Thus, we have two types of LFs for determiner-quantifiers, (48) and (49). (48) is the quantificational structure of a cardinal DP, whereas (49) is the quantificational structure of a presuppositional DP. In the former case, the common noun phrase is part of the nuclear scope of the determiner-quantifier. In the latter case, it is part of the restrictive clause of the determiner-quantifier.

$$
\text { cardinal DP: } \quad \text { DET C } \quad \text { [NS ... NP... ] }
$$

presuppositional DP:

DET C $[R C$... NP... ] [NS ... ]

Moreover, I argued that the resource domain variable of any determiner is restrictively interpreted. Thus, according to this proposal, all DPs provide at LF a nuclear scope as well as restrictively interpreted material. With presuppositional

24 For a different approach to focus-affected readings, see Büring (1995). 
DPs, the restrictively interpreted material consists of the resource domain variable and the overt restrictive clause, whereas with cardinal DPs, it consists only of the resource domain variable. Since in my proposal, the mapping of the NP-material into the nuclear scope or into the restrictive clause is the crucial difference between cardinal and presuppositional DPs, I will call them henceforth UNRESTRICTIVE and RESTRICTIVE DPs, respectively. It should be kept in mind though that this terminology reflects the interpretation of the NP-material and not the semantics of the determiner: as I just pointed out, determiners of both restrictive DPs and unrestrictive DPs are associated with restrictively interpreted material.

\subsubsection{The interpretation of resource domain variables with restrictive nouns}

After proposing how to interpret the resource domain variable of unrestrictive DPs, I want to turn in this subsection to the question of how the combination of resource domain variables and overt restrictive material is to be calculated. In contrast to the preceding subsections, this subsection returns to my proposal in Subsection 4.1., namely to adopt a stage-semantics. The point I want to show is that, given the stage-semantics I sketched, the resource domain variable and the overt nominal restrictor of restrictive noun phrases cannot be intersectively interpreted (as was suggested by von Fintel (1994)), but must be interpreted with a non-Boolean "and". In order to establish this point, let me first introduce some more details concerning the semantics of quantification and stages.

I proposed above that determiner quantifiers quantify over stages of individuals. I will mark variables ranging over stages with a subscript "st". Thus, $x_{s t}$ is a variable ranging over stages, whereas $x$ is a variable ranging over whole individuals.

Let me briefly sketch how nouns are interpreted. For ease of representation, I will henceforth assume that stage-level nouns do not have a location argument. Thus, stage-level nouns and individual-level nouns get the same kind of lexical entry - here illustrated with professor:

[professor ] $=f: D_{e} \rightarrow D_{t}$

For any $x_{s t} \in D_{e}, f\left(x_{s t}\right)=1$

iff for all stages $y_{s t}$, such that $y_{s t}$ is a part of $x_{s t}$,

$y_{s t}$ is professor. 


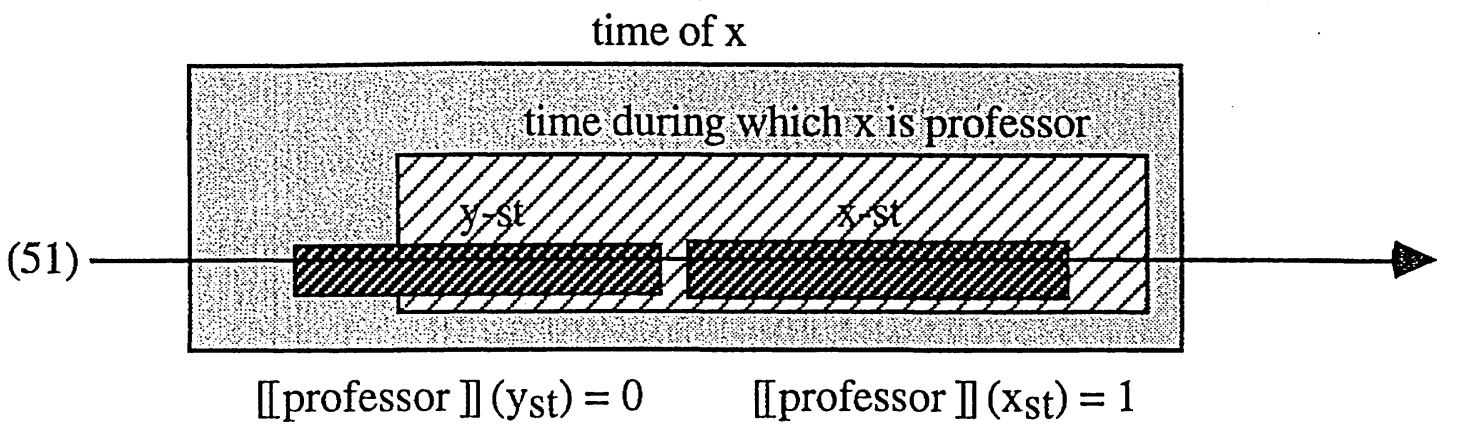

According to this lexical entry, a noun can be truly predicated of a stage if the property denoted by the noun holds of the stage during its whole temporal extendedness. In principle, the same condition holds for other - i.e. verbal or adjectival - stage-level predicates and individual-level predicates.

Recall here from Chapter II that stage-level predicates - like professor and sick - and invididual-level predicates - like cat and intelligent can only be predicated of individuals - or stages of individuals - during their time of existence. Thus, for instance predicating professor or sick of a stage $\mathrm{x}_{\mathrm{St}}$ presupposes that sick holds of $\mathrm{x}_{\mathrm{St}}$ during $\mathrm{x}_{\mathrm{St}}$ 's time of existence. This establishes a temporal dependence between the predication times of stage-level predicates or individuallevel predicates and the individual or stage of which they are predicated.

As we learned in Chapter II, this does not hold for existence-independent predicates like famous or forgotten. These predicates do not impose life-time presuppositions on their subjects. We will not be concerned with this fact here, but it will become crucial below in Section 5 .

In the remainder of this subsection, I will explain step by step how determiner quantifiers have to be interpreted, given the framework of a stage-semantics and lexical entries for nouns as sketched above. I have argued above that determiners of unrestrictive noun phrases as well as determiners of restrictive noun phrases are restrictive. One of the leading ideas throughout is that determiners of unrestrictive noun phrases and determiners of restrictive noun phrases receive in principle exactly the same interpretation. Differences between them are solely derived from whether the noun is mapped into the restrictive clause or into the nuclear scope. In particular, differences concerning the temporal interpretation of noun phrases are derived from this difference. In the following, I will first focus on determiners in restrictive noun phrases and develop 
an analysis step by step. When I have established the semantics of these determiners, I will consider the semantics of determiners in unrestrictive noun phrases. Note that in what follows, I will simplify the temporal interpretation of main predicates of clauses in order to be able to focus on the questions at issue here. 25

1. The first version of a lexical entry for quantifiers. The determiner quantifier together with the resource domain variable is represented below as a constituent; many $C$ corresponds to what is usually assumed to be the quantificational determiner insofar as it is an expression of type $\langle e t,\langle e t, t>>$. The lexical entry for many itself is something like the following, where $k$ is the characteristic function of the resource domain.

$$
\begin{aligned}
& \text { [TO BE REVISED] }
\end{aligned}
$$

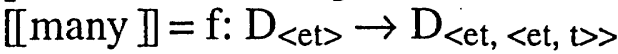

$$
\begin{aligned}
& \text { For any } k, h, j \in D_{<e t>}, f(k)(h)(j)=1 \\
& \text { iff for many } \mathrm{x}_{\mathrm{st}} \in \mathrm{D}_{\mathrm{e}} \text {, such that } \mathrm{k}\left(\mathrm{x}_{\mathrm{st}}\right)=1 \text { and } \mathrm{h}\left(\mathrm{x}_{\mathrm{st}}\right)=1 \text {, } \\
& \mathrm{j}\left(\mathrm{x}_{\mathrm{st}}\right)=1 \text {. }
\end{aligned}
$$

2. Maximality. This lexical entry has to be revised, because it leads to wrong predictions: Consider the sentence (without any specifics concerning $k$ here)

$$
\begin{aligned}
& \text { a. Many students cooked for parties } \\
& \text { b. } \\
& \text { iff for many students cooked for parties } \Pi=1 \\
& \mathrm{x}_{\mathrm{st}} \text { cooked for parties. }
\end{aligned}
$$

According to the truth conditions stated, the sentence is predicted to be true, if and only if many student-stages are such that they cooked for parties. Unfortunately, since stages can be arbitrarily long stages of individuals, whenever there is a single student who cooked for parties, the sentence is thus predicted to be true, because the single student can provide many, even infinitely many, stages that satisfy the LF.

25 E.g., I will omit time arguments, implicit temporal restrictions and implicit quantifiers over times. 
$\mathrm{x}$ is student

(54)

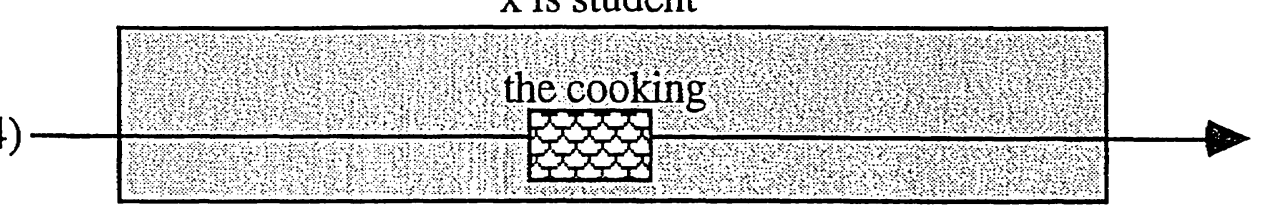

Even though this problem may only be a conceptual but not "real" problem with proportional quantifiers, it turns out to be a serious problem with cardinal quantifiers, i.e. unrestrictive DPs.

In order to avoid this problem, I introduce a notion of maximality: Quantification is over "maximal" stages that satisfy the restriction; this guarantees that with a noun phrase like most students, one "counts" per person only one stage as the person's student-stage. In Section 10, I will consider a revision of this assumption, in order to be able to deal with other phenomena of natural language. But for the purpose of this section, this assumption seems desirable. Thus, we get the revised lexical entry

$$
\begin{aligned}
& \text { [TO BE REVISED] } \\
& \llbracket \text { most } \rrbracket=f: D_{<e t>} \rightarrow D_{<e t,<e t, t>>} \\
& \text { For any } k, h, j \in D_{<e t>}, f(k)(h)(j)=1 \\
& \text { iff for most maximal } \mathrm{x}_{\mathrm{st}} \in \mathrm{D}_{\mathrm{e}} \text {, } \\
& \text { such that } \mathrm{k}\left(\mathrm{x}_{\mathrm{st}}\right)=1 \text { and } \mathrm{h}\left(\mathrm{x}_{\mathrm{st}}\right)=1 \text {, } \\
& \mathrm{j}\left(\mathrm{x}_{\mathrm{st}}\right)=1 \text {. }
\end{aligned}
$$

3. Against intersective interpretation of resource domain variable and overt restrictive material. According to von Fintel (1994), the resource domain and the overt restrictor of the quantifier are intersectively interpreted. I.e., the bold-face printed "and" marks an intersective interpretation. I will argue that what we need (at least within my approach that makes use of stages and the interpretation schemata suggested above) is in fact a different interpretation.

With (50) above, I introduced interpretation schemata for predicates that state that a predicate can be truly predicated of a stage if the property denoted by the predicate holds of the stage during the whole time interval which the stage covers. Thus, for example, when a stage is tired during the whole stretch of time covered by the stage, one can truly predicate tired of the stage. But when a stage extends beyond its time of being tired, one cannot truly predicate tired of the stage. 
Now imagine we have a conversation about the people that were in my class when I went to school. Thinking about what these people are doing today, I state (56a). Obviously, in that context, the sentence must have an LF that is schematically constructed like (56b). 26

a. Most scientists are unmarried.

b. $\quad$ MOST $_{x \text {-st }} C_{\text {[in my class] }}$ [scientist] [unmarried]

Given my assumptions about stages and interpretation schemata, a problem arises with this LF: If we interpret the restrictor by intersection, we will probably not be able to find a single individual that satisfies the restrictor of the LF. This is, because with an intersective interpretation, the restrictor is satisfied for a stage $x_{\text {st }}$ if and only if [[in my class $]\left(\mathrm{x}_{\mathrm{st}}\right)=1$ and [[scientist $]\left(\mathrm{x}_{\mathrm{st}}\right)=1$.

c. [NOT THE INTERPRETATION WE WANT, TO BE REVISED] [[MOST ${ }_{\mathrm{x} \text {-st }} \mathrm{C}$ [in my class] [scientist] [unmarried] $]=1$ iff for most maximal $\mathrm{x}_{\mathrm{st}}$, such that [[in my class $\rrbracket\left(\mathrm{x}_{\mathrm{st}}\right)=1$ and $[$ scientist $]\left(\mathrm{x}_{\mathrm{st}}\right)=1$, . [unmarried $\rrbracket\left(\mathrm{x}_{\mathrm{st}}\right)=1$.

Since my interpretation schema prohibits for $\mathrm{x}_{\mathrm{st}}$ to be larger than the predication time of in my class in order to make [[in my class ]] $\left(x_{s t}\right)$ true, and it also prohibits for $\mathrm{x}_{\mathrm{st}}$ to be larger than the predication time of scientist in order to make II scientist $]]\left(x_{s t}\right)$ true, $\mathrm{x}_{\mathrm{st}}$ can only satisfy the restriction if the individual it belongs to was at some time both in my class and a scientist. Since none of the people I went to school with was a scientist while we went to school,

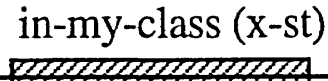
scientist (y-st)

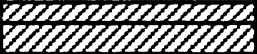

there is not a single individual that satisfies the restriction. This does not correspond to intuitions of course; rather, we want to be able to use a sentence like Most scientists are unmarried in a context as the one described above to be able to say something about people who were in my class then and are scientists now. (In general, an analogous problem arises of course when one considers the

26 In the following, I will often exploit schematic LFs whose purpose is mainly to indicate which linguistic material is mapped into the restrictive clause and which is mapped into the nuclear scope of a quantificational structure. 
nuclear scope in addition to the restrictive clause; for the moment, I want to ignore this; coming back to this point is exactly what I am aiming at.)

The problem can be avoided if we do not interpret the restriction of quantifiers strictly intersectively but adopt a non-Boolean meaning for the "and" in the lexical entry of most. Although the non-Boolean "and" I want to argue for is a meta-language operator, I want to illustrate the use and usefulness of the nonBoolean "and" with an object-language example which I find quite illuminating.

Krifka (1989) discusses the necessity of assuming a non-Boolean and as a lexical item of natural language. With predicates of type $<$ et $>$, the necessity of such an interpretation in addition to intersective interpretations can be shown with examples like

(58) a. The flag is g:een and white.

b. $\quad \neq$ The flag is green and the flag is white.

c. = The flag has a green part and a white part.

Krifka makes use of an analysis of Link (1983), according to which non-Boolean and is analyzed in terms of a (mereological) sum operation " $\oplus$ " on individuals, which is a function from pairs of individuals into individuals - i.e., a function that takes two individuals and yields another individual. For the non-Boolean conjunction in The flag is green and white, one can make use of the sum operation " $\oplus$ " as shown with the denotation of green and white:

[green and white ] $=f: D_{e} \rightarrow D_{t}$

For any $x^{\prime \prime} \in D_{e}, f\left(x^{\prime \prime}\right)=1$

iff there is an $x \in D_{e}$ and an $x^{\prime} \in D_{e}$, such that $\mathrm{x}^{\prime \prime}=\mathrm{x} \oplus \mathrm{x}^{\prime}$ and [ [green $\rrbracket(\mathrm{x})=1$ and $\left[\left[\right.\right.$ white $\rrbracket\left(\mathrm{x}^{\prime}\right)=1$.

In other words, green and white can be truly predicated of an individual if and only if that individual consists of a green part and a white part and nothing else.

Having thus illustrated the use of a non-Boolean object-language and, let me show how it can be applied to the understanding of the meta-language "and" in the lexical entry of most. It can be used to avoid the problem with Most scientists are unmarried that arose in the context of talking about people in my former highschool-class. Basically, I want an interpretation based on the use of " $\oplus$ " to replace the intersection of predicates at least in some cases. Of course, the questions in which cases this non-Boolean interpretation of "and" applies and 
why the distribution of the two versions of "and" is as it is should be raised at some point. 27

In order to avoid the problem with (56), I want to give the bold-face printed "and" in the lexical entry for most above a meaning that is not strictly intersective.

I.e., the lexical entry has to be rewritten:

$$
\begin{aligned}
& \text { [TO BE REVISED] } \\
& \llbracket \text { most } \rrbracket=f: D_{<e t>} \rightarrow D_{<e t,<e t, t>>} \\
& \text { For any } k, h, j \in D_{<e t>}, f(k)(h)(j)=1 \\
& \text { iff for most maximal } x_{s t} \in D_{e} \text {, } \\
& \text { such that there is an } x_{s t}^{\prime} \in D_{e} \text { and an } x_{s t} \in D_{e} \text {, } \\
& \text { such that } \mathrm{x}_{\mathrm{st}}=\mathrm{x}_{\mathrm{st}}^{\prime} \oplus \mathrm{x}_{\mathrm{st}} \\
& \text { and } \mathrm{k}\left(\mathrm{x}_{\mathrm{st}}^{\prime}\right)=1 \\
& \mathrm{j}\left(\mathrm{x}_{\mathrm{st}}\right)=1 \text {. } \\
& \text { and } h\left(\mathrm{x}_{\mathrm{st}}\right)=1 \text {, }
\end{aligned}
$$

4. Discontinuous stages. Note that the construction of sums by " $\oplus$ " will lead in many cases to discontinuous stages. Although this may appear strange, it is not an unwanted consequence. Thus, I claim that quantification can be over discontinuous entities. The part of the lexical entry though makes sure that these discontinuous cannot "spread over more than one individual", where "individual" is to be understood in the traditional sense. - With this lexical entry for most, we get the following interpretation for Most scientists are unmarried:

c. [NOT YET THE INTERPRETATION WE WANT, TO BE REVISED] [IMOST $\mathrm{x}_{\mathrm{x} \text {-st }} \mathrm{C}$ [in my class] [scientist] [unmarried] $\rrbracket=1$ iff for most maximal $\mathrm{x}_{\mathrm{st}} \in \mathrm{D}_{\mathrm{e}}$, such that there is an $\mathrm{x}_{\mathrm{st}}^{\prime} \in \mathrm{D}_{\mathrm{e}}$ and an $\mathrm{x}_{\mathrm{st}} \in \mathrm{D}_{\mathrm{e}}$, such that $\mathrm{x}_{\mathrm{st}}=\mathrm{x}_{\mathrm{st}}^{\prime} \oplus \mathrm{x}_{\text {st }}^{\prime}$ and

【in my class $\rrbracket\left(x_{s t}^{\prime}\right)=1$ and

[scientist $\rrbracket\left(\mathrm{x}_{\mathrm{st}} \mathrm{s}\right)=1$,

[unmarried $\rrbracket\left(\mathrm{x}_{\mathrm{st}}\right)=1$.

27 One may have to discuss the question of whether the sum operation really captures the full meaning of the non-Boolean "and". Certain examples suggest that we don't really need the sum operation but something weaker like " $\mathrm{z}$ has a part $\mathrm{x}$ such that $\mathrm{P}$ and $\mathrm{z}$ has a part $\mathrm{y}$ such that $\mathrm{Q}^{\prime}$ leaving the possibility of $\mathrm{x} \oplus \mathrm{y}$ being not the whole $\mathrm{z}$ but only part of it. This was pointed out to me by a member of the audience when I presented this material in Tübingen. If this is so, then we are not forced to introduce non-continuant stages. - Note that there are interesting restrictions on whether constructions as the one in (a) get a nonBoolean interpretation. I.e., \# The flag is green and torn when the flag is partly blue and partly untorn. Also \# The flag is torn and repaired (examples due to David Pesetsky). 
(61)

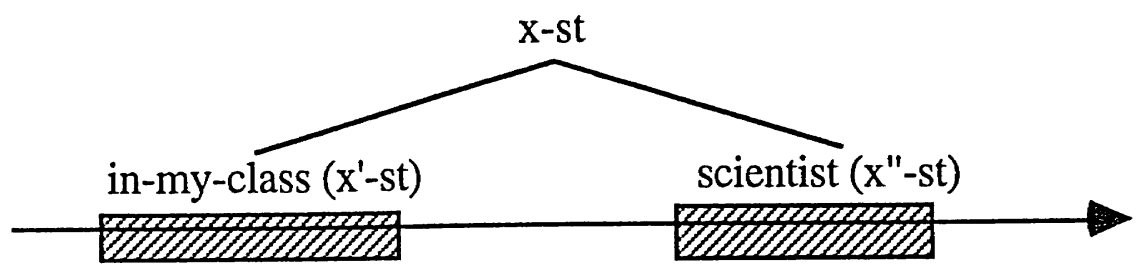

5. Inclusion of the stage that makes the nuclear scope true in the stage introduced by the restrictive material. It seems that the revision of the lexical entry solved the problem with this example. But the revision is not yet good enough. Note that $j\left(x_{s t}\right)$ can only be true if $\mathrm{x}_{\mathrm{st}}$ is $\mathrm{j}$ during all the time covered by $\mathrm{x}_{\mathrm{st}}$. Since we want to be able to ascribe short term properties to individuals - as in (62):

(62) Most scientists sneezed at the meeting.

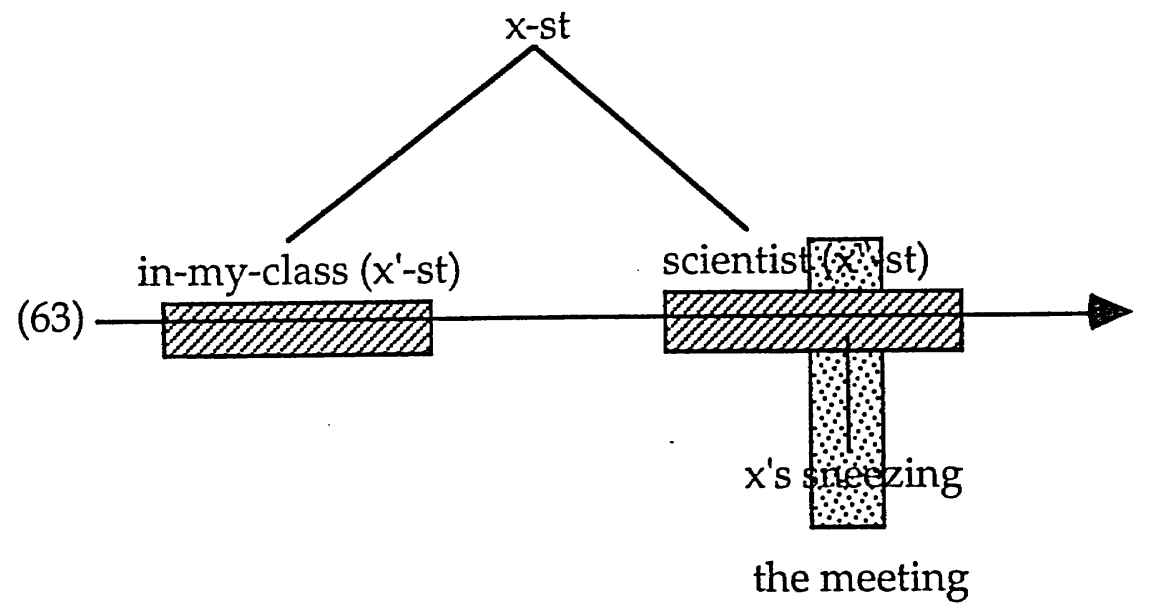

we have to revise the lexical entry again:28

28 It would be interesting to compare this lexical entry with von Fintel's (1994) entry for adverbs of quantification. 


$$
\begin{aligned}
& \llbracket \text { most } \rrbracket=f: D_{<e t>} \rightarrow D_{<e t,<e t, ~ t>>} \\
& \text { For any } k, h, j \in D_{<e t>}, f(k)(h)(j)=1 \\
& \text { iff for most maximal } x_{s t} \in D_{e} \text {, } \\
& \text { such that there is an } \mathrm{x}_{\mathrm{st}} \in \mathrm{D}_{\mathrm{e}} \text { and an } \mathrm{x}_{\mathrm{st}} \in \mathrm{D}_{\mathrm{e}} \text {, } \\
& \text { such that } \mathrm{x}_{\mathrm{st}}=\mathrm{x}_{\mathrm{st}} \oplus \mathrm{x}^{\prime \prime}{ }_{\mathrm{st}} \\
& \text { and } \mathrm{k}\left(\mathrm{x}_{\mathrm{st}}^{\prime}\right)=1 \\
& \text { there is a } y_{s t} \in D_{e} \text {, } \\
& \text { and } h\left(\mathrm{x}_{\mathrm{st}}\right)=1 \text {, } \\
& \text { such that } y_{s t} \text { is part of } x_{s t} \in D_{e} \\
& \text { and } j\left(y_{s t}\right)=1.29
\end{aligned}
$$

With this revision, we can now interpret the sentence Most scientists sneezed at the meeting, uttered in the same context as Most scientist are unmarried above, as follows:

a. $\quad$ Most scientists sneezed at the meeting.

b. MOST $\mathrm{x}_{\text {-st }} \mathrm{C}_{\text {[in my class] [scientist] [sneezed-at-the-meeting] }}$

c. $\quad\left[M O S T_{x-s t} C_{\text {in my class] }}\right.$ [scientist] [sneezed-at-the-meeting] $\rrbracket=1$ iff for most maximal $\mathrm{x}_{\mathrm{st}} \in \mathrm{D}_{\mathrm{e}}$, such that there is an $x_{s t}^{\prime} \in D_{e}$ and an $x_{s t} \in D_{e}$, such that $\mathrm{x}_{\mathrm{st}}=\mathrm{x}_{\mathrm{st}}^{\prime} \oplus \mathrm{x}^{\prime \prime}$ st and

【in my class $\rrbracket\left(x^{\prime}{ }_{s t}\right)=1$ and

there is a $y_{\mathrm{st}} \in \mathrm{D}_{\mathrm{e}}$, [scientist $]\left(\mathrm{x}_{\mathrm{st}}{ }_{\mathrm{t}}\right)=1$, such that $y_{s t}$ is part of $x_{s t} \in D_{e}$ and [[sneezed-at-the-meeting $]\left(y_{\mathrm{st}}\right)=1$.

To conclude, note that as the element introducing a stage, the restrictor of a determiner plays a special role for the determination of the stage. In particular, it determines the temporal extendedness of the stage, i.e., the length of the time interval the stage covers. The predication time(s) supplied by the resource domain variable and the noun provide the maximal temporal extension of the stage introduced by the restrictive noun phrase. This has the following consequences: Since the noun of restrictive noun phrases is part of the determiner's restrictive clause, restrictive noun phrases provide predication times via the noun AND via modifications of the resource domain variable. The noun of unrestrictive noun phrases is not part of the determiner's restrictive clause.

29 Irene Heim points out that an alternative to introducing the part $y$-st with the nuclear scope would be to repeat the restriction as part of the nuclear scope, so that the interpretation follows the schema [[Most As are B]] = 1 iff most As are A and B. This would amount to stating for the nuclear scope that $x$-stage equals the sum of three stages, $x^{\prime}-$ st and $x^{\prime \prime}-$ st as before, and in addition $x^{\prime \prime \prime}$-st where $j\left(x^{\prime \prime \prime}-s t\right)=1$. 
Thus, only the predication time supplied by the resource domain variable provide the maximal temporal extension of the stage introduced by the unrestrictive noun phrase.

\subsection{Temporally dependent and temporally independent noun phrase interpretations}

\subsubsection{Temporal restrictions and temporal adverbials modify resource domain variables}

In Chapter II, I adopted a temporal framework that is based on the assumption that all clauses contain a (possibly implicit) adverb of quantification that quantifies over times (TAQ). It takes tense, overt temporal adverbials (TAs), and implicit temporal restrictions (C) as restrictive material. Thus, LFs are of the general form (66).

(66) TAQ [RC TENSE \& TA \& C] [NS ... ]

In this subsection, I want to argue that definite temporal adverbials and implicit temporal restrictions are able to modify the resource domain variables of quantificational noun phrases. The resulting temporal modifications of the resource domain variable can extend the stages over which a quantifier quantifies and ultimately explain the occurrence and distribution of temporally independent noun phrase interpretations.

Suppose we talk about present professors. In that context, (67a) may have an LF basically like (67b), where I simplify the temporal interpretation for a moment:

(67) a. Most present professors were young in the forties.

b. MOST $_{\mathrm{x} \text {-st }} \mathrm{C}[\mathrm{\text {[present }}$ professor] [young-in-the-forties]

Intuitively, we want to be able to use the sentence to say something about individuals who are now professors but were possibly not professors in the forties - specifically, we want to be able to say about those individuals whether most of them were young in the forties. 
$(68)$

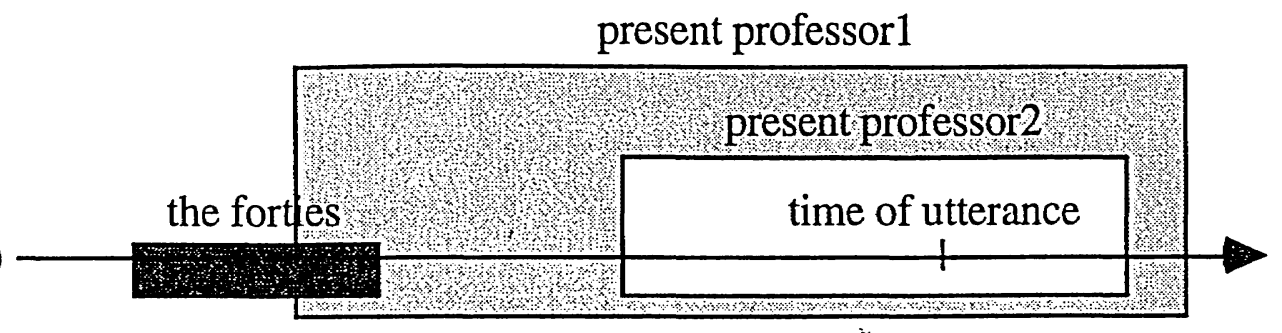

But with the semantics we have at this point, the LF in (67b) is true if and only if for most maximal $\mathrm{x}_{\mathrm{st}}$ such that there is an $\mathrm{x}_{\mathrm{st}}^{\prime} \in \mathrm{D}_{\mathrm{e}}$ and an $\mathrm{x}_{\mathrm{st}} \in \mathrm{D}_{\mathrm{e}}$, such that $\mathrm{x}_{\mathrm{st}}$ $=\mathrm{x}_{\mathrm{st}}^{\prime} \oplus \mathrm{x}_{\mathrm{st}}^{\prime \prime}$ and $\llbracket \mathrm{C} \rrbracket\left(\mathrm{x}_{\mathrm{st}}^{\prime}\right)=1$ and [[present professor $\rrbracket\left(\mathrm{x}_{\mathrm{st}}\right)=1$, there is a $\mathrm{y}_{\mathrm{st}}$ $\in D_{e}$, such that $y_{s t}$ is part of $x_{s t}$ and [lyoung in the forties $]\left(y_{s t}\right)=1$. Thus, the sentence can only be true for a particular $\mathrm{x}_{\mathrm{st}}$ if the $\mathrm{x}_{\mathrm{st}}$ contains a part that is located in the forties (and was young then). For professor 1 in (68), this is guaranteed by the fact that his or her time of being a professor reaches into the forties. But since, for professor 2, the time of being a professor does not reach into the forties, for him or her this can only be provided by an appropriate value for the resource domain variable - a value that reaches into the forties. If $\mathrm{x}_{\mathrm{st}}$ under a particular variable assignment was not yet a professor in the forties, then $\mathrm{x}_{\mathrm{st}}$ would be unable to satisfy the restriction of the quantifier if the resource domain variable didn't provide an appropriate stage. Since (67a) can clearly be understood as a statement about present professors regardless of whether they were professors in the forties, we must find a way of providing systematically stages that are big enough to make such an interpretation possible.

My claim is that we can get the desired interpretation when definite temporal adverbials and temporal restrictions modify the resource domain variable of most. There is a simple and straightforward way how to motivate the claim that these items are able to modify the resource domain variable:

Because of their definite nature and their givenness in the context, definite temporal adverbials and implicit temporal restrictions are topical elements and provide topic times for the interpretation of their clause. These topic times are, because of their topical nature, able to modify the resource domain. Since von Fintel (1994) argues anyway that topics can modify resource domains in the context, this is a well-motivated assumption. 30 Thus, exploiting at this point again a more detailed representation of the temporal semantics of main predicates of clauses, we get an LF-representation like (69).

30 The term "topic time" is in fact used by Wolfgang Klein (1991). 
Once the definite temporal adverbial modifies the resource domain variable modifier of the determiner-quantifier, we have to make sure that it is able to modify the resource domain in such a way that the stages quantified over are temporally extended. I will assume here that the value indicated as "in the forties" in (69) is a predicate of type $\langle e, t\rangle$. Thus, it can apply to individuals or stages of individuals. In particular, I will assume the following definition:

$$
\begin{aligned}
& \text { [in the forties } \rrbracket=f: D_{e} \rightarrow D_{t} \\
& \text { For any } x_{s t} \in D_{e}, f\left(x_{s t}\right)=1 \\
& \text { iff for all stages } y_{s t} \text {, such that } y_{s t} \text { is a part of } x_{s t} \text {, } \\
& y_{s t} \text { is located in the forties. }
\end{aligned}
$$

With the LF (69), the definition in (70), our present semantics, and (for ease of presentation) omitting details of temporal interpretation, (67a) is predicted to be true if and only if: for most maximal $\mathrm{x}_{\mathrm{st}}$, such that $\mathrm{x}_{\mathrm{st}}$ consists of a part $\mathrm{x}_{\mathrm{st}}$ that is now a professor and a part $\mathrm{x}_{\text {st }}$ such that $\mathrm{x}_{\mathrm{st}}$ is located in the forties, $\mathrm{x}_{\mathrm{st}}$ has a part $\mathrm{y}_{\mathrm{st}}$ such that $\mathrm{y}_{\mathrm{st}}$ is young in the forties.

Thus, the modification of $\mathrm{C}$ by "in the forties" leads to a temporal extension of $\mathrm{x}_{\mathrm{st}}$, so that it includes the forties, even if the stage $\mathrm{x}_{\mathrm{st}}$ was then not a professor.

\subsubsection{The difference between restrictive (presuppositional) noun phrases and unrestrictive (cardinal) noun phrases}

We are now in a position to explain why restrictive noun phrases can have temporally independent interpretations whereas unrestrictive noun phrases (with the exception of subjects of existence-independent predicates) can't. In fact, this distribution of temporally dependent and temporally independent interpretations is exactly what is predicted by the semantics I developed in this chapter.

The crucial point is that I argued that determiners of both cardinal (unrestrictive) and presuppositional (restrictive) noun phrases are restrictive, but that the two types of noun phrases differ insofar as the noun of cardinal noun phrases is mapped into the nuclear scope of the determiner, whereas the noun of 
the presuppositional noun phrase is mapped into the restrictive clause of the determiner. Suppose that cardinal and presuppositional noun phrases get analogous interpretations, as I proposed above. Roughly speaking, I argued that presuppositional quantificational structures are interpreted as follows: The clause is judged true if and only if the stage introduced by the restrictor is such that the predicate in the nuclear scope applied to a part of this stage is true. I claim that the same holds for cardinal quantificational structures. I also claim that the resource domain variables of both cardinal and presuppositional noun phrases can be modified by definite temporal adverbials. The crucial difference arises only because of the noun's role at LF: when it is part of the restrictive clause, the restrictor as a whole introduces a stage that is - because of the non-Boolean "and" - built up out of parts for which the resource domain holds and parts for which the noun holds. But when the noun is part of the nuclear scope, the restrictor introduces a stage that is only introduced by the resource domain variable.

In order to see how this leads to the difference with respect to temporal interpretation, compare (71) and (72). The truth conditions are here for ease of presentation slightly simplified. As proposed above, restrictor internal combinations of predicates are interpreted by use of the non-Boolean "and", whereas nuclear scope internal combinations of predicates are intersectively interpreted.

(71) a. Most students were sick.

b. MOST $_{\mathrm{X} \text {-st }} \mathrm{C}$ [student] [sick]

c. For most maximal stages $\mathrm{x}_{\mathrm{st}}$ such that $\exists y_{s t}, z_{s t}$ such that $x_{s t}=y_{s t} \oplus z_{s t}$, $\mathrm{x}_{\mathrm{st}}$ has a part $\mathrm{v}_{\mathrm{st}}$, and [[C] $\left(\mathrm{y}_{\mathrm{st}}\right)=1$ and [ $[$ student $]\left(\mathrm{z}_{\mathrm{st}}\right)=1$, such that $[[\operatorname{sick}]]\left(v_{s t}\right)=1$.

(72) a. There were few students sick.

b. $\quad \mathrm{FEW}_{\mathrm{X} \text {-st }} \mathrm{C}$ [student \& sick ]

c. For few maximal stages $\mathrm{x}_{\mathrm{st}}$ such that $\left[[C]\left(x_{s t}\right)=1\right.$,

$\mathrm{x}_{\mathrm{st}}$ has a part $\mathrm{v}_{\mathrm{st}}$ such that $\left[\left[\operatorname{student} \rrbracket\left(v_{\mathrm{st}}\right)=1\right.\right.$ and $\left[\left[\operatorname{sick} \rrbracket\left(\mathrm{v}_{\mathrm{st}}\right)=1\right.\right.$. 
Suppose now that the resource domain for both sentences is provided by a silent temporal restriction to 1993. Then we get truth conditions (71d) and (72d) with the pictures (71e) and (72e), respectively. 31

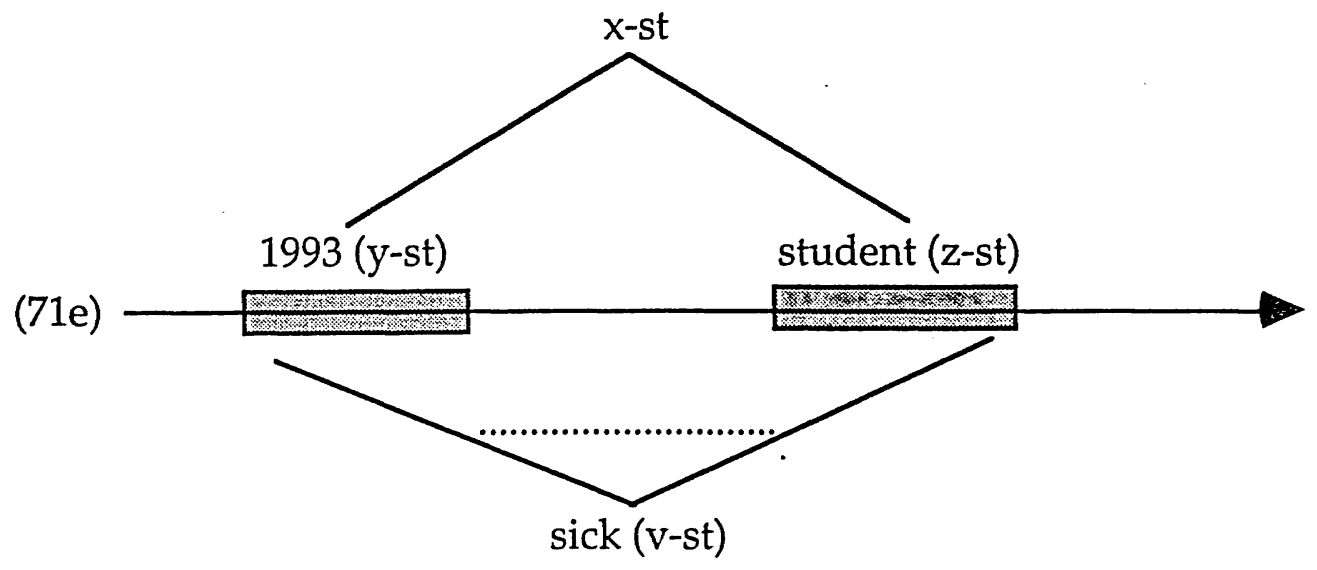

(72) d. For few stages $x_{\text {st }}$ such that $x_{s t}$ is located within 1993 , $\mathrm{x}_{\text {st }}$ has a part $\mathrm{v}_{\mathrm{st}}$ such that $\left[\left[\right.\right.$ student $\rrbracket\left(v_{s t}\right)=1$ and $\left[\left[\operatorname{sick} \rrbracket\left(v_{s t}\right)=1\right.\right.$.

$(72 \mathrm{e})$

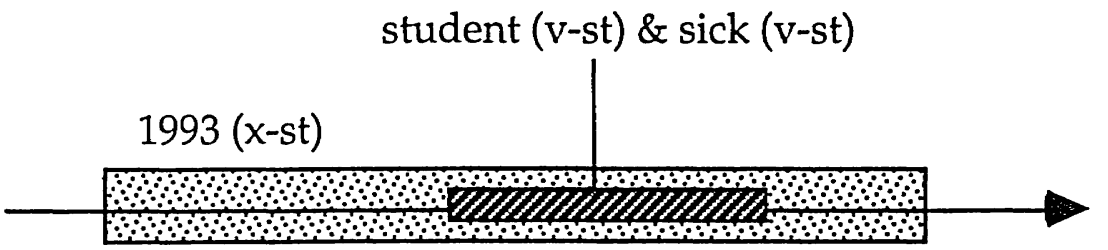

As a consequence, the predication time of the predicate student must intersect with the time interval of 1993 in (72), but need not intersect with it in (71). Thus, the restrictive noun phrase can have a temporally independent interpretation, whereas the unrestrictive noun phrase can only have a temporally dependent interpretation because of the intersective interpretation in the nuclear scope.

31 The vertical dotted line in the picture is supposed to indicate the range of possible locations of $\mathrm{v}_{\mathrm{St}}$ within the stage $\mathrm{x}_{\mathrm{St}}$, 


\section{Appendix to Section 4.3.: Modifications of resource domain variables by temporal adverbials are mediated by the context: scope interactions of temporal adverbials and DPs}

Introductory remarks. I assumed in Section 4.3.1. that by modifying resource domain variables, temporal adverbials can extend the stages the noun phrases quantify over and lead, in the case of restrictive noun phrases, to temporally independent noun phrase interpretations. I have not yet presented arguments that make clear what the status of this interaction is. So far, I have just assumed that the interaction is not due to a direct effect but mediated by the context.

Note that there are cases of quantifiers where resource domain variables have arguably a more complex structure and involve binding as von Fintel $(1994,31)$ shows: In Only one class was so bad that no student passed the exam, the resource domain variable is in fact a variable complex $f 2(v 1)$. The $v_{1}$ is bound by the higher quantifier only one class. 32 But the function $f_{2}$ remains free. Hence the context must supply a value for this function variable. It supplies a value such that $f_{2}$ is a function that takes classes as its argument and yields the students in that class.

(73) [only one class $]_{1}$ was so bad that [nof2(v1) student $]_{3}$ passed the exam.

Of course, since a relation of binding is involved, the modification of the resource domain variable must here be part of the semantic representation. That is, as far as binding is involved, the value assignment of the resource domain variable cannot be only due to requirements on the discourse context, and the context cannot supply the value. It is conceivable that an analogous mechanism might be at work when temporal adverbials modify resource domain variables of determinerquantifiers.

In this appendix, I will present a strong argument that shows that an approach with binding into the resource domain variable cannot be exploited for the modification by temporal adverbials. I will conclude that the view that the modification is mediated by the context is inevitable.

The argument explores how scope interactions of temporal adverbials and quantificational noun phrases correlate with the possibility of temporally independent noun phrase interpretations. The idea is basically to force the

32 The original source of the example is Heim (1991). 
temporal adverbial into an LF-position where it must have narrower scope than a certain quantificational noun phrase; this can be achieved by placing a pronoun into the temporal adverbial that must be bound by the quantificational noun phrase. We will see then that the binding noun phrase is perfectly able to exhibit a temporally independent interpretation. According to standard assumptions, the temporal adverbial can not be in an LF-position where it c-commands the temporally independent noun phrase. Thus, the occurrence of the temporally independent reading cannot hinge on the ability of the temporal adverbial to ccommand the noun phrase at LF. I conclude from this that in my proposal, the apparent modifying effect temporal adverbials have on noun phrases - or, to be precise, on their resource domain variables - cannot be a direct one, but must be mediated by the context. Since the modification of resource domains is often mediated by the context, this is not a very surprising result.

\section{What functionally interpreted temporal adverbials and temporally} independent noun phrases reveal about the role of the context. There are some interactions of temporal and noun phrase interpretation where scope is crucial: FUNCTIONALLY INTERPRETED TEMPORAL ADVERBIALS contain a bound variable pronoun. Consequently, at LF the adverbial will be required to have narrower scope than the item which binds the variable. ${ }^{33}$

Functional readings can occur with explicit temporal adverbials as well as with implicit temporal restrictions (indicated as $C$ ); (74) illustrates the former case, (75) the latter. In both examples, the values of the temporal adverbial or the restriction can vary with the choice of managers. This type of reading arises when the subject noun phrase binds a variable that is contained in the temporal adverbial or restriction as demonstrated.

(74) Viele Manager spielten in ihrem Studium Fußball. many managers played in their studies soccer ('Many Managers played soccer when they studied.) $=[\text { Viele Manager }]_{i}$ spielten in ihremi Studium Fußball.

(75) [Most managers were more adventurous when they studied than today...] ... Viele Manager spielten $C$ Fußball.

many managers played soccer $=[\text { Viele Manager }]_{i}$ spielten (in ihremi Studium) Fußball.

33 Functional readings of temporal adverbials have frequently been observed in the literature. See for instance Vlach (1993). 
Thus, (74) and (75) show that sentences can have LFs with quantificational noun phrases that have wider scope than definite temporal adverbials. ${ }^{34}$

Moreover, (74) and (75) show that functionally interpreted temporal adverbials are able to modify the resource domain variable of the quantificational

34 Note that if we assume that definite temporal adverbials are adjoined to TP, then it follows that quantificational NPs are at LF in a position at least as high as adjoined to TP. This view is compatible with assuming adjunction of QRed DPs to TP, AGRsP, or CP. Thus, LFs can exploit a hierarchy as shown in structure (A). However structures like (B) are also possible.

(A)

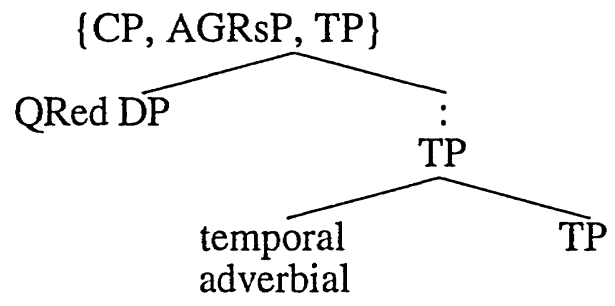

(B)

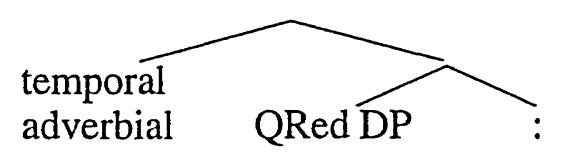

Narrow scope as in (B) can be demonstrated with readings of quantificational temporal adverbials where they have narrower scope than a quantificational noun phrase, as reading $(\mathrm{Cb})$ of $(\mathrm{Ca})$. However, at least with quantificational temporal frame adverbials it is also possible for temporal adverbials to have wider scope than quantificational noun phrases, as shown with reading $(\mathrm{Cc})$ of $(\mathrm{Ca})$. With this reading, the busdrivers vary with the weeks.

(C) a. [In jeder Woche im März] halfen [mindestens zwei Busfahrer] in every week in March helped at least two busdrivers einem Fahrgast mit schweren Taschen.

a passenger with heavy bags

('Every week in March, at least two busdrivers helped a passenger with heavy bags.')

b. possible reading: There are at least two busdrivers $\mathrm{x}$ such that for every $\mathrm{t}$ such that $t$ is a week in in March, $x$ helped a passenger with heavy bags at $t$.

c. possible reading: For every $t$ such that $t$ is a week in March, there are at least two busdrivers $\mathrm{x}$, such that $\mathrm{x}$ helped a passenger with heavy bags at $\mathrm{t}$.

In German, the wide scope reading of temporal adverbials is possible with various surface orderings of the noun phrase and the temporal adverbial (as is narrow scope reading):

(D) a. [Mindestens zwei Busfahrer] halfen [in jeder Woche im März] einem Fahrgast mit schweren Taschen.

b. weil [mindestens zwei Busfahrer] [in jeder Woche im März] einem Fahrgast mit schweren Taschen halfen

c. weil [in jeder Woche im März] [mindestens zwei Busfahrer] einem Fahrgast mit schweren Taschen halfen 
noun phrase which binds their variable. Within the framework I have developed in this chapter, this can be concluded from the fact that the quantificational noun phrases in (74) and (75) exploit temporally independent readings: the managers mentioned in (74) and (75) became managers only after they were students. Thus, their time of being managers and their relevant times of playing soccer don't coincide. I.e., the noun phrase is temporally independently interpreted.

Note that if the modification of resource domain variables by definite temporal adverbials were achieved by binding, we would have reached a scope paradox at this point: the definite temporal adverbial would be required to be at LF both lower than the quantificational noun phrase (in order to have the variable contained in it properly bound by the noun phrase) and higher than the noun phrase (in order to be able to bind into the resource domain variable complex). Thus, (74) and (75) show that temporal adverbials do not modify resource domain variables directly but via the context.

The interpretation of functional temporal adverbials. Now I want to present an LF and calculations of truth conditions for an example sentence in order to show how functional temporal adverbials can be interpreted. For this purpose, I won't exploit my stage-semantics and pretend that quantification is over whole individuals. After carrying out the calculations, I will present the truth conditions of the example under the assumption of the stage-semantics.

I take the possessive pronoun to be composed of two elements. One is a genitive/possessive element that denotes a function from individuals into functions from properties of individuals into individuals. The other is an individual denoting variable 3.PL. Here are lexical entries for GEN/POSS and in.

$$
\begin{aligned}
& \text { [GEN/POSS ] }]^{c}=f: D e \rightarrow D<<e, t>, e>\text { such that, } \\
& \text { for any } x \in D e, h \in D<e, D, \\
& f(x)(h)=\text { the unique } y \in D e \text {, such that } h(y)=1 \text { and } y \text { stands in the } \\
& \text { contextually relevant relation of "belonging to" to } x \text {. } \\
& \text { If there is no unique } y \text { of that kind, then the denotation of } \\
& \text { GEN/POSS is undefined. }
\end{aligned}
$$

(77) 【in \ $]^{c}=f: D e \rightarrow D<i, t>$ such that, for any $x \in D e, t^{*} \in D i, f(x)\left(t^{*}\right)=1$ iff $t^{*}$ is located within the time (of existence) of $x$.

I will now go into the calculation of the truth conditions of a version of sentence (74), namely the verb-final version (78). 
(78) [viele Manager 1 [in ihrem 1 Studium] Fußball spielten many managers in their studies soccer played ('Many managers played soccer while they studied.')

As I mentioned above, I will ignore for now my stage-semantics. Note, however, that it would be simple to implement the stage-semantics in order to obtain the temporally independent reading in the way proposed in this chapter. For that purpose, we would use something like "period of studying" as the value of the resource domain variable of viele ('many'). Similarly to in the forties in Section 4.3.2., this predicate would be interpreted as shown in (79).

(79)

[Lperiod of studying ]] $\mathrm{c}=\mathrm{f}: \mathrm{De} \rightarrow \mathrm{Dt}$ such that,

for any $x_{S t} \in \operatorname{De}, f\left(x_{S t}\right)=1$

iff for all stages $y_{s t}$ such that $y_{s t}$ is a part of $x_{s t}$,

$y_{s t}$ is located within a period of studying of $x_{s t}$.

The LF-representation of (78) follows in (80).

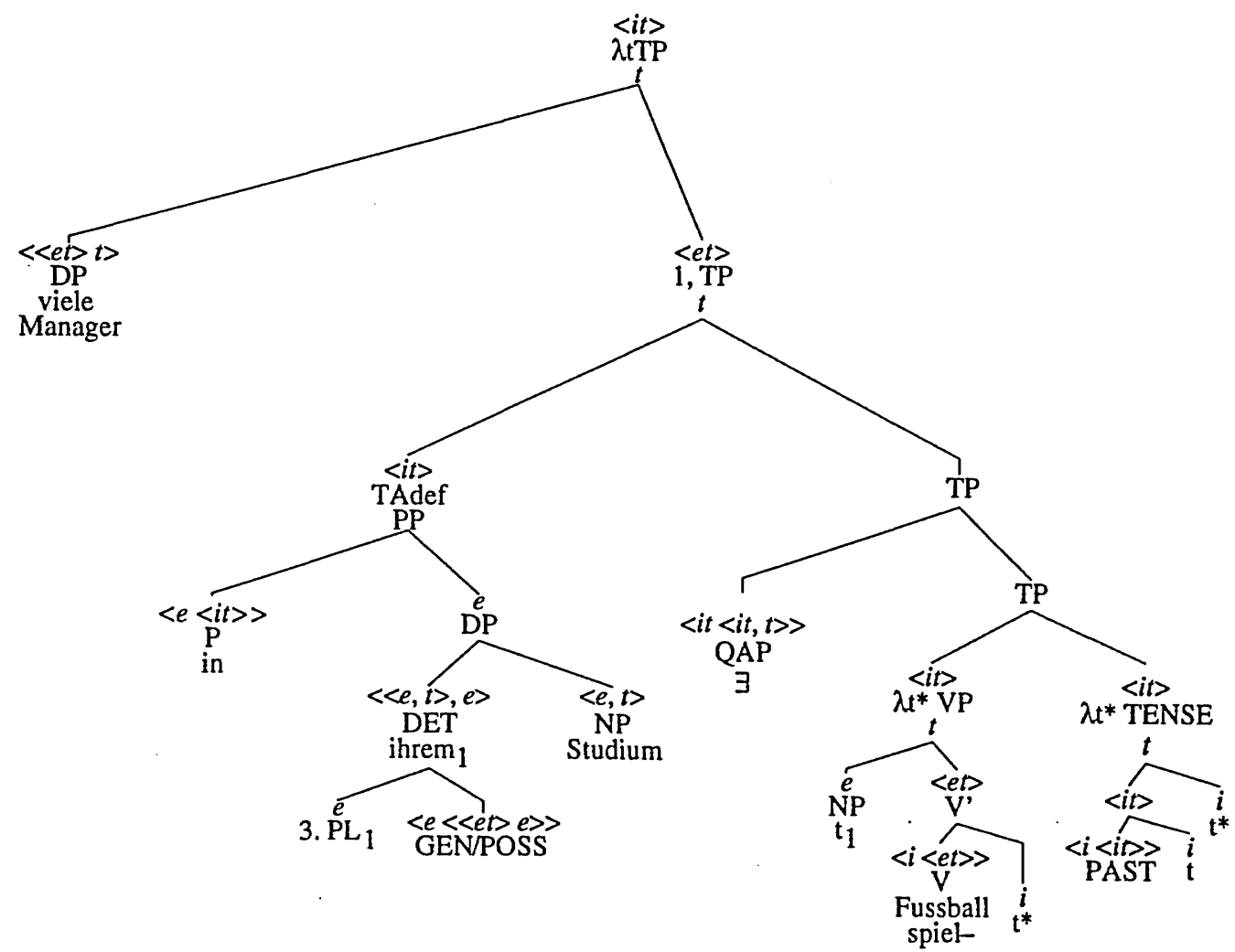


Below is the calculation of truth conditions of the sentence under the assumption of an LF as shown above and the framework of temporal interpretation presented in Chapter II. I am disregarding my stage-semantics at this point. The time of utterance of the sentence is indicated as $t_{u}$.

[I viele Manager 1 in ihrem1 Studium $\exists \mathrm{t}_{1}$ Fußball spielten ]] $\mathrm{c}, \mathrm{g}\left(\mathrm{t}_{\mathrm{u}}\right)=1$

iff [by entry of translations and Tripartite Structure Construction]

II $\lambda t$ [viele Manager $1\left(\exists\left[\lambda t^{*}\right.\right.$ (in ihrem 1 Studium $\left.\left(t^{*}\right)\right) \& \lambda t^{*}\left(\operatorname{PAST}(t)\left(t^{*}\right)\right]$

$\left[\lambda t^{*}\left(\right.\right.$ Fußball-spielen $\left.\left.\left.\left.\left.\left.\left(t^{*}\right)\left(t_{1}\right)\right)\right]\right)\right]\right]\right]^{c, g}\left(t_{u}\right)=1$

iff [by $\lambda$-Conversion]

[I viele Manager $1\left(\exists\left[\lambda t^{*}\right.\right.$ (in ihrem1 Studium $\left.\left(t^{*}\right)\right) \& \lambda t^{*}\left(\operatorname{PAST}(t)\left(t^{*}\right)\right]$

$\left[\lambda t^{*}\left(\right.\right.$ Fußball-spielen $\left.\left.\left.\left.\left.\left(t^{*}\right)\left(t_{1}\right)\right)\right]\right)\right]\right]$ c, $g[t \rightarrow t u]=1$

iff [by $2 \times$ Functional Application, lexical entries of viele and Manager]

for many $x$ such that $x$ is a manager, $\left[\left[1\left(\exists\left[\lambda t^{*}\right.\right.\right.\right.$ (in ihrem 1 Studium $\left.\left(t^{*}\right)\right) \&$ $\lambda t^{*}\left(\operatorname{PAST}(t)\left(t^{*}\right)\right]\left[\lambda t^{*}\left(\right.\right.$ Fußball-spielen $\left.\left.\left.\left.\left.\left(t^{*}\right)\left(t_{1}\right)\right)\right]\right)\right]\right]^{c, g}[t \rightarrow t u](x)=1$

iff [by Predicate Abstraction]

for many $x$ such that $x$ is a manager, $\left[\left[\exists\left[\lambda t^{*}\right.\right.\right.$ (in ihrem 1 Studium $\left.\left(t^{*}\right)\right) \&$

$\lambda t^{*}\left(\operatorname{PAST}(\mathrm{t})\left(\mathrm{t}^{*}\right)\right]\left[\lambda \mathrm{t}^{*}\left(\right.\right.$ Fußball-spielen $\left.\left.\left.\left.\left(\mathrm{t}^{*}\right)(\mathrm{t} 1)\right)\right]\right]\right]^{\mathrm{c}, \mathrm{g}}{ }^{\left[\begin{array}{l}\mathrm{t} \rightarrow \mathrm{tu} \\ 1 \rightarrow \mathrm{x}\end{array}\right]}=1$

iff [by lexical entry of $\exists$ ]

for many $x$ such that $x$ is a manager, there is a time $t^{*}$ such that

$\llbracket \lambda t^{*}$ (in ihrem 1 Studium $\left.\left.\left(t^{*}\right)\right) \& \lambda t^{*}\left(\operatorname{PAST}(t)\left(t^{*}\right)\right]\right]^{c, g} \stackrel{\left[\begin{array}{l}t \rightarrow \\ 1 \rightarrow x\end{array}\right]}{(t)}\left(t^{*}\right)=1$ and

$\left[\left[\lambda t^{*}\left(\text { Fußball-spielen }\left(t^{*}\right)(t 1)\right)\right]\right]^{c, g}{ }^{\left[\begin{array}{l}t \rightarrow t u \\ 1 \rightarrow x\end{array}\right]}\left(t^{*}\right)=1$

iff [by Predicate Modification applied to the restrictive clause]

for many $\mathrm{x}$ such that $\mathrm{x}$ is a manager, there is a time $\mathrm{t}^{*}$ such that

$\llbracket \lambda t^{*}$ (in ihrem1 Studium $\left.\left.\left.\left(t^{*}\right)\right)\right]\right]^{c, g}{ }^{\left[\begin{array}{l}t \rightarrow t u \\ 1 \rightarrow x\end{array}\right]}\left(t^{*}\right)=1$ and

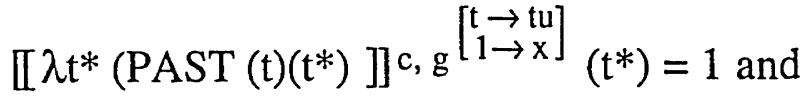

[I $\lambda t^{*}\left(\right.$ Fußball-spielen $\left.\left.\left.\left(t^{*}\right)\left(t_{1}\right)\right)\right]\right]^{c, g}{ }^{\left[\begin{array}{l}t \rightarrow t u \\ 1 \rightarrow x\end{array}\right]}\left(t^{*}\right)=1$

iff [by $\lambda$-Conversion]

for many $x$ such that $x$ is a manager, there is a time $t^{*}$ such that

[Iin ihrem1 Studium $\left.\left.\left(t^{*}\right)\right]\right]^{c, g}\left[\begin{array}{c}t \rightarrow t u \\ 1 \rightarrow x \\ t^{*} \rightarrow t^{*}\end{array}\right]=1$ and

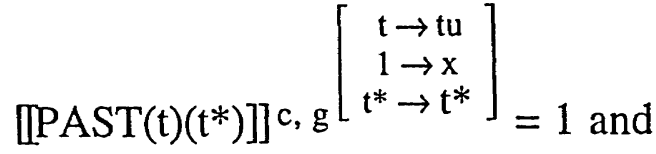


$\left[\right.$ Fußball-spielen $\left.\left.\left(t^{*}\right)\left(t_{1}\right)\right]\right]^{c, g}\left[\begin{array}{c}t \rightarrow t u \\ 1 \rightarrow x \\ t^{*} \rightarrow t^{*}\end{array}\right]=1$

iff [by $3 \times$ Functional Application, unessential variable assignments left out]

for many $\mathrm{x}$ such that $\mathrm{x}$ is a manager, there is a time $t^{*}$ such that

$\llbracket$ in $\rrbracket^{c}\left(\llbracket\right.$ GEN/POSS $\rrbracket^{c}\left(\llbracket 3 . P L_{1} \rrbracket^{c, g}\left[\begin{array}{c}t \rightarrow t u \\ 1 \rightarrow x \\ t^{*} \rightarrow t^{*}\end{array}\right]\right)\left(\llbracket\right.$ Studium $\left.\left.\rrbracket^{c}\right)\right)$

$\left.\left(\left[\mathrm{t}^{*}\right]\right]^{c, g}\left[\begin{array}{c}\mathrm{t} \rightarrow \mathrm{tu} \\ 1 \rightarrow \mathrm{x} \\ \mathrm{t}^{*} \rightarrow \mathrm{t}^{*}\end{array}\right]\right)=1$ and

$\left.\left.\operatorname{IPAST}(\mathrm{t})\left(\mathrm{t}^{*}\right)\right]\right]^{\mathrm{c}, \mathrm{g}}\left[\begin{array}{c}1 \rightarrow \mathrm{x} \\ \mathrm{t}^{*} \rightarrow \mathrm{t}^{*}\end{array}\right]=1$ and

[I Fußball-spielen $\left.\left.\left.\left(t^{*}\right)(\mathrm{t} 1)\right]\right]\right]^{c, g}\left[\begin{array}{c}1 \rightarrow x \\ t^{*} \rightarrow t^{*}\end{array}\right]=1$

iff [by lexical entries of the remaining elements, variable assigment applied to $t, 1$, and $t^{*}$ ]

for many $\mathrm{x}$ such that $\mathrm{x}$ is a manager, there is a time $t^{*}$ such that

$t^{*}$ is a subinterval of the unique study of $x$, and

$\mathrm{t}^{*}<\mathrm{t}_{\mathrm{u}}$, and

$\mathrm{x}$ plays soccer at $\mathrm{t}^{*}$.

Let me now add a more precise definition of the truth condition of the sentence, i.e. a definition of its truth conditions as gained using my stage-semantics.

(82) [I viele Manager1 in ihrem 1 Studium $\exists \mathrm{t}_{1}$ Fußball spielten $\rrbracket^{\mathrm{c}, \mathrm{g}}\left(\mathrm{t}_{\mathrm{u}}\right)=1$ iff for many maximal stages $\mathrm{x}_{\mathrm{st}}$

such that $\exists y_{s t}, z_{s t}$ such that $x_{s t}=y_{s t} \oplus z_{s t}$,

and for all stages $w_{S t}$ such that $w_{s t}$ is a part of $y_{s t}$, $\mathrm{w}_{\mathrm{St}}$ is located within a period of studying of yst.

and $z_{s t}$ is a manager,

$\mathrm{x}_{\mathrm{st}}$ has a part $\mathrm{v}_{\mathrm{st}}$, such that

there is a time $t^{*}$ such that

$t^{*}$ is a subinterval of the unique study of $x_{s t}$, and

$\mathrm{t}^{*}<\mathrm{t}_{\mathrm{u}}$, and

$\mathrm{v}_{\mathrm{st}}$ plays soccer at $\mathrm{t}^{*}$. 


\section{Unrestrictive noun phrases that get temporally independent interpretations: an explanation under the stage-approach}

I showed above that certain unrestrictive noun phrases can get temporally independent interpretations, namely subjects of existence-independent predicates. I will show here that the effects are not a problem under my account, but are in fact predicted by the stage-semantics I suggested in this chapter in combination with my account of life-time effects in Chapter II.

Recall from Chapter II that I distinguished stage-level predicates and individual-level predicates on the one hand from existence-independent predicates on the other hand. The crucial difference between the predicates is that stage-level predicates (e.g. available or sick) and individual-level predicates (e.g. altruistic or intelligent) impose life-time presuppositions on their subjects, but existence-independent predicates (e.g. famous or forgotten) don't.

Thus, Frege is intelligent is inappropriate for reasons of presupposition failure: we can't predicate intelligent of Frege, because predicating intelligent of an individual presupposes that the individual is alive - and Frege is dead. Similarly, Frege is sick is inappropriate because Frege is dead and thus, the lifetime presupposition of sick is not fulfilled.

But Frege is famous does not suffer from presupposition failure and is thus appropriate. Moreover, the sentence is judged true at present, because Frege is presently famous. Since famous can be predicated of people when they are dead, one can see that famous does not impose a life-time presupposition on its subject. For Frege is famous, the present tense of the clause locates the being famous at the time of utterance. The predicate famous denotes a relation between the individual Frege and some temporal (and perhaps spatial) location. This relation is independent of Frege's life-time, so that we can use the sentence appropriately and truthfully to describe a situation like (83).

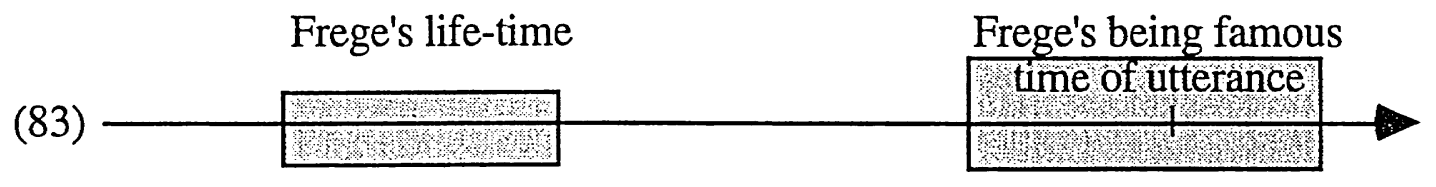

Having established this point with the proper name Frege and the individual Frege in his whole temporal extendedness, I want to show now that it makes sense to predict an analogous effect with stages that are introduced by 
quantificational noun phrases. The analogous effect we expect with stages and quantificational noun phrases is that quantificational subject noun phrases of existence-independent predicates should always be able to be temporally independent, even when being unrestrictive.

For quantificational noun phrases, one would expect that one should be able to predicate famous of a stage introduced by the subject noun phrase no matter whether the stage exists at the time when famous is asserted to hold of the stage just as one can predicate famous of Frege at the present time, although Frege doesn't exist anymore.

Consequently, one should be able to utter Many STUDENTS are famous (where stress on the noun triggers the unrestrictive interpretation) in order to describe the situation in (84).

student (x-st)

It should not matter whether the noun phrase many students is unrestrictive or restrictive. Thus, existence-independent predicates like famous should be able to be predicated of student-stages during non-student-times in constructions where the noun phrase is weak. This prediction is borne out with examples like (12b), repeated here as (85).

(85) Es sind heutzutage lauter Studenten berühmt. it are today many students famous ('Today, many students are famous.')

Thus, the data that seemed surprising above can be easily explained and provide in fact additional evidence for the stage-approach, because the stage-approach predicts the phenomenon.

To summarize, the stage-account predicts that any noun phrase argument with respect to which the main predicate is existence-independent should not get an obligatorily temporally dependent interpretation - not even when the noun phrase is unrestrictive. This is, because the stage introduced by such a noun phrase argument is not bound to the event time of the main predicate, since the main predicate does not impose life-time presuppositions on the argument. 


\section{Constructions with adverbs of quantification}

A construction that turned out to be a problem for the scope-approach was the construction in (24a), repeated here as (86a). The observation that remained unexplained under the scope-approach was that (86a) can have a reading roughly like (86b). With this reading, alle Professoren gets a temporally independent interpretation. This was problematic for the scope-approach, because the scope configuration indicated in (86b) is such that, under the scopeapproach, one would expect the noun phrase to be obligatorily temporally dependent.

a. In den sechziger Jahren spielten meistens alle Professoren, deren in the sixties Eltern gerade in Urlaub waren, Federball. parents just in vacation were badminton

('In the forties, most often all professors whose parents were just then on vacation, played badminton.')

b. For most times $t$, such that $t$ is in the past and in the sixties, all $x$ such that $\mathrm{x}$ is now a professor and $\mathrm{x}$ 's parents were on vacation at $t, x$ played badminton at $t$.

Under the stage-approach, (86) is not problematic. In fact, the stage-approach predicts that the noun phrase alle Professoren should be able to be temporally independent. According my proposal, the temporal adverbial in den sechziger Jahren is able to modify the resource domain variable of alle Professoren. Thus, (83a) is predicted to be able to have the truth conditions in (86c). 
(86) c. For most times t, such that $t$ is in the past and in the sixties, all maximal stages $\mathrm{x}_{\mathrm{st}}$ such that $\exists y_{s t}, z_{s t}$ such that $x_{s t}=y_{s t} \oplus z_{s t}$,

and $y_{s t}$ has a part that is located within the sixties and a part that is now a professor and a part at which $\mathrm{y}_{\mathrm{st}}$ 's parents were on vacation, 35

$\mathrm{x}_{\mathrm{st}}$ has a part $\mathrm{v}_{\mathrm{st}}$, and [ $[$ professor $]\left(\mathrm{z}_{\mathrm{st}}\right)=1$, such that [[play badminton $\rrbracket\left(v_{s t}, t\right)=1$.

Thus, the approach can easily explain the occurrence of temporally independent readings of restrictive noun phrases regardless of their position at LF.

Noanimals were harmed in the writing of this thesis.

\section{Generic noun phrases}

In this section, I want to come back to an observation made in connection with (4a), repeated here as (87). The underlined noun phrase in (87), read generically, is obligatorily temporally dependent.

In the forties, professors were young.

Given that generic noun phrases are standardly considered to be a special case of restrictive noun phrases (cf. Diesing (1992) and others), this is surprising.

Generally speaking, it seems that generic noun phrases are particularly strongly affected by temporal adverbials. Whereas determiner-quantified noun phrases can easily have a temporally independent reading when they occur to the

35 Note that yst is itself here a complex, discontinuous stage. This is, because the resource domain variable in this example is crucially modified by three predicates. One is caused by our talking about present professors, another comes into play by the time interval provided by the temporal adverbial, and the third is provided by the relative clause. Note also that the interpretation of the relative clause makes it crucially necessary to interpret relative clause and noun non-intersectively. 
right of a temporal adverbial, generic noun phrases in this position cannot get a temporally independent reading at all with most speakers. This is illustrated by the contrast between the generic bare plural in (88a) and the universally quantified DP in (88b). The latter can easily get a temporally free reading.

(88) a. In den vierziger Jahren waren Professoren ja doch jung. (weil) in den vierziger Jahren Professoren ja doch jung waren. ('In the forties, professors were young.') possible reading: "For typical professor of the forties, they were young in the forties."

impossible reading: "For typical present professors, they were young in the forties"

b. In den vierziger Jahren waren alle Professoren ja doch jung. (weil) in den vierziger Jahren ja doch alle Professoren jung waren. ('In the forties, all professors were young.') possible reading: "For all $\mathrm{x}$, such that $\mathrm{x}$ is now a professor, $\mathrm{x}$ was young in the forties.

Note, though, that generic bare plurals do not always get temporally dependent readings. This is demonstrated with (89a), whose possible readings (89c) shows that generic bare plurals can get temporally independent readings.

a. Professors were young (once too).

b. possible reading: All typical past-professors were young.

c. possible reading: All typical now-professors had a time in the past where they were young.

Note that (89c) is only one of several examples of temporally independent interpretations of (89a). (89a) does not contain a temporal adverbial. Thus, (89) may suggest at first sight that it is the presence of the temporal adverbial in (88a) that leads to the obligatorily temporally dependent interpretation of the noun phrase.

But a closer look shows that generic bare plurals do not always get temporally dependent readings when a temporal adverbial is present. Thus, in (90a), where the temporal adverbial occurs to the right of the generic noun phrase, the noun phrase can have a temporally independent reading.

(90) a. Professors were young in the forties.

b. possible reading: All typical professors of the forties were young in the forties.

c. possible reading: All typical now-professors were young in the forties. 
Furthermore, as Kai von Fintel has pointed out to me, when narrow scope of the temporal adverbial is forced by a bound variable pronoun inside the adverbial that must be bound by the generic noun phrase, it is very easy to get a free reading, even if the temporal adverbial appears in the same position as in (88a):

(91) In ihreri Jugend sind/waren Politikeri meistens schüchtern. in their youth are/were politicians mostly shy ('In their youth, politicians are/were mostly shy.')

To summarize, the crucial observation is that the position of the temporal adverbial, and specifically - as (91) suggests - its position at LF, determines whether a generic noun phrase gets a temporally dependent or temporally independent interpretation.

I will assume in what follows that the topicalized surface position of a temporal adverbial strongly suggests that the temporal adverbial is mapped at LF into a position where it obligatorily determines the temporal interpretation of a generic noun phrase. This effect can be overcome if the presence of a variable as in (91) - requires reconstruction of the temporal adverbial into a lower position. In (91), the bound variable pronoun requires the temporal adverbial to be reconstructed into a position that is lower than the generically interpreted noun phrase Politiker ('politicians'). But when the temporal adverbial appears in another, lower, position at surface structure, it is preferredly mapped into a position at LF where it does not determine the temporal interpretation of the generic noun phrase obligatorily.

In recent approaches to genericity, it is commonly assumed that generic readings are caused by an implicit generic quantifier. This has been argued for and pursued, used, or presupposed by Wilkinson (1991), Krifka (1987), Carlson (1988, 1989), Kratzer (1988), Diesing $(1990,1992)$ and others. As far as the type of quantifier involved is concerned, the common assumption is that the generic quantifier is a kind of non-overt adverb of quantification with a meaning like "mostly" or "usually". I will adopt this general approach to genericity. Moreover, I will assume with von Fintel (1994) that adverbs of quantification quantify over situations.

Note that temporal adverbials can plausibly be viewed as suitable predicates of situations. When predicated of a situation, they locate the situation temporally. As a consequence, temporal adverbials are able to function as restrictors in the 
restrictive clause of a generic quantifier. Thus, omitting again details of temporal interpretation of the main predicate as well as a detailed account of quantification over situations $36,(88 a)$, repeated here as (92a), can have an LF roughly like (92b). It cannot have an interpretation like (92c), though.

(92) a. In the forties, professors were young.

b. GENS [RC professor (s) \& in the forties (s)] [Ns were young (s)]

c. * GEN $\mathrm{S}$ [RC professor (s)] [NS were young in the forties (s)]

(93a) on the other hand, can exhibit both reading (93b) and reading (93c).

(93) a. Professors were young in the forties.

b. $\quad G_{S}$ [RC professor (s) \& in the forties (s)] . [Ns were young (s)]

c. GEN $[\mathrm{RC}$ professor (s)] [NS were young in the forties (s)]

Given the approach to genericity I sketched above, I want to show in the remainder of this section that the strong tendency of topicalized temporal adverbials to determine the temporal interpretation of generic noun phrases is not at all surprising: it comes out as a special case of the generally acknowledged mapping behavior of temporal adverbials.

It has been noted repeatedly that when-clause constructions exhibit two different readings when the when-clause is in a sentence-final position, but not when it is in sentence-initial position (Rooth (1985), Johnston (1994, 17f)). Consider (94) and (95). In (94), the when-clause is in sentence-final position. (94a) can have the two readings (94b) and (94c). As observed by Rooth, each of these readings is strongly supported by a certain focus structure as indicated in the schematic LF-representations below. 37

(94) a. Marcia always writes a letter when she is at the cafe.

b. ALWAYS [she is at the cafe (s)] [Marcia writes a LETTER (s)] For all situations where Marcia writes a letter, she is at the cafe.

c. $\quad$ ALWAYS $_{\mathrm{S}}$ [Marcia writes a letter (s)] [she is at the CAFE (s)] For all situations where she is at the cafe, Marcia writes a letter.

In contrast to (94a), (95a) exhibits only the reading corresponding to (94b), but not the reading corresponding to $(94 \mathrm{c})$.

36 For a detailed proposal, see von Fintel (1994).

37 The sentences are taken from Johnston $(1994,17 f)$. 
(95) a. When she is at the cafe, Marcia always writes a letter.

b. ALWAYS $\mathrm{S}$ [she is at the cafe (s)] [Marcia writes a LETTER(s)] For all situations where Marcia writes a letter, she is at the cafe.

c. * ALWAYS [Marcia writes a letter (s)] [she is at the CAFE (s)]

For all situations where she is at the cafe, Marcia writes a letter.

Thus, the sentence-final when-clause in (94a) can be mapped into the nuclear scope of the adverb of quantification always, while the sentence-initial whenclause in (95a) can't. It can only be mapped into the restrictive clause of always.

Johnston (1994, 48-55) argues that the lack of the (c)-reading with sentenceinitial when-clauses can be explained as a consequence of the application of Diesing's (1992) mapping procedure to when-clauses: Diesing argued for indefinite noun phrases that they are mapped into the restrictive clause of an adverb of quantification when part of the IP-structure, and into the nuclear scope when part of the VP. Johnston applies this to temporal adverbials in general, and to when-clauses in particular. Specifically, he argues that when-clauses in sentence-final position can be either IP-adjuncts or VP-adjuncts and can thus be mapped into the restrictive clause or the nuclear scope of the adverb of quantification, respectively. But when-clauses in sentence-initial position can only be IP-adjuncts and are thus mapped into the restrictive clause.

So far Johnston's explanation. Whether or not this particular explanation of the lack of the (c)-reading of (95) turns out to be adequate, it should be obvious at this point that whatever explains the lack of the reading can also be applied to the lack of the (c)-reading in (92). Thus, the lack of the reading is a special case of the mapping behavior of temporal adverbials with adverbs of quantification.

Note that in order for this explanation to work, it is crucial to assume that temporal adverbials are suitable predicates of the type of entities adverbs of quantification quantify over. Only because of this can they appear directly as restrictors in the restrictive clause of the generic operator.

Recall that determiner-quantified noun phrases do not share the tendency of generics to be temporally determined by topicalized temporal adverbials. This difference in the behavior of determiner-quantifiers and the generic quantifier is in fact expected, given the proposal I have sketched: it simply follows from the assumption that determiner-quantifiers quantify over individuals or stages of individuals, not over situations. Thus, temporal adverbials cannot function directly as restrictors of determiner-quantifiers. I argued above that when they have some effect on the restriction of determiner-quantifiers (i.e., when they 
modify the resource domain variable of a determiner-quantifier in order to give rise to temporally independent noun phrase interpretations), this is an indirect effect mediated by the context. Thus, temporal adverbials can provide a contextually salient time interval which can modify the resource domain of a determiner-quantifier, but they can crucially not function directly as restrictors of determiner-quantifiers. 38

"'Neineinja', sagte der Prinz, 'wohl eher nein.' " - Janosch, DerFroschkönig-

\section{Remarks on temporally independent noun phrases}

Above, I have argued that restrictive noun phrases can in general have temporally independent interpretations. However, when looking at particular occurrences of restrictive noun phrases, it turns out that not all restrictive noun phrases can have all conceivable temporally independent readings, or at least not with equal ease. In this section, I want to determine at least some of the factors that play a role in whether a particular occurrence of a restrictive noun phrase can have a particular temporally independent interpretation. We will see that the relevant factors are of a pragmatic nature.

38 As pointed out in von Fintel $(1994,177 \mathrm{f})$, this is usually so, but perhaps not always. The tendency of a distinction between entity-restrictors and situation-restrictors seems to be clear though. Here are some more examples of his, illustrating the point at issue here with wif/when-clauses. The original source of these sentences are lecture notes by Irene Heim (a, b) and Carlson $(1977,420)(c-e)$. With (a) and (b), the if-clauses can restrict the entities quantified over, but the when-clauses in (c-e) can't.

(a) Most letters are answered if they are shorter than 5 pages.

(b) Few people like New York if they didn't grow up there.

(c) * Bill hates any dog when it is of a rare breed.

(d) * All hotels are uneconomical when they have less than 200 rooms.

(e) * Each wolf is intelligent when it has blue eyes. 


\subsection{The salience of properties and the choice of nouns}

In general, common nouns can be viewed as characterizing individuals by ascribing a property to them. Enç $(1981,88)$ observed that there are some very strong pragmatic restrictions on which properties of an individual are salient enough so that they can characterize the individual in question successfully. This effect is illustrated with two of her examples in (96), which appear quite strange when uttered out of the blue.

(96) a. \# All the little boys are eighty years old.

b. \# The tadpoles croaked all night long.

Enç suggests that "this deviance may be explained by appealing to certain pragmatic principles" (p89). She points out that "[t]he property a speaker chooses to pick out the objects is important in that it must enable the other participants in the discourse to access the objects easily. Therefore these properties tend to be permanent properties or salient temporary properties." (p89).

In other words, the use of nouns is pragmatically restricted by the necessity to link properties and individuals. The property denoted by a noun must be salient enough to identify the individuals characterized by the noun. And in general, we expect that the most salient property results in the most felicitous noun phrase. What precisely affects the degree of salience of a property and, consequently, the degree of felicitousness of the use of a particular noun in order to characterize particular individuals? There are various factors that play a role here. Let me list some of the obvious ones.

First, a property of an individual that is accessible by general worldknowledge is more salient than a property that is not accessible by general worldknowledge. Consider the noun phrase most students in (97a) and (98a) with the context indicated in square brackets. Since world-knowledge tells us that students were kids at some time and that students are usually grown-ups, reading (97b) is much less likely than reading (97c), although (97b) exhibits a temporally dependent reading. But world-knowledge doesn't suggest a special developmental link between soccerplayerhood and studenthood. Thus, (98b) rather than (98c) is the preferred reading for (98a).

(97) a. [I have to tell you something about the people Amanda met when she studied: as far as I know, ...]

... most students were terrifying kids. 
b. Possible reading, unlikely for reasons of world-knowledge:

When Amanda studied, most of the individuals who were students then were terrifying kids at that time.

c. Possible reading, preferred for reasons of world-knowledge:

At some time in the past, most of the individuals who were students when Amanda studied were terrifying kids.

(98) a. [I have to tell you something about the people Amanda met when she studied: as far as I know, ...]

... most students were terrifying soccerplayers.

b. Possible, and preferred, reading:

When Amanda studied, most of the individuals who were students then were terrifying soccerplayers at that time.

c. Possible reading:

At some time in the past, most of the individuals who were students when Amanda studied were terrifying soccerplayers.

Second, a related effect occurs when one tries to make sense of sentences that would be plainly contradictory if a noun phrase were not understood with a temporally independent reading. This is illustrated in (99).39

(99) a. [Today, the social system is comparatively progressive and humane.] Most homeless people live in publicly financed apartments.

b. Possible reading, easily accessible:

Most former homeless people live in publicly financed apartments now.

Third, some notion of familiarity and novelty of decriptive content seems to be relevant for the felicitousness of temporally independent noun phrases. Thus, a property that was mentioned in the previous discourse is certainly more salient than a property that has never been mentioned before. Thus, since the students are mentioned in the context surrounding (100a), it is easily possible to exploit the temporally independent noun phrase in most students giggled. But since the softballteam of the class of 1982 was not mentioned before, it is hardly possible to utter (101a) with the reading (101b) felicitously.

(100) a. [36 former students of the class of 1982 came to the alumni meeting last year. When it was announced that the campus was haunted by a ghost, ... ]

... most students giggled.

39 This example is due to Kai von Fintel (pc). 
b. Possible reading, easily accessible:

Most of the individuals who were students of the class of 1982 giggled at the alumni-meeting after the ghost-announcement.

(101) a. [36 former students of the class of 1982 came to the alumni meeting last year. When it was announced that the campus was haunted by a ghost, ... ]

... most softballplayers giggled.

b. Possible reading, hardly available:

Most of the individuals who belonged to the softballteam of the class of 1982 giggled at the alumni-meeting after the ghostannouncement.

But also properties that are not directly mentioned but are indirectly strongly suggested by the discourse context can be relatively salient. (102) is an example that shows this.

(102) a. [At the alumni meeting in 2004, it will be announced that the campus is haunted by a ghost. (I am sure the audience will listen attentively.)] Most students will giggle.

b. Possible reading:

Most of the individuals who are now students will giggle.

Fourth, a property that characterizes an individual in a completely different state than the one it has at the predication time of the main predicate is certainly less felicitous than one that is less different. Thus,(a) is less felicitous than (b).

(103) a. \# The ice cubes, which had become steam, went up to the ceiling.

b. The water, which had become steam, went up to the ceiling.

Interestingly, the inappropriateness of sentences like (a) disappears when the relationship between two fundamentally different states is an issue of the utterance. Thus, the following two predicate nominal constructions illustrate this. They are perfectly acceptable.

(104) a. The steam is now ice.

b. My tadpole is now a frog.

Moreover, assuming that the inappropriateness of the sentences in (96) is due to the significant difference between the boy- or tadpole-state and the man- or frogstate of an individual, it is important to note that depending on the context, one can in some situations easily use predicates that would under other circumstances 
be quite inappropriate. For instance, imagine a class meeting about sixty years after the class left school. The former teacher, now about 100 years old, is also invited to the meeting. Entering the room, she cries in surprise "Oh! All the little boys are eighty years old!" - I think there is almost nothing especially strange about the utterance of (96a) in this situation.

Note that at least some of the factors that I just listed are not only relevant for licensing temporally independent noun phrase interpretations; at least some of them are in principle equally important for the choice of a noun whose predication time coincides with the event time of the main predicate, or for nouns that are modified by temporal modifiers like former or future. Thus, consider the following examples that try to transfer some of the principles at work in (96)(103) to cases that exhibit a noun phrase whose predication time coincides with the predication time of the main predicte of their clause.

Consider $\left(100^{\prime}\right)$ and $\left(101^{\prime}\right)$ and imagine that the 10 students who came to the meeting were all members of the softball team. Imagine furthermore that it is wellknown that these students are softball players. Even if this is well-known, (101') appears inappropriate.

(100') [About 10 students came to the meeting on Wednesday morning. When one of the faculty members started arguing as usual, ... ]

... most students giggled.

(101') [About 10 students came to the meeting on Wednesday morning. When one of the faculty members started arguing as usual, ... ]

... most softballplayers giggled.

We also get the effect that properties that are not directly mentioned but are indirectly strongly suggested by the discourse context can be used without problems:

(102') [About 19 members of the department were at the meeting on Wednesday morning. When a greenish ghost appeared from behind the blackboard, ...] ... most professors were totally upset.

And (103') shows that the use of modifiers like former and future doesn't help much with respect to making the use of noun phrases felicitous if the noun 
phrases used try to characterize individuals by mentioning some very far-fetched states of them. 40

(103') \# The former pile of bricks collapsed into a future wall.

To summarize, in this subsection, I have looked at the ease with which one can get temporally independent interpretations for noun phrases from the perspective of the choice of nouns. In general, the more salient a property is in a context, the more felicitous it is to use the corresponding predicate to characterize individuals.

\subsection{The salience of the time of utterance and the choice of predication times}

In this subsection, I want to briefly look at the ease with which one can get temporally independent interpretations for noun phrases from another perspective, namely from the perspective of how much the predication time of the noun matters.

In general, it seems easiest to get a temporally independent reading when the noun holds at the time of utterance: when a noun phrase is temporally independent, the most likely predication time of the noun phrase intersects with the time of utterance, i.e., the easiest, most salient temporally independent noun phrase interpretation assumes that the noun can be truly predicated of the characterized individual(s) at the time of utterance. This is illustrated in (105).

(105) a. [On July 15, 1992, there was a big party in Washington.] Most of the congressmen were there.

b. Possible temporally independent reading where the noun's predication time coincides with the time of utterance; preferred:

Most of the individuals who are now congressmen were at the party.

c. Possible temporally independent reading where the predication time of the noun does not coincide with the time of utterance; less accessible:

Most of the individuals who were congressmen at any time were at the party.

40 This sentence was given to me by David Pesetsky (pc) who thinks the example was used in a talk by Mürvet Enç. 
It seems most likely that this effect is due to the fact that the time of utterance is for any utterance naturally a particularly salient time.

Furthermore, for times that differ from the time of utterance, although in principle all times can provide felicitous predication times for the noun, we can observe that past times are in general much more accessible than future times. Recall example (2) from the beginning of this chapter, repeated here as (106).

(106) a. John's murderer hid behind the curtain.

b. John was murdered on May 15th 1992. At some time in the past, the man who murdered John (which was that man's first murder) hid behind the curtain.

c. John is being murdered just while (105a) is uttered. At some time in the past, the man who is murdering John (which is that man's first murder) hid behind the curtain.

d. It is known that a certain man plans to murder John. According to what we know about that man (whatever he plans, he does it), we know that he will commit the murder. At some time in the past, the man who will murder John (which will be that man's first murder) hid behind the curtain.

We can observe that of the three possible readings (106b-d), it is most difficult to get $(106 \mathrm{~d})$, where the predication time of the noun is located in the future. In order to get a reading like (106d), we need to make specific assumptions about a future time. And, moreover, we have to treat these assumptions as knowledge about future situations, although we cannot really have knowledge, in a serious sense, about these future situations. In Chapter IV, we will be concerned with certain effects - called "upper limit effects" - which are probably related to the restricted accessibility of future predication times for nouns.

\subsection{Competing times and the salience of established discourse topics}

An interesting question to be raised is what happens when there are several competing factors at work that can potentially affect the temporally independent interpretation of a particular noun phrase. Are the potential factors equally strong? If not, which factors "win" against other factors?

I want to look here at a particular case. We have seen above that the time of utterance is particularly salient and preferredly chosen as the predication time of a temporally independent noun (105). We have also seen that a previously established set of individuals seems to be easily accessible for temporally 
independent interpretations (100). What happens when these two factors are both present?

Suppose (107) is uttered now, and the noun president means "president of the U.S.". Suppose furthermore that (107) occurs in a context where someone is telling stories about Ronald Reagan. The relevant situation about presidents is the following: Bill Clinton is president now, George Bush was president on July 15, 1992, and Ronald Reagan was president before Bush. According to what we learned above about the salience of predication times, the president in (107) would preferredly either get a temporally dependent interpretation - i.e., refer to George Bush - or it will refer to the president at the time of utterance - i.e. to Bill Clinton.

(107) On July 15, 1992, the president hid behind the curtain.

I think intuitions are very clear that in the context of story-telling about Ronald Reagan, the president will most likely be understood as refering to Reagan, that is, to an individual that is neither the president of the U.S. now nor was the president on July 15, 1992.

To summarize, the example I,considered in this subsection showed that when the discourse has already identified a salient individual we are talking about, the factors regarding the salience of predication times of the noun do not play an important role anymore.

\subsection{Different types of noun phrases}

Overtly partitive noun phrases can particularly easily get temporally independent interpretations, more easy than non-partitive restrictive noun phrases. Thus, with (108b) it is easier to get an independent interpretation than with (108a)

(108) a. Most criminals were at the party.

b. Most of the criminals were at the party.

Although both sentences can have a reading "Most of the individuals who are now criminals were at the party (when they were not yet necessarily criminals)", one can observe that the reading is more salient with (108b), where the restrictive noun phrase is overtly partitive. Thus, overt partitivity seems to affect the temporal interpretation of noun phrases insofar as it makes temporally 
independent interpretations easier. Why do partitive noun phrases have thị effect?

Partitive noun phrases presuppose a previously established set of discourse referents to which they are linked This link licenses the use of the definite description that is part of a partitive noun phrase. As pointed out to me by Kai von Fintel (pc), the previous establishing of a set of discourse referents can take place in a temporal frame that is completely independent of the temporal frame of the clause in which the partitive noun phrase occurs. This independently establishing of the set of discourse referents is responsible for the significant ease of temporally independend interpretations with partitive noun phrases.

\section{Conclusion}

I started out this chapter by reviewing Enç's (1981) claim that the temporal interpretation of noun phrases is independent of the temporal interpretation of the rest of their clause and only dependent on the discourse context. I showed that this claim is an overgeneralization, and raised the questions of what the distribution of temporally dependent noun phrases is and what mechanisms are responsible for the occurrence of temporally dependent and independent noun phrases. In concluding this chapter, I would like to reconsider and relativize the results of Enç's (1981) dissertation in addition to summarizing my own results.

I showed that in for most cases, we can state that a noun phrase can be temporally independent if and only if it is restrictive. This generalization does not hold for existence-independent arguments though. I argued that the distribution of temporally dependent and independent noun phrases can be explained in a semantics that assumes that determiner-quantification is quantification over stages of individuals. How do these results relate to Enç's (1981) work?

One of the things we learned from Enç's work is that a sentence-operator analysis of tenses is inadequate to capture the temporal interpretation of noun phrases. There is no doubt that Enç's work has shown this convincingly.

Second, according to Enç, nouns are in general temporally independent. I have argued at length that this is an overgeneralization; there are systematic cases of noun phrases that cannot be temporally independent. Enç's generalization holds correctly though for the types of noun phrases she looked at when 
drawing her conclusion - which were exclusively noun phrases that can be restrictive.

Third, Enç suggests an indexical analysis of nouns (pp77-92). As far as I can see, the indices are a kind of contextual restriction, i.e., on a certain level, they can be compared to resource domain variables. Enç sees the source for temporal freedom in these indices. In my analysis, it is in fact the value of resource domain variables that provides the possibility to "anchor" the main predicate's time in the stage given by the restrictive material. Thus, the contextual restriction provides in a certain sense the possibility to create the necessary temporal dependence of the main predicate's stage on the restrictive-material-stage.

Fourth, for the explanation of noun phrases that should be able to exploit temporally independent readings but don't, Enç exploits pragmatic principles. In Section 8, I showed that there are in fact principles like the one she suggested at work. Some of the important observations concerning the ease of availability of temporally independent interpretations of noun phrases were these: Restrictions on felicity and contextual salience play a role. Furthermore, among restrictive noun phrases, overtly partitive noun phrases can most easily get temporally independent interpretations. Yet another observation is that temporally independent interpretations are easiest to get in cases where the temporally independent noun has a predication time that intersects with the time of utterance of the sentence in which the noun phrase occurs. These factors are all pragmatic. 
'The whale has a two-fold distinction among the fishes: first, when seen from a distance, it boms large among them and, secondly, on close examination it is found to be no fish at all."

-M F. Meyer, cited in: Katz \& Fodor, The Structure of Language -

\section{More on stages}

\subsection{Ships passing through locks and how to determine and count stages}

\subsubsection{Object-related readings and event-related readings}

Krifka $(1990,487)$ observes that sentences like the ones in (99) are ambiguous. They exhibit two readings which Krifka calls OBJECT-RELATED READINGS and EVENT-RELATED READINGS, respectively. 41

(109) a. Four thousand ships passed through the lock last year.

b. The library lent out 23,000 books in 1987 .

c. 12,000 persons walked through the turnstile yesterday.

d. National Airlines served at least two million passengers in 1975.

e. After facing 35 batters, the pitcher got tired.

With (109a), the object-related reading means something like "There are four thousand (different) ships which passed through the lock last year". The eventrelated reading means something like "There were four thousand events of passing through the lock by a ship last year (some of which were possibly undertaken by the same ship)". Analogous considerations apply to the other examples in (109).

Krifka points out that event-related readings occur also in cases with quantificational noun phrases (pp509ff). Here are his examples:

(110) a. Most ships passed through the lock at night.

b. Every ship passed through the lock at night.

c. No ship passed through the lock at night.

41 Examples (a-d) are directly taken from Krifka (1990, 487f), example (e) is made up using Krifka's comments. 
According to Krifka, "[(110a)] can either mean that more than half of the ships (of a given domain of entities) passed through the lock during the night. Or it can mean that more than half of the lock traversals of a ship occurred at night." Again, analogous readings occur with the examples (110b) and (110c).

Krifka observes that the choice of interpretation in the case of quantificational noun phrases depends on which constituent is focussed (p511). He illustrates this with the following two sentences, which both trigger eventrelated readings, but different ones (pp511f):

(111) a. Most books were lent out from counter A in the MORNINGS (rather than in the afternoons).

$=$ Most events of lending out a book from counter A happened in the mornings.

b. Most books were lent out in the mornings from COUNTER A (rather than from counter B).

$=$ Most events of lending out a book in the mornings happened from counter A.

For (111a), Krifka states that "[i]n the most natural reading of [(111a)], the adverbial phrase at night is in focus, and it is said that most events of a ship passing through the lock happened at night (rather than at daytime)" (p512). It seems that a strong focussing is not obligatory in order to get the object-related reading. Thus, we have:

(112) $a^{\prime}$. object-related reading: Most ships passed through the lock at night.

a". $\quad$ event-related reading: Most ships passed through the lock AT NIGHT.

Krifka discusses briefly two possible analyses of the basic ambiguity between object-related readings and event-related readings by Gupta (1980) and Carlson (1982).42 According to Krifka (p488), Gupta's analysis assumes that common nouns are not predicates of individuals but predicates of individual concepts, where the ambiguity may be derived from the assumption that two non-identical individual concepts might have the same value at certain reference times without being identical altogether. Carlson exploits his 1977 stage-ontology and can derive the ambiguity from the assumption that individuals have stages that can optionally be counted instead of individuals.

Krifka's conclusion is that neither Gupta's nor Carlson's approach can treat the ambiguity adequately, because they locate the event-related reading in the

42 For a new approach of the ambiguity, see Honcoop and Doetjes (1995). 
meaning of the noun, but the set-up of their approaches allows only for capturing the ambiguity with stage-level nouns like passenger or batter. If this is so, then neither Gupta nor Carlson can deal with the occurrence of the ambiguity in (109a-c), where it clearly shows up. Krifka argues further (p489):

"If we want to... claim that a noun like ship is indeed ambiguous and denotes either ships or, say, ship stages, we face a serious problem. (...) we cannot count just any stages of ships, but only those which perform one, and only one, complete pass through the lock. Now, take the ship Eleonore, which has two stages, $s_{1}$ and $s_{2}$, which passed through the lock. But then our way of counting breaks down: we have suddenly at least three stages, $s_{1}, s_{2}$, and the sum of $s_{1}$ and $s_{2}$, which passed through the lock."

For obvious reasons, the ambiguity and Krifka's comments are relevant for the stage-semantics I have adopted in this chapter. In particular, the question should be raised whether my stage-semantics is capable of dealing with the ambiguity between object-related readings and event-related readings. One of the core questions in this respect is how stages should be determined, counted and/or merged for purposes of quantification. In the following subsection, I want to recall the notion of maximality I introduced in Section 4.2.3.3.

\subsubsection{Maximality of stages}

In Section 4.2.3.3., I introduced a notion of maximality. The reason for this step was that without such a notion, we wouldn't have known how to count stages for a sentence like (53), Many students cooked for parties. Since stages can in principle be instantaneous, there would always be many student-stages that cooked for parties, whenever there was a single student that cooked for parties. In order to avoid this problem, I introduced a maximality-requirement as part of the lexical entry of quantifiers. The idea of this step was to quantify over "maximal" stages that satisfy the restriction of the quantifier. The way I wanted this to be understood in Section 4 was to "count" per individual at most one stage, namely the maximal stage, that fulfills the restriction. Since we crucially allowed for merging discontinuous stages within an individual, the maximalityrequirement would force us to merge all discontinuous student-stages of a single individual to the maximal student-stage of that individual. For purposes of quantification, this would thus count as one stage. At the end of Section 4, I 
arrived at truth conditions like (71) and (72) for sentences with quantificational noun phrases, repeated here as (113) and (114).

(113) a. Most students were sick.

b. MOST $_{\mathrm{X} \text {-st }} \mathrm{C}$ [student] [sick]

c. For most maximal stages $\mathrm{x}_{\mathrm{st}}$ such that $\exists y_{\mathrm{st}}, \mathrm{z}_{\mathrm{st}}$ such that $\mathrm{x}_{\mathrm{st}}=\mathrm{y}_{\mathrm{st}} \oplus \mathrm{z}_{\mathrm{st}}$, $\mathrm{x}_{\text {st }}$ has a part $\mathrm{v}_{\text {st }}$, and $\left[[\mathrm{C}]\left(\mathrm{y}_{\mathrm{st}}\right)=1\right.$ and $\left[[\right.$ student $]\left(\mathrm{z}_{\mathrm{st}}\right)=1$, such that $\left[\left[\operatorname{sick} \rrbracket\left(v_{\mathrm{st}}\right)=1\right.\right.$.

(114) a. There were few students sick.

b. $\quad$ FEW $_{\mathrm{X}-\mathrm{st}} \mathrm{C}$ [student \& sick]

c. For few maximal stages $\mathrm{x}_{\mathrm{st}}$ such that $\left[[C]\left(x_{s t}\right)=1\right.$,

$\mathrm{x}_{\mathrm{st}}$ has a part $\mathrm{v}_{\mathrm{st}}$ such that $\left[\left[\right.\right.$ student $\rrbracket\left(\mathrm{v}_{\mathrm{st}}\right)=1$ and $\left[\right.$ sick $\rrbracket\left(\mathrm{v}_{\mathrm{st}}\right)=1$.

Following a suggestion of Kai von Fintel (pc), we may define of maximality of a stage $\alpha_{\text {St }}$ with respect to a predicate $P$ as exploited in this chapter as in (115):

(115) $\alpha_{S t}$ is maximal with respect to a predicate $P$ iff $\mathrm{P}\left(\alpha_{\mathrm{st}}\right) \& \neg \exists \mathrm{y}_{\mathrm{st}}\left(\mathrm{P}\left(\alpha_{\mathrm{st}} \oplus \mathrm{y}_{\mathrm{st}}\right) \& \alpha_{\mathrm{st}} \neq\left(\alpha_{\mathrm{st}} \oplus \mathrm{y}_{\mathrm{st}}\right)\right)$

(115) gives us the desired result, because we assumed that the ontology provides only stage-entities that belong to the same host individual.

Since for our lexical entries to give us the maximal stage per individual of which the restrictor holds, we have to consider not only one predicate, but at least two (one provided by the overt restrictor and one by the resource domain variable), (115) has to be modified as shown in (115').

$\left(115^{\prime}\right) \alpha_{\text {St }}$ is maximal with respect to a restrictor consisting of a resource domain $\mathrm{P}$ and a restrictive predicate $\mathrm{Q}$ iff $\exists v_{\mathrm{st}}, \mathrm{z}_{\mathrm{st}}\left[\alpha_{\mathrm{st}}=\left(\mathrm{v}_{\mathrm{st}} \oplus \mathrm{z}_{\mathrm{St}}\right) \& \mathrm{P}\left(\mathrm{v}_{\mathrm{st}}\right) \& \mathrm{Q}\left(\mathrm{z}_{\mathrm{St}}\right)\right]$

$$
\& \neg \exists y_{s t}\left(\left[P\left(\alpha_{s t} \oplus y_{s t}\right) \vee Q\left(\alpha_{s t} \oplus y_{s t}\right)\right] \& \alpha_{s t} \neq\left(\alpha_{s t} \oplus y_{s t}\right)\right)
$$

The question that must be raised now is whether we really want to count always only one stage that fulfills the restriction per individual. Krifka's sentences suggest that it may be desirable to count at least sometimes different restrictor-stages of a single individual separately where the stages that fulfill the main predicate provide a limiting criterion. Despite Krifka's refutation of Carlson's 
stage-account, I want to investigate here whether my particular stage-semantics can account for the ambiguity between object-related readings and eventreleated readings. In my discussion below, I am basically following an idea of Kai von Fintel (pc).

\subsubsection{How to account for the ambiguity of object-related readings and event-related readings}

Let me summarize the observations we are facing at this point. It is clear that for the purpose of quantification we want to count only one ship-stage for the case of a situation as described and illustrated in (116), where a ship underwent exactly one lock transferral. In the pictures below, lock-transferral stages are marked with bubbles. 43

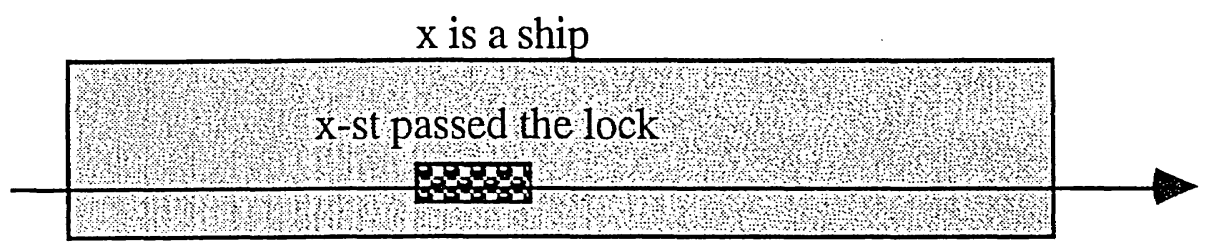

It is also clear that, for the purpose of capturing object-related readings,-we don't want to consider several stages of lock transferrals of a single ship separately. Rather, we just want to look at the ship-individual as a temporal whole and say whether it passed the lock at all. A situation illustrating an object-related reading is shown in (117).

$\mathrm{x}$-st is a ship, $\mathrm{x}$-st has a part $\mathrm{y}$-st that passed through the lock

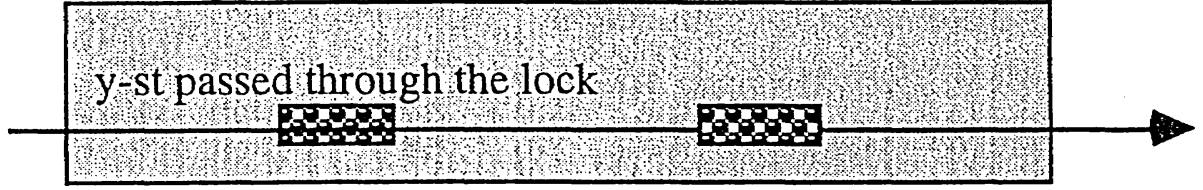

And, finally, the occurrence of event-related readings suggests that we sometimes want to count several stages of lock transferrals of a single ship separately. This is illustrated in (118).

43 I want to point out here that for this observation it is not crucial that to pass the lock is an accomplishment. 
$\mathrm{x}$ is a ship

(118)

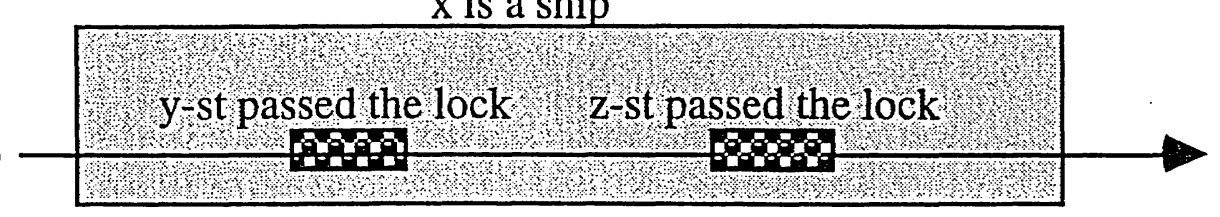

Let us see how we can capture object-related readings and event-related readings. I will exploit here the individual-level noun ship and the locktransferral-sentences that were presented above. Stage-level nouns are expected to behave analogously in all relevant aspects. The basic idea of the account is that the choice of appropriate values for the resource domain variable of the determiner leads either to object-related readings or to event-related readings.

Let us see how the choice of values for the resource domain variable accounts for the readings with restrictive noun phrases. We are considering the sentence Most ships passed through the lock at night. Suppose we take a neutral predicate like "exist" as a value for the resource domain variable of most as in (119). With this choice of value, we quantify over ships in their whole temporal extendedness. Not caring about lock-transferral-stages, we count each ship once and get the object-related reading.

(119) a. Most ships passed through the lock at night.

$=$ more than $50 \%$ of the ships passed through the lock at night

b. For most maximal stages $\mathrm{x}_{\mathrm{st}}$

such that $\exists y_{s t}, z_{\text {st }}$ such that $x_{\text {st }}=y_{s t} \oplus z_{\text {St }}$, and $[$ exist $]\left(y_{s t}\right)=1$

$\mathrm{x}_{\mathrm{St}}$ has a part $\mathrm{v}_{\mathrm{St}}$, and $[[$ ship $]]\left(\mathrm{zst}_{\mathrm{st}}\right)=1$, such that $\left[\right.$ passed through the lock at night $\rrbracket\left(v_{s t}\right)=1$.

The entities counted may look as indicated in the picture (119c). Note that the second lock-transferral-stage of $\mathrm{x}_{\mathrm{St}}$ is simply irrelevant here.

$\mathrm{x}$-st is a ship

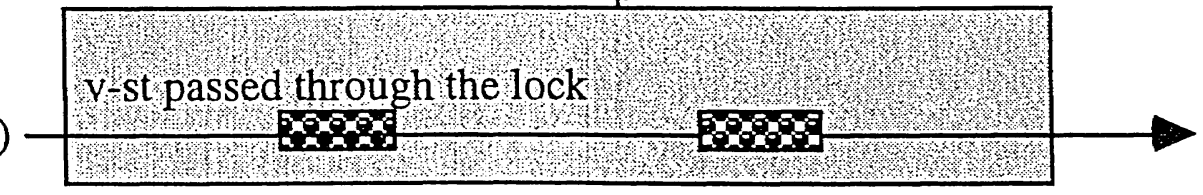


Suppose now we take a different value for the resource domain variable, namely a value like "passed through the lock once".44 With this value, each locktransferral-stage of any ship counts as a stage $y_{\text {st }}$ that is merged with a ship-stage $z_{\text {St. }}$ As a result, we count any ship for each time when it passed through the lock. This gives us the event-related reading. 45

(120) a. Most ships passed through the lock AT NIGHT. = (Krifka's paraphrase) most events of a ship passing through the lock happened at night $=$ (my paraphrase) most ship-stages that passed through the lock once are ship-stages that passed through the lock at night

b. For most maximal stages $\mathrm{x}_{\mathrm{St}}$ such that $\exists y_{s t}, z_{s t}$ such that $x_{s t}=y_{s t} \oplus z_{s t}$, and [[passed through the lock once] $\left(\mathrm{y}_{\mathrm{st}}\right)=1$ $\mathrm{x}_{\mathrm{st}}$ has a part $\mathrm{v}_{\mathrm{st}}$, and $[[$ ship $]]\left(\mathrm{z}_{\mathrm{St}}\right)=1$, such that $\left[\left[\right.\right.$ passed through the lock at night $\rrbracket\left(v_{S t}\right)=1$.

To make the manner of counting clear, it is important to realize that a ship that passed through the lock twice - like the one illustrated in (118) - is counted twice, whereby each time only one of the lock-transferral-stages is relevant. Thus, the two entities that are counted can be illustrated as follows. 46

44 Note that we cannot just take the value "passed through the lock". Since according to my assumptions, stages can merge discontinuously and we quantify over maximal stages that satisfy the restriction, this would give us for each ship one big lock-transferral-stage that contains all smaller lock-transferral-stages of that ship. This would make it impossible to count single lock-transferral-events of ships separately.

45 Recall that Krifka (1990) claimed that with presuppositional noun phrases, the placement of focus on at night is crucial in order to get an event-related reading at all. Actually, I don't see why that is so. Of course, focus structure is well-known to help constructing quantifier domains. But in this particular case I don't see why the reading should be unavailable without focus on at night. Kai von Fintel argues that it might be relevant that the choice of "pass through the lock at night" as a value for the resource domain variable instead of "pass through the lock" leads to a trivial reading.

46 Note that these two entities are not distinguished by standard assumptions of mereology: the sum of an entity $z_{S t}$ and an entity $y_{s t}$ that is part of $z_{S t}$ gives us just $z_{S t}$ again. Thus, the ability to distinguish the two $\mathrm{z}_{\mathrm{st}} \mathrm{t}^{-e n t i t i e s}$ in the picture must come from some other level. Irene Heim (pc) points out that both entities are different situations (cf. Kratzer (1989)). 
(120c)
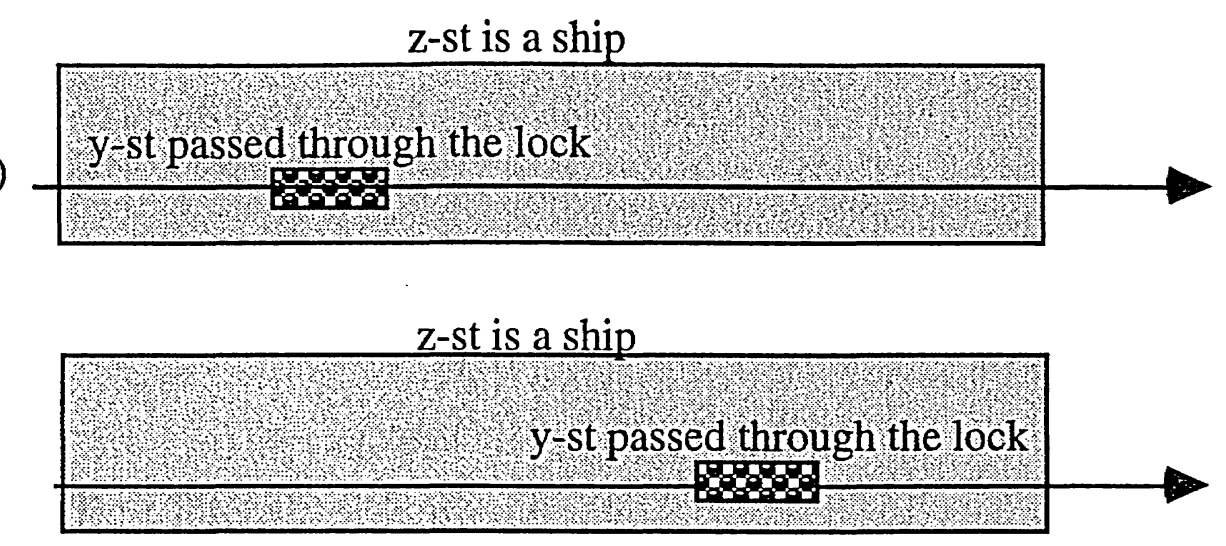

Let us now consider unrestrictive noun phrases. We will see that they differ from restrictive noun phrases in that we quantify over differently looking entities with the two readings. Suppose we take again the value "exist" as a value for the resource domain variable of fourthousand. This results in counting again whole ships only once and yields the object-related reading.

(121) a. Fourthousand ships passed through the lock last year.

b. For fourthousand maximal stages $\mathrm{x}_{\mathrm{St}}$ such that $\left[[\right.$ exist $]\left(\mathrm{x}_{\mathrm{St}}\right)=1$,

$\mathrm{x}_{\text {St }}$ has a part $\mathrm{v}_{\text {st }}$ such that $\left[[\operatorname{ship}]\left(v_{s t}\right)=1\right.$ and [[passed through the lock last year] $]\left(\mathrm{v}_{\mathrm{st}}\right)=1$.

The entities counted in (121b) can be illustrated as in (121c). Since existence determines how entities are counted, the $\mathrm{x}_{\mathrm{St}}$ is counted only once, even if it passed through the lock twice.

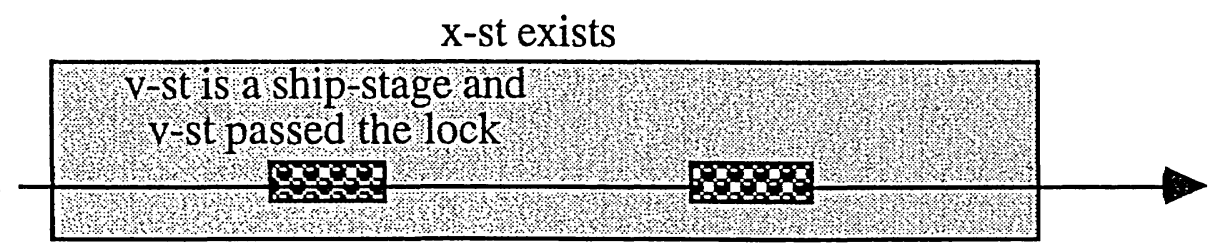

But when we take "passed through the lock last year once" as the value of the resource domain variable, we count stages that passed through the lock last year rather than whole ships. This gives us the event-related reading. 
(122) a. Fourthousand ships passed through the lock last year.

b. For fourthousand maximal stages $\mathrm{x}_{\mathrm{st}}$ such that [lpassed through the lock last year once]] $\left(\mathrm{x}_{\mathrm{St}}\right)=1$, $\mathrm{x}_{\text {st }}$ has a part $\mathrm{v}_{\mathrm{st}}$ such that $[$ ship $]\left(v_{s t}\right)=1$

and [ $[$ passed through the lock last year $]\left(v_{\text {St }}\right)=1$.

Here the illustrating picture looks quite different from the pictures we saw in (119)-(121). The reason for this is that the entities counted are here really determined by the temporal extendedness of the lock-transferral-stages alone. The counted entities we get for a ship that passed through the lock twice last year look as shown in (122c). 47

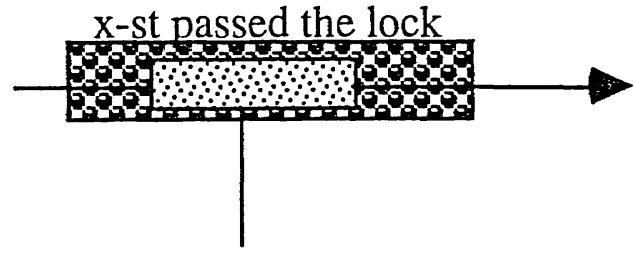

$\mathrm{v}$-st is a ship-stage and passed through the lock last year

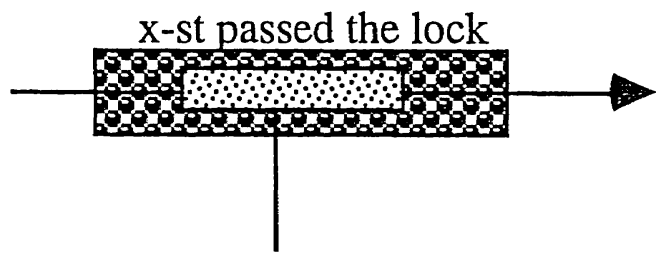

$\mathrm{v}$-st is a ship-stage and passed through the lock last year

For getting the event-related readings, I exploited predicates like "passed through the lock once". Here I want to raise the question of whether there is some additional motivation or some trigger for taking a value like this that narrows the perspective down to stages of single lock-transferral-events. According to what we know about implicit quantifier restrictions, the modification of the resource domain variable is highly dependent on the preceding or surrounding context of the quantification. Thus, we expect that implicit restrictions like "passed through the lock once" are most felicitous in contexts that suggest lock-transferral-events. There seems to be some evidence that this indeed plays a role for the availability of event-related readings. Consider (123). It seems that the change from the definite description the lock to a lock or some lock makes it much harder to get event-related readings for the resulting sentences. This effect is predicted by my approach to the ambiguity. When exploiting the definite description the lock, locks and presumably locktransferrals are familiar in the context. Consequently, reference to single lock-

47 The picture does not really quite show what we quantify over: to make the point clear that the lock-transferral stages $x_{S t}$ are what is counted, I drew them bigger than the $v_{S t}-$ stages. In fact, both have exactly the same size. 
transferral-events for restricting the quantifier is much more felicitous for those sentences than for sentences that introduce locks as unfamiliar in the context.

(123) a. 4000 ships passed through a lock/some lock last year.

b. Most ships passed through a lock/some lock last year.

Moreover, consider again (112a"), repeated here as (124). Krifka argued that the presence of focus plays an important role for the availability of event-related readings.

(124) Most ships passed through the lock AT NIGHT.

A natural explanation of the presence of the focus on at night is that pass through the lock is here destressed because it is familiar from the context. This corresponds nicely to my claim that when we get the most felicitous event-related readings with our ship-sentences, lock-transferral-events are suggested by the context. Thus, the focus on at night is an epiphenomenon of the familiarity of lock-transferral-events.

Thus, my proposal can account for the occurrence of event-related readings as well as object-related readings. Since I did not have to make any additional stipulations but just exploited the mechanisms of resource domain variables which seem to be independently necessary, the account of the ambiguity seems highly desirable. It remains to be shown whether and how this approach can deal with other constructions (cf. Krifka $(1990,507 \mathrm{ff})$ ). Furthermore, it may be interesting to investigate how the occurrence of event-related readings is restricted. For instance, sentence (125), which is due to Kai von Fintel, does not seem to be able to exhibit an event-related reading.

(125) Last semester, most students met with Chomsky.

Sentences like (125) raise the question how the relevant restrictions can be incorporated into my account. 


\subsection{The president of the U.S. and how to merge stages}

\subsubsection{Stages merging across individuals?}

In Section 4.2.1., I proposed that only stages belonging to the same host individual can be merged. Equivalently, one may say that I proposed that any stage has only one host individual. There are data that make it advisable to reconsider this assumption: Carlson $(1977,451-462)$ investigates a certain aspect of the behavior of definite descriptions. He considers sentences like.(126a), which exhibit an ambiguity between readings like (126b) and readings like (126c).

(126) a. The president fears the people.

b. The individial who is the unique contextually relevant president fears the people.

c. Whoever is the president at some time fears the people.

Exploiting his stage-ontology, Carlson illustrates the situation underlying these readings graphically roughly as shown in (127). The letters "a" - "o" are stages of the host individuals Nixon, Ford, and Carter, and the stages connected by lines with "the President" are the stages when they were president. Basically, the idea is that in order to represent reading (126c) adequately, one has to assume the existence of the entity represented as "the President", which at first sight appears to be the result of merging stages that belong to a plurality of host individuals.

host-individual1 host-individual2 host-individual3

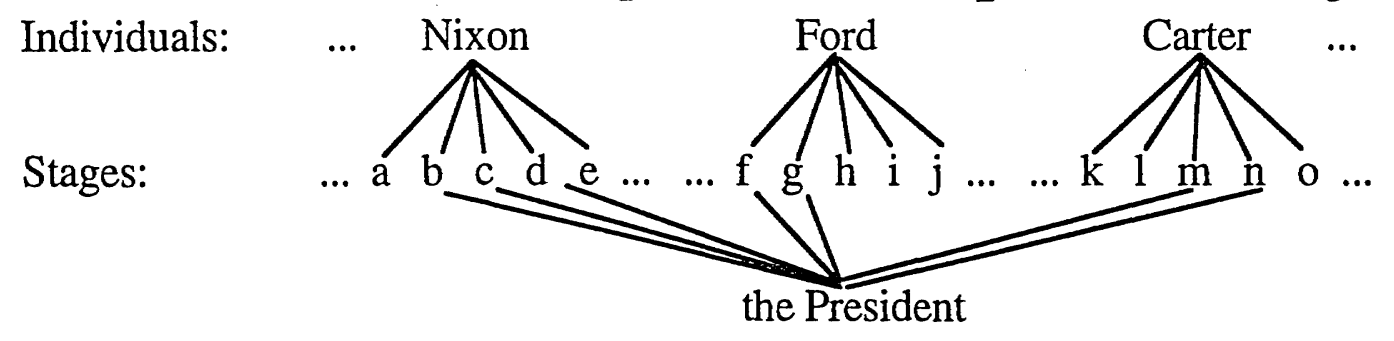

Does this mean that we have to revise the basic assumption that stages belonging to different individuals cannot be merged, i.e. that a stage has only one host individual? 


\subsubsection{Individuals, stages, and kinds}

Carlson doesn't draw this conclusion. Rather, he assumes that the entity represented as "the President" above is not a stage merged of stages of different host individuals, but a KIND. And kinds are a special, primitive, type of entity. If this is so, then the first impression of (127) was just misleading: the entity "the President" is not the result of merging stages; rather, it is an entity that counts as a host individual of stages that happen to be also stages of non-kind individuals like Nixon, Ford, and Carter. Assuming that reading (126c) arises because the president is understood as referring to the kind "the President" makes it possible to avoid having to give up the assumption that every stage has only one host individual, or in Carlson's terms: "the assumption that for every stage there is one and only one object that that stage realizes" (Carlson $(1977,455)$ ).

I will adopt Carlson's proposals that kinds are a special type of entity and that "the President" in the picture above is a kind. Thus, let us tentatively assume that the domain of entities $D_{e}$ consists of elements as indicated in (128): individuals in their whole temporal extendedness, stages of individuals, and kinds.

$$
\begin{aligned}
& {[\text { TO BE REVISED SHORTLY] }} \\
& \mathrm{D}_{\mathrm{e}}=\{\text { Nixon, Ford, Carter, Kaline, ... , Carter-on-March-15-1977, Carter- } \\
& \text { on-June-10-1995, Kaline-on-June-10-1995, ... , the kind "the } \\
&\text { President", the kind cats, ... }\}
\end{aligned}
$$

Assuming that kinds are a special type of entity raises the question what kind of entity they are - i.e., what does belong to a particular kind and what doesn't? I propose the definition (129). As with stages, I will indicate variables ranging over kind-individuals with a subscript "k".

(129) For any predicate $\mathrm{P}$, a kind $\mathrm{x}_{\mathrm{k}}$ is the kind of $\mathrm{Ps}$ if and only if $\mathrm{x}_{\mathrm{k}}$ is the sum of all stages $\mathrm{x}_{\mathrm{St}}$ such that $\left.[\mathrm{P}]\right]\left(\mathrm{x}_{\mathrm{St}}\right)=1.48$

48 This definition is built on the assumption that in principle every noun can be used as a kind-noun. I believe that this is indeed what is needed. There is certainly a preference for kind readings with nouns that denote natural kinds; in these cases the idea of having kindentities is spontaneously more accessible. I think that is depends on the context how easily kind-readings are accessible for other nouns - or noun phrases. The following example, which is due to Kai von Fintel, shows that even a noun phrase like Annegretes Auto ('Annegrete' car') can be used as referring to the kind of Annegrete's cars: Annegrete's Auto wird auch immer größer. 
According to definition (129), the kind the President is the sum of all stages $\mathrm{x}_{\mathrm{St}}$ such that [ $\left[\right.$ president $\rrbracket\left(\mathrm{x}_{\mathrm{St}}\right)=1$.

Note that (129) is only supposed to characterize what is contained in a kind, but it does not necessarily have any linguistic implications. That taking the sumcharacter of a kind linguistically too seriously may have undesirable consequences is shown in Krifka et al. $(1992,56)$. There it is pointed out that although it may be true that the collection of all the existing rabbits has a weight of more than 10,000 tons, a sentence like (130) is quite strange.

(130) The rabbit has a weight of more than 10,000 tons.

\subsubsection{On the behavior of kind-nouns}

It is important to note that just as we can distinguish between INDIVIDUALS in their whole temporal extendedness and STAGES OF INDIVIDUALS, we can also distinguish between KINDS in their whole temporal extendedness and STAGES OF KINDS.

$$
\begin{aligned}
\mathrm{D}_{\mathrm{e}}= & \{\text { Nixon, Ford, Carter, Kaline, ..., Carter-on-March-15-1977, Carter- } \\
& \text { on-June-10-1995, Kaline-on-June-10-1995, ... the kind "the } \\
& \text { President", the kind cats, ... , the-kind-"the President"-in-this- } \\
& \text { century, the-kind-cats-last-week, ... }\}
\end{aligned}
$$

Kinds can have a very different outer appearance, as far as their correspondence to stages and individuals in reality is concerned. Thus, the kind of cats in its whole temporal extendedness can be split up into cat-individuals in their whole temporal extendedness as well as into cat-stages. But there is no way to split up the kind of students or the kind the President systematically into individuals in their whole temporal extendedness. This is because student and president are stage-level nouns; consequently the host individuals of studentstages and president-stages contain many non-student-stages and non-presidentstages, respectively.

The possibilities to split up kinds into entities of a different level have consequences for the behavior of noun phrases in various contexts and for their ability to co-occur with predicates.

One of the predictions I am making is that for a definite kind-noun-phrase like the President it is not possible to get temporally independent interpretations that 
pick up non-president-stages of individuals that have president-stages. It seems to me that this prediction is borne out. Thus, for (132), it seems to be impossible to get the reading indicated.

(132) The President was often a boring child.

$\neq$ The kind the President is such that many of the individuals that it consists of are such that they have stages where they were boring children.

If the kind President consisted of individuals in their whole temporal extendedness that happened to be president at some time of their life, the reading should be possible. But if the kind President consists only of president-stages of individuals - i.e. stages like the ones marked by bubbles in (133) - then the lack of the reading in (132) is predicted.

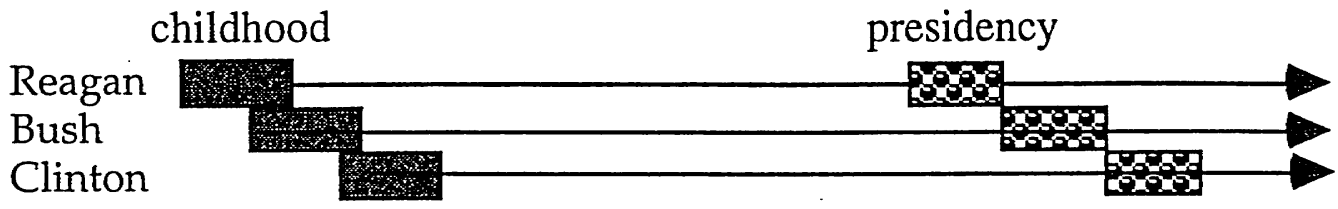

The only reading that seems to me to be available for (132) is the one where many presidents were kids while being presidents. 49

49 Enç $(1981,175 f)$ assumes that such noun phrases can have a temporally independent reading. Thus, she suggests two possible readings for the sentence The president marries an influential woman in order to get elected to his first term.. Judgements of informants are - as usual - not entirely clear but show a clear tendency towards my judgements: of 26 judgements I got about my and Enç's example, 16 declare the independent reading to be completely impossible, 3 judge it as available, and 5 as available with varying degrees of difficulties (and sometimes slight changes of the sentences). 
"She planned to leave the same way. Butplans are one thing and fate another. When they coincide, sucoess results. Yet success mustn' tbe considered the absolute. It is questionable, for that matter, whether success is an adequate response to life. Success can eliminate as many options as failure."

-TomRobbins, Even Cowgins get the Blues -

\section{CHAPTER IV.}

\section{ON TEMPORAL NP-MODIFIERS AND UPPER LIMIT EFFECTS}

\section{Introduction}

\subsection{Preliminaries on temporal NP-modifiers}

DPs can contain various kinds of expressions that function semantically as temporal modifiers of the noun. Here are some examples:

(1) a. clausal modifiers: [The war when my grandfather was young] lasted four years.

b. genitive modifiers: [The sixties' rebels] are quite established today.

c. adverbial modifiers: [The quarrel yesterday] was totally superfluous.

d. adjectival modifiers: [The present wife of Klaus] is [a former student of his].

e. prepositional modifiers: [The chancellor in 1989] made some serious mistakes.

In this chapter, I will focus solely on prepositional phrases as in (1e). Relying on the commonly accepted assumption that in V2-constructions in German only one 
constituent can stand in the position before the finite verb, we can conclude that in the following sentences the PPs am Donnerstag ('on Thursday') and am Freitag ('on Friday') are indeed part of the DP.
a. [Den Vortrag am Donnerstag] hat Viviane gehalten. the talk on-the Thursday has Viviane hold
('Viviane gave [the talk on Thursday].' or, to make the structure clearer: 'The talk on Thursday was given by Viviane.')
b. [Die Vortragende am Donnerstag] war Viviane. the speaker on-the Thursday was Viviane ('The speaker on Thursday was Viviane.')
c. [Den Spinatsalat am Freitag] hat Colin zubereitet. the spinach-salad on-the Friday has Colin prepared
('Colin prepared [the spinach salad on Friday].' or 'The spinach salad on Friday was prepared by Colin.')

It is important to note that in addition to the syntactic evidence provided by V2constructions, there is also semantic evidence that DP-internal modifiers as illustrated in (1) and (2) are NP-modifiers and not modifiers of the main predicate of their clause. This can be shown with sentence (2c) for instance. Sentence (2c) can easily be understood as meaning something like "Colin prepared the spinach salad that was present at the party on Friday" or "Colin prepared the spinach salad we ate on Friday". Whereas the spinach salad must have been present on Friday, its preparation need not have taken place on Friday - Colin may have prepared it on Thursday. This shows clearly that on Friday modifies the NP but not the main predicate of the clause.

Temporal modifiers can modify nouns denoting temporary properties as well as nouns denoting life-time properties. The former type of predicate corresponds intutively to the class of stage-level predicates, whereas the latter type of predicate corresponds intutitively to the class of individual-level predicates as described by Kratzer (1988). But since I will make reference to the classes of predicates in this chapter with regard to nouns and moreover in a non-technical sense - i.e., disregarding grammatical differences attributed to the difference between stage-level predicates and individual-level predicates (Kratzer (1988)), I will also use the terms TEMPORARY-PROPERTY NOUN and LIFE-TIMEPROPERTY NOUN: If a nominal predicate holds of an individual during all its life or time of existence, then I classify it as a temporary-property noun. For example, an individual that is once a spinach salad is always a spinach salad until it ceases to exist, i.e., in this case, until it's eaten; thus spinach salad is classified as a life- 
time predicate. But an individual that is once a speaker is typically not a speaker during all his or her life, thus speaker is classified as a temporary property. Since the temporal modifier in $(2 \mathrm{~b})$ modifies a temporary-property noun and the one in (2c) modifies a life-time-property noun, the acceptability of temporal modifiers cannot in principle depend on whether the head noun is a stage-level or individual-level predicate. But there is a difference between temporary-property nouns and life-time-property nouns that concerns the way in which the temporal modifier is interpreted. The temporal modifier in (2b) locates the being a speaker temporally, but the modifier in (2c) does not locate the being a spinach salad temporally. Rather, it needs some kind of contextual specification in order to make the sentence perfectly acceptable and perfectly interpretable - in the suggested readings for example (2c), the contextual specifications are the being present on Friday or the being eaten on Friday.

The modification of an NP by a temporal modifier leaves space for a certain degree of semantic variability when the modifier does not locate the situation (or event) argument of the noun. In the case of such a semantic-variabilityinterpretation, the modifier relates the individual referred to by the NP to a temporal location. The specific relation between the individual and the location is contextually determined. For (2c) the relation can be " $x$ be present at $t$ " or " $x$ be eaten at $t^{\prime \prime}$ or, depending on the context, something else. Such a semanticvariability-interpretation is in general the only possibility of interpretation for a temporal modifier when the noun is an individual-level predicate. 1

1 The property of being interpreted by the addition of contextually determined relations in dependency of the lexically given argument structure is by no means a special characteristic of temporal modifier constructions. In fact, there are many constructions in natural language whose compositional interpretation involves systematically a contextually specified relation that leads to a significant degree of semantic variability: For instance, Partee (1984) and Barker (1991) argued that genitive or possessive modifiers are often interpreted by the addition of a contextually specified relation. This is illustrated in $(\mathrm{Ab})$. (Aa), which contains the inherently relational noun brother, does not show the degree of semantic variability that arises with $(\mathrm{Ab})$.

(A) a. John's brother

strongly preferred meaning: "the individual $\mathrm{x}$, such that $\mathrm{x}$ is the brother of John"

b. John's team

possible meanings, depending on the context: "the team John is leading", "the team John is a fan of", "the team in which John plays or works"

The semantic variability in (Ab) can be analyzed in terms of Partee's (1984) proposal concerning the interpretation of genitive or possessive constructions: Partee suggests that it can be accounted for by giving John's team a semantic representation the $e_{x}$ [team $(x) \& R$ $(J o h n, x)]$ where $\mathrm{R}$ is a contextually or pragmatically determined relation. What the 


\subsection{In-modifiers and of-modifiers}

There are two types of PPs that can appear as temporal modifiers in DPs. Because of the prepositions they are most typically headed by in English, I call them $I N$ MODIFIERS and $O F$-MODIFIERS. I will show shortly that they differ crucially with respect to their semantic behavior. (3) shows some examples of both types.
a. in-modifiers:
lottery winners in the forties speakers on Sunday
b. of-modifiers: lottery winners of the forties professors from the forties

Thus, in-modifiers are headed by in or on in English; in German, prepositions heading in-modifiers are in and an. Of-modifiers are headed by of or from in English, and by von or aus in German.

In contrast to of-modifiers, in-modifiers have inclusive meanings. Thus, whereas from Sunday establishes a relation between Sunday and some other time, on Sunday locates something within Sunday. Note that because of their

relation $\mathrm{R}$ is can be pragmatically determined and can often not possibly be detected without precise knowledge of the context of utterance.

Stump (1984) suggested a similar analysis involving additional contextually determined relations for the semantic variability of certain free adjunct constructions (B) and also with absolute constructions (see, for example, pp325ff).

(B) Being a sailor, John sometimes smokes a pipe.

possible meanings, depending on the context: "John sometimes smokes a pipe, because he is a sailor", "John sometimes smokes a pipe, although he is a sailor"

Also compounds are notorious for the vaguely pragmatically restricted freedom of interpretation (cf. Fanselow (1981) e.a.). A beautiful example for the wide range of possible interpretations of compounds is provided by the expression Kaffeestrasse ('coffee-road') (C). What might a "Kaffeestrasse" be? One might think at first of a road that was traditionally used for transporting coffee - analogously to the so-called "Seidenstrasse" ('silk-road') in Asia. In a fairy-tale, it might be a street built of coffee -

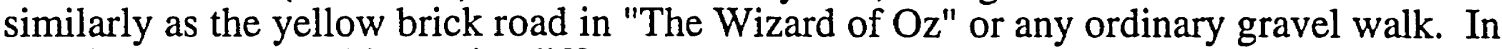
fact, it can be something quite different: Once when driving in a car with my parents, my mother offered me a cup of coffee. Unfortunately, the field-path on which we were driving made it quite impossible to drink without spilling the coffee. Reacting to my swearing, my mother gave me the advice: "Warte doch, bis eine Kaffeestrasse kommt!" ('Wait until we are driving on a coffee-street!') - In this situation, Kaffeestrasse means obviously something like "street that is appropriate for drinking coffee while driving on it". Of course, this meaning would not at all be detectable without my description of the context.

(C) Kaffeestrasse ('coffee-street')

possible meanings, depending on the context: "street that is traditionally used for transporting coffee", "street that is built of coffee", "street that is appropriate for drinking coffee while driving on it" 
inclusive meaning, in-modifiers can, if standing in another syntactic configuration, function as VP-modifiers. Thus, (4c) is grammatical, but (4d) is ungrammatical.

(4) a. [Most professors in the sixties] played badminton.

b. [Most professors from the sixties] played badminton.

c. Most professors played badminton in the sixties.

d. * Most professors played badminton from the sixties.

The aim of this chapter is to explain some observations concerning the distribution of these modifiers and their ability to affect the temporal interpretation of the rest of the clause:

First, in-modifiers are only fully acceptable when modifying restrictive noun phrases, but unacceptable when modifying unrestrictive noun phrases. As an initial illustration, compare (5a) and (5b). The host noun phrase of the modifier in (5a) can be restrictive, the one in (5b) is obligatorily unrestrictive. (5a) is acceptable, but $(5 b)$ is unacceptable.

(5) a. Many students in the sixties were rebellious then.

b. *? There were [many students in the sixties] rebellious then.

Second, in-modifiers cause incompatibilities with tenses whose exact nature will be made precise below. (6) is again just a first illustration of the effect: (6a) is a past tense clause, whereas (6b) is a present tense clause. Since the difference in tense is the only significant difference between (6a) and (6b), the contrast in acceptability between (6a) and (6b) is most likely caused by the difference in tense.

(6) a. [Most students in the sixties] were rebellious then.

b. * [Most students in the sixties] are established professionals today.

Third, of-modifiers exhibit neither of the aforementioned properties. This is shown in (5b') and $\left(6 b^{\prime}\right)$. These examples differ from the corresponding data (5b) and (6b) in that the in-modifiers are here replaced by of-modifiers. The resulting sentences are acceptable.

$\left(5 b^{\prime}\right)$ There were [many students from the sixties] happy then.

(6b') [Most students from/of the sixties] are established professionals today. 
The aim of this chapter is to account for the restricted distribution of inmodifiers and their effect on the tense of their clause. My claim will be that it is not a coincidence that the restricted distribution and the effects on tense cooccur with in-modifiers. Thus, I will derive both effects from some deeper property of in-modifiers that is not shared by of-modifiers. I will assume that inmodifiers differ from of-modifiers in that they are inherently restrictive - in the sense that they want to restrict a quantifier. Although it is not yet clear to me why in-modifiers have this property, I will exploit this assumption because it can explain the behavior of in-modifiers. The chapter proceeds as follows:

In Section 2, I will provide more evidence supporting the generalization that in-modifiers need to be part of a restrictive noun phrase, whereas the unrestrictive/restrictive distinction does not matter for the acceptability of ofmodifiers. In Section 3, I will establish the assumption that in-modifiers are obligatory restrictors of quantifiers and I will derive their distributional restrictedness from this property. Section 4 serves to give a thorough description of the effects in-modifiers have on tenses. Section 5 aims at providing an explanation of why in-modifiers affect the tense of their clause. Section 6 finally is a conclusion and summary of the results achieved in the chapter and raises some further questions.

\section{On the distribution of in-modifiers: unrestrictive and restrictive DPs}

The purpose of this section is to provide extensive evidence supporting the generalization that the distribution of in-modifiers correlates with the distinction between unrestrictive and restrictive noun phrases, i.e. that in-modifiers are acceptable with restrictive noun phrases, but not (or hardly) with unrestrictive 
noun phrases. As I mentioned in Section 1, this generalization does not hold for of-modifiers. The evidence for these claims is presented in (7)-(11).2, 3

Restrictive noun phrases are partitive DPs, DPs with strong determiners (e.g., most, all, every), DPs with weak determiners (e.g., some, few, many...) that are stressed on the determiner, and generic bare plural noun phrases. Unrestrictive noun phrases are DPs with weak determiners in certain syntactic positions (e.g., in there-constructions), DPs with weak determiners that are stressed on the noun, and existential bare plural noun phrases (cf. Milsark (1974), Diesing (1992), and others).

First, the data in (7) involve again in-modifiers in there-constructions and contrasting sentences. DPs occurring in a there-construction are commonly assumed to be unrestrictive or cardinal. The modified DPs in (7a, b) and (7d, e) occur in there-constructions and can consequently be classified as unrestrictive DPs. But whereas the DPs in (7a,d) contain in-modifiers and are unacceptable, the DPs in $(7 b, e)$ contain of-modifiers and are acceptable. Moreover, $(7 \mathrm{c}, \mathrm{f})$ contain the same DPs as $(7 a, d)$ - but here they stand in a position where they are not obligatorily cardinal but can be strong or restrictive. In such a position, they are acceptable.

a. *? There were [many speakers on Sunday] in the department then.

b. There were [many speakers from Sunday] in the department then.

c. [Many speakers on Sunday] were in the department then.

d. *? There were [many students in the sixties] living in Cambridge then.

e. There were [many students of the sixties] living in Cambridge then.

f. [Many students in the sixties] were living in Cambridge then.

Thus, the data in (7) confirm both the generalization that in-modifiers are acceptable as part of restrictive DPs, but not as part of unrestrictive DPs, and the generalization that of-modifiers don't show this distributional restrictedness.

Second, the sentences in (8) involve the German ja-doch-construction. The particle $j a$ doch (following a suggestion of Diesing translated as 'indeed') has

2 Note that the specific constructions used below make sure that the in-modifiers are indeed syntactically part of the DP. In (7) and (8), this is for instance achieved by the presence of damals ('then'), in other examples by the preverbal position of the DP or by word order regularities. In all the data used in this chapter, one device or other makes sure that the inmodifiers are syntactically part of the DP with which they occur.

3 All judgements used below are confirmed by other speakers. Apparently not all speakers are sensitive to all contrasts illustrated in the various constructions below. But since ALL speakers get the relevant contrast at least with some constructions, I consider the generalization sufficiently justified. 
been claimed to mark roughly the left edge of the VP and thus, the areas in a clause where either generic, i.e. restrictive, or existential, i.e. unrestrictive, readings of bare plurals are preferredly triggered (cf. Diesing (1992)). In (8), the position of the host noun phrase of the modifier in den siebziger Jahren ('in the seventies') varies with respect to the particle ja doch. When an indefinite subject of a stagelevel predicate occurs to the left of the particle ja doch, the restrictive reading of the indefinite is usually strongly preferred. When it occurs to the right of the particle, usually the unrestrictive reading of the indefinite is strongly preferred. In (8a), the noun phrase appears to the left of $j a$ doch and is thus preferredly restrictive. In (8b) and (8c), it appears to the right of $j a$ doch and is thus preferredly unrestrictive. (8b) and (8c) differ insofar as the noun phrase in (8c) is modified by an in-modifier, whereas the one in ( $8 b)$ isn't. Whereas (8a) and (8b) are acceptable, (8c) is unacceptable. (8d) illustrates that of-modifiers - in contrast to in-modifiers - don't care at all about the restrictiveness of their host noun phrase: (8d) is fine in contrast to (8c), although the noun phrase ein paar Studenten aus den sechziger Jahren is preferredly unrestrictive in (8d).

a. (weil) [Feuerwehrleute in den siebziger Jahren] damals (since)firemen in the seventies then ja doch verfügbar waren indeed available were [RESTRICTIVE reading] ('since firemen in the seventies were available then')

b. (weil) ja doch [Feuerwehrleute] damals verfügbar waren (since) indeed firemen then available were

('since firemen in the seventies were available then')

c.* (weil) ja doch [Feuerwehrleute in den siebziger Jahren] (since) indeed firemen in the seventies damals verfügbar waren then available were [UNRESTRICTIVE reading] ('since firemen in the seventies were available then')

d. (weil) ja doch [Feuerwehrleute aus den siebziger Jahren] (since) indeed firemen damals verfügbar waren from the seventies then available were [UNRESTRICTIVE reading] ('since firemen from the seventies were available then')

Thus, the generalizations formulated above are also supported by the behavior of in-modifiers and of-modifiers in ja-doch-constructions. 
Third, the construction in (9) exploits the fact that DPs used as predicate nominals are obligatorily unrestrictive. The fact that $(9 a)$ is unacceptable confirms again that there is an incompatibility of in-modifiers with unrestrictive noun phrases. And the fact that (9b) is acceptable illustrates that this incompatibility does not show up with the temporal modifier aus den vierziger Jahren. 4

(9) a. * Hans war [ein Professor in den vierziger Jahren]. Hans was a professor in the forties ('Hans was a professor in the forties.')

b. Hans war [ein Professor aus den vierziger Jahren]. Hans was a professor from the forties ('Hans was a professor from the forties.')

Fourth, informants' judgements lead to the conclusion that there is also a contrast in (10) which corresponds to the distribution of restrictive and unrestrictive readings of the DP: Definite DPs are restrictive and can easily host the temporal modifier. Indefinite DPs are restrictive when their determiner is stressed, and unrestrictive when it is not stressed. That (10e-f) are less acceptable than $(10 \mathrm{a}-\mathrm{d})$ correlates with the fact that (10e-f) are constructed with unrestrictive noun phrases and (10a-d) with restrictive noun phrases. Also, (10a-c) contrast with $(10 \mathrm{~g}-\mathrm{i})$; here we do not find a difference in acceptability varying with restrictiveity of the host DP. Again, the only difference between the sentences is the choice of preposition; $(10 \mathrm{a}-\mathrm{c})$ contain am, whereas $(10 \mathrm{~g}-\mathrm{i})$ contain vom.

(10)a. [Die Vorlesung am Montag] war furchtbar langweilig.

the lecture on Monday was awfully boring

('The lecture on Monday was terribly boring')

b. [about a certain bookstore:]

[Der Besitzer in den siebziger Jahren] war immer nett, wenn man komische Bücher the owner in the seventies was always nice when one strange books bestellen wollte.

order wanted

('The owner in the seventies was always nice when someone wanted to order strange books.')

c. [EINE Vorlesung am Montag] war furchtbar langweilig.

a lecture on Monday was awfully boring

('A lecture on Monday was terribly boring')

4 Note that in the German sentence (a) the temporal modifier can hardly be a temporal adverbial because of its sentence final position, whereas it can in the corresponding English sentence Hans was a professor in the forties. 
d. [EIN Besitzer in den siebziger Jahren] war immer nett, wenn man komische an owner in the seventies was always nice when one strange books bestellen wollte.

books order wanted

('An owner in the seventies was always nice when someone wanted to order strange books.')

e. ? [Eine VORlesung am Montag] war furchtbar langweilig. a lecture on Monday was awfully boring

('A lecture on Monday was terribly boring')

f. ? [Ein BeSITzer in den siebziger Jahren] war immer nett, wenn man komische an owner in the seventies was always nice when one strange books bestellen wollte.

books order wanted ('An owner in the seventies was always nice when someone wanted to order strange books.')

g. [Der Redner vom letzten Sonntag] war erkältet. the speaker of last Sunday was having-a-cold ('Last Sunday's speaker had a cold')

h. [EIN Redner vom letzten Sonntag] war erkältet. a speaker of last Sunday was having-a-cold ('A speaker of last Sunday had a cold.')

i. [Ein REDner vom letzten Sonntag] war erkältet. a speaker of last Sunday was having-a-cold ('A speaker of last Sunday had a cold.')

Fifth, (11) illustrates an interesting related observation. Note that, in a world where Martians do not exist, (11b) and (11d) are judged false, whereas (11a) and (11c) seem to be cases of presupposition failure, because an existence presupposition is not met. Thus, locative in seems to trigger an existence presupposition.

(11) a. Die meisten Marsmenschen sind auf der Terrasse. most Martians are on the porch

('Most Martians are on the porch.')

b. Viele Marsmenschen sind auf der Terrasse. many Martians are on the porch ('Many Martians are on the porch.')

c. [Viele Marsmenschen in meinem Garten] haben weiße Ohren. many Martians in my garden have white ears ('Many Martians in my garden have white ears.')

d. [Viele Marsmenschen mit weissen Ohren] sind in meinem Garten. many Martians with white ears are in my garden ('Many Martians with white ears are in my garden.')

To summarize, in-modifiers cannot, or not easily, occur within unrestrictive noun phrases, but only within restrictive noun phrases. This generalization does not hold for of-modifiers. The observations made so far in this chapter raise the 
questions why in-modifiers and of-modifiers differ in this striking way and how the distributional constraints on in-modifiers can be captured. The next section starts a discussion of these issues.

\section{In-modifiers as obligatory restrictors}

\subsection{The restricted distribution of $i n$-modifiers}

In this section, I will establish the claim that in-modifiers differ from of-quantifiers in that they are inherent restrictors of quantifiers. I will argue that their specific distribution, i.e. their inability to occur as part of an unrestrictive noun phrase, can be explained as a consequence of this property.

Recall my analysis of unrestrictive and restrictive noun phrase which I presented in Chapter III. According to my proposal, all determiners - i.e., weak ones as well as strong ones - are raised at LF and all determiners are associated with a resource domain variable $C$, which can get a value supplied by the context. Unrestrictive DPs and restrictive DPs differ with respect to the presence of the restrictive clause: restrictive DPs have a restrictive clause at LF, whereas unrestrictive ones don't. Accordingly, nouns are interpreted differently depending on whether they occur in an unrestrictive or in a restrictive DP. A noun that occurs as the complement of a restrictive DP is raised into the restrictive clause, whereas a noun that occurs as the complement of an unrestrictive DP remains in the nuclear scope. Thus, we have two types of LFs for determinerquantifiers, (12) and (13). (12) is the quantificational structure of an unrestrictive noun phrase, whereas (13) is the quantificational structure of a restrictive noun phrase. In the former case, the common noun phrase is part of the nuclear scope of the determiner-quantifier. In the latter case, it is part of the restrictive clause of the determiner-quantifier.

(13) restrictive noun phrase:

$$
\begin{aligned}
& \operatorname{DET} C[\mathrm{NS} \ldots \mathrm{NP} . . .] \\
& \operatorname{DET} \mathrm{C}[\mathrm{RC} \ldots \mathrm{NP} \ldots .] \text { [NS ... ] }
\end{aligned}
$$

Moreover, I argued that the resource domain variable of any determiner is restrictively interpreted. Thus, according to this proposal, all DPs provide at LF a 
nuclear scope as well as restrictively interpreted material. With restrictive DPs, the restrictively interpreted material consists of the resource domain variable and the overt restrictive clause, whereas with unrestrictive DPs, it consists only of the resource domain variable. I will refer below to the restrictively interpreted material of a quantifier as its restrictive area.

Since in-modifiers are syntactically part of their host-NP and semantically a modifier of the noun, they appear at LF wherever the NP ends up. If the NP appears in the nuclear scope of a determiner because it is the complement of an unrestrictive DP, then the in-modifier will also appear as part of the nuclear scope (14). And if the NP appears in the restrictive clause because it happens to be the complement of a restrictive DP, then the in-modifier will also appear as part of the restrictive clause (15).

unrestrictive noun phrase:

restrictive noun phrase:
* DET C [NS ... [NP N PP]... ]

DET C [RC ... [NP N PP]... ] [NS ... ]

Now if being an inherent restrictor meant for in-modifiers just that they need to occur as part of the restrictive area of some quantifier, we would be all set at this point and have an explanation for why in-modifiers are unacceptable when contained in unrestrictive noun phrases: according to my argument above, inmodifiers contained in an unrestrictive noun phrase would not be able to appear as part of the restrictive area, because they have to stay with the NP they modify in the nuclear scope, resulting in a structure like (14). But if in-modifiers are of an inherently restrictive nature in the sense that they want to occur as part of the restrictive area of a quantifier, then a structure like (14) would conflict with the requirement of the in-modifier to appear in the restrictive clause. Consequently, a structure like (14)' could not be acceptable. But if a restrictive noun phrase contains an in-modifier, then the requirement of the in-modifier at LF would be fulfilled (15).

Unfortunately, it seems that things are not quite that simple; exploiting a typology of restrictors suggested by von Fintel (1994, 33f and 77), it seems likely that in-modifiers are a type of restrictor that doesn't make it possible to make use of the simple account I sketched in the preceding paragraph. According to von Fintel, there are three ways in which particular expressions may serve (obligatorily or optionally) as restrictors of quantifiers. 
First, expressions may be syntactic restrictor arguments of quantifiers and thus be syntactically required to be present, like nouns for restrictive determinerquantifiers,

Second, expressions may be restrictors that affect quantifiers indirectly because they affect the context directly and thus can influence which value the hidden resource domain variable gets assigned by the context. Von Fintel treats the interactions of topic-focus-structure and presuppositions with quantification as processes of restriction of this type: Since topic-focus-structure or presuppositions impose requirements on what an appropriate context for an utterance is, it often seems that they supply the functions that modify the resource domain variable directly. Von Fintel argues that they can do this indirectly by imposing requirements on the context.

Third, expressions may be restrictors that constrain a quantifier via a hidden resource domain variable without being a syntactic argument of the quantifier Von Fintel argues that this may be the correct analysis of conditional clauses.

Given this typology, which type of restrictors do inmodifiers belong to? It is clear that in-modifiers can't be syntactic restrictor arguments of quantifiers, for their presence is not at all required by the presence of a determiner-quantifier. Thus, the first of the three possibilities can be immediately excluded. Is one of the other two possibilities able to give us an adequate account of the behavior of inmodifiers?

Suppose in-modifiers were expressions that affect the context directly and thus influence which value the resource domain variable gets assigned by the context. 'Why then should it be the case that in-modifiers want to be part of the restrictive clause at LF and are unacceptable if they are bound to occur in the nuclear scope? This would remain a complete mystery, for if in-modifiers affected the resource domain variable indirectly by affecting the context directly, there would be no (obvious) motivation for why in-modifiers have to be in a special structural position at LF in order to perform the function of affecting the context.

Thus, we are left with the third possibility, according to which in-modifiers are obligatory modifiers of resource domain variables - as perhaps conditional clauses are. I will assume that this is the adequate analysis of $i n$-modifiers.

But this step raises obvious further questions. Since according to my proposal, unrestrictive as well as restrictive noun phrases provide a resource domain variable, we must crucially assume that items in the restrictive clause can 
perform the function of being obligatory modifiers of resource domain variables, but that items in the nuclear scope can't. Why should this be the case?

I will assume that in-modifiers are obligatory modifiers of resource domain variables and that their modification of the resource domain variable presupposes that the in-modifier is copied to the resource domain variable at LF. Thus, given that the resource domain variables and the overt restrictive material are intersectively interpreted, as suggested in von Fintel (1994) and shown in (16),

$$
[\mathrm{Q} \mathrm{Q}](\mathrm{A}, \mathrm{B})=[[\mathrm{Q}]](\mathrm{C} \cap \mathrm{A}, \mathrm{B})
$$

and given that noun and in-modifier are also intersectively interpreted, we predict that a sentence like Most students in the sixties were rebellious has roughly the truth conditions in (17). 5

[[ Most students in the sixties were rebellious ]] $=1$

iff $\left[\left[\right.\right.$ most $\left.\left._{C}\right]\right]$ ([[ students in the sixties $\left.]\right]$ ) ([[ were rebellious $\left.\left.]\right]\right)=1$

iff [by copying of the in-modifier to the resource domain variable]

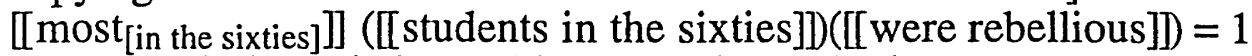

iff for most $\mathrm{x}$ such that $\mathrm{x}$ is located in the sixties and $\mathrm{x}$ is a student and $\mathrm{x}$ is located in the sixties, $\mathrm{x}$ was rebellious.

In order to account for the fact that in-modifiers can't perform their function of modifying the resource domain variable when being part of the nuclear scope, but only when they are part of the restrictive clause, I will assume henceforth that copying of material can happen within the restrictive area, but not across the boundary between the nuclear scope and the restrictive clause. 6 In the structures

5 For ease of presentation, I am disregarding here the stage-semantics I suggested in Chapter III as well as details of temporal interpretation. See Section 7 for a more detailed semantics.

6 Kai von Fintel (pc) drew my attention to the fact that in this respect, copying of material differs crucially from movement of material. Thus, Diesing (1992) argued for LFscrambling of certain object noun phrases from the nuclear scope into the restrictive clause. Moreover, the process of presupposition accommodation from the nuclear scope into the restrictive clause as exploited in Berman (1989) works differently - if it exists at all (According to Berman, presuppositions of the material in the nuclear scope of a quantificational structure are accommodated into the restrictive clause.). However, von Fintel $(1994,66 \mathrm{ff})$ argues at length, and convincingly, against Berman's proposal. With an alternative approach as suggested in von Fintel (1994), where apparent presupposition accommodation is captured as a case of discourse anaphora, these cases do not pose any questions or problems for my constraint on copying of material from the nuclear scope into the restrictive area. 
below, the copying of in-modifiers to resource domain variables will be indicated by coindexing the modifier and the resource domain variable.

Thus, the following picture emerges. Suppose an in-modifier occurs as part of an unrestrictive noun phrase. The unrestrictive NP stays in the nuclear scope of the determiner at LF. Since the in-modifier is a modifier of the NP, it has to stay at LF in the same area as the NP. But when it remains in the nuclear scope, it can't be copied across the boundary of the nuclear scope to the resource domain variable, as indicated by the index $i$ in (18a). Consequently a structure like (18a) can't occur. But if that is so, then the in-modifier cannot function as it wants to namely, it can't modify the resource domain variable of the determiner. As a consequence of this, structures with an in-modifier as part of an unrestrictive noun phrase are not well-formed. But with restrictive noun phrases, the inmodifier can be together with its NP in the restrictive clause. Thus, the copying indicated by the index $i$ in (18b) is possible, and the structure is well-formed.

(18) a. unrestrictive noun phrase:

* many $\left[\mathrm{C}_{\mathrm{i}}\right] \quad[\mathrm{NS} \ldots[\mathrm{NP} \mathrm{N} \mathrm{PP}$ ] $\ldots]$

b. restrictive noun phrase:

most $\left[\mathrm{C}_{\mathrm{i}}\right] \quad[\mathrm{RC} \ldots[\mathrm{NP} N \mathrm{NPP}$ ] $\ldots]$ [NS $\ldots$.

In this way, the observation that in-modifiers are acceptable in restrictive noun phrases but unacceptable in unrestrictive noun phrases can be explained as a consequence of their being obligatory modifiers of resource domain variables. 7

\subsection{On obligatory restrictors in natural language}

Although the hypothesis I just suggested appears to be plausible, it is so far unclear why in-modifiers should be of an inherently restrictive or restrictive nature. Here, I can offer only vague speculations concerning the issue. I believe

7 Here it may be important to note that in-modifiers are at least marginally acceptable with proper names: cf. (?) Angela in den siebziger Jahren war ein braves Schulmädchen. I am not quite sure about the acceptability of this type of sentence, but it doesn't seem too odd. Paul $(1994,269)$ also seems to assume in the text of his paper that temporal inmodifiers are acceptable with proper names, although he actually doesn't use them in any examples, but exploits only of-modifiers, e.g. in The Paris of the $20 \mathrm{~s}$ was exciting. If in-modifiers are fully acceptable with proper names and proper names don't have resource domain variables (which seems to me the most likely analysis), then my generalization that in-modifiers are always modifiers of resource domain variables turns out to be problematic. 
that the reason must be some internal properties of the modifier - perhaps it has something to do with the inclusive meaning of in-modifiers. In light of this vagueness, it may appear as if saying that in-modifiers are inherently restrictive or restrictive just shifts the question of why they are largely incompatible with unrestrictive noun phrases to another question. Raising one question or the other may indeed not make a big difference with respect to explanatory adequacy.

But it becomes evident that the question is part of a larger unsolved problem. There is some evidence that natural language exploits expressions which are only acceptable if they can function as the restrictor of some quantifier. This is for instance arguably the case with if-clauses (cf. Lewis (1975), Rooth $(1985,203)$, Kratzer (1991) and von Fintel (1994)): they are only acceptable when functioning as restrictors of a quantifier.

This is demonstrated in (19) and (20) with an argument taken from Rooth (1985, 203). (19a) and (19b) show that the sentence He always shaves when he is in the shower can have two readings, depending on the focus structure of the sentence. When shaves is focussed, as in (19a), the when-clause functions as the restrictor of the adverb of quantification always. But when shower is focussed, the when-clause does not have to function as a restrictor. Instead, the material provided by the matrix clause does.

(19) a. He always SHAVES when he is in the shower.

ALWAYS [he is in the shower] [he shaves]

b. He always shaves when he is in the SHOWER.

ALWAYS [he shaves] [he is in the shower]

The crucial observation now is that if-clauses behave differently. In (20a), and (20b), shaves and shower are focussed, respectively, analogously to the variation in (19a) and (19b). But here focus doesn't trigger reading alternations: in each case, the if-clause has to function as the restrictor of the adverb of quantification.

(20) a. He always SHAVES if he is in the shower.

ALWAYS [he is in the shower] [he shaves]

b. He always shaves if he is in the SHOWER.

ALWAYS [he is in the shower] [he shaves]

* ALWAYS [he shaves] [he is in the shower]

To summarize, if-clauses are only acceptable when serving as restrictors. Thus, ifclauses are obligatory restrictors of quantifiers. Under this analysis, one has to 
assume implicit quantifiers whenever an if-clause occurs without an overt quantifier. Although (19) and (20) seem to suggest at first sight that whenclauses differ from if-clauses in that they do not have to function obligatorily as restrictors, when-clauses may in fact be another case of an expression that serves obligatorily as a restrictor of some quantifier. This is the view taken for instance by Kratzer $(1988,7)$. Kratzer's view is refused though by Johnston (1994, see for instance pp 51f) - at least on a certain level. On the other hand, when-clauses appear in Johnston's approach always either in the restrictive clause of an adverb of quantification (with readings like (19a)), or in the restrictive clause of an existential quantifier within the nuclear scope of an adverb of quantification (with readings like (19b)) (p71), or in the restrictive clause of an existential quantifier (with episodic constructions involving when-clauses) (p114). Thus, Johnston's proposal may in fact be viewed as a special version of Kratzer's claim.

To conclude this section, it seems plausible that there is a larger class of expressions in natural language that are obligatory restrictors. This observation may lend some support to my hypothesis that in-modifiers are obligatory restrictors. They are just one particular kind of expression in the class of obligatory restrictors in natural language. Thus, the question must be raised why there are obligatory restrictors at all in natural language, but as far as I can see, there is not yet an answer to this question.

"You could cheat about the data.." -- "No, Idon't want to do THAT..." - - "Well you could IDEALIZE the data"

- Anonymous -

"We have to see what the facts are."

-Moris -

\section{Interactions of in-modifiers and tense}

\subsection{What precisely are the effects?}

As I mentioned in Section 1, in-modifiers can trigger incompatibilities with the tense of their clause. Thus, we have seen above that in-modifiers with a past 
meaning seem to be incompatible with present tense. In contrast to in-modifiers, of-modifiers do not interact with the tense of their clause. In the remainder of this chapter, I will discuss the question of how this observation can be explained. In order to do this, I will spend this section on showing what precisely the effect of in-modifiers on the tense interpretation is. In the next section, I will then link the occurrence of tense incompatibilities to the distributional requirements on inmodifiers that were discussed in the preceding sections and provide an account of how the effects on tense come about. Before I present the crucial data, I want to summarize here briefly on a purely descriptive level what they will show8:

Basically, we will see that in-modifiers impose an upper limit on the event time of their clause, i.e., the event time of the clause is not allowed to follow the time denoted by the modifier. Thus, the effects in-modifiers have on tenses do not concern incompatibilities with certain tenses viewed as morphemes. Rather, the incompatibilities at issue concern crucially the meaning of temporal elements. On the other hand, there is evidence that - as far as the in-modifier's contribution to the incompatibilities is concerned - it is not only meanings that count. Thus, implicit material that has arguably the same meaning as a certain in-modifier does not share its ability to affect tenses. After this survey, let's have a look at the data.

(21) shows that modifiers with a past meaning - like in the sixties - are good with past tense.

(21) Die meisten Lottogewinner in den sechziger Jahren waren damals unglücklich. the most lottery winners in the sixties were then unhappy ('Most lottery winners in the sixties were unhappy then')

(22a) shows that past modifiers with present tense and the temporal adverbial today are unacceptable. Note that the incompatibility in (22a) must be caused by the modifier and not by the meaning of the sentence; this can be concluded from the fact that $(22 b)$ is perfectly acceptable even when it gets a contextual restriction of the DP that is synonymous with the meaning resulting from the overt modifier in (22a), i.e., when it is understood as having a meaning like "For most $\mathrm{x}$, such that $\mathrm{x}$ was a lottery-winner in the sixties, $\mathrm{x}$ is unhappy today".

(22) a.* Die meisten Lottogewinner in den sechziger Jahren sind heute unglücklich. the most lottery winners in the sixties are today unhappy ('Most lottery winners in the sixties are unhappy today.')

8 The English data behave very much like the German data, but since I worked mostly with German informants, I will rely on the German data here. 
b. [context: In the sixties, lots of people won amazing amounts of money in the lottery, but...]

... die meisten Lottogewinner sind heute unglücklich. the most lottery winners are today unhappy

Thus, it is not the meaning resulting from the presence of the in-modifier that causes the incompatibility with present tense in (22a), but it is rather something else about the modifier that is responsible for the unacceptability of (22b).

(23) illustrates that present modifiers together with present tense are acceptable.

(23) Die meisten Lottogewinner in diesem Jahrzehnt sind unglücklich. the most lottery winners. in this decade are unhappy ('Most lottery winners in this decade are unhappy.')

Thus, the incompatibility in (23) cannot be caused by a general incompatibility of in-modifiers with present tense.

(24) shows that past modifiers can sometimes occur with present tense. However, (24) is only good when it gets a historic present tense reading - i.e. in the context of a report about the lives of lottery winners, but only when it has a reading "Most lottery winners in the sixties were unhappy then."

(24) Die meisten Lottogewinner in den sechziger Jahren sind unglücklich. the most lottery winners in the sixties are unhappy ('Most lottery winners in the sixties are unhappy.')

The data presented so far may suggest at first sight that for some reason, the modifiers lead to obligatorily temporally dependent readings. Thus, (21) seems to be acceptable and true if and only if for most $\mathrm{x}$, such that $\mathrm{x}$ was a lottery-winner in the sixties, $x$ was unhappy in the sixties. (23), where the time of winning the lottery is located in the decade that includes the time of utterance, is also acceptable. On the historic present tense reading of (24), the predication times of the noun lottery winner and the predicate be unhappy coincide. Thus, using the terminology introduced in Chapter III, these three sentences have in common that the subject noun phrases appear to have temporally dependent interpretations. And coinciding predication times of the subject and the main predicate are made impossible in (22a) by the presence of the temporal adverbial heute; the sentence is unacceptable. Hence, the data presented so far seem compatible with the hypothesis that in-modifiers are acceptable if and only if the host DP of the modifier has a temporally dependent interpretation. 
But other sentences show that this cannot be quite the right generalization. There are fully acceptable sentences with in-modifiers which can easily have predication times of host DP and main predicate that don't coincide. When a temporal adverbial is present in the clause, as in den vierziger Jahren in (25), the predication time of the main predicate can be located at a time that does not overlap the time denoted by the temporal modifier.

(25) Die meisten Lottogewinner in den 60er Jahren waren in den 40er Jahren arm. the most lottery winners in the sixties were in the forties poor ('Most lottery winners in the sixties were poor in the forties.')

Thus, the incompatibilities with in-modifiers are not caused by some requirement that forces in-modifier clauses to exploit temporally dependent readings of the host DP.

If this is not the right generalization, how then can we capture the incompatibilities illustrated above? The most informative contrast for finding the right generalization is presented in (26). (26a) and (26b) are almost the same sentence. The only difference between (26a) and (26b) is that (26a) contains the temporal adverbial in the twenties, and (26b) contains the temporal adverbial in the sixties. And (26a) is acceptable, but (26b) is mostly judged unacceptable. 9

(26) a. Die meisten Politiker in den 40er Jahren waren in den 20er Jahren unzufrieden. the most politicians in the forties were in the twenties dissatisfied ('Most politicians in the forties were dissatisfied in the twenties.')

b.*? Die meisten Politiker in den 40er Jahren waren in den 60er Jahren unzufrieden. the most politicians in the forties were in the sixties dissatisfied ('Most politicians in the forties were dissatisfied in the sixties.')

I find the comments of one of my informants in connection with in-modifiers very enlightening. Basically, she complained about the "temporal jumping back and forth" in sentences like (26b) and sentences with [+PAST] modifiers and present tense. 10 This intuition is surprising, since there does not seem to be any more

9 Since judgements are not entirely clear, I want to add that (a) was judged acceptable by about $72 \%$ and unacceptable by about $28 \%$ of the 15 informants I asked. (b) was judged acceptable by $25 \%$ and unacceptable by $75 \%$ of the 8 informants that gave me judgements on this sentence.

10 "Das zeitliche 'Hin-und-her-gehopse' in den Sätzen (1) und (4) mag mir so gar nicht gefallen, am schlimmsten finde ich dabei Satz (4), der meiner Meinung nach irgendwie eigentlich gar nicht gehen können sollte, auch wenn mir klar ist, daß er erklärbar ist. Ich finde ihn aber ganz furchtbar." (Andrea G.)

(1) Die meisten Politiker in den 40er Jahren sind heute tot.

(2) Die meisten Politiker in den 40er Jahren waren unzufrieden. 
objective "jumping back and forth" in (26b) than in (26a). The crucial difference between (26a) and (26b) is that, because of the choice of different temporal adverbials, the event time of the main predicate in (26a) is located before the time denoted by the modifier, whereas it is located after the time denoted by the modifier in (26b). Thus, it seems as if it is somehow conceptually more difficult to relate an in-modifier's time to a following main predicate's event time than to a preceding event time.

In light of the contrast in (26), the adequate descriptive generalization for all the sentences in (21) - (26) seems to be that the event time of the main predicate is not allowed to follow the time of the modifier. The picture in (27) shows the possible and impossible temporal configurations of in-modifiers and event times.

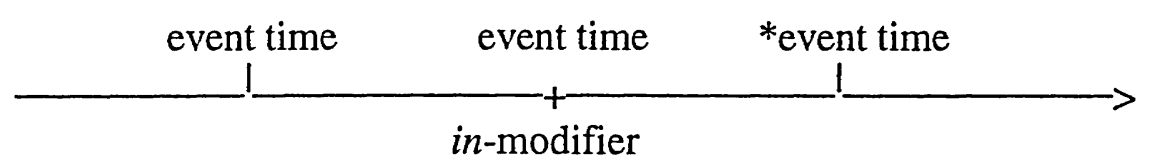

What is interesting about this generalization is that there are other constructions in natural language that seem to be subject to a similar constraint, i.e. complex sentences. Abusch (1994) suggested that there is an UPPER LIMIT CONSTRAINT on the reference of tenses in matrix and embedded clauses. What this constraint says is basically that the reference of the tense in an embedded clause is not allowed to follow the reference of the tense in the matrix clause - or: the reference of the tense of the matrix clause imposes an UPPER LIMIT on the reference of the time of the embedded clause. Using these terms, one might say that the time of the in-modifiers discussed in this chapter imposes an upper limit on the event time of the main predicate of its clause. The following subsection introduces Abusch's Upper Limit Constraint and its original range of application.

\subsection{Abusch's (1994) Upper Limit Constraint in complex sentences}

There are two constructions relevant with regard to the behavior of tenses in embedded clauses, the sequence-of-tense construction and the double access construction.

(3) Die meisten Politiker in den 40er Jahren waren in den 20er Jahren unzufrieden.

(4) Die meisten Politiker in den 40er Jahren waren in den 60er Jahren unzufrieden. 
Sequence-of-tense constructions are sentences where an intensional past tense verb has a complement with a stative past tense verb - as in (28a) John said that Peter was sick. In such a configuration, the embedded clause can have a backward shifted tense reading (28b) or a simultaneous reading (28c), but not a forward shifted reading (28d). Thus, the event time of Peter's being sick in (28a) can be located before (28b) or at the time of John's saying (28c). But it cannot be located at a time between John's saying and the time when (28a) is uttered, as in (28d).

(28) a. John said that Peter was sick.

b. Backward shifted tense reading: John said at a time $t$ before $t_{u}$ that Peter was sick at a time $t^{\prime}$ before $t$.

c. Simultaneous tense reading: John said at a time $t$ before tu that Peter was sick at $\mathrm{t}$

d. $\quad$ NO forward shifted tense reading: $*$ John said at a time $t$ before $t_{u}$ that Peter was sick at a time $t^{\prime}$ before $t_{u}$ (and after $t$ ).

With the backward shifted tense reading, John said that Peter was sick corresponds to a situation where what John said at $\mathrm{t}$ was something like "Peter was sick". I.e., roughly speaking, the embedded clause takes the event time of the embedding clause as its evaluation time and constructs from that point a past meaning. With the simultaneous reading the sentence corresponds to a situation where what John said originally was something like "Peter is sick". At this point, it is - although much simplified compared to Abusch (1994) - adequate enough to explain the possibility of these two readings by saying that the embedded past tense may locate the event time of the embedded predicate somewhere before the time of utterance $t_{u}$.

But what about the lack of the forward shifted reading? According to what I just said, the forward shifted reading (28d) should also be possible. Adopting a referential analysis of tense, Abusch captures the lack of the forward shifted tense reading by stating the Upper Limit Constraint (ULC, p24) on the reference of tenses. This constraint prohibits basically a situation where the reference of the tense in the embedded clause is located after the reference of the tense of the matrix clause. Since the reference of the tense of the matrix clause is taken by Abusch to be the local evaluation time for the embedded clause, the effect can be formulated as a constraint on the relation between local evaluation times and tenses. 
The resulting picture of possible relations between matrix tenses and embedded tenses (30) is exactly parallel to (27).

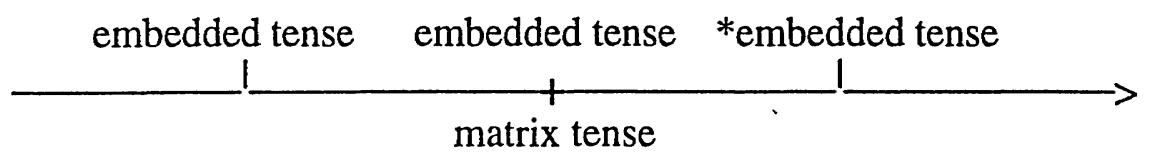

The idea of the ULC is, according to Abusch, that tenses can only refer to times with which one can be "acquainted" from the perspective of the respective local evaluation time. Roughly speaking, possible acquaintance relations involve in general some kind of causal connection. Since causal connections can only go backward but not forward, forward relations between the local evaluation time and a time referred to by a tense are prohibited.

Note that the "local evaluation time" in Abusch's proposal does not do what one expects from an evaluation time in traditional approaches: The "local evaluation time" set by a matrix clause is in Abusch's proposal not a time from which past tense "counts" backwards. This is due to Abusch's referential tense semantics. If the "local evaluation time" were a time from which past tense counted backwards, the occurrence of simultaneous readings for past-under-past constructions would not be captured. The effect of the "local evaluation time" is that it provides a hierarchically higher temporal element in the sentence that determines the relevant point of view or orientation as far as the ULC is concerned. This point is crucial in connection with my application of the ULC to the behavior of $i$-modifiers below.

A very important point about Abusch's proposal is that the ULC concerns only tenses. It does not concern modalities. Since Abusch treats future "tense" not as a tense category, but as a modal category (as has been suggested before for independent reasons12), the constraint allows for future tenses to refer to times that are located after the local evaluation time given by a matrix clause - i.e., they can change the evaluation time.

11 According to Abusch, future "tense" is a modal category and does consequently not undergo the ULC.

12 See for instance Enç (1985). Of course, the opposite claim has also been defended, for instance by Declerck (1991). 
Speaking on a descriptive level, one may say that the event time of an embedded clause is subject to an upper limit imposed by the event time of the matrix clause. Since the tense semantics I am exploiting in this thesis is not referential, I will henceforth assume that it is the event time of clauses that are subject to the ULC. Thus, adopting this terminology, the ULC prohibits basically a situation where the event time of the embedded clause is located after the event time of the matrix clause. For the present purpose, I will thus reformulate the ULC as in (31).

(31) Upper Limit Constraint (first reformulated version):

The event time of the matrix clause is an upper limit for the event time of the embedded clause.

Thus, it seems that the ULC is a more general constraint on possible relations of the denotations of temporal elements. It not only captures an aspect of the behavior of embedded event times in relation to matrix event times, but also the behavior of event times of clauses in relation to in-modifiers that are contained in the clause. I.e., just as the event time of a matrix clause fixes an upper limit for the event time of an embedded clause, the time of an in-modifier fixes an upper limit for the event time of the clause.

The Upper Limit Constraint can also capture the lack of forward shifted readings with double access constructions. In double access constructions, a present tense is embedded under a matrix past tense - as in (32a) John said that Peter is sick. The crucial property of this construction is that in English, it admits only readings where the event time of the complement clause denotes an interval that includes the time of John's saying as well as the time at which the whole sentence is uttered. I.e., Peter's time of being sick cannot be located completely after the time of John's saying. The picture in (32b) illustrates this effect.

a. John said that Peter is sick.

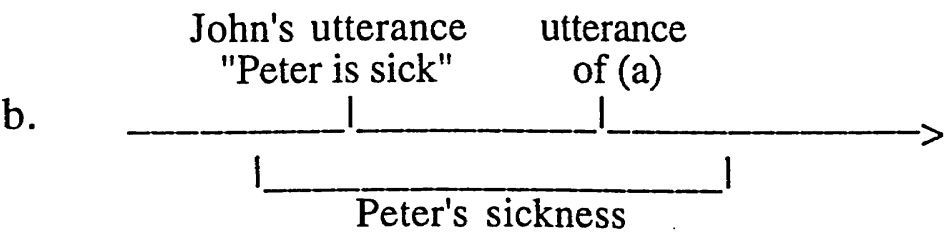

Thus, roughly speaking, present tense under past tense leads to interpretations where the event time of the embedded main predicate extends at least from the 
evaluation time provided by the embedding clause until the time of utterance of the whole sentence. 13,14

\subsection{Other combinations of in-modifiers and tenses}

My claim is that the incompatibilities of in-modifiers with certain tense interpretations are due to some generalized version of the ULC. We have seen above that some combinations of in-modifiers and tenses behave accordingly. In this subsection, I will show that other combinations of in-modifiers and tenses provide further evidence for the hypothesis that the relations between inmodifiers and event times obey some such constraint.

In particular, the proposal to view the observed incompatibilities as an effect of the ULC predicts that in-modifiers denoting present time intervals or future time intervals should be acceptable with past tenses and with present tense. This prediction is indeed borne out, as the sentences and judgements in (33) show.15

13 This is a very rough characterization of the reading. The event time of the embedded clause does not have to extend like this. In fact, the double access effect does not concern an actual event time, but rather an interest of the speaker in the asserted main property during the respective span of time (cf. Ogihara (1989) and Abusch (1994, 33f)).

14 In German, the situation is not quite that clear; judgements vary among speakers and even among sentences, and it seems that contextual information can play a crucial role on whether a particular sentence like (A) gets a double access reading.

(A) Hans sagte, daß Peter krank ist.

Hans said that Peter sick is

('Hans said that Peter is sick.')

With (A), about $50 \%$ of the German speakers I asked get the DA effect. But with a more elaborate sentence the DA effect may be much weaker if present at all. This can be observed with (B).

(B) Als ich Hans am Montag traf, sagte er mir, daB ihm schlecht ist when I Hans on Monday met said he me that him sick is ('When I met Hans on Monday, he told me that he feels sick.').

Thus, the DA phenomenon occurs at least to a certain degree also in German. In fact, there are good reasons why the intuitions of German speakers should not be all that clear: Kai von Fintel suggests that the vagueness of judgements may be due to the fact that German also exploits subjunctive forms in certain embedded clauses, e.g., for speech reports; this may confuse intuitions - even more so since German seems to undergo a process of eliminating subjunctive constructions.

15 (a), (b), (d) were judged acceptable by all speakers, (c), (e), and (f) were judged unacceptable by $20-25 \%$ of the informants. 
(33) a. Die meisten Politiker in diesem Jahrzehnt sind resigniert. the most politicians in this decade are resigned ('Most politicians in this decade are resigned')

b. Die meisten Politiker in diesem Jahrzehnt gingen 1960 zur Schule. the most politicians in this decade went 1960 to-the school ('Most politicians in this decade went to school in 1960.')

c. Die meisten Politiker in diesem Jahrzehnt waren 1960 zur Schule gegangen. the most politicians in this decade were 1960 to-the school gone ('Most politicians in this decade went to school in 1960.')

d. Die meisten Politiker in diesem Jahrzehnt sind 1960 zur Schule gegangen. the most politicians in this decade are 1960 to-the school gone ('Most politicians in this decade went to school in 1960.')

e. Die meisten Politiker in den 90er Jahren werden 2020 pensioniert sein. the most politicians in thie nineties become 2020 retired be ('Most politicians in the nineties will be retired in 2020.')

f. Die meisten Politiker im nächsten Jahrhundert sind heute noch Kinder. the most politicians in the next century are today still kids ('Most politicians in the next century are today still kids.')

All these judgements are compatible with the proposal that the ULC applies to the relation between in-modifiers and the event time of their clause.

Another question to be asked is what the ULC-analysis predicts with regard to the behavior of future tenses. As I mentioned above, Abusch (1994) does not treat future "tense" as a tense category, but as a modal category. This analysis accounts for the fact that future "tense" do not undergo the ULC, as can be easily seen with (34); here, the event time of the embedded clause can be located at a time after the event time of the matrix clause.

John said that Peter will be sick.

Thus, according to Abusch, the range of the ULC is restricted to proper tenses. Considering again in-modifier constructions though, this does not mean that future "tense" is predicted to be acceptable with all in-modifiers, regardless of what time they denote. The reason for that is that analyzing future "tense" as a modal category doesn't mean that the respective clauses are tenseless. Thus, I propose to analyze future "tense" as the present tense version of a modal category. If we assume such an analysis, then our proposal predicts that future "tense" clauses behave just like present tense clauses. Thus, they are predicted to be unacceptable with in-modifiers that denote past time intervals. This prediction is indeed borne out, as is shown in (35). Note that the sentences in (35) contrast with $(33 \mathrm{e})$, where the in-modifier denotes a present time interval. 16

16 Here, (a) was judged unacceptable by $100 \%$ of the informants, (b) by about $86 \%$. 
(35) a. *? Die meisten Studenten in den 50er Jahren werden im nächsten Jahrzehnt pensioniert sein.

('Most students in the fifties will be retired in the next decade.')

b. *? Die meisten Studenten in den 50er Jahren werden im nächsten Jahrzehnt pensioniert worden sein.

('Most student in the fifties will have been retired in the next decade.')

Furthermore, future "tense" clauses should be acceptable with in-modifiers denoting present time intervals. This prediction is also borne out, as (36) shows.

(36) a. Die meisten Politiker in diesem Jahrzehnt werden im nächsten Jahrzehnt pensioniert sein.

('Most politicians in this decade will be retired in the next decade.')

b. Die meisten Politiker in diesem Jahrzehnt werden im nächsten Jahrzehnt pensioniert worden sein.

('Most politicians in this decade will have been retired in the next decade.')

Having thus dealt with future tenses, the behavior of the present perfect tense deserves also some more attention. In German, present perfect is usually used exactly like past tense in English. That is, in contrast to English, in German present perfect requires no particular link to the time of utterance. In fact, in some southern dialects, simple past tense is completely substituted by present perfect. English behaves quite differently from German in this respect; present perfect in English is notoriously bound to contexts that provide a strong connection to the present. Interestingly, English speakers judge present perfect clauses with past temporal modifiers different than German speakers: Thus, sentences like (37)

Most professors in the sixties have been unhappy recently/since then.

are judged just as bad as the corresponding present tense construction by two speakers; another speaker judged it as intermediate between the present tense construction and the past tense construction. Thus, it seems that present perfect behaves in English in an important respect like present tense, whereas in German it behaves in this respect like past tense. This explanation seems even more convincing because present perfect sentences in German seem also pretty bad when present perfect is used in a variety where it implies a strong connection to the time of utterance. This is illustrated in (38), where (38a) corresponds to the English example (37). 
a. ?? Die meisten Professoren in den sechziger Jahren sind seitdem unglücklich the most professors in the sixties are since-then unhappy gewesen.

been

('Most professors in the sixties have been unhappy since then.')

b. ?? Die meisten Professoren in den vierziger Jahren sind schon gestorben. the most professors in the forties are already died ('Most professors in the forties have already died.')

To summarize, various combinations of in-modifiers and the event time of their clause support the generalization that the relationship between the denotations of these two temporal elements is subject to some version of the ULC.

"That's better," said Wimsey. "Napoleon or somebody said you could always tum a tragedy into a comedy, by sittin' down. Pefectly tue, isn'tit? Let's talk about something ordinary till Miss Phelps comes in. Shall we?"

-Dorothy L Sayers, The Unpleasantness at the Bellona Aub-

\section{In-modifiers and upper limits}

What I have shown in the preceding section is that in-modifiers impose an "upper limit" on the event time of the main predicate of their clause. Thus, I have argued that the temporal incompatibilities arising with in-modifiers are a special case of more generally occurring incompatibilities between temporal elements that have to do with temporal ordering. In this section, I will deal with the question of why in-modifiers are able to fix upper limits for the event time of their clause. In 5.1., I will consider and abandon a pragmatic account of the conditions under which upper limit effects can be triggered. Since this approach fails, I will then in the remainder of the chapter consider and adopt a syntactic account. 
We have already seen that the ability of in-modifiers to fix upper limits is not only due to their meaning, but also to their explicit presence. This was shown with the contrast between examples that exploit implicit restrictions on quantifiers and examples with explicit in-modifiers that have the same meaning: whereas the former construction is not able to fix upper limits, the latter construction is. I will propose that elements that can fix upper limits have to stand in a certain syntactic relation to the element that is subject to the Upper Limit Constraint in order to be able to impose an upper limit on that element. Evidence for this claim is provided by the contrast between partitive and nonpartitive DPs. Whereas in-modifiers contained in the former type of DP cannot fix upper limits for the event time of their clause, in-modifiers contained in the latter type of DP can. This has to do with the depth of embedding of the minimal host $\mathrm{DP}$ of the in-modifier.

I will assume that the element that corresponds structurally to the event time is the time argument of the main predicate. Syntactically, it appears as the sister of the predicate. The syntactic relationship between upper-limit-fixer and upperlimit-fixee will be linked to my claim that in-modifiers are modifiers of resource domain variables. Moreover, the syntactic relationship seems to be a general condition on the occurrence of ULC-effects. The observation that the depth of embedding of the host DP is relevant will be linked to the claim that in-modifiers are obligatory modifiers of resource domain variables.

Knowing why in-modifiers have effects on the tense interpretation of their clause is not necessarily the same as knowing how they do it. Although I will speculate somewhat about this point, many questions concerning the ULCapproach will still be left open at the end of the chapter.

\subsection{Do in-modifiers pragmatically provide local evaluation times?}

The goal of this subsection is to check whether one can plausibly argue that inmodifiers fix a kind of local evaluation time for their clause. The initial motivation for this idea are observations concerning the interaction of in-modifiers and implicit temporal restrictions. The interaction of these two elements shows that in-modifiers are suitable providers of semantic values for implicit temporal restrictions. This suggests that they may perhaps also be suitable providers of semantic values for local evaluation times. However, I will argue at length that 
the strong ability of in-modifiers to provide semantic values for implicit temporal elements cannot usefully be applied to the fixing of upper limits.

Let us begin by having a look at the interaction of implicit temporal restrictions and in-modifiers. (39a) is a well-known example of Partee (1973). It shows that many sentences behave as if they contain an implicit temporal frame adverbial; it has a meaning like (39b), where the bracketed expression provides a definite time interval that seems to provide a temporal frame for the main predicate of the clause. In Chapter II I attributed this effect to the presence of an implicit temporal restriction of an implicit adverb of quantification. The specific meaning of the implicit temporal restriction is supplied by the discourse context.

a. I didn't turn off the stove. (Partee (1973))

b. [At the time before we left], I didn't turn off the stove.

(40) shows a related observation: when there is an in-modifier in the clause, it introduces a time interval which is then preferredly used as the value for the implicit temporal restriction. As a result, (40a) can get a reading that is indistinguishable from a temporally dependent reading of the host DP - i.e., a reading where the predication time of the noun lottery winners and the predication time of be poor coincide: "Most lottery winners in the sixties were poor in the sixties" (40b). Many informants get this reading preferredly, although it is pragmatically certainly not favoured.

(40) a. Most lottery winners in the sixties were poor.

b. [In the sixties], most lottery winners in the sixties were poor.

However, if there is another suitable time interval introduced either in the context or in the same clause, we can see that the in-modifier doesn't provide the value for the temporal restriction obligatorily. (41a) shows that the in-modifier need not provide a value for the temporal restriction when there is an explicit temporal adverbial present in the clause. Here, no conflict arises about which item provides a temporal frame for the clause as it does when there are two temporal adverbials simultaneously present in the same clause (41b).

(41) a. Most lottery winners in the sixties were poor in the forties.

b. * In the sixties, most lottery winners were poor in the forties. 
Thus, an in-modifier can, but does not have to, provide a value for the implicit temporal restriction of its clause. This shows that the effect illustrated in (40) probably comes about because the time interval introduced by the in-modifier is contextually salient in its clause.

Let us now return to the observed ability of in-modifiers to fix "upper limits" for the event time of their clause. What one might try to argue for in light of the observations above is that the fixing of the upper limit is another case of fixing the value of an implicit element. Let us call this element for the moment the "local evaluation time" of the clause - where I want to leave open for now what kind of element this might be precisely. In other words, one may be led to argue that inmodifiers fix an upper limit for their clause because they introduce a contextually salient time interval that serves as the local evaluation time.

(42) may be viewed as providing further evidence for this claim. The sentences presented in (42) show that in-modifiers fix an upper limit for the main predicate regardless of their position in the clause.

Thus, $(42 \mathrm{a}, \mathrm{b})$ show that in-modifiers in subject as well as object noun phrases can trigger upper limit effects. Furthermore, $(42 c, d)$ shows that in-modifiers in German scrambled DPs can also trigger upper limit effects regardless of their position.

(42) a. *? David kennt die meisten MIT-Studenten in den 80er Jahren. David knows the most MIT-student in the eighties ('David knows most MIT-students in the eighties')

b. *? Marianne liebt alle berühmten Schauspieler in den 50er Jahren. Marianne loves all famous actors in the fifties ('Marianne likes all famous actors in the fifties')

c. *? weil den David die meisten MIT-Studenten in den 80er Jahren kennen since the-ACC David the most MIT-students in the eighties know ('most MIT-students in the eighties know David')

d. *? weil alle berühmten Schauspieler in den 50er Jahren die Marianne liebt since all famous actors in the fifties the-NOM Marianne loves ('Marianne likes all famous actors in the fifties')

If the fixing of the local evaluation time is pragmatically determined, then this is expected. Thus, at first sight it does not seem implausible to assume that inmodifiers fix upper limits for their clause by way of pragmatics.

However, there is plenty of evidence against a pragmatic account in these terms. In the remainder of this subsection, I will present some arguments against it. 
First, the relation between in-modifiers and the event time of main predicates is - as we already know - not the only relationship between temporal elements that undergoes the ULC. It seems desirable to find a unified account of upper limit phenomena. So far, we have dealt with two upper limit sensitive relationships, the one between in-modifiers and the event time of main predicates, and the one between matrix tenses and embedded tenses.

There is at least one other ULC-sensitive relationship that was not yet mentioned, namely the one between topicalized temporal adverbials and inmodifiers. (43a) shows that temporal adverbials are capable of fixing upper limits for an in-modifier in their clause. In (43a), the time of the modifier follows the time of the temporal adverbial, and the sentence is bad. Thus, the temporal adverbial imposes here an upper limit on the temporal modifier. But (43b), which differs from (43a) only with regard to ordering, is fully acceptable. Thus, it seems that the temporal adverbial can only impose an upper limit on the temporal modifier, when it is topicalized but not when it is in sentence-final position.

a. *? In the forties, most lottery winners in the sixties had been poor.

b. Most lottery winners in the sixties had been poor in the forties.

In a pragmatic account, one may perhaps argue that temporal adverbials get more salient in the context when they are topicalized and can therefore only impose upper limits on anything when topicalized.17

Let us try also to give a pragmatic account for the ULC-relationship between matrix tenses and embedded tenses. Note that in an account based on contextual salience, we may expect that the fixing of upper limits by contextually salient times works similar to the determination of the reference of pronouns: one of the standard strategies for finding a referent for a pronoun is to go back to the last possible referent introduced in the discourse. If the fixing of upper limits works

17 In a pragmatic approach, the phenomena may perhaps roughly be accounted for as follows. Whereas in-modifiers are able to fix upper limits regardless of their position in the clause, temporal adverbials fix upper limits only when topicalized. It seems that, with respect to the ULC, in-modifiers behave like topicalized temporal adverbials in that they play quite in general a special role in the discourse. If in-modifiers are inherently restrictive, and if restrictive material is in general contextually salient, then we expect inmodifiers to be always able to fix evaluation times. Temporal adverbials on the other hand are not inherently appropriate elements for fixing upper limits, but only when their position in the clause causes them to play a special discourse role that makes them contextually especially salient. Thus, for a temporal element to impose an upper limit on another temporal element, it may be necessary that the former is contextually salient. 
similarly, then one would expect to find constructions where a second time is introduced after the matrix time that is contextually more salient when the embedded clause is processed. Thus, what we would need to argue against the pragmatic approach would be a sentence exploiting the temporal relationships indicated in (44a). If this sentence showed an upper limit effect, then one might argue that the pragmatic approach failed. (44b) is in principle an example of the type we are looking for. Here, the blocking time is introduced by an in-modifier.

a.

matrix tense

embedded tense time of the in-modifier $=$ blocking time, introduced . in the embedded clause

b. \# John told me two months ago that every speaker on this Sunday was mentioned in an interview last week.

(44b) shows in fact an upper limit effect - i.e., it is not possible to have a forward shifted reading for the embedded tense. Since the definite temporal adverbials allow only for such a reading, the sentence does not allow for any acceptable reading and is just strange. Thus, (44) seems to provide an argument against a pragmatic account in terms of contextual salience. But note that in order show anything with that example, one has to prove that the temporal element that is supposed to block the upper limit effect of the matrix tense by introducing another contextually salient time, i.e., the in-modifier does not stand in an ULCsensitive relationship with the matrix tense. This can indeed be shown; consider (45).

a.

embedded tense

matrix tense

time of the in-modifier $=$ blocking time, introduced

.

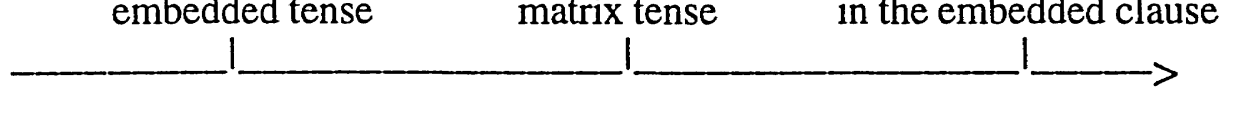

b. John told me last week that every speaker on this Sunday was mentioned in an interview two months ago.

(45b), where the time of the embedded tense and the time of the matrix tense are exchanged, is fine. Thus, the matrix tense does not impose an upper limit on the in-modifier. Thus, at least under the assumption that the fixing of upper limits works similar to the search for antecedents of pronouns, this provides an argument against the contextually-salience-approach. 
Second, a fundamental question must be raised: what is it that is fixed? With the fixing of values for implicit temporal restrictions, it is clear what is being fixed; the implicit temporal restriction is an independently motivated entity that plays an important role for temporal interpretation, as should be clear from preceding chapters. But an upper limit as fixed by in-modifiers does not seem to correspond to some particular entity. In order to make this point clear, I want to discuss here the question whether upper limits can be identified with reference times. Reichenbach (1947) introduced the concept of reference time (R) in addition to event time (E) and time of utterance $(U)$ for a treatment of temporal interpretation in natural language. Roughly speaking, the reference time of a clause is the time starting with which the time of the event is located.18 Tenses are then defined by specific orderings of reference time, event time, and time of utterance. Here are some examples, where " + " means that the elements are simultaneous or at least intersecting, and "-." means that the time on the right side follows the one on the left side.

$$
\begin{aligned}
& \text { simple past: } \mathbf{E}+\mathbf{R}-\mathbf{U} \\
& \text { past perfect: } \mathbf{E}-\mathbf{R}=\mathbf{U} \\
& \text { simple present: } \mathbf{E}+\mathbf{R}+\mathbf{U}
\end{aligned}
$$

Corresponding to the distinction between reference time and event time, one can distinguish two types of temporal adverbials. Temporal adverbials can either locate the event time of the main predicate, i.e. the time when the event (action, process, state, property) of the main predicate takes place, or they can locate the "reference time" of the clause (e.g. Hornstein $(1990,25)$ and others). I will refer to them as event-time-adverbials and reference-time-adverbials, respectively. The difference is visible with past perfect clauses as in (47) (taken from Hornstein (1990)).

a. John had left the store at 3 p.m. $=$ John's leaving the store took place at 3 p.m.

b. At 3 p.m., John had left the store. $=$ At 3 p.m., John was in a state of having left the store.

18 The reference time of a clause has been characterized as "the time from which the perspective on the action... of the clause is construed" (Helbig and Buscha) or "the time that is the topic of the clause" (Klein), i.e. it is a kind of "topic time" that is taken as a source of perspective on the event (action, process, state, property) denoted by the main predicate. 
As (47) indicates, event-time-adverbials and reference-time-adverbials are though not strictly, but only by preference - associated with different positions in the clause. When a temporal adverbial is sentence-initial, it is preferredly understood as a reference-time-adverbial. When it is sentence-final, it is preferredly understood as an event-time-adverbial.

The question I want to investigate briefly is whether either of the two times can be identified with upper limits. Since topicalized temporal adverbials are able to fix upper limits but non-topicalized temporal adverbials don't (as we have seen above), this may suggest at first sight that upper limits are reference times. Note that if upper limits fixed by in-modifiers correspond in general to reference times, then we make the following prediction: When a past modifier occurs in a past perfect clause without temporal adverbials, the in-modifier provides the reference time. Unfortunately, this prediction is not borne out. (48) exploits on Sunday afternoon in reading (b) as an event-time-adverbial and in reading (c) as a reference-time-adverbial. Both readings seem to be clearly possible.

(48) a. Die meisten Redner am Sonntagnachmittag hatten einen Schnupfen gehabt.

('Most speakers on Sunday afternoon had had a cold.')

b. $\quad=$ On Sunday afternoon, most then-speakers had a cold.

c. = On Sunday afternoon, most then-speakers were in a state of having had a cold.

Thus, it seems that in-modifiers can fix either event times or reference times. As we can conclude from the fact that constructions violating the ULC are in general unacceptable, in-modifiers in either of these roles can fix upper limits for tense (for if they couldn't in one of these roles, we would expect constructions to be more acceptable). Thus, an upper limit is not a particular independent entity that is implicit, but it can correspond to various elements - sometimes to reference times, sometimes to event times, and perhaps sometimes to still other elements. Thus, the pragmatic account, which is based on the idea that in-modifiers can fix values for implicit temporal material, looses much of its appeal.

Third, (49) (which corresponds to (22) above) shows that pragmatics can't be the only relevant factor that is at work for the triggering of the upper limit effect in (49a), for if there is - in an example like (49b) whose meaning is very similar to the meaning of (49a) - only pragmatics at work, then there is no upper limit effect. (49b) contains a contextually derived implicit modification of the resource 
domain of the quantifier most that has the same meaning as the in-modifier in (49a). But in contrast to the explicit restriction provided by the in-modifier in (49a), the implicit restriction in (49b) does not trigger an upper limit effect.
a. * Most lottery winners in the sixties are unhappy today.
b. [context: In the sixties, lots of people won amazing amounts of money in the lottery, but...]
... most lottery winners are unhappy today.

Thus, it seems that the presence of the in-modifier plays some important role for the triggering of the upper limit effect and that pragmatics alone is not enough to account for upper limit effects.

Fourth, there are data that suggest strongly that the depth of embedding of the in-modifier plays a role. There is a contrast between partitive and nonpartitive DPs as far as the triggering of upper limit effects by in-modifiers is concerned; in-modifiers in non-partitive DPs trigger - as we have frequently seen - upper limit effects, but in-modifiers in partitive DPs don't.19 Consider (50) and (51). (50) shows the by now familiar construction where the event time of the main predicate is located after the time of the in-modifier; as expected, the sentence is unacceptable since the in-modifier imposes an upper limit on the event time of the clause. In contrast to (50), (51) is acceptable, i.e. here the inmodifier does not impose an upper limit on the event time of the clause. Note that in (51), the host DP of the in-modifier is a partitive DP.

(50) * [DP Die meisten [NP Politiker in den 60er Jahren] ] sind heute verzweifelt. the most politicians in the sixties are today desparate ('[DP Most [NP politicians in the sixties]] are desperate today.')

(51) [DP Die meisten [PP von [DP den [NP Politikern in den 60er Jahren]]]] sind heute verzweifelt. the most of the politicians in the sixties are today desperate ('[DP Most [PP of [DP the [NP politicians in the sixties]]]] are desperate today.')

19 For some reason which I do not yet understand, the contrast is pretty stable and strong for German speakers but much less clear for English speakers. 
Since the in-modifier is more deeply embedded in partitive DPs than in nonpartitive DPs, this suggests that syntactic hierarchy plays a role for whether an element can trigger upper limit effects.

I will discuss the implications of these data below in more detail. Let me conclude here just that the arguments I presented cast serious doubt on accounts of the fixing of upper limits that attribute the fixing to a pragmatically determined process and try to treat upper limits as some independent element in a clause (like the local evaluation time, for instance). Thus, I will present in the remainder of this section an account of upper limit effects that assumes first, that upper limit effects can in principle occur between any temporal elements, and second, that the occurrence of upper limit effects is subject to some syntactic condition.

\subsection{The syntactic relation between ULC-related temporal elements}

The contrast between (50) and (51) provides an argument for the relevance of syntactic configurations. Thus, it seems that the depth of the embedding of the in-modifier determines whether it imposes an upper limit on the event time of the clause.

Recall that I suggested to analyze in-modifiers as obligatory modifiers of the resource domain variable of their host DP. I assumed that the modification of the resource domain variable is made possible by copying the modifier from the restrictive clause of the quantifier to its resource domain variable at LF. Resource domain variables are associated with their quantifier. By copying the in-modifier to the resource domain variable, the modifier gets in turn associated with the determiner. It seems plausible to assume that when the in-modifier is in this way associated with the determiner, its scope of upper limit effectiveness projects to the maximal projection of the determiner, that is, to DP. Because of this, the scope of upper limit effectiveness of the modifier is the c-command domain of the DP.

To summarize, relying on this analysis, we can state that an in-modifier imposes an upper limit on the event time of its clause when the DP whose resource domain variable it modifies c-commands into the sentence structure at 
$\mathrm{LF}$, the level at which the in-modifier's being a resource domain variable-modifier is relevant. 20 The structures are illustrated in (52a, b). 21

(52) a. Non-partitive DP (LF): ULC-effects triggered

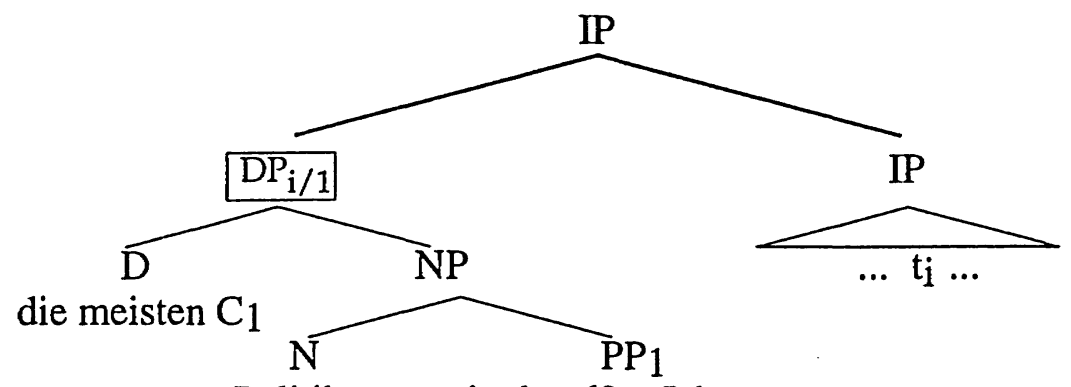

Politiker in den 60er Jahren

b. Partitive DP (LF): ULC-effects not triggered

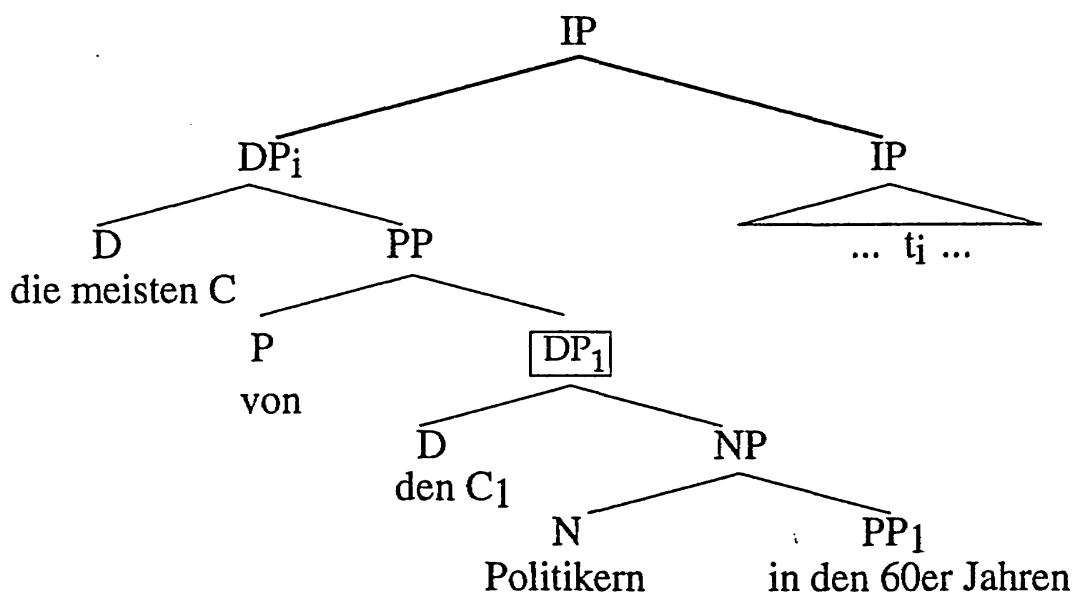

According to this proposal, in-modifiers extend the scope of their upper limit effectiveness beyond their NP to the scope or c-command domain of their minimal host DP, because they are obligatory modifiers of the resource domain variable that is associated with the determiner of their host DP, If that is so, then inmodifiers that are part of a non-partitive DP have a scope of effectiveness that includes their whole sentence. But in-modifiers that are part of a partitive DP have only a scope of effectiveness that includes the lower DP. This predicts that in-modifiers in non-partitive DPs can yield upper limit effects with the main

20 Incidentally, the DP in question also c-commands into the sentence structure at S- or Dstructure. Nevertheless, I will take LF to be the relevant level.

21 Here, the DPs whose RDVs are modified by the in-modifier are marked by boxes; the modification of the RDV and the projection to DP is indicated by the index "1"; the index "i" results from the application of Quantifier Raising. 
predicate of their clause, whereas in-modifiers in partitive DPs don't, because they are too deeply embedded.

There are data that provide support for the assumption that the LF-position rather than the S-structure position or D-structure position of a DP is crucial: (53) shows another construction that exhibits an ULC-effect. But here the relevant upper-limit-relations do not occur between an in-modifier and the event time, but between two in-modifiers. Note that the value of in the sixties is strongly preferredly taken as the temporal frame during which the hating takes place. Thus, since with simple past tense, event time and reference time coincide, in the sixties may be viewed as providing a frame for the event time as well as for the reference time of the clause. Since the the forties are not located after the sixties, we can safely assume that the ULC-effect in (53) is not one between reference time and in-modifier (or, perhaps, between event time and in-modifier), but one between the two in-modifiers.

In (53), the time of the in-modifier in the subject DP comes after the time of the in-modifier in the object DP. If only S-structural configurations were relevant for the triggering of ULC-effects, there would be no reason for the unacceptability of (53).

(53) *? [Many professors in the 60s] hated [some students in the 40s].

But if LF-configurations are relevant, then the unacceptability of (53) can be captured as a special case of ULC-effects: at LF, the object DP is QRed and can thus be in a position where it c-commands the subject DP.

Moreover, the in-modifier that is contained in the object DP can also trigger ULC-effects in the subject DP when the subject DP has wider scope than the object DP. (54) shows this. In (54a), the occurrence of the bound variable pronoun in the object DP forces the subject DP to have wide scope, and the sentence is still bad. The same holds for (54b).

(54) a. * [Many professors in the 60s]i hated [some students in the 40s who theyi knew very well].

b. * [Many professors in the 40s]i hated [some students in the 60 s who theyi knew very well].

These data suggest that the triggering of ULC-effects can be described as formulated in (55). 
(55)

a. Temporal elements trigger ULC-effects from their LF-position.

b. Temporal elements are subject to the ULC in their base position.

These facts could presumably be captured in a copy theory of movement as suggested by Chomsky (1992).

Since the ULC does not only concern the relation between event times in matrix clauses and event times in embedded clauses, I propose to reformulate the ULC as in (56), where it is taken as a constraint between elements in the class of ULC-triggers and elements that are subject to the ULC.

(56) Upper Limit Constraint (first reformulated version):

The event time of the matrix clause is an upper limit for the event time of the embedded clause.

It is not yet clear what exactly makes a temporal element be an ULC-trigger (as event times, in-modifiers, or reference-time-adverbials) or an element that is subject to the ULC (as event times and in-modifiers).

(57) is a structure that shows the relevant positions of items that enter into the occurrence of ULC-effects. Here, bold print marks elements that fix upper limits, whereas underlining marks elements that are subject to the ULC.
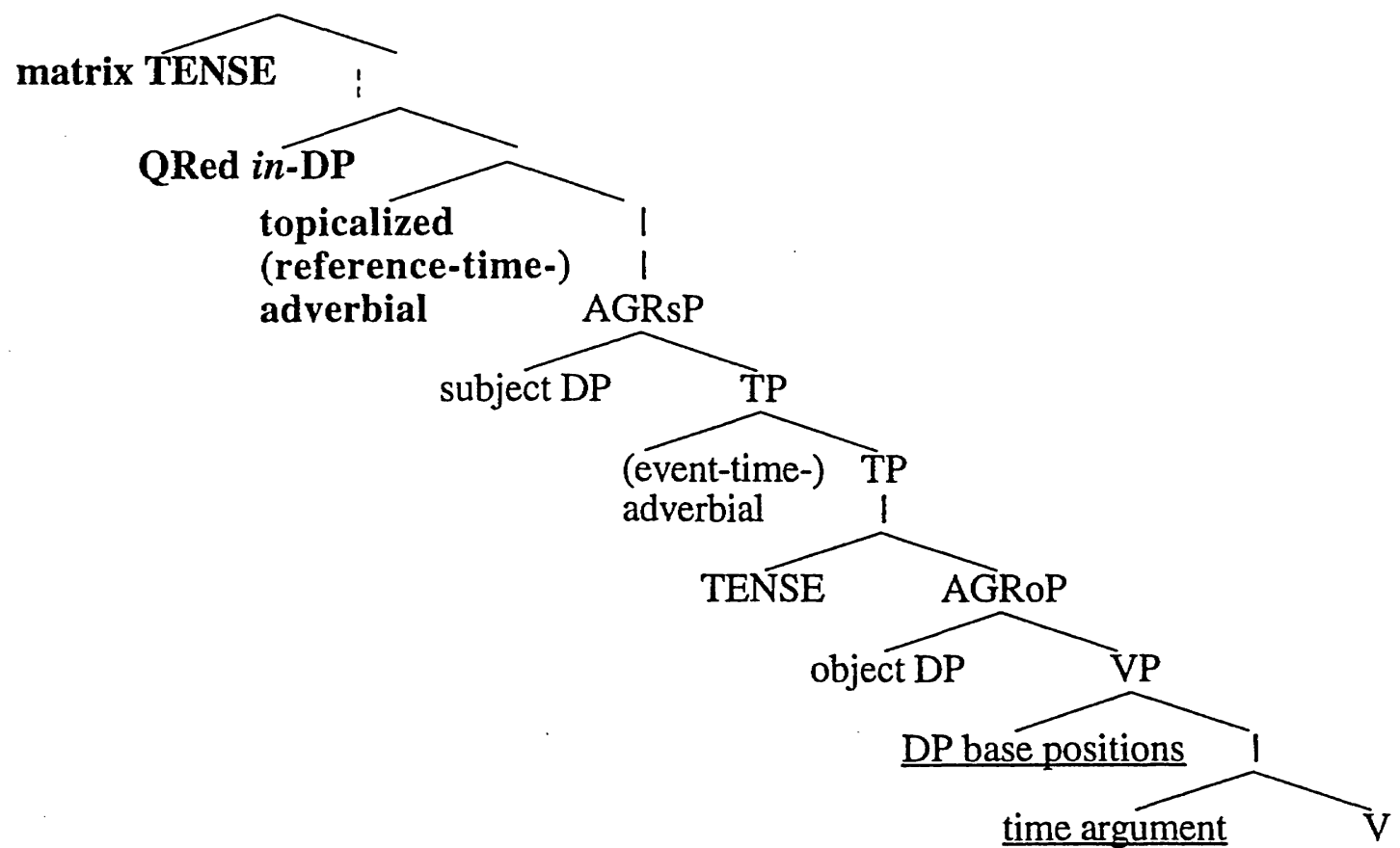
"Azebrafelt likeescaping and took off." - Angelika Krara, An Investigation of the Lumps of Thought -

\section{Conclusion}

In this chapter, I have investigated a particular type of NP-internal modifier, socalled in-modifiers, that differs crucially from other NP-internal modifiers, e.g. ofmodifiers. I have argued that in-modifiers, like if-clauses, belong to the class of obligatory restrictors in natural language. In particular, they can be analyzed as modifiers of resource domain variables. Because of their being inherent restrictors, in-modifiers can only appear as part of restrictive DPs. Since resource domain variables are associated with determiners, the modification of a resource domain variable by an in-modifier leads in turn to an association of the inmodifier with the determiner and furthermore, with the DP. Because of their association with their host DP, in-modifiers can affect temporal elements in the ccommand domain of the DP.

I argued that the effects of in-modifiers are due to their special syntactic properties which are caused by their being modifiers of resource domain variables. For a temporal element to impose ULC-effects on another item, the elements have to stand in a certain syntactic configuration. In particular, the LFposition of the element triggering the ULC-effect has to c-command the Sstructural position of the element that are subject to the ULC.

I want to add here that the occurrence of ULC-effects is even more widespread than the work in this chapter suggested. Recall that we observed in Section 8.2. of Chapter III that the access to predication times of noun phrases was restricted insofar as future times are in general less available. This effect is obviously related to the phenomenon of ULC-effects we saw in this chapter.

Moreover, there are also examples that show ULC-effects in connection with times of existence. The following examples are due to David Pesetsky (pc). Consider the sentence Her crib was beautiful in a situation where we are talking about a baby's crib where the baby has died before but the crib is still there. The 
sentence seems entirely felicitous in that situation. But the future oriented counterpart Her crib will be beautiful in a situation where the baby is not yet conceived but the crib is already present seems rather strange.

Despite the interesting results presented in this chapter, there are many questions left open which require thorough further investigations in order to be answered. Let me conclude by sketching some interesting and important problems for future research:

First, one problem that was mentioned above concerns the class of obligatory restrictors in natural language. We have argued that there is such a class of expressions that hae the property of being obligatory restrictors. This raises the question of what makes certain expressions or types of expressions members of this class.

Second, I observed above that the fixing of upper limits can be captured by saying that elements in their LF-position can fix upper limits, but elements in their base position are subject to the ULC. It would be highly desirable if this aspect of the behavior of temporal elements could be derived from independent principles.

Third, recall that I tentatively concluded that temporal adverbials can fix upper limits when they function as reference-time-adverbials, but not when they function as event-time-adverbials. This raises the question why reference-timeadverbials and event-time-adverbials differ in this way.

Fourth, the specific effects in-modifiers have on the temporal interpretation of the main predicate of their clause provide additional support for the ULC proposed by Abusch (1994). On the other hand, they raise further questions concerning the ULC. It seems that the ULC has a wider range than suggested in Abusch's work: it affects not only relations between matrix tenses and embedded tenses and does not only work in intensional contexts, but it also causes effects between temporal elements within the same clause. Abusch's conceptual explanation of the existence of the ULC is that tenses can only refer to times with which one can be "acquainted" from the perspective of the local evaluation time. Roughly speaking, possible acquaintance relations involve in general some kind of causal connection. Since causal connections can only go backward but not forward, 
forward relations between the local evaluation time and a time referred to by a tense are prohibited. It is not at all clear how this explanation of the background of the ULC could be applied to the case of in-modifiers.

Fifth, it remains unclear why ULC-effects between event times in matrix clauses and embedded clauses are absolutely strict, whereas the effects within clauses are in general not that strong.

\section{How to interpret in-modifiers}

For the sake of simplicity and clarity, I have so far avoided integrating my approach to in-modifiers into a detailed framework of temporal interpretation and my stage-semantics as suggested in Chapter III. Before concluding this chapter, I want to show in this section how in-modifiers can be interpreted in the framework I developed and exploited in this thesis up to this point. To illustrate this, I will go again, and now in detail, through the calculation of the truth conditions of (17), repeated here as (58a).

(58) Most students in the sixties were rebellious.

I will assume here basically the framework of temporal interpretation as developed in Section 3.2. of Chapter II and the stage semantics developed in Chapter III. Moreover, I will assume that the quantificational noun phrase most students in the sixties is raised at LF by Quantifier Raising to a position above the adverb of quantification $\exists$. Thus, (58) has the LF (59). 
(59)

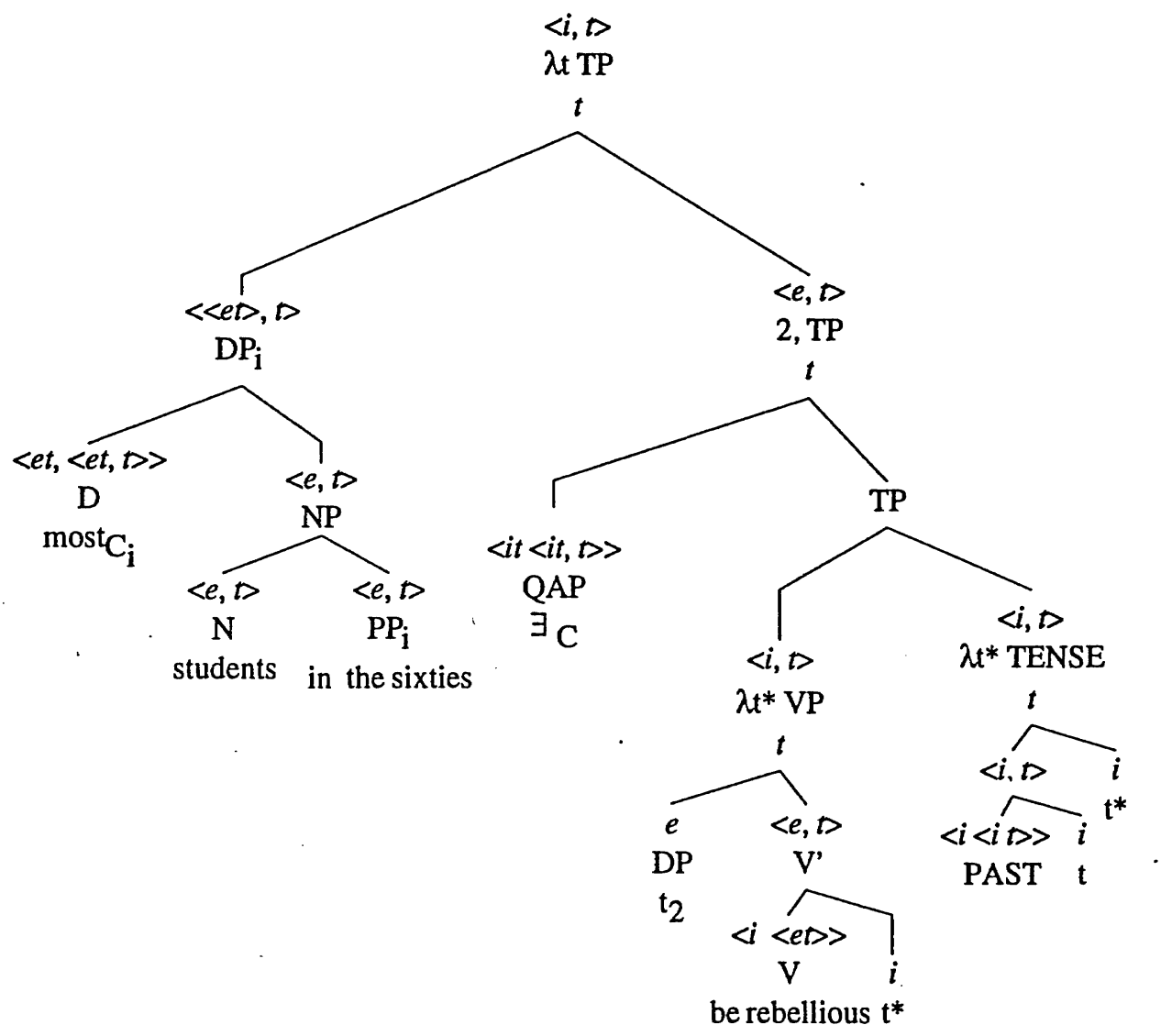

The calculation of truth conditions follows in (60). I will assume that the inmodifier in the sixties and the noun students are interpreted by Predicate Modification, i.e. intersectively.

(60) $\left[\lambda t\left[\text { most }_{C} \text { students in the sixties }\right]_{2}\left[\exists \mathrm{C} \mathrm{t} t_{2}\right.\right.$ were rebellious $\left.\left.]\right]\right]^{c, g}\left(t_{u}\right)=1$ iff [by $\lambda$-Conversion]

[I $\lambda \mathrm{t}\left[\mathrm{most}_{\mathrm{C}} \text { students in the sixties }\right]_{2}$

$\left[\exists \mathrm{C} \mathrm{t}_{2}\right.$ were rebellious $] \rrbracket \mathrm{c}, \mathrm{g}[\mathrm{t} \rightarrow \mathrm{tu}]=1$

iff [by (obligatory) copying of the in-modifier to the resource domain variable and by (optionally) taking the time of the in-modifier as a value for the temporal restriction of $\exists]$

[I [most ${ }_{\text {[in the sixties] }}$ students in the sixties $]_{2}$

$[\exists$ [the sixties $] t_{2}$ were rebellious $\left.]\right]$ c, $g[t \rightarrow t u]$ (now) $=1$

iff [by $2 \times$ Functional Application and the lexical entry of most as suggested in Chapter III]

for most maximal $x_{s t} \in D_{e}$, such that there is a (whole) individual $x$, such that $\mathrm{x}_{\mathrm{st}}$ is a part of $\mathrm{x}$ and there is an $\mathrm{x}_{\mathrm{st}}^{\prime} \in \mathrm{D}_{\mathrm{e}}$ and an $\mathrm{x}_{\mathrm{st}} \in \mathrm{D}_{\mathrm{e}}$, such that $\mathrm{x}_{\mathrm{st}}=\mathrm{x}_{\mathrm{st}}^{\prime} \oplus \mathrm{x}_{\mathrm{st}}$ and 
[Iin the sixties]]c, $\mathrm{g}[\mathrm{t} \rightarrow \mathrm{tu}]\left(\mathrm{x}_{\mathrm{st}}^{\prime}\right)=1$ and

[student in the sixties]] $\mathrm{c}, \mathrm{g}[\mathrm{t} \rightarrow \mathrm{tu}]\left(\mathrm{x}_{\mathrm{st}}\right)=1$, there is a $y_{s t} \in D_{e}$, such that $y_{s t}$ is part of $x_{s t} \in D_{e}$ and

[I $2\left[\exists\right.$ [the sixties] $\mathrm{t}_{2}$ were rebellious $\left.\left.]\right]\right]^{\mathrm{c}, \mathrm{g}[\mathrm{t} \rightarrow \mathrm{tu}]}\left(\mathrm{y}_{\mathrm{st}}\right)=1$

iff [by Predicate Modification, entry of translations, and Tripartite Structure Construction]

for most maximal $x_{s t} \in D_{e}$, such that there is a (whole) individual $x$, such that $\mathrm{x}_{\mathrm{st}}$ is a part of $\mathrm{x}$ and there is an $\mathrm{x}_{\mathrm{st}}^{\prime} \in \mathrm{D}_{\mathrm{e}}$ and an $\mathrm{x}_{\mathrm{st}} \in \mathrm{D}_{\mathrm{e}}$, such that $\mathrm{x}_{\mathrm{st}}=\mathrm{x}_{\mathrm{st}}^{\prime} \oplus \mathrm{x}_{\mathrm{st}}$ and

[[in the sixties]] $\mathrm{c}, \mathrm{g}[\mathrm{t} \rightarrow \mathrm{tu}]\left(\mathrm{x}_{\mathrm{st}}^{\prime}\right)=1$ and

[[student]] $\mathrm{c}, \mathrm{g}[\mathrm{t} \rightarrow \mathrm{tu}]\left(\mathrm{x}_{\mathrm{st}}\right)=1$ and [[in the sixties]] $\mathrm{c}, \mathrm{g}[\mathrm{t} \rightarrow \mathrm{tu}]\left(\mathrm{x}_{\mathrm{st}}\right)=1$, there is a $y_{s t} \in D_{e}$, such that $y_{s t}$ is part of $x_{s t} \in D_{e}$ and

[I $2\left[\left(\exists\left[\lambda t^{*}\left(\left[\right.\right.\right.\right.\right.$ the sixties] $\left.\left(t^{*}\right)\right) \& \lambda t^{*}\left(\right.$ PAST $\left.\left.(t)\left(t^{*}\right)\right)\right]$

$\left[\lambda t^{*}\right.$ (be rebellious $\left.\left.\left.\left.\left.\left(t^{*}\right)\left(t_{2}\right)\right)\right]\right)\right]\right]$ c, $g[t \rightarrow t u]\left(y_{s t}\right)=1$

iff [by Predicate Abstraction and lexical entries related to student in the sixties]

for most maximal $x_{s t} \in D_{e}$, such that there is a (whole) individual $x$, such that $\mathrm{x}_{\mathrm{st}}$ is a part of $\mathrm{x}$ and there is an $\mathrm{x}_{\mathrm{st}}^{\prime} \in \mathrm{D}_{\mathrm{e}}$ and an $\mathrm{x}^{\prime \prime}{ }_{\mathrm{st}} \in \mathrm{D}_{\mathrm{e}}$, such that $\mathrm{x}_{\mathrm{st}}=\mathrm{x}_{\mathrm{st}}^{\prime} \oplus \mathrm{x}_{\mathrm{st}}$ and

$\mathrm{x}_{\text {st }}^{\prime}$ is located in the sixties and

$\mathrm{X}_{\mathrm{st}}$ st is a student and $\mathrm{x}_{\mathrm{st}}$ is located in the sixties,

there is a $y_{s t} \in D_{e}$, such that $y_{s t}$ is part of $x_{s t} \in D_{e}$ and

$\left[\left[\exists\left[\lambda t^{*}\left(\left[\right.\right.\right.\right.\right.$ the sixties] $\left.\left.\left(t^{*}\right)\right) \& \lambda t^{*}\left(\operatorname{PAST}(t)\left(t^{*}\right)\right)\right]$

$$
\left.\left.\left.\left[\lambda t^{*} \text { (be rebellious }\left(t^{*}\right)\left(t_{2}\right)\right)\right]\right]\right] \text { c, g }\left[\begin{array}{l}
\mathrm{t} \rightarrow \mathrm{tu} \\
2 \rightarrow \mathrm{y}-\mathrm{st} t
\end{array}\right]=1
$$

iff [by lexical entry of $\exists$ and Predicate Modification applied to the restrictive clause]

for most maximal $x_{s t} \in D_{e}$, such that there is a (whole) individual $x$, such that $x_{s t}$ is a part of $x$ and there is an $x_{s t}^{\prime} \in D_{e}$ and an $x_{s t}{ }_{s t} \in D_{e}$, such that $\mathrm{x}_{\mathrm{st}}=\mathrm{x}_{\mathrm{st}}^{\prime} \oplus \mathrm{x}_{\mathrm{st}}$ and

$\mathrm{x}_{\text {st }}^{\prime}$ is located in the sixties and

$\mathrm{x}^{\prime \prime}{ }_{\mathrm{st}}$ is a student and $\mathrm{x}_{\mathrm{st}}$ is located in the sixties,

there is a $y_{s t} \in D_{e}$, such that $y_{s t}$ is part of $x_{s t} \in D_{e}$ and

there is a time $t^{*}$ such that

II $\lambda \mathrm{t}^{*}\left(\left[\right.\right.$ the sixties] $\left.\left.\left.\left(\mathrm{t}^{*}\right)\right)\right]\right] \mathrm{c}, \mathrm{g}\left[\begin{array}{l}\mathrm{t} \rightarrow \mathrm{tu} \\ 2 \rightarrow \mathrm{y}-\mathrm{st}\end{array}\right]\left(\mathrm{t}^{*}\right)=1$ and

$\left.\left[\lambda \mathrm{t}^{*}\left(\operatorname{PAST}(\mathrm{t})\left(\mathrm{t}^{*}\right)\right)\right]\right]^{\mathrm{c}, \mathrm{g}}\left[\begin{array}{l}\mathrm{t} \rightarrow \mathrm{tu} \\ 2 \rightarrow \mathrm{y}-\mathrm{st}\end{array}\right]\left(\mathrm{t}^{*}\right)=1$ and

$\left[\left[\lambda t^{*}\right.\right.$ (be rebellious $\left.\left.\left.\left(t^{*}\right)\left(t_{2}\right)\right)\right]\right]^{c, g}\left[\begin{array}{c}t \rightarrow t u \\ 2 \rightarrow y-s t\end{array}\right]\left(t^{*}\right)=1$

iff [by $\lambda$-Conversion]

for most maximal $x_{s t} \in D_{e}$, such that there is a (whole) individual $\mathrm{x}$, such that $\mathrm{x}_{\mathrm{st}}$ is a part of $\mathrm{x}$ and there is an $\mathrm{x}_{\mathrm{st}}^{\prime} \in \mathrm{D}_{\mathrm{e}}$ and an $\mathrm{x}_{\mathrm{st}}{ }_{\mathrm{s}} \in \mathrm{D}_{\mathrm{e}}$, such that $\mathrm{x}_{\mathrm{st}}=\mathrm{x}_{\mathrm{st}}^{\prime} \oplus \mathrm{x}_{\mathrm{st}}^{\prime \prime}$ and

$\mathrm{x}_{\text {st }}^{\prime}$ is located in the sixties and

$\mathrm{X}^{\prime \prime}{ }_{\mathrm{st}}$ is a student and $\mathrm{x}_{\mathrm{st}}$ is located in the sixties, 
there is a $y_{s t} \in D_{e}$, such that $y_{s t}$ is part of $x_{s t} \in D_{e}$ and there is a time $t^{*}$ such that

$\left[\right.$ [the sixties] $\left.\left.\left(t^{*}\right)\right]\right]^{c, g}\left[\begin{array}{c}t \rightarrow t u \\ 2 \rightarrow y-s t \\ t^{*} \rightarrow t^{*}\end{array}\right]=1$ and

[IPAST $\left.\left.(t)\left(t^{*}\right)\right]\right]^{c, g}\left[\begin{array}{c}t \rightarrow t u \\ 2 \rightarrow y-s t \\ t^{*} \rightarrow t^{*}\end{array}\right]=1$ and

[L be rebellious $\left.\left.\left(t^{*}\right)\left(t_{2}\right)\right]\right] c, g\left[\begin{array}{c}t \rightarrow t u \\ 2 \rightarrow y-s t \\ t^{*} \rightarrow t^{*}\end{array}\right]=1$

iff [by lexical entries of the remaining elements, variable assignment applied to $t, t^{*}$, and $t_{2}$ ]

for most maximal $x_{s t} \in D_{e}$, such that there is a (whole) individual $x$, such that $\mathrm{x}_{\mathrm{st}}$ is a part of $\mathrm{x}$ and there is an $\mathrm{x}_{\mathrm{st}}^{\prime} \in \mathrm{D}_{\mathrm{e}}$ and an $\mathrm{x}_{\mathrm{st}} \in \mathrm{D}_{\mathrm{e}}$, such that $\mathrm{x}_{\mathrm{st}}=\mathrm{x}_{\mathrm{st}}^{\prime} \oplus \mathrm{x}_{\mathrm{st}}$ and

$\mathrm{x}_{\text {st }}^{\prime}$ is located in the sixties and

$\mathrm{x}^{\prime \prime}{ }_{\mathrm{st}}$ is a student and $\mathrm{x}_{\mathrm{st}}$ is located in the sixties,

there is a $y_{s t} \in D_{e}$, such that $y_{s t}$ is part of $x_{s t} \in D_{e}$ and

there is a time $t^{*}$ such that

$t^{*}$ is a subinterval of the time in the sixties, and

$t^{*}<t_{u}$, and

( $\mathrm{y}_{\mathrm{st}}$ is alive at $\mathrm{t}^{*}$, and)

$y_{s t}$ is rebellious at $t^{*}$.

As should be obvious at this point, the occurrence of ULC-effects does not follow from independently exploited principles of temporal interpretation. Rather, clauses containing in-modifiers that violate the ULC are perfectly interpretable and yield interpretations that seem, on a theoretical level, just as fine as interpretations of clauses that don't show ULC-effects. Thus, for a sentence like (59), which involves an ULC-violation, we would get the truth conditions in (60), which seem quite reasonable. 
(59)*? Most students in the forties were rebellious in the sixties.

(60) $\llbracket \lambda t\left[\text { most }_{C} \text { students in the forties }\right]_{2}$

$\left[\exists\right.$ [in the sixties] $t_{2}$ were rebellious $\left.]\right]^{c, g}\left(t_{u}\right)=1$

iff for most maximal $x_{s t} \in D_{e}$, such that there is a (whole) individual $x$, such that $x_{s t}$ is a part of $x$ and there is an $x_{s t}^{\prime} \in D_{e}$ and an $x_{s t}^{\prime \prime} \in D_{e}$, such that $\mathrm{x}_{\mathrm{st}}=\mathrm{x}_{\mathrm{st}}^{\prime} \oplus \mathrm{x}_{\mathrm{st}}^{\prime}$ and

$\mathrm{x}_{\text {st }}^{\prime}$ is located in the forties and

$\mathrm{x}^{\prime \prime}$ st is a student and

$\mathrm{X}_{\text {st }}$ is located in the forties, there is a $y_{s t} \in D_{e}$, such that $y_{s t}$ is part of $x_{s t} \in D_{e}$ and there is a time $\mathrm{t}^{*}$ such that

$t^{*}$ is a subinterval of the time in the sixties

$\mathrm{t}^{*}<\mathrm{tu}_{\mathrm{u}}$, and

( $y_{s t}$ is alive at $t^{*}$, and)

$y_{s t}$ is rebellious at $t^{*}$.

Thus, it is clear that the ULC is a constraint that has to be stipulated in addition to the semantics we have developed so far. 
"Wichtig ist, woraufes ankommt. Und umgekehtr."

-Ede-

\section{Chapter V. CONCLUSION AND SPECUlations}

\section{Results achieved in previous chapters}

In Chapters II-IV, I investigated the temporal interpretation of noun phrases. The most important results were achieved in Chapter II and Chapter III, where I explored the temporal location of individuals and the temporal location of predication times, respectively. Let me present here a survey of the relevant components of these two aspects of sentence interpretation.

\section{TEMPORAL LOCATION OF INDIVIDUALS}

Is the temporal location of existence times of individuals affected by the temporal interpretation of the rest of the clause? Previous result: yes.

My result: no - at least not directly.

How come previous research didn't come to this conclusion? - Because life-time effects were treated as a semantic phenomenon. In fact, they are a pragmatic phenomenon.

\section{TEMPORAL LOCATION OF PREDICATION} TIMES

Is the temporal location of predication times of nouns affected by the temporal interpretation of the rest of the clause? Previous result: no.

My result: yes, because determiners quantify over stages of individuals.

How come previous research didn't come to this conclusion? - Because it doesn't always show; some noun phrases are temporally independent. 
What does tense do?

- Individuals are not located by tense.

- Tenses (and temporal adverbials) locate the time

within which a truth interval of the main predicate is asserted to exist.

What is crucial to the temporal location of individuals?

- Some predicates impose life-time presuppositions on (some of) their arguments. I.e., most individuals must exist at the asserted predication time of the predicate that introduces them.

What does the semantics do?

- With a sentence of the form "At that time, a was $\mathbf{P}$ ", where "P" stands for a predicate that imposes a life-time presupposition on its subject argument, it is presupposed that a exists at that time.
What does tense do?

- Predication times are not located by tense.

- Tenses (and temporal adverbials) locate the time within which a truth interval of the main predicate is asserted to exist.

\section{What is crucial to the temporal location of} predication times?

- Determiner-quantifiers quantify over stages of individuals. Specifically, they quantify over the largest stages that satisfy the (implicit or explicit) restrictive predicates of the quantifier:

[everyC $P$ was $Q \rrbracket=1$ iff every maximal stage $\mathrm{x}_{\mathbf{S t}}$ that satisfies $\mathbf{C}$ AND $\mathbf{P}$ contains a part $\mathrm{y}_{\mathrm{st}}$ that satisfies $\mathbf{Q}$.

What does the semantics do?

- Roughly speaking,

1. the predication time of $Q$ is located by tense, e.g.

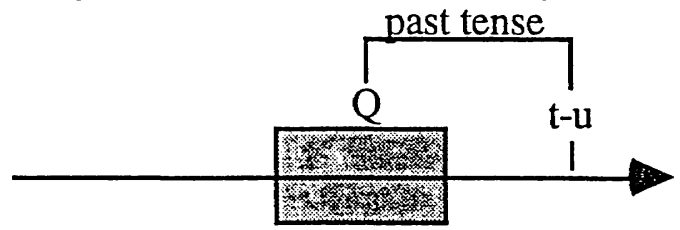

2. $y_{s t}$ is located by the life-time presupposition of $\mathrm{Q}$ : with most predicates, the time of $y_{\text {st }}$ must be part of the predication time of $\mathrm{Q}$,

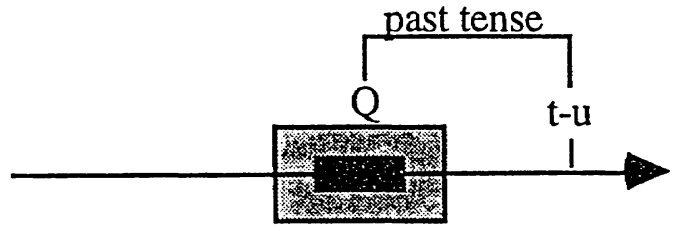

3. $x_{s t}$ is located by the relation that the lexical entry of a determiner-quantifier imposes on $\mathrm{x}_{\mathrm{St}}$ and yst:

$\mathrm{x}_{\text {St }}$ must include $\mathrm{y}_{\mathrm{st}}$.

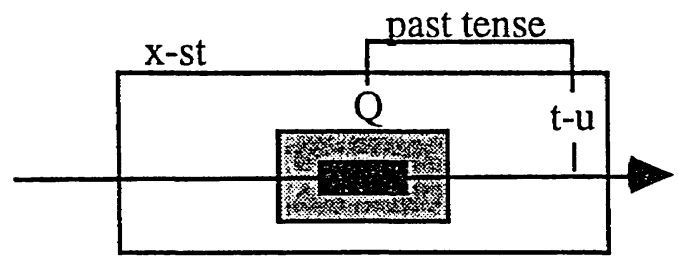

4. the predication time of $\mathrm{P}$ and $\mathrm{C}$ is located a. by the relation that the lexical entry of the determiner-quantifier imposes on $\mathrm{P}$ and $\mathrm{C}$ and $\mathrm{x}_{\mathrm{st}}$ : basically, the (sum of the) predication time(s) of $P$ and $\mathrm{C}$ coincides with the time of $\mathrm{x}_{\mathrm{st}}$. 
Pragmatics

(1) A proposition $\Phi$ is more informative than a proposition $\Psi$ if and only if

1. for all worlds $w$ such that $\Phi$ is true in $w, \Psi$ is true in $w$, and

2. it is not the case that for all worlds $w^{*}$ such that

$\Psi$ is true in $w^{*}, \Phi$ is true in $w^{*}$.

(2) 1. For all worlds w such that "A is $\mathbf{B}$ " is true in $\mathrm{w}$, "A was B" is true in $\mathrm{w}$, and

2. It is not the case that for all worlds $w^{*}$ such that

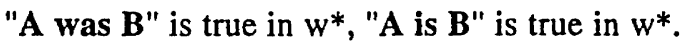

(3) Maxim of quality: Be informative.

Consequence 1: If both " $\mathbf{A}$ is $B$ " and "A was $B$ " are true, use "A is B".

Consequence 2: If "A was B" is used, one concludes that "A is $\mathbf{B}$ " is not true. I.e., $\mathbf{A}$ 's being $\mathbf{B}$ is over. I.e., if "B" is an individual-level predicate, $\mathbf{A}$ doesn't exist anymore.

This effect can be neutralized by temporally specific contexts. If "Yesterday, A was B" is used, the present tense version of the clause is not an appropriate alternative. b. by the life-time presupposition that $\mathrm{P}$ and $\mathrm{C}$ impose on $\mathrm{x}_{\mathrm{St}}$ : with most predicates ${ }^{1}$, the predication time of $\mathrm{P}$ and $\mathrm{C}$ must include $\mathrm{x}_{\mathrm{St}}{ }^{2}$

\section{Pragmatics}

Temporal restrictions, explicit ones as well as implicit ones, can modify resource domain variables of noun phrases. Because of this, stages introduced by the restrictive material of a determiner-quantifier can be extended beyond the predication time of the overt restrictors.

As should be obvious from the summary above, the role of pragmatics and the role of semantics are differently weighted for the temporal location of individuals and the temporal location of predication times. For phenomena concerning the former aspect of the temporal interpretation of noun phrases, the pragmatics does more work than the semantics, whereas for the latter aspect, the semantics does more work.

In the course of this thesis, I investigated various aspects of the interaction between the temporal interpretation of main predicates and noun phrase interpretation. We have seen that there are some interesting connections between the temporal interpretation of main predicates and noun phrase interpretation. Here is a list of some important results:

- Existence times introduced by topic noun phrases can provide time intervals that serve as values for implicit temporal restrictions of temporal adverbs of

1 Maybe with all predicates, as far as nouns are concerned - cf. the contrast Frege ist berühmt vs. \#Frege ist eine Berühmtheit.

2 At first sight, $4 \mathrm{a}$ and $4 \mathrm{~b}$ appear redundant and one might think that $4 \mathrm{a}$ is dispensable. But this would lead to wrong predictions: we need the maximal stages that satisfy the restrictive material. 
quantification in their clause. Evidence for this was presented in Chapter II in order to explain the presence or absence of life-time effects. Since it was shown that topichood plays a role for the triggering of this restricting effect, we can safely assume that the effect is not syntactically governed, but mediated by the context.

- Implicit temporal restrictions and explicit temporal adverbials can modify resource domain variables of noun phrases. I argued for this in Chapter III. I also presented an argument exploiting functionally interpreted temporal adverbials that proved that the crucial modification of resource domain variables must be able to happen indirectly (i.e., via the context) and not directly (for instance, via binding).

- In Chapter IV, I argued that resource domain variables of quantificational noun phrases can also be modified by in-modifiers. This assumption was used to explain the distribution of in-modifiers and also their ability to impose upper limit effects on the event time of their clause. According to what I said in Chapter IV, the effects of in-modifiers on the event time undergo syntactic restrictions. I.e., they are not mediated by the context.

We have thus seen that temporal interpretation on the one hand side and noun phrase interpretation on the other hand side affect each other in several respects. Interestingly, the effects between these two components of interpretation can be attributed to a large extent to effects that elements of one component have on quantifier restrictions of the other component: times of existence introduced by noun phrases provide implicit restrictions for temporal adverbs of quantification, temporal restrictions can also restrict determinerquantifiers, and in-modifiers affect the resource domain variable of their host DP.

As far as the interactions of temporal interpretation and noun phrase interpretation are concerned, we have thus arrived at a picture roughly as follows, where elements and processes concerning the temporal interpretation of noun phrases appear on the left side of the chart below and elements and processes concerning the temporal interpretation of the main predicate of a clause (including temporal adverbials and tense) appear on the right side: 
DPs introduce individuals (or stages of individuals).

These have times of existence which can provide values for

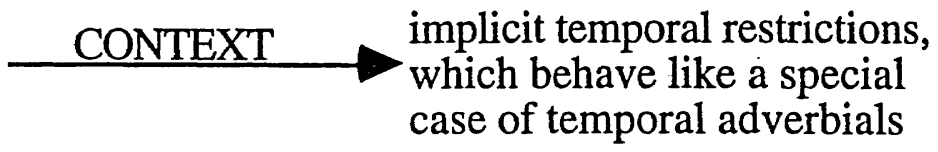

DPs can bind variables in temporal adverbials and lead to functionally interpreted temporal adverbials

resource domain variables (RDVs) of determiners

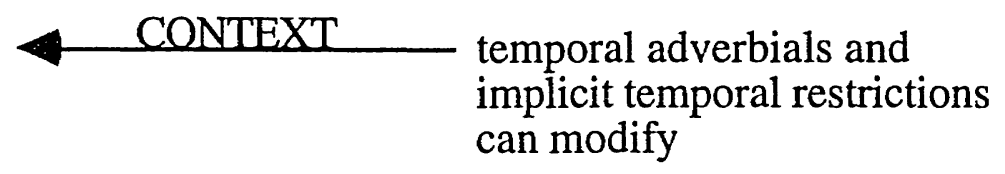

in-modifiers in noun phrases are modifiers of the RDV of the DP they are contained in

impose upper limits on the event time of their clause

In the remainder of this chapter, I want to consider some speculations about the possibilities of extending the proposals I presented in this thesis. In particular, I want to sketch connections to some issues that are not directly related to temporal interpretation but that, in my opinion, deserve some comparative consideration in continuing research, namely spatial aspects and modal aspects of noun phrase interpretation.

\section{Possible extensions I: Time and space}

The stages I exploited in this thesis, especially in Chapter III, were defined as temporal parts of individuals. So far, I did not at all care about the spatial dimension. In the literature, stages have usually been constructed as temporalspatial parts of individuals. ${ }^{3}$ Thus, one may want to investigate whether a slightly differently constructed ontology in these terms makes interesting predictions

3 See for instance Goodman (1951), Quine (1960), Carlson (1977), Hinrichs (1985), Lewis (1986), and Paul (1994). 
about natural language. Quite in general, temporal and spatial aspects are often seen in connection with each other.

In analogy to the research presented in this thesis, one of the questions to ask is how individuals that are introduced by noun phrases are spatially located with respect to the eventuality of their clause. The answer to this question seems pretty straightforward: just as some predicates impose temporal presuppositions i.e., what I called "life-time presuppositions" - on their arguments, some predicates also impose locative presuppositions on their arguments. For example, in order to perform an action of running around Building 20, one obviously has to be present both at the time and at the place where the action of running occurs. It is not necessarily the case that temporal presuppositions and locative presuppositions imposed on individuals are simultaneously present.

Note though that there is an important difference concerning the temporal and spatial location of individuals. Since - at least in the languages I have been considering in this thesis - there are no locative elements corresponding to tenses, there won't be any locative effects corresponding to life-time effects - i.e., there won't be any locative "having-left-the-scene"-effects.

To follow the line of investigation concerning the temporal interpretation of noun phrases, a second question to ask is whether it makes sense to distinguish anything like spatially dependent and spatially independent readings of noun phrases. Keeping things analogous to the question of temporal dependence of noun phrases, a spatially dependent reading of a noun phrase would be one where the place where the noun can be truly predicated of an individual has to coincide with the place where the eventuality denoted by the main predicate of the clause is located.

Of course, there are more open questions about the relation between the temporal interpretation of noun phrases and their spatial interpretation that deserve being considered. We have seen at least one interesting case of interaction between temporal and spatial interpretation, namely with the behavior of in-modifiers in Chapter IV: we observed that spatial in-modifiers also have a restriction with respect to their distribution, i.e., they also seem to be restricted to presuppositional noun phrases. - In general, it seems desirable to aim at a detailed analysis of the ways in which temporal and spatial interpretation are similar, and in what respects they differ. 


\section{Possible extensions II: Times and worlds}

Similarly to the case of the spatial dimension, one might also want to consider cross-world aspects of noun phrase interpretation in comparison to their temporal interpretation. An important question to ask is under which circumstances the interpretation of noun phrases is bound to particular worlds and under which circumstances it isn't. Furthermore, we may ask how world-dependent and worldindependent interpretations of noun phrases relate to temporally dependent and independent interpretations.

Let me illustrate with an example what world-dependent and worldindependent interpretations of noun phrases may look like. The following example (1a) has at least two possible readings, (1b) and (1c), depending on whether the king's belief is about someone who is the archbishop in the actual world or not. For reading (1b) to be true, there has to exist an archbishop in the actual world, while for (1c) to be true there doesn't have to exist an actual archbishop. 4

(1) a. The king believes that the archbishop is bald..$^{5}$

b. In all the possible worlds w* compatible with what the king in the actual world $\mathrm{w}_{0}$ believes in $\mathrm{w}_{0}$, it is the case that the individual who is the archbishop in $\mathrm{w}_{0}$ is bald in $\mathrm{w}^{*}$.

c. In all the possible worlds $\mathrm{w}^{*}$ compatible with what the king in the actual world $\mathrm{w}_{0}$ believes in $\mathrm{w}_{0}$, it is the case that the individual who is the archbishop in $\mathrm{w}^{*}$ is bald in $\mathrm{w}^{*}$.

Analogous to the notion of temporally (in)dependent noun phrase interpretation, I used in the preceding chapters, I will call the noun phrase the archbishop in (1b) WORLD-INDEPENDENTLY INTERPRETED because it can be interpreted relative to $\mathrm{w}_{0}$, a world which is not the evaluation world of the main predicate be bald.

In the remainder of this section, I only want to sketch some points that I consider important for an investigation of the world-interpretation of noun phrases. Although I am not in a position to achieve much in terms of results, I hope to be able to sketch at least some promising questions and directions for future research.

4 The example is my English version of an example of Bäuerle $(1983,130)$.

5 Paraphrases for propositional attitude sentences basically like the ones in (1b) and (1c) are suggested by Hintikka $(1969,145)$. 


\subsection{Basic considerations}

There is at least one crucial difference between considering world-dependence and considering time-dependence of noun phrases. This difference has to do with the basic ontology of individuals in relation to possible worlds. There have been two views on this issue defended in the literature. One is that individuals strictly belong to one world only and cannot be extended across worlds (cf. Lewis (1968, 1986)); a particular individual in one world may have a COUNTERPART in another world, but the individual itself exists exclusively in one world. The other, more traditional, view is that a particular individual can be present in different worlds.

Depending on which view we take, our perspective on individuals implies already to a certain extent that we can say certain things about the worldinterpretation of noun phrases, but not others. Consequently, the ontological assumptions might restrict us too much for us to express what we want to say. Whether this is the case or not is, of course, ultimately an empirical question. But I think it is in any case important to be aware of it.

For instance, if we take the counterpart-view of individuals, then of course it doesn't make sense to think literally about individuals having different properties in different worlds in the same way in which we thought about individuals having different properties at different times. Consider the following example (2a) and its rough paraphrases in (2b) and (2c). ${ }^{6}$

(2) a. John thinks that every cat meowed.

b. In all the possible worlds w* compatible with what John believes in $\mathrm{w}_{0}$, it is the case that every individual who is a cat in $\mathrm{w}_{0}$ meowed in $\mathrm{w}^{*}$.

c. In all the possible worlds w* compatible with what John believes in $\mathrm{w}_{0}$, it is the case that every individual who is a cat in $\mathrm{w}^{*}$ meowed in $\mathrm{w}^{*}$.

Suppose we took the counterpart-view of individuals. If individuals can't extend across worlds, then it doesn't make sense to say that a cat that exists in one world meows in another world - he simply can't meow in a world other than his world, because he has to exist in order to be able to meow. Thus, (2b), if taken literally,

6 The example is taken from Cresti $(1995,11)$. 
doesn't make sense. Thus, the paraphrase ( $2 b)$ should be reformulated to something like $\left(2 b^{\prime}\right)$. (2c) could be reformulated as $\left(2 c^{\prime}\right)$.

(2) b'. In all the possible worlds w* compatible with what John believes in $\mathrm{w}_{0}$, it is the case that every individual in $\mathrm{w}_{0}$ that is a cat has a counterpart $\mathrm{y}$ in $\mathrm{w}^{*}$ such that $\mathrm{y}$ meows (in $\mathrm{w}^{*}$ ).

c'. In all the possible worlds $\mathrm{w}^{*}$ compatible with what John believes in $\mathrm{w}_{0}$, it is the case that every individual in $\mathrm{w}^{*}$ that is a cat meowed (in $\left.\mathrm{w}^{*}\right)$.

Note that this formulation shows that when investigating the world-interpretation of noun phrases under a strict counterpart-theory of individuals, we couldn't really say anything about the world-location of properties (i.e. what corresponds in the investigation of the temporal interpretation of noun phrases to the temporal location of predication times). Instead we would have to investigate the worldlocation of individuals and their options of establishing relationships to counterparts in other worlds.

Thus, under the counterpart-view of individuals, a formulation like (3a) below means the same as (3b). I.e. it doesn't play an important role in the question of whether the world-interpretation of the noun phrase we saw above is taken as a world-argument of the noun or as a restriction on quantification.
a. $\quad$ "all individuals $\mathrm{x}$, such that $\mathrm{x}$ is a cat in $\mathrm{w}^{*}$ "
b. "all individuals $\mathrm{x}$ in $\mathrm{w}^{*}$ such that $\mathrm{x}$ is a cat"

All this of course does not mean that the world-dependence of noun phrases can't be investigated under a counterpart-view of individuals. This is even more so since it is of course possible to construe trans-world individuals, or MODAL CONTINUANTS, in a counterpart theory of individuals. This can be done by construing cross-world sums of individuals that are counterparts of each other. The single "original" individuals can then be viewed as world-stages of the crossworld sum. Lewis $(1968,40 \mathrm{ff})$ considers this possibility. I just think that using a version of the counterpart-theory might be somewhat confusing, because some parallels to results concerning the temporal interpretation of noun phrases might be lost. Hence I will assume for the present purpose that individuals can be modal continuants. For the moment, I want to leave open whether these modal continuants should be treated as primitives in the ontology or as entities constructed from sets of counterparts of individuals. 


\subsection{Previous results: Bäuerle (1983)}

In a paper on noun phrase interpretation, Bäuerle (1983) suggests to treat the distinction between transparent and opaque readings, which has traditionally been viewed as a semantic ambiguity, as a pragmatic phenomenon. Here is an illustration of the ambiguity. According to Bäuerle, (4a) can be true in two different sets of possible worlds, (4b) and (4c). Under its opaque reading, (4a) is true in worlds from the set described in (4b); under its transparent reading, it is true in worlds from the set described in (4c). ${ }^{7}$
a. Ismay wants to marry the king of France.
b. the set of worlds $u$ in which Ismay has the wish to marry someone who is the king of France
c. the set of worlds $v$ such that there is exactly one king of France in $v$ and Ismay wants to marry him in $\mathrm{v}$

Thus, under the transparent reading, the noun phrase is interpreted relative to the actual world. Under the opaque reading, it is interpreted relative to some nonactual world:

Bäuerle's arguments in favor of a pragmatic treatment are derived from scope paradoxes that arise when the ambiguity is treated as a scope phenomenon (pp123f). For instance, (5a) has a reading that can be roughly paraphrased as (5b). Under this reading, Georg believes that there is a woman from Stuttgart who loves every actual player of the $\operatorname{VfB} .8$ Since the woman in question may only exist in Georg's belief-world, the underlined noun phrase, under this reading, is interpreted relative to Georg's belief-worlds w*.

(5) a. Georg believes that a woman from Stuttgart loves every player of the VfB.

b. In all the possible worlds w* compatible with what George believes in $\mathrm{w}_{0}$, it is the case that there is a woman from Stuttgart in $\mathrm{w}^{*}$ who loves in $\mathrm{w}^{*}$ every player of the VfB in $\mathrm{w}_{0}$.

7 To be precise, (4c) is relevant for the transparent-attributive reading of the noun phrase the king of France. There is also a transparent-referential reading where (4a) is true in worlds belonging to the set of worlds $w$ such that there is in w a particular person a such that Ismay wants to marry a in $\mathrm{w}$, and coincidentally a is in the actual world the king of France (Bäuerle $(1983,121)$ ). Since the attributive/referential distinction is irrelevant for our present purpose, I will ignore this reading completely. - The examples here are taken from Bäuerle's paper but are translated into English.

8 I think the VfB is a famous German soccer team. 
It seems plausible at first sight, and has often been assumed, that the transparent and opaque readings are due to the scope of the noun phrase. Basically, the idea is that a noun phrase is transparent when having wider scope than a beliefoperator and opaque when it has narrower scope. For (5a), this approach may give rise to the readings in (6).
a. There is an (actual) woman $\mathrm{x}$ from Stuttgart such that for every (actual) player of the VfB y, Georg believes that $x$ loves $y$.
b. There is an (actual) woman $x$ from Stuttgart such that Georg believes that for every player of the VfB y, $x$ loves $y$.
c. For every (actual) player of the VfB y, there is an (actual) woman $\mathrm{x}$ from Stuttgart such that Georg believes that $x$ loves $y$.
d. For every (actual) player of the VfB y, Georg believes that there is a woman from Stuttgart $x$ such that $x$ loves $y$.

The problem is that none of these representations captures the occurrence of the possible reading (5b) from above. In fact, in a scope approach, (5b) is not representable at all, because $(5 b)$ implies three different scope requirements which are obviously incompatible: ${ }^{9}$

$$
\begin{aligned}
& \text { believe }<\text { a woman from Stuttgart } \\
& \text { every player of the } \mathrm{VfB}<\text { believe } \\
& \text { a woman from Stuttgart }<\text { every player of the VfB }
\end{aligned}
$$

The occurrence of such scope paradoxes is reminiscent of some of Enç's arguments concerning the temporal interpretation of noun phrases (Chapter I, Section 2.1.). Actually, Bäuerle remarks that noun phrases seem to behave in a largely parallel manner, insofar as their temporal and their world-interpretation is concerned (p124). Interestingly, independently of Enç (1981), Bäuerle develops an indexical analysis of noun phrases that is very similar to Enç's analysis.

Specifically, Bäuerle suggests to treat the occurrence of transparent and opaque readings of noun phrases in terms of pragmatically assigned indices. His idea is that during interpretation, a store is created that contains a list of contextually salient evaluation worlds. ${ }^{10}$ Verbs of propositional attitudes shift the

\footnotetext{
9 This is in fact only so for a simple scope approach. Irene Heim (pc) pointed out to me that one can get the relevant reading by quantifying in the NP player of the VfB. This mechanism gives rise to LFs like (A).

(A) player of the $\operatorname{VfB} \lambda \mathrm{X}$ [George believes that a woman from Stuttgart loves every $\mathrm{X}$ ] 10 His treatment of evaluation times is analogous.
} 
evaluation index of a clause and thus provide a new evaluation world in the store. Hence they make it possible to gain access to different world-indices for noun phrases.

\subsection{Individuals and worlds}

I think that the notion of shifting evaluation indices can be enhanced by making more precise what it means for evaluation indices to be shifted. Let me say that when a predicate shifts the evaluation index for the interpretation of one of its arguments, then it does so because it doesn't impose a SAME-WORLDPRESUPPOSITION on these arguments. Since shifting the evaluation index with a verb like believe does not only give access to a particular, single world, but to a certain set of worlds that can be characerized in a certain way (namely by the content of the belief), the shifting of the evaluation index is associated with quantification over worlds - in the paraphrases exploited above, with universal quantification. Viewed from the other perspective, I want to say that most predicates impose same-world-presuppositions on their arguments.

The idea behind the concept of same-world-presuppositions is very simple. Moreover, it is very similar to the idea behind the concept of life-time presuppositions which I introduced in Chapter II. We can do many things to individuals in the actual world, but we can't do too many things to individuals in other worlds. We can, for instance, think about non-actual individuals, i.e. individuals in other worlds, or want to have individuals that exist only in other worlds, but we can't meet or see individuals in worlds other than the actual world.

\subsection{Properties of individuals and worlds}

In the preceding subsection, I have briefly outlined how one might approach the question of the world-location of individuals. Another question now is what we can say about the world-location of properties of individuals.

A first question to ask is under which conditions is it possible at all to ascribe to individuals properties they have in a world other than the actual world?

A second question to ask is under which conditions can a noun be interpreted world-independently? Note that this is a question that should be carefully distinguished from the first question. The first questions asks under 
which circumstances we have the possibility to switch to worlds other than the actual world for interpreting a noun phrase; the second question asks under which circumstances we really have a free choice of evaluation worlds, provided that there is a possibility to switch.

I think that the first question is easy to answer, and it can be answered by just considering the assumptions established above: given the existence of sameworld-presuppositions postulated in the preceding subsection, we expect that we can ascribe to an individual properties it has in a non-actual world whenever one of the following situations is given:

- the individual occurs in a linguistic context where a predicate of which it is an argument does not impose a same-world-presupposition on it (as in (8a) below), or

- the individual is part of an argument of a predicate that does not impose a same-world-presupposition on that argument (as in (8b)), or

- there is a contextually salient world other than the actual world introduced into the discourse context, for instance by a WORLD FRAME ADVERBIAL; in this case, the adverbial also determines the world relative to which the main predicate of the clause is interpreted (as in (8c)).

Here are some examples that illustrate each of these cases. ${ }^{11}$

(8) a. Ismay is looking for the king of France.

b. Ismay believes [that the king of France loves her]

c. In Ismay's dream, the king of France married her.

The second question is much more difficult to answer, and it can only be answered on the basis of an empirical investigation of linguistic data. It would be quite nice if the distribution of world-independent interpretations of noun phrases were basically parallel to the distribution of temporally independent interpretations of noun phrases, and if discrepancies between the two aspects of noun phrase interpretation could be explained by independently motivated assumptions or principles.

There is some initial evidence that there are in fact significant parallels between the two aspects of noun phrase interpretation. Consider the following two examples. It seems that (9a) has two readings as roughly indicated, while (9b) has only one reading, namely one where the underlined noun phrase has a

11 There are probably other devices that make it possible to get access to non-actual worlds for the interpretation of noun phrases. 
world-dependent interpretation. Note that the underlined noun phrase in (9a) can have a presuppositional reading, whereas the underlined noun phrase in (9b) can only have a cardinal reading because it occurs in a there-construction. ${ }^{12}$

(9) a. Things would be different if a senator had grown up to be a rancher instead.

$=$ For all worlds $\mathrm{w}_{1}$ such that there is a senator in $\mathrm{w}_{1}$ that grew up to be a rancher in $w_{1}$, things are different in $w_{1}$.

$=$ For all worlds $w_{1}$ such that there is a senator in $w_{0}$ that grew up to be a rancher in $w_{1}$, things are different in $w_{1}$.

b. Things would be different if there was a senator having grown up to be a rancher instead.

$=$ For all worlds $\mathrm{w}_{1}$ such that there is a senator in $\mathrm{w}_{1}$ that grew up to be a rancher in $\mathrm{w}_{1}$, things are different in $\mathrm{w}_{1}$.

$\neq$ For all worlds $w_{1}$ such that there is a senator in wo that grew up to be a rancher in $\mathrm{w}_{1}$, things are different in $\mathrm{w}_{1}$.

Thus, the example suggests that there is a correspondence between the occurrence of cardinal and presuppositional noun phrases and the occurrence of world-dependent and world-independent interpretation of noun phrases.

If the distribution of world-independent noun phrases indeed turns out to be subject to the same conditions as the distribution of temporally independent noun phrases, then this indicates that on some level we have to assume modally continuant individuals that can be split up into world-stages. As I said above, I have to leave a thorough investigation of these issues to future research.

12 The sentence in $(9 a)$ is taken from Abusch $(1994,104)$. (9b) is due to Kai von Fintel (pc). 
"... and when we leave the landlord will come and paint overitall" - AniDifranoo-

\section{REFERENCES}

Abusch, Dorit (1988): "Sequence of Tense, Intensionality and Scope." Proceedings of WCCFL 7, 1-14.

Abusch, Dorit (1991): "The Present under Past as De Re Interpretation." Proceedings of WCCFL 10, 1-12.

Abusch, Dorit (1994): "Sequence of Tense Revisited: Two Semantic Accounts of Tense in Intensional Contexts." In: Hans Kamp (ed.): Ellipsis, Tense, and Questions. Dyana Deliverable R2.2.B, ILLC/Dept. of Philosophy, University of Amsterdam, 1994, pp 85-139.

Abusch, Dorit (1994): "The Scope of Indefinites." Natural Language Semantics 2, 83-135.

Anderson, John (1973): "The Ghost of Times Past." Foundations of Language 9, 481-491.

Barker, Chris (1991): Possessive Descriptions. PhD Dissertation, UCSC.

Barwise, John and Cooper, Robin (1981): "Generalized Quantifiers and Natural Language." Linguistics and Philosophy 4, 159-219.

Bäuerle, Rainer (1977): Tempus, Temporaladverb und die temporale Frage. Konstanz, Papiere des SFB 99, Nr. 13 + Nr. 15.

Bäuerle, Rainer (1979): Temporale Deixis, temporale Frage. Tübingen: Narr. 
Bäuerle, Rainer (1983): "Pragmatisch-semantische Aspekte der NPInterpretation." In: Allgemeine Sprachwissenschaft, Sprachtypologie und Textlinguistik. Festschrift für Peter Hartmann. Ed. Manfred Faust, Roland Harweg, Werner Lehfeldt, Götz Wienold. Tübingen: Narr, 121-131.

Beck, Sigrid (1994): Quantified Structures as Barriers for LF Movement. Ms., Unversität Tübingen.

Berman, Stephen (1989): "An Analysis of Quantificational Variability in Indirect Questions." In: Emmon Bach, Angelika Kratzer, and Barbara Partee (eds.): Papers on Quantification. UMass, Amherst.

Binnick, Robert I. (1991): Tense and the Verb. A Guide to Tense and Aspect. Oxford: Oxford University Press.

Büring, Daniel (1994): "Mittelfeldreport V." In: Brigitte Haftka (ed.): Was determiniert Wortstellungsvariation? Studien zu einem Interaktionsfeld von Grammatik, Pragmatik und Sprachtypologie. Opladen: Westdeutscher Verlag.

Büring, Daniel (1995): The 59th Street Bridge Accent. Ph-D Dissertation, Tübingen.

Carlson, Greg N. (1977a): Reference to Kinds in English. Ph-D Dissertation, University of Massachusetts, Amherst.

Carlson, Greg N. (1977b): "A Unified Analysis of the English Bare Plural." Linguistics and Philosophy 1, 413-457.

Carlson, Greg N. (1979): "Generics and Atemporal when." Linguistics and Philosophy 3, 49-98.

Carlson, Greg. N. (1982): "Generic Terms and Generic Sentences." Journal of Philosophical Logic 11, 145-81.

Carlson, Greg N. (1988): "Truth Conditions of Generic Sentences: Two Contrasting Views." In: Manfred Krifka (ed.): Genericity in Natural Language. Proceedings of the 1988 Tübingen Conference, 31-51.

Carlson, Greg N. (1989): "On the Semantic Composition of English Generic Sentences." In: G. Chierchia, B. Partee, and R. Turner (eds.): Property Theory, Type Theory, and Semantics. D. Reidel Publishing Co.

Chomsky, Noam (1981): Lectures on Government and Binding. Dordrecht: Foris.

Chomsky, Noam (1992): A Minimalist Program for Linguistic Theory. MIT Occasional Papers in Linguistics 1. 
Condoravdi, Cleo (1992): "Weakly and Strongly Novel Noun Phrases." Proceedings of WCCFL 11, Stanford, 93-107.

Condoravdi, Cleo (1992): "Strong and Weak Novelty and Familiarity." Proceedings of SALT 2, Ohio, 1992, 17-37.

Cresswell, M. J. (1973): Logics and Languages. London: Methuen.

Cresti, Diana (1995): Indefinite Topics. PhD Dissertation, MIT.

Declerck, Renaat (1988): "Restrictive when-Clauses." Linguistics and Philosophy 11, 131-168.

Declerck, Renaat (1991): Tense in English. London: Routledge.

Diesing, Molly (1988): "Bare Plural Subjects and the Stage/Individual Contrast." In: Manfred Krifka (ed.): Genericity in Natural Language. Proceedings of the 1988 Tübingen Conference. 107-154.

Diesing, Molly (1990): The Syntactic Roots of Semantic Partition. Doctoral Dissertation, University of Massachusetts, Amherst.

Diesing, Molly (1992): Indefinites. Cambridge/Mass.: MIT Press.

Doron, Edit (1991): "Point of View as a Factor of Content." In: Proceedings of SALT 1, Cornell, 51-64.

Ejerhed, Eva (1981): "Tense as a Source of Intensional Ambiguity." In: F. Heny (ed.): Ambiguities in Intensional Contexts. Dordrecht: Reidel, 231-252.

Enç, Mürvet (1981): Tense without Scope: An Analysis of Nouns as Indexicals. Ph-D Dissertation, University of Wisconsin - Madison.

Enç, Mürvet (1982): "Definite Descriptions and Indexicality." Proceedings of WCCFL 1, 93-103.

Enç, Mürvet (1985): Temporal Interpretation. Ms. (= earlier version of Enç (1987))

Enç, Mürvet (1986): "Towards a Referential Analysis of Temporal Expressions." Linguistics and Philosophy 9, 405-426.

Enç, Mürvet (1987): "Anchoring Conditions for Tense." Linguistic Inquiry 18, 633-657.

Enç, Mürvet (1991): "The Semantics of Specificity." Linguistic Inquiry 22, 1-25.

Enç, Mürvet (1991): On the Absence of the Present Tense Morpheme in English. Ms., University of Wisconsin, Madison. 
Fabricius-Hansen, Cathrine (1986): Tempus fugit: Über die Interpretation temporaler Strukturen im Deutschen. Düsseldorf: Schwann.

Fabricius-Hansen, Cathrine (1991): "Tempus." In: A. v. Stechow and D. Wunderlich (eds.): Semantics. An International Handbook of Contemporary Research. Berlin/New York: de Gruyter.

Fanselow, Gisbert (1981): Zur Syntax und Semantik der Nominalkomposition. Tübingen: Niemeyer.

Farkas, Donka F. and Sugioka, Yoko (1983): "Restrictive if/when Clauses." Linguistics and Philosophy 6, 225-258.

Fintel, Kai von (1994): Restrictions on Quantifier Domains. Ph.D. Dissertation, University of Massachusetts, Amherst.

Gabbay, D. and Moravcsik, J. (1973): "Sameness and Individuation." Journal of Philosophy 20, 513-526.

Gamut, L.T.F. (1991): Logic, Language, and Meaning. Vol. 2: Intensional Logic and Logical Grammar. Chicago: University of Chicago Press.

Gerstner, Claudia and Krifka, Manfred (1993): "Genericity." In: Joachim Jacobs, Arnim von Stechow, Wolfgang Sternefeld, and Theo Vennemann (eds.): Syntax. Ein internationales Handbuch zeitgenössischer Forschung. Berlin: de Gruyter, 966-978.

Goodman, Nelson (1951): The Structure of Appearance. New York: BobbsMerrill.

Grice, H. P. (1975): "Logic and Conversation." In: P. Cole and J. L. Morgan (eds.): Syntax and Semantics 3: Speech Acts. New York: Academic Press, 41-58.

Gupta, Anil (1980): The Logic of Common Nouns: An Investigation in Quantified Modal Logic. New Haven: Yale University Press.

Heim, Irene (1982): The Semantics of Definite and Indefinite Noun Phrases. Doctoral Dissertation, University of Massachusetts, Amherst.

Heim, Irene (1987): "Where does the Definiteness Restriction apply? Evidence from the Definiteness of Variables." In: Alice G. B. ter Meulen and Eric J. Reuland (eds.): The Representation of (In)definiteness. Cambridge: MIT Press, 21-42.

Heim, Irene (1991): "Artikel und Definitheit." In: A. v. Stechow and D. Wunderlich (eds.): Semantics. An International Handbook of Contemporary Research. Berlin/New York: de Gruyter, 487-535. 
Heim, Irene and Kratzer, Angelika (1992): Lecture Notes. Ms., MIT and UMass, Amherst.

Helbig, Gerhard and Buscha, Joachim (1989): Deutsche Grammatik. 12., unveränderte Auflage. Leipzig: VEB.

Herburger, Elena (1993): "Focus and the LF of NP Quantification." Proceedings of SALT 3 77-96.

Herweg, Michael (1990): Zeitaspekte: Die Bedeutung von Tempus, Aspekt und temporalen Konjunktionen. Wiesbaden: Deutscher Universitätsverlag.

Higginbotham, James (1985): "On Semantics." Linguistic Inquiry 16, 547-593.

Higginbotham, James (1987): "Indefiniteness and Predication." In: Eric J. Reuland and Alice G. B. ter Meulen (eds.): The Representation of (In)definiteness. Cambridge/Mass.: MIT Press, 43-70.

Hinrichs, Erhard W. (1985): A Compositional Semantics for Aktionsarten and NP Reference in English. Ph.D. Dissertation, Ohio State University.

Hintikka, Jaakko (1969): "Semantics for Propositional Attitudes." In: Leonard Linsky (ed.) (1971): Reference and Modality. Oxford: Oxford University Press, 1971, 145-167. [Also in: J. W. Davis et al. (ed.) (1969): Philosophical Logic. Dordrecht: Reidel, 21-45.]

Honcoop, Martin and Doetjes, Jenny (1995): "Conditions on the Event-Related Reading." To appear in: Proceedings of WCCFL 14.

Hornstein, Norbert (1990): As Time Goes By. Tense and Universal Grammar. Cambridge/Mass.: MIT Press.

Huang, Cheng-Teh James (1982): Logical Relations in Chinese and the Theory of Grammar. Ph. D. Dissertation, MIT.

Iatridou, Sabine (1990): "The Past, the Possible, and the Evident." Linguistic Inquiry 21, 123-129.

Inoue, Kyoko (1975): Studies in the Perfect. Ph. D. Dissertation, University of Michigan.

van Inwagen, Peter (1990): "Four-Dimensional Objects." Noûs 24, 245-255.

Jäger, Gerhard (1995): "Topic, scrambling and aktionsart." To appear in: Proceedings of CONSOLE 1994, Venice.

Kadmon, Nirit and Landman, Fred (1993): "Any." Linguistics and Philosophy 16, 353-422. 
Kamp, J. A. W. (1975): "Two Theories about Adjectives." In: Edward L. Keenan (ed.): Formal Semantics of Natural Language. Cambridge: Cambridge University Press, 123-155.

Karttunen, Lauri and Peters, Stanley (1979): "Conventional Implicature." In: Syntax and Semantics 11: Presuppositions. Ed. by Choon-Kyu Oh and David A. Dinnen. New York: Academic Press, 1-56.

Klein, Wolfgang (1991): Time in Language. Ms., Max-Planck-Institut für Psycholinguistik, Nijmegen.

Kratzer, Angelika (1978): Semantik der Rede. Kontexttheorie - Modalwörter Konditionalsätze. Königstein/Taunus: Scriptor.

Kratzer, Angelika (1988): "Stage-Level and Individual-Level Predicates." In: Emmon Bach, Angelika Kratzer, and Barbara Partee (ed.): Papers on Quantification. University of Massachusetts, Amherst. [also in: Pelletier, Francis Jeffry and Carlson, Greg N. (eds.) (1995): The Generic Book. Chicago: University of Chicago Press.]

Kratzer, Angelika (1989): "An Investigation of the Lumps of Thought." Linguistics and Philosophy 12, 607-653.

Kratzer, Angelika (1991): "Conditionals." In: A. v. Stechow and D. Wunderlich (eds.): Semantics. An International Handbook of Contemporary Research. Berlin/New York: de Gruyter, 651-656.

Kratzer, Angelika (1991): "Modality." In: A. v. Stechow and D. Wunderlich (eds.): Semantics. An International Handbook of Contemporary Research. Berlin/New York: de Gruyter, 639-650.

Krifka, Manfred (1987): An Outline of Genericity. Ms., Universität Tübingen.

Krifka, Manfred (ed.) (1988a): "Genericity in Natural Language." In: Manfred Krifka (ed.): Genericity in Natural Language. Proceedings of the 1988 Tübingen Conference. SNS-Bericht. 88-42.

Krifka, Manfred (1988b): "The Relational Theory of Genericity." In: Manfred Krifka (ed.): Genericity in Natural Language. Proceedings of the 1988 Tübingen Conference, 285-312.

Krifka, Manfred (1989): Boolean and Non-Boolean "and". Ms., Tübingen and Austin.

Krifka, Manfred (1990): "Four thousand ships passed through the lock: Objectinduced measure functions on events." Linguistics and Philosophy 13, 487-520. 
Krifka, Manfred (1992): Focus, Quantification, and Dynamic Interpretation. Paper presented at the 8th Amsterdam Colloquium, December 1991. Ms.

Krifka, Manfred, Greg Carlson, Gennnaro Chierchia, Godehard Link, Jeff Pelletier, and Alice ter Meulen (1992): Genericity: An Introduction. Ms. [also in: Pelletier, Francis Jeffry and Carlson, Greg N. (eds.) (1995): The Generic Book. Chicago: University of Chicago Press.]

Ladusaw, Bill (1983): "Logical Form and Conditions on Grammaticality." Linguistics and Philosophy 6, 373-392.

Larson, Richard K. (1983): Restrictive Modification: Relative Clauses and Adverbs. Ph-D Dissertation, University of Wisconsin-Madison.

Lewis, David (1968): "Counterpart Theory and Quantified Modal Logic." In: Philosophical Papers Vol. 1. Oxford: Oxford University Press, 1983, 2646. [also in: Journal of Philosophy 65, 113-126.]

Lewis, David (1973): Counterfactuals. Oxford: Blackwell.

Lewis, David (1975): "Adverbs of Quantification." In: Edward L. Keenan (ed.): Formal Semantics of Natural Language. Cambridge: Cambridge University Press, 3-15.

Lewis, David (1976): "Survival and Identity." In: Philosophical Papers Vol. 1. Oxford: Oxford University Press, 1983, 55-77. [also in: Amelie O. Rorty (ed.): The Identities of Persons. University of California Press, 17-40.]

Lewis, David (1986): On the Plurality of Worlds. Oxford and New York: Blackwell.

Lewis, David (1991): Parts of Classes. Oxford and New York: Blackwell.

Linebarger, Marcia (1980): The Grammar of Negative Polarity. Ph. D. Dissertation, MIT.

Linebarger, Marcia (1987): "Negative Polarity and Grammtical Representation." Linguistics and Philosophy 10, 325-387.

Link, Godehard (1983): "The Logical Analysis of Plurals and Mass Terms: A Lattice-Theoretical Approach." In: Rainer Bäuerle et.al. (eds.): Meaning, Use, and Interpretation of Language. Berlin: de Gruyter, 302-323.

Link, Godehard (1987): "Generalized Quantifiers and Plurals." In: Peter Gärdenfors (ed.): Generalized Quantifiers. Dordrecht: Reidel, 151-180. 
Link, Godehard (1991): "Plural." In: A. v. Stechow and D. Wunderlich (eds.): Semantics. An International Handbook of Contemporary Research. Berlin/New York: de Gruyter.

Löbner, Sebastian (1987): "The conceptual nature of natural language quantification." In: A. Szabolcsi (ed.): Proceedings of the Symposium on "Logic and Language" at Debrecen, Aug. 1987. Hungarian Academy of Sciences, Budapest.

Lønning, Jan Tore (1987): "Mass Terms and Quantification." Linguistics and Philosophy, 10, 1-52.

May, Robert C. (1977): The Grammar of Quantification. Ph.D. Dissertation, MIT.

May, Robert C. (1985): Logical Form: Its Structure and Derivation. Cambridge: MIT Press.

ter Meulen, Alice G. B. and Reuland, Eric J. (eds.): The Representation of (In)definiteness. Cambridge: MIT Press.

McCawley, J. (1979): Presupposition and Discourse Structure. Syntax and Semantics 11: Presuppositions. New York: Academic Press, 371-388.

Milsark, G. (1974): Existential Sentences in English. Ph.D. Dissertation, MIT.

Musan, Renate (1993): Quantification over individuals and over individualtime-slices, and the temporal interpretation of NPs, Paper presented at CONSOLE, Tübingen, December 1993.

Musan, Renate (1995): "NP-internal modifiers and temporal upper limit effects." To appear in: Proceedings of WCCFL 14.

Musan, Renate (1995): "Tense, Predicates, and Life-Time Effects." Paper submitted to Natural Language Semantics.

Neale, Stephen (1990): Descriptions. Cambridge/Mass.: MIT Press.

Ogihara, Toshiyuki (1989): Temporal Reference in English and Japanese. Ph.D. Dissertation, University of Texas at Austin.

Parsons, Terence (1990): Events in the Semantics of English. Cambridge, MITPress.

Partee, Barbara (1973): "Some Structural Analogies between Tenses and Pronouns in English." Journal of Philosophy 70, 601-609. 
Partee, Barbara (1984): "Compositionality." In: Fred Landman and Frank Veltman (eds.): Varieties of Formal Semantics. Proceedings of the Fourth Amsterdam Colloquium, September 1982. Dordrecht: Foris, 281-311.

Partee, Barbara (1984): "Nominal and Temporal Anaphora." Linguistics and Philosophy 7, 243-286.

Partee, Barbara H., Alice ter Meulen, and Robert E. Wall (1990): Mathematical Methods in Linguistics. Dordrecht: Kluwer.

Paul, Matthias (1994): "Young Mozart and the Joking Woody Allen. Proper Names, Individuals and Parts." Proceedings of SALT 4, 268-281.

Pelletier, Francis Jeffry (1979) (ed.): Mass Terms: Some Philosophical Problems. Dordrecht: Reidel.

Pelletier, Francis Jeffry (1985): "Scope Ambiguity with Tense and Quantifiers." Linguistic Inquiry 16, 330-334.

Pelletier, Francis Jeffry and Schubert, Lenhart K. (1989): "Mass Expressions." In: D. Gabbay and F. Günthner (eds.): Handbook of Philosophical Logic, Vol. 4. Dordrecht: Reidel, 327-407.

Pelletier, Francis Jeffry and Carlson, Greg N. (eds.) (1995): The Generic Book. Chicago: University of Chicago Press.

Perlmutter, David M. and Postal, Paul M. (1984): "The 1-Advancement Exclusiveness Law." In: D. Perlmutter and C.G. Rosen (eds.): Studies in Relational Grammar 2. University of Chicago Press, 81-125.

Prior, A. (1967): Past, Present and Future. London: Methuen.

Quine, Willard Van Orman (1960): Word and Object. The Technology Press of MIT and John Wiley \& Sons, New York and London.

Reichenbach, H. (1947): Elements of Symbolic Logic. Reprinted in 1966 by Free Press.

Roberts, Craige (1990): Modal Subordination, Anaphora, and Distributivity. New York and London: Garland, 1990. [Revised version of the Ph. D. Dissertation, University of Massachusetts, Amherst, 1987.]

Rooth, Mats (1985): Association with Focus. PhD Dissertation. UMass, Amherst.

Rooth, Mats (1992): "A Theory of Focus Interpretation." Natural Language Semantics 1, 75-116. 
Sadock, Jerrold M. (1978): "On Testing for Conversational Implicature." In: Syntax and Semantics, Vol. 9: Pragmatics. Ed. by Peter Cole, New York: Academic Press, 281-296.

Schubert, Lenhart K. and Pelletier, Francis Jeffry (1987): "Problems in the Representation of the Logical Form of Generics, Plurals, and Mass Nouns." In: Ernest LePore (ed.): New Directions in Semantics. London: Academic Press, 385-451.

Siegel, Muffy E. A. (1976): Capturing the Adjective. PhD Dissertation. UMass, Amherst.

Simons, Peter (1987): Parts. A Study in Ontology. Oxford, Clarendon Press.

Soames, Scott (1986): "Incomplete Definite Descriptions." Notre Dame Journal of Formal Logic 27, 349-375.

Soames, Scott (1989): "Presupposition." In: D. Gabbay and F. Günthner (eds.): Handbook of Philosophical Logic, Vol. 4, 553-616. Dordrecht: Reidel.

Stalnaker, Robert C. (1970): "Pragmatics." Synthese 22, 272-289. - Reprinted in: A. P. Martinich (ed.) (1990): the Philosophy of Language. Second edition. Oxford: Oxford University Press, 176-186.

Stalnaker, Robert C. (1974): "Pragmatic Presuppositions." In: M. K. Munitz and P. K. Unger (eds.): Semantics and Philosophy. New York: New York University Press, 197-214.

Stalnaker, Robert C. (1978): "Assertion." Syntax and Semantics 9: Pragmatics. New York: Academic Press, 315-332.

Stalnaker, Robert C. (1984): Inquiry. Cambridge/Mass.: MIT Press.

Stalnaker, Robert C. (1988): "Belief Attribution and Context." In: R. Grimm and D. Merrill (ed.): Contents of Thought. Tucson: University of Arizona Press, 140-156.

Stechow, Arnim von (1980): "Modification of Noun Phrases: A Challenge for Compositional Semantics." Theoretical Linguistics 7, 57-109.

Stechow, Arnim von (1991): Course on Logical Form. Script, Summer School Saarbrücken, 1991.

Stechow, Arnim von and Dieter Wunderlich (eds.) (1991): Semantics. An International Handbook of Contemporary Research. Berlin/New York: de Gruyter. 
Stechow, Arnim von (1992): Intensionale Semantik - eingeführt anhand der Temporalität. Universität Konstanz, Fachgruppe Sprachwissenschaft, Arbeitspapier Nr. 40.

Stechow, Arnim von (1995): 'On the Proper Treatment of Tense.' To appear in the Proceedings of SALT 1995.

Stowell, Tim (1993): Syntax of Tense. Ms, UCLA/Madrid.

Strawson, P. (1952): Introduction to Logical Theory. London: Methuen.

Stump, Gregory T. (1985): The Semantic Variability of Absolute Constructions. Dordrecht: Reidel.

de Swart, Henriëtte (1991): Adverbs of Quantification: a Generalized Quantifier Approach. Ph-D Dissertation, Groningen.

Uribe-Etxebarria, Maria (1994): "Towards an LF Theory of Negative Polarity Licensing." Proceedings of the 23rd Western Conference on Linguistics.

Uribe-Etxebarria, Maria (1994): Interface Licensing Conditions on Negative Polarity Items: a Theory of Polarity and Tense Interactions. Ph-D Dissertation, University of Connecticut, 1994.

van Benthem, J. F. A. K. (1983): The Logic of Time. A Model-Theoretic Investigation into the Varieties of Temporal Ontology and Temporal Discourse. Dordrecht: Reidel.

Vlach, Frank (1993): "Temporal Adverbials, Tenses, and the Perfect." Linguistics and Philosophy 16, 231-283.

Westerståhl, Dag (1984): "Determiners and Context Sets." In: Johan van Benthem and Alice ter Meulen (eds.): Generalized Quantifiers in Natural Language. Dordrecht: Foris, 45-71.

Wilkinson, Karina (1991): Studies in the Semantics of Generic Noun Phrases. PhD Dissertation, University of Massachusetts, Amherst.

Williams, E. (1981): "Argument Structure and Morphology." The Linguistic Review 1, 81-114.

Zeller, Jochen (1994): Die Syntax des Tempus: zur strukturellen Repräsentation temporaler Ausdrücke. Westdeutscher Verlag: Opladen.

Zimmermann, Thomas Ede (1993): "On the Proper Treatment of Opacity in Certain Verbs." Natural Language Semantics 1, 149-179. 
"there's a complete life waiting for you behind the back cover of your dissertation."

- Yosi, December 17, 1994

$7963-46$ 